\begin{tabular}{|l|l|}
\hline 2. To: (Receiving Organization) & 3. From: (Originating Organization) \\
Distribution & FFTF Engineering \\
\hline 5. Proj./Prog./Dept./Div.: & 6. Design Authority/ Design Agent/Cog. \\
FFTF Plant & Dngr.: \\
\hline 8. L. Polzin
\end{tabular}

8. Originator Remarks:

This EDT releases the 1998 Annual System Assessment Reports for the Fast Flux Test Facility.

11. Receiver Remarks: 11A. Design Baseline Document? [] Yes [X] No $N / A$

4. Related EDT No.:
N/A
7. Purchase Order No.:
N/A

9. Equip./Component No.: $\mathrm{N} / \mathrm{A}$

10. System/Bldg./Facility: FFTF

12. Major Assm. Dwg. No.:

$\mathrm{N} / \mathrm{A}$

13. Permit/Permit Application No.: $N / A$

14. Required Response Date: $\mathrm{N} / \mathrm{A}$

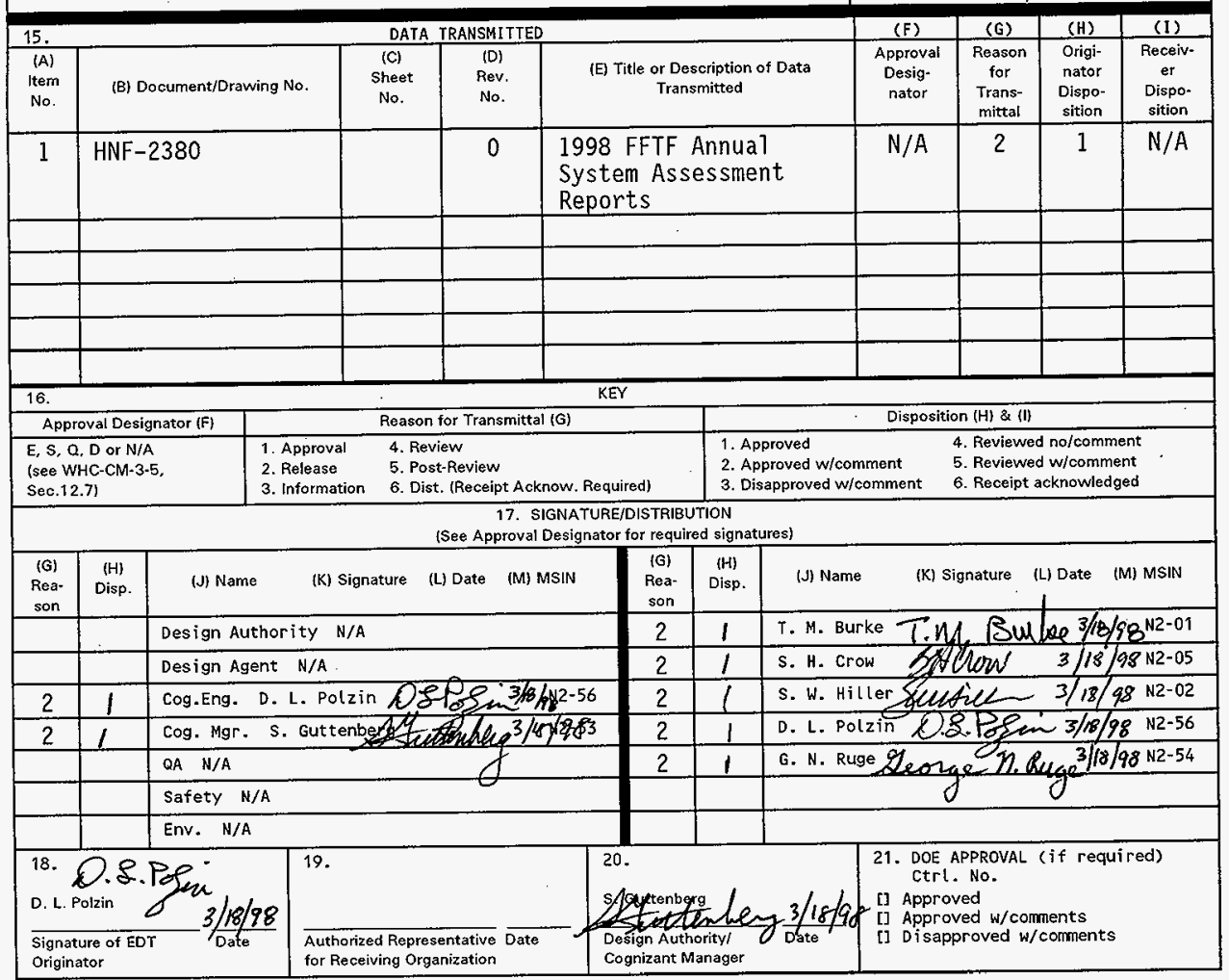


HNF-2380, Rev. 0

\title{
1998 FFTF Annual System Assessment Reports
}

\author{
S. Guttenberg \\ B\&W Hanford Company, Richland, WA 99352 \\ U.S. Department of Energy Contract DE-AC06-96RL13200 \\ EDT/ECN: 619619 \\ UC: 530 \\ Org Code: 18200 \\ B\&R Code: 600301020 \\ Charge Code: B1244 \\ Total Pages: $35 T^{2} 354$ U.
}

Key Words: FFTF Assessments, FFTF Systems.

Abstract: The health of FFTF systems was assessed assuming a continued facility standby condition. The review was accomplished in accordance with the guidelines of FFTF-EI-083, "Plant Evaluation Program." The attached document includes an executive summary of the significant conclusions and assessment reports for each system evaluated.

TRADEMARK DISCLAIMER. Reference herein to any specific commercial product, process, or service by trade name, trademark, manufacturer, or otherwise, does not necessarily constitute or imply its endorsement, recommendation, or favoring by the United States Government or any agency thereof or its contractors or subcontractors.

Printed in the United States of America. To obtain copies of this document, contact: Document Control Services, P.O. Box 950, Mailstop H6-08, Richland WA 99352, Phone (509) 372-2420;

Fax (509) 376-4989.
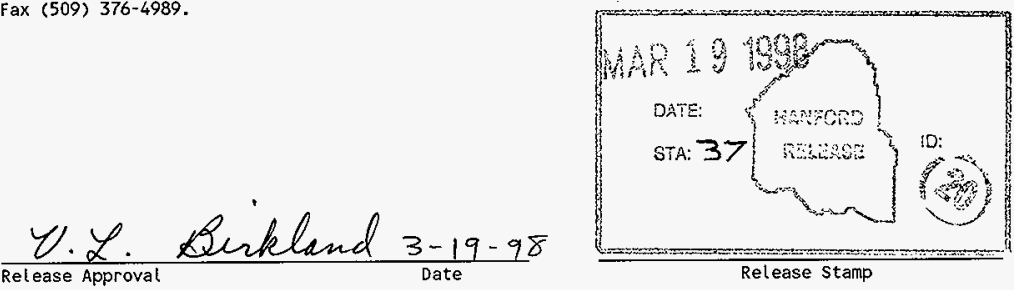
HNF-2380

Revision 0

\section{FFTF Annual System Assessment Reports}

Date Published

March 1998

Prepared for the U.S. Department of Energy

Fluor Daniel Hanford, Inc.

P.O. Box 1000
Richland, Washington

Hanford Management and Integration Contractor for the

U.S. Department of Energy under Contract DE-AC06-96RL13200 
LEGAL DISCLAIMER

This report was prepared as an account of. work sponsored by an agency of the United States Government. Neither the United States Government nor any agency thereof, nor any of their employees, nor any of their contractors, subcontractors or their employees, makes any warranty, express or implied, or assumes any legal liability or responsibility for the accuracy, completeness, or any third party's use or the results of such use of any information, apparatus, product, or process disclosed, or represents that its use would not infringe privately owned rights. Reference herein to any specific commercial product, process, or service by trade name, trademark, manufacturer, or otherwise, does not necessarily constitute or imply its endorsement, recommendation, or favoring by the United States Government or any agency thereof or its contractors or subcontractors. The views and opinions of authors expressed herein do not necessarily state or reflect those of the United States Government or any agency thereof.

This report has been reproduced from the best available copy. Available in paper copy and microfiche.

Available to the U.S. Department of Energy and its contractors from U.S. Department of Energy Office of Scientific and Technical Information (OST)

P.O. Box 62

Oak Ridge, TN 37831

(615) $576-8401$

Available to the public from the U.S. Department of Commerce National Technical Information Service (NTIS).

5285 Port Royal Road

Springfield, VA 22161

(703) $487-4650$

Printed in the United States of Americs

DISCLM-1.CHP (8-95) 


\section{TABLE OF CONTENTS}

System

Description

Page

Executive Summary $\ldots \ldots \ldots \ldots \ldots \ldots \ldots \ldots \ldots \ldots \ldots \ldots \ldots$

Primary Electric Power . . . . . . . . . . . . . . . . . . . 12

Building Electrical Power (includes Gas Turbine Generator) $\ldots \ldots \ldots \ldots$

Communications (including MASF M34) $\ldots \ldots \ldots \ldots \ldots \ldots \ldots \ldots \ldots$

Reactor Support Buildings (Cranes only) $\ldots \ldots \ldots \ldots \ldots \ldots \ldots \ldots$

Service Piping $\ldots \ldots \ldots \ldots \ldots \ldots \ldots \ldots \ldots \ldots \ldots \ldots \ldots \ldots \ldots$

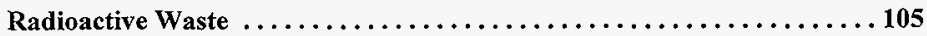

Heating, Ventilation, Air Conditioning $\ldots \ldots \ldots \ldots \ldots \ldots \ldots \ldots \ldots$

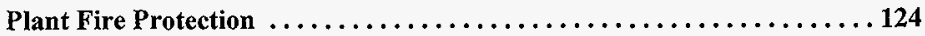

Reactor Internals (includes portions of System 90) $\ldots \ldots \ldots \ldots \ldots \ldots 130$

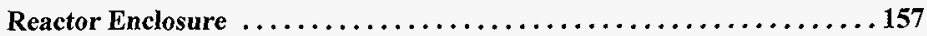

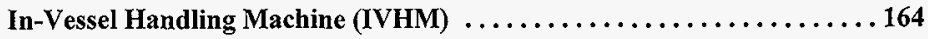

Closed Loop Ex-Vessel Machine (CLEM) . . . . . . . . . . . . 168

Interim Decay Storage $($ IDS) $\ldots \ldots \ldots \ldots \ldots \ldots \ldots \ldots \ldots \ldots \ldots \ldots \ldots \ldots \ldots \ldots$

Conditioning Stations (CCCS, TACS, SPSS) $\ldots \ldots \ldots \ldots \ldots \ldots \ldots 2$

Floor Valves $\ldots \ldots \ldots \ldots \ldots \ldots \ldots \ldots \ldots \ldots \ldots \ldots \ldots \ldots \ldots \ldots \ldots \ldots$

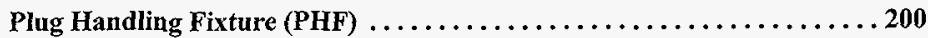

Interim Examination \& Maintenance Cell (SRS, PMM, WMM) . . . . . 206

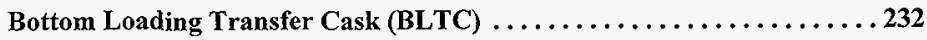

Auxiliary Refueling Support Equipment (MPRT, CLS) . . . . . . . . 240

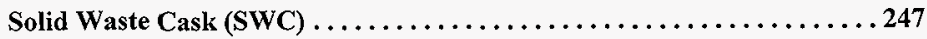

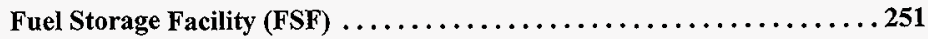

Reactor Heat Transport (includes 93-2 I\&C) ................ 257

Auxiliary Liquid Metal System (includes 93-10 I\&C) ........... 276

Inert Gas Receiving and Processing $\ldots \ldots \ldots \ldots \ldots \ldots \ldots \ldots \ldots$

Impurity Monitoring and Analysis (includes 93-9 I\&C) . . . . . . . 294 


\section{TABLE OF CONTENTS (CON'T)}

System

Description

Page

93-4

Service Piping Instrumentation System (System 23) $\ldots \ldots \ldots \ldots \ldots$

93-6

Heating and Ventilation Instrumentation System (System 25)

.313

93-7 Plant Fire Protection Instrumentation System (System 26; includes MASF M26)

93-8 Inert Gas Receiving and Processing Instrumentation System

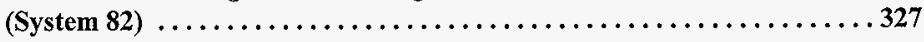

93-15 Piping and Equipment Electrical Heating Control System . . . . . . . 332

96

Radiation Monitoring (includes MASF M18)

L12

Landlord Electrical .346 
HNF-2380

Rev. 0, Page 1

\section{EXECUTIVE SUMMARY}

\section{FFTF ANNUAL SYSTEM ASSESSMENT REPORTS}

The 1998 FFTF Annual System Assessment Reports (ASARs) were completed in accordance with FFTF-EI-083, "Plant Evaluation Program," and assess the "health of the facility" in standby. The last ASAR evaluation was conducted in 1992 for power operation. Some limited scope ASARs were subsequently performed in support of shutdown activities.

The ASARs contained herein are prepared by the cognizant engineer(s) for selected systems and are approved by their respective system engineering manager. Each report assesses the adequacy of the system being addressed to support standby over an assumed nominal two year period. For convenience, the format of the report is identical to the previous ASARs prepared for power operation. Accordingly, it should be recognized that there are one or two subtle differences. The use of the term "Required By" in Section 3, now denotes a recommendation by the cognizant engineer. These recommendations will then form the basis for the input to the phase planning process described in administrative procedure A-33, "Work Prioritization and Scheduling." This process takes the recommendation of individual engineers and integrates them across all systems and organizations, such that the highest priority actions are conducted from a total plant perspective. In addition, the A33 process considers resource constraints which the ASAR authors do not evaluate.

\section{Plant Evaluation}

A synopsis of the key points from this evaluation was prepared by each Engineering group and is delineated below. The individual ASARS then follow.

\section{REACTOR SYSTEMS MECHANICAL ENGINEERING}

\section{$\underline{\text { Restore Systematic Preventative Maintenance }}$}

Due to the prior shutdown direction and existing resource limitations, many preventative maintenance (PM) activities were deferred and are now overdue. It is critical that this situation be corrected. Engineering has previously performed several reviews of the PM categories and frequencies and established what was considered to be appropriate for the standby period (with an unspecified duration). Recently, Engineering committed to performing another PM review with more defined guidelines (e.g., assume standby continues for an additional two years). Once this review is completed and the PM requirements are reestablished, performance of the required PMs should be one of the highest priority activities for the facility since the primary mission is to maintain the plant in a condition to allow restart in a relatively short time period.

\section{Continue to Install System 26 Backflow Preventers as Scheduled}

FFTF and associated 400 Area buildings are currently not in compliance with WAC requirements for having backflow preventers installed between the sanitary and fire protection water systems. A 
HNF-2380

Rev. 0, Page 2

schedule has been established for achieving compliance by FY-2001 by installing twenty backflow preventers. If we do not stay reasonably on schedule, there is a risk that the water purveyor could shut down the water systems and/or fines could be levied by the state.

\section{Repair P-16 Well Pump}

The P-16 well pump has shown a slow reduction in capacity over the past several years. This is probably due to wear of the impellers/pump bowl. Since P-16 is the preferred source of 400 Area water (lowest tritium level), it should be repaired. Current plans are to complete repairs prior to the onset of hot weather (high water demand) this year.

\section{Replace Refrigerant in ECCW Chillers}

The existing R-12 refrigerant in the two remaining ECCW chillers will be replaced with "environmentally friendly" R-134a (this has already been done on all four of the ICCW chillers and two of the ECCW chillers). Although not driven by any regulatory requirement at this time, it is prudent to do it now for economic reasons: there is currently an R-12 refrigerant buy-back program in place that will help to defray the cost of the change and additional funds to support this change have been made available from a DOE Return on Investment program.

\section{Modify FSF Argon Dewar}

FSF was recently connected to the FFTF plant argon system. It was planned to allow the FSF argon dewar to "float" as an on-line argon gas accumulator. However, a check valve in the system has prevented effective backflow into the FSF dewar. Therefore, the check valve internals will be removed. In addition, the discharge from the economizer regulator will be routed into the argon header to allow boil off (when liquid argon is present in the dewar) to be fed into the system rather than discharged to the atmosphere. These simple modifications will give Operations several options for using the dewar: fill it with liquid argon to serve as a backup to the plant dewars, use it to supply the header, or maintain the tank empty but inerted.

\section{Perform Repairs/Modifications on Cooling Towers}

The cooling towers (especially those placed into layup) are experiencing some degradation. In particular, several are in need of sheet metal repairs and/or protection. In addition, the fans on the laid up towers should be rotated in order to assess and minimize damage to the bearings. Finally, strainers will be added upstream of the blowdown valves on selected operating towers to assess whether this will reduce frequent problems with operation of these valves due to debris accumulation.

\section{Restore Inventory of Spares for Auxiliary Liquid Metal Systems}

Due to component aging and resource limitations, there is currently a very limited inventory of useable spare parts for the I\&C portion of the liquid metal systems (e.g., EM pump and PTI controls). An effort should be made to repair the available failed components so that they are available to allow rapid repair of future failures. See The Auxiliary Systems Electrical Engineering report for additional information. 
HNF-2380

Rev. 0, Page 3

\section{Perform OSP to Test Operation on Two Secondary Main Motors}

During standby, plant temperature is maintained primarily by heat input from the secondary pumps. Evaluations indicate that operation of two main motors at high speed would result in a substantial cost savings compared to running all three pumps at lower speed (due to the increased motor efficiency at higher speeds). In order to avoid wear of the brushes in the inactive main motor while allowing for rapid restart of that motor, the inactive loop would be operated in natural circulation (i.e., pony motor off). However, there are some operational concerns which require investigation to confirm the adequacy of this operating mode. An OSP has been prepared to test this operating configuration, including potential failure scenarios. If the OSP results are acceptable, the two pump mode of operation will be instituted.

\section{Install New ICCB Outlet Filter}

Contaminated artifact oil from the CAPS and ICCBs has saturated the ICCB outlet filter. By experience we know that a small amount of this oil re-entrains in the gas stream accumulating slowly in the downstream pipe and $\mathrm{H} \& \mathrm{~V}$ duct. Work package 4F-97-870 will replace the existing outlet filter with a clean filter and will add an oil coalescing prefilter. While not urgent, this activity will correct a continuing problem which has a potential for personnel contamination.

\section{AUXILIARY SYSTEMS ELECTRICAL ENGINEERING}

\section{General Evaluation}

The overall health of the FFTF auxiliary electrical systems is good. System functions are maintained primarily by using corrective maintenance. There is a large preventive maintenance backlog, especially in the electrical distribution system, which increases the chances of erroneous indications, unplanned system outages, and catastrophic failures. There is also a large number of broken spare parts that have not been repaired. In some instances, these broken parts must be repaired prior to the performance of emergent corrective maintenance.

\section{Significant Actions}

Near term items requiring attention include:

- preventive maintenance for the 451B substation DC1 battery bank.

- preventive maintenance for 451B transformer TRR2

- preventive maintenance for H52-11R and downstream switchgear

- preventive maintenance for 451B switchgear $\mathrm{H} 11$ and $\mathrm{H} 12$

- preventive maintenance for secondary main motor switchgear

- installation of a new G-3 control system

- removal of PA system battery D-33 and installation of a DC power supply

- installation of cooling fans in PA amplifier cabinets 
HNF-2380

Rev. 0, Page 4

- installation of a new IEM Cell gas cooler control system

- installation of new EM Pump C-1 controllers

- installation of a new MASF fire detection and alarm system power supply.

Long term items requiring attention include:

- preventive maintenance for the 451A substation and switchgear

- preventive maintenance for $\mathrm{H} 4$ and $\mathrm{H} 5$ emergency switchgear

- preventive maintenance for FSF MCCs B910 and B911

- replacement of PA system amplifiers with commercially available units

- replacement of PA system override handsets and tone generators

- upgrade of the FSF fire detection and alarm system.

\section{System Aging and Trends}

The effects of system aging have been observed in several areas. Age related failures have occurred in the G-3 control system due to heat stressed components and in power supplies due to failed capacitors. The obsolete inert gas cooler control system experiences intermittent failures that are difficult to isolate and repair. The public address system amplifiers and tone generators are obsolete and have experienced an increased failure rate. The electrical distribution system has experienced breaker racking mechanism, motor starter, and station battery degradation.

Aging has also increased the time required to perform repairs. For example, a failure of the G-3 control system required the special manufacture of an obsolescent circuit card. During $1997 \mathrm{G}-3$ was inoperable for almost three months because of age related failures. In another case, an obsolete and unique non- $1 \mathrm{E}$ battery reverse current module was returned to a vendor three times for repair. This repair task has taken eight months to complete.

\section{Spare Parts}

Near term spare parts are primarily provided by an inventory of both repaired and currently broken parts. Some spare parts are obtained from permanently secured equipment such as the closed loop panels. Other spare parts, such as trace heat power controllers, transmitters, and annunciator alarm cards must be repaired prior to performing emergent corrective maintenance. Many parts are not in spare inventory but are readily purchased as needed. Replacement parts for large equipment, primarily in the electrical distribution system, are not stocked but are commercially available and would also be purchased as needed.

\section{Maintenance Philosophy}

Standby maintenance plans focus on minimizing equipment degradation but do not extend beyond the next two years. Most systems will continue to be maintained in their current condition.

Equipment will be repaired as it fails and system upgrades will be minimized. Some systems will be upgraded because of poor equipment operability and high maintenance costs caused by age related failures and obsolescence. Systems that will be upgraded have been carefully chosen due to funding limitations. Examples of upgrades include EM Pump C-1 controllers, IEM Cell atmosphere cooling 
HNF-2380

Rev. 0, Page 5

system controllers, and ex-containment chiller controllers. The MASF fire detection and alarm power supply system will be upgraded to correct an original design error. Public address system amplifiers should be replaced with commercially available equipment.

\section{MECHANICAL EQUIPMENT AND INSERVICE INSPECTION ENGINEERING}

\section{System 23.J, Instrument Air System}

The instrument air system and its components are fully capable of supporting the plant during standby operations. The R-1 and R-2 instrument air compressors need new piston rings on the second stage pistons. The piston rings for R-1 are being replaced as part of the 7000-hour overhaul work, which started the last week of January. Overhaul of R-2, which has also accumulated 7000 hours since the last overhaul, will be subsequently performed later this year. The 7000 hour overhaul interval was established, through trending, as the hours the piston rings on the second stage will last before the rings start to fall apart, causing excessive vibration.

The instrument air dryers are fully functional, with the only discrepancy being that T-194 is marginal for carrying the drying load during high humidity days. This in not a major problem since we have another backup dryer, T-196. The T-196 dryer is presently connected with temporary hoses, which will need to be replaced with hard piping in the long term.

\section{System 24(A), Radioactive Waste System}

The radioactive liquid waste system and its components are fully capable of supporting the plant during standby operations. We were recently notified that the Hanford Site Railroad will cease operation on September 30, 1998. This decision means that FFTF will need to excess our existing 8,000 gallon rail car, and develop another method of transporting liquid waste for disposal. The most promising scenario involves the 200 area Effluent Treatment Facility (ETF), which owns three 5,000 gallon tanker trucks. We will have to modify the loadout facilities in MASF and FFTF, but this may simply require construction of jumpers to connect to the trucks.

\section{System 31, Reactor Internals}

For this report, only the Low Level Flux Monitor (mechanical), the Control Rod Drive Mechanism and Disconnect Actuator, and the Instrument Trees were evaluated.

The Low Level Flux Monitors (LLFM) have remained inserted fully into the thimbles in the outer core region with the electrical/electronic components deactivated and layed-up. When FFTF restart was first considered, the immediate action to maintain the health of these units was to restore the cooling system pressure and gas flow to the detectors. The cooling system was also converted from nitrogen to instrument air. The LLFM will remain in this minimal operational status for at least the next two years.

The Control Rod Drive Mechanisms (CRDM) are mechanically functional after three years of deactivation. The reconnects of the drivelines through the Instrument Trees was successful, with no 
indications of binding or sodium frost buildup. Control Rod Drop Testing was completed in January 1998. Although flow through the reactor was from pony motors on the pumps versus main motor flow, the insertion times were consistent with similar testing performed in 1989. Stationary and rotating dropout currents and release times were within the acceptable range and in line with historical data. The electrical system components (MG sets, ALPHA regulators, control drawers, ARPI and RRPI) all performed satisfactorily during the testing.

The Instrument Trees (IT) were exercised and rotated over core in July 1997, and actually showed improved rotational torques. The seals were also tested in July 1997, with the inflatable seals showing increased leakage of the inflation gas, but the overall boundary is still maintained. The ASME check valves have not been tested since the ASME boundary is not required in standby. The Instrument Trees will remain immersed in sodium and rotated over the core, with no further testing or movement planned until a new core would be loaded prior to a restart. The Instrument Trees also provide the support over the core for the Control Rod Driveline Disconnects, which have been reconnected, and the Flow Temperature Reactor Instrument Assemblies.

\section{System 51C, Dump Heat Exchangers and Preheaters}

The Dump Heat Exchangers have remained dormant and inoperable due to the FFTF standby conditions, except for the preheaters, which have been maintained at a minimum of two per loop in accordance with MOE requirements.

One preheater in each loop (Q-1, Q-6, Q-9) was abandoned in place due to problems in keeping them repaired. For the remaining nine units, a program was established to start and operate the preheaters in each loop on a periodic basis. Long periods of inactivity had caused past startup problems. The program has appeared to work well for the last two years, both in mechanical and electrical operations. The fuel oil supply to the preheaters is normally trace heated to prevent wax coagulation in the fuel, which plugs the fuel filter. Failure of numerous trace heat circuits this winter caused us to use an anti-gel fluid to reduce the cloud point of the fuel to $15^{\circ} \mathrm{F}$ below zero. Further trace heat repairs will not be required since this anti-gel fluid seems to work well.

In an effort to minimize heat losses from the DHXs during standby, a barrier was installed on the tornado grill above the dampers to prevent convective heat loss. The barrier consists of a thin sheet of silicone foam rubber, sealed with RTV at the lap joints, and covered with a two inch layer of fiberglass insulation board. This barrier was very efficient in reducing the heat loss, but will have to be removed if startup proceeds.

During this standby period, the Dump Heat Exchanger stacks became a major target for starling roosting in the louvered areas of the stacks. This allowed access into the internal portions of the stack where they deposited wastes onto the dampers, the tornado grill above the dampers, and the insulation barrier on the tornado grill. In 1997, screens were installed over the louvered portion of the stack to prevent large flocks of birds from roosting on the stack louvers. Small flocks still came and roosted on the handrails and equipment around E-11 and created a mess. This equipment needs to be cleaned for personnel health reasons as well as equipment health. The flocks are being dispersed using propane cannons which operate on a daily basis at dusk to prevent the starling roosting at night. 
As a planning aid for restart, we plan to inspect the condition of bearings in one DHX fan drive train per loop. This information will help plan the necessary maintenance/upgrades that will be required for restart. Additionally, in order to prevent further degradation, a program will be established to periodically rotate DHX fans.

\section{Polar Crane (M-004) and RSB Crane (M-709)}

The polar crane is presently in operable status. Annual PMPs continue to be performed on a routine basis. During a monthly wire-rope inspection in September, 1997, the auxiliary hoist wire-rope was found to have a damaged lay and was replaced. During a monthly wire-rope inspection in October, 1997 , the main hoist wire-rope was found to have an apparent opening of the wire-rope lays. Conversations with industry recognized wire-rope experts and performance of a thorough wire-rope inspection indicated that there were no safety related problems. As described by the wire-rope experts, the rope was "creeping", which can occur on older, low duty cycle/low load wire rope, without impairing its functionality.

The RSB crane is presently in operable condition except that the main hoist is not to be used. A vibration was noted in the main hoist motor, which caused the use of the RSB crane to be restricted to the auxiliary hoist only. The work package to evaluate and repair the condition should be worked in the next work phase. Annual PMPs continue to be performed on a routine basis. A control system upgrade to a radio controller was completed in September, 1996. The upgrade reduced operator risk of repetitive use injuries that had occurred with the use of the high-force, pendant push buttons (see Fuel Handling I\&C Engineering summary for further details).

\section{INTERIM EXAMINATION AND MAINTENANCE CELL AND REFUELING MECHANICAL ENGINEERING}

\section{System 32, Reactor Enclosure}

This assessment focused only on the Center Island and Outer Head Heating and Cooling Systems and not all parts and aspects of this system. This is currently the only active portion of the system and the only area of concern where continued degradation would be an issue.

The reactor head heating and cooling systems are operating acceptably for Standby. A recent evaluation of these systems was performed and found 12 of the 40 heating zones either not operating or of questionable operation. One of these has since been repaired and the others require further evaluation and troubleshooting. Since all of the head temperatures are above the $250^{\circ} \mathrm{F}$ minimum with acceptable temperature differences between zones, this further evaluation will be pursued only as time permits during standby.

\section{System 41, Reactor Refueling System}

The following subsystems of System 41 are addressed due to the previously ongoing efforts for fuel offload and the potential that a near term shutdown decision would require putting this activity back 
HNF-2380

Rev. 0, Page 8

on critical path. For that reason the following components and subsystems are deemed important to maintain their operability.

\section{Inflatable Seals}

There exists a generic issue with several of the reactor refueling system machines. Most of the major refueling components that interface with or are part of an inert facility have inflatable seals. These include the IVHM, CLEM, FVs, PHF, IEMC Ceiling Valves and BLTC. Due to aging problems with the spare seals and the age of the installed seals, there is a recognized impact to fuel handling operations should any of these need replacement. As a result, there is a need to initiate an inflatable seal qualification program. This program would need to evaluate the NCR'd seals received from manufacturers as well as attempt to recertify the aged seals presently in spares with the hope that some could be found useable. This evaluation would also need to look at possibly an improved, single design for the inflatable seals and then establish a vendor for these seals. It is only then that we would have the confidence that in support of either startup or shutdown activities there would be minimal delays due to problems with these seals. Therefore, if time permits, this is expected to be an activity Engineering will pursue during standby. As a higher priority, Engineering will pursue procurement of spare inflatable seals for the IEM Cell 9'6" port and $28^{\prime \prime}$ port since there are currently no spares available.

\section{In-Vessel Handling Machine (IVHM)}

A thorough checkout of the IVHMs occurred during this past year to determine the status of these units since they had not been operated for several years. All mechanical functions of these machines were tested and shown to be in excellent condition, with no signs of deterioration since they were last operated. There will be a new procedure written to determine annually, while in standby, what the condition of the IVHM boundary is (inflatable seals, buffers, etc.). This is the only remaining area of concern for maintaining these machines operable. These checks would be to ensure air (oxygen or moisture) does not enter any sodium wetted areas, where oxide formation could render these machines inoperable.

\section{Floor Valves (FV)}

The FVs (five) are all operable at this time, although several have deficiencies that should be worked off as time permits. Therefore, it is planned to continue to input corrective maintenance items for these components during the standby period to ensure these are ready to support any fuel offload or other component handling activities.

\section{Interim Examination and Maintenance (IEM) Cell}

- Sodium Removal System (SRS)

The SRS requires several work activities during standby. A relief valve (PSV-677) needs to be relocated and two other valves (HV-141 and HV-161) need to be repaired prior to continuing SRS operations. Presently, PSV-677 has been moved and is awaiting leak testing upon completion of the HV-141 repair. The repair of HV-161 will be performed as resources are available. This valve requires removal from the IEM Cell with transfer to MASF for repair. Also pending 
available resources is replacement of the depleted ion exchange system resin beds. Completion of this activity would then have the system ready to support either a startup or shutdown mission. (See FHI\&C summary for discussion of the system control panel.)

- Electro-Mechanical Manipulators (EMM)

The EMMs include both the Pedestal Mounted Manipulator (PMM) and the Wall Mounted Manipulator (WMM). These machines are critical components to all IEM Cell operations and have performed very well. The main problem encountered in the recent past are wrist failures which stem from extended wrist rotation drives required to install bolted lids on the Core Component Containers (CCCs). This is an operation that the equipment was not designed for. It has been determined that a speed wrench would be better suited for this service. A design and fabrication activity to provide this equipment is planned during the standby period.

\section{Solid Waste Cask (SWC)}

The SWC is currently not operational. During its last transfer operation to place a fully loaded CCC into an Interim Storage Cask, the grapple chain jammed, damaging the drive sheave. It appears that this failure mode is inherent to the current design, and that a design change would be required, recognizing that the SWC would be used extensively during either startup or shutdown. Accordingly, an upgrade project was undertaken to resolve this drive system problem.

\section{FUEL HANDLING INSTRUMENTATION AND CONTROL ENGINEERING}

\section{System 12F, Lighting}

As the system ages fluorescent ballast's continue to fail. However, the implementation of the Fix It Now! team and the revised A-28 procedure should allow repairs to be made more effectively without involving engineering to prepare resolutions for these routine work packages. Upgrades are planned for the IEM Cell galleries and Control Room lighting circuits, both of which utilize dimmers that are no longer supported. And lastly, lighting level tests are planned for the emergency lighting in the Fuel Storage Area, e.g., stairwells. It is expected that some additional lighting fixtures will be required for deficient areas uncovered during these tests.

\section{System 12G, Regulated and Non-Regulated 120 VAC}

The existing Sola voltage regulators are beginning to fail after 20 years of service. Since the factory no longer supports our units, it was decided to select an alternate design from Staco for replacing these units as they fail. One unit per quarter is recommended for replacement during 1998.

\section{System 27, Reactor Service Building Crane}

During the reporting period radio controls were added to the overhead bridge crane in the Reactor Service Building. This was done in response to complaints by the crane operators, some of whom 
HNF-2380

Rev. 0, Page 10

developed repetitive motion syndrome in their wrists due to operating the heavy and awkward pendant crane control. The new radio controls have operated without fault since their installation.

\section{System 41, Reactor Refueling System}

\section{In-Vessel Handling Machine (IVHM)}

Exercising the IVHM's disclosed a weakness with the Ectron load signal conditioners. They typically developed a load offset and had to be replaced. Discussions with the vendor revealed that a known capacitor-aging problem exists with our signal conditioning equipment and actions were subsequently taken to replace all such capacitors. This action permitted testing to proceed, however, due to their overall unreliability and aging design, it is recognized that these load signal conditioners will require replacement if a startup order is received.

\section{Closed Loop Ex-Vessel Machine (CLEM)}

The CLEM is fully operational and ready to support all planned Standby activities. The major improvement being pursued during Standby is replacement of the computer and related control systems. Although the number of repairs required in the past several years has been low, the age related potential for failure of computer system components justifies this action, regardless of whether shutdown is continued or a restart is authorized, as either scenario requires handling large numbers of components.

\section{Floor Valves (FV)}

Operations has championed a modification to the FV control system which automates the sequence of evacuating the buffer cavity prior to deflating seals to minimize the potential for spreading contamination.

\section{Multipurpose Rail Transporter (MPRT)}

During this reporting period the overly complex microprocessor control system on the MPRT was replaced with simplified relay logic. This has improved the reliability of the unit while making future troubleshooting much easier to perform.

\section{Bottom Loading Transfer Cask (BLTC)}

During this reporting period minor modifications were made to the BLTC computer control system, e.g., automated the slow withdrawal sequence to facilitate drainage while removing an assembly from a sodium pool. This change allows this withdrawal sequence to be performed in a uniform manner without requiring the constant surveillance and intervention by the operator.

The computer hardware and software for the BLTC are not Year 2000 compliant. This deficiency will not inhibit normal process operations but will result in erroneous date information being included on printed reports. It has been agreed that it is not cost effective to replace the BLTC hardware and 
software at this time, which would be required to make it fully Year 2000 compliant, but rather resolve the problem administratively, e.g., have FFTF Operations correct the date information on the printed reports.

\section{Solid Waste Cask (SWC) and Interim Decay Storage (IDS)}

The control systems for the SWC and IDS basket rotation were previously updated to include a modern computer interface which utilizes a standard programmable logic controller, identical to that being used on the BLTC. Since the upgrade the control systems have proved to be very reliable and much easier to maintain due to the diagnostics which were designed into the computer monitoring systems.

These two systems, like the BLTC, are not Year 2000 compliant. However, this deficiency does not inhibit normal process operations and unlike BLTC, no printed reports are generated, therefore, no actions are required to address this concern on these components.

\section{Sodium Removal System}

A major activity being supported in standby is an upgrade to the SRS control system. The existing control system, although operational, has several areas of concern (e.g. - loss of automatic data recording capability, meters that are hard to calibrate, aged components, and a control panel that is very difficult to work on due to restricted access and multiple power supplies). This upgrade has the potential to improve each of these areas and greatly increase the reliability of the system and therefore would be a savings for either a startup or shutdown mission. Although funding has not been identified at this time for procurement and implementation of the upgrade, the design of the system will be pursued during standby with a decision later for completion of this activity. 


\section{ANNUAL SYSTEM ASSESSMENT REPORT}

(Sheet 1 of 6 )

Date of This Report January 28, 1998

Date of Previous Report January 20, 1992

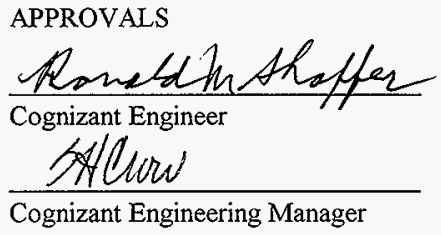

1. SCOPE

\section{System 11, Primary Electrical Power}

2. SUMMARY EVALUATION (Provide a general assessment of the overall health of the system. Include a discussion of the system's minimum operable equipment from plant procedure $\mathrm{PN}-7$.)

System 11 provides the primary power $(115 \mathrm{KV})$ to the 400 area from the BPA electrical power grid. The $115 \mathrm{KV}$ is transformed to $13.8 \mathrm{KV}$ by transformers in the $451 \mathrm{~A}$ and $451 \mathrm{~B}$ substations.

The overall health of the system is good; however, the system is showing signs of deterioration from normal aging and from the fact that preventive maintenance on the system has not been kept up to date. Preventive maintenance has not been kept up to date because we have been in a shut down or standby mode with limited resources.

The transformers at $451 \mathrm{~B}$ reduce the $115 \mathrm{KV}$ to $13.8 \mathrm{KV}$ which is then the primary and the backup supply to switchgear $\mathrm{H} 1$. The backup $13.8 \mathrm{KV}$ power for switchgear $\mathrm{H} 1$ and the alternate preferred $13.8 \mathrm{KV}$ power are listed as minimum operable equipment in procedure PN-7.

3. ITEMS REQUIRING ACTION (Items on PTS, Procedures, Software, etc.)

A. Near Term Items

Required By

WORK PACKAGE 4F-97-2640/W

This work package will perform preventive maintenance on battery set $\mathrm{DCl}$ at 451B. The work will include replacing all battery bus bars, cleaning battery terminals, measuring battery terminal resistance, performing a battery equalization charge, and a battery discharge test. 


\section{ANNUAL SYSTEM ASSESSMENT REPORT}

(Sheet 2 of 6 )

A. Near Term Items (cont'd)

Required By

WORK PACKAGES 4F-95-557/P AND 4F-95-558/P

$98-2$

These work packages perform preventive maintenance on transformer TRR2 at 451B. This work will include cleaning, testing high voltage bushings, testing the sudden pressure relay, testing tap changer, testing cables, and testing the main breaker in $\mathrm{H} 12$ switchgear. This work will be performed by Electrical Utilities.

WORK PACKAGES 4F-96-1352/W AND 4F-96-1920/W

The low pressure alarm on transformer $\mathrm{X} 1$ will be repaired and the potential transformer will be inspected for oil leaks.

SUBSTATION 451A \& 451B INFRARED INSPECTION

The two high voltage substations $451 \mathrm{~A} \& \mathrm{~B}$ need to be surveyed with an infrared viewer to determine if there are any hot connections developing from loose connections that will show up as hot spot. Infrared inspections of high voltage substations is a standard method of inspecting live equipment for potential maintenance problems.

B. Long Term Items

Required By

\section{PREVENTIVE MAINTENANCE ON THE 45IA SUBSTATION AND} SWITCHGEAR H2 AND H3

This work will include testing and inspecting transformer $\mathrm{Xl}$ and the potential transformers. In addition, the substation bus work will be inspected, insulators cleaned, bushings cleaned and tested. The high voltage switches B290 and B291 will be inspected, cleaned, and operated. The B290 switch is a motor operated switch that needs to be tested for proper operation. The transformer needs oil residue cleaned off its surfaces.

The high voltage distribution switches $\mathrm{S} 7, \mathrm{~S} 8$, and $\mathrm{S} 9$ will be inspected, cleaned, and tested. The $13.8 \mathrm{KV}$ cables will be tested and the $\mathrm{H} 2$ and $\mathrm{H} 3$ switchgear will be inspected, cleaned, and tested. 


\section{ANNUAL SYSTEM ASSESSMENT REPORT}

(Sheet 3 of 6 )

4. TRENDS (Discuss trended parameters. See Appendix K for typical parameters which can be used for trending studies.)

There have not been any failures in system 11 to provide any failure trends. The primary power system is beginning to show the effects of being in use for approximately twenty years and not receiving as much preventive maintenance as it should have been receiving. An example of this is the insulators and bushings on the two $115 \mathrm{KV} / 13.8 \mathrm{KV}$ transformers at $451 \mathrm{~B}$ became dirty and stained from rusting hardware. In addition, the bolts were not torqued to the correct tightness. The hardware was replaced with stainless steel hardware.

The trend is for equipment to deteriorate with time and at a faster rate when it is outdoor equipment. The system in general is in good condition; however, the trend to deleting preventive maintenance from work schedules in favor of modification work and canceling preventive maintenance procedures will have to be reversed or we will be faced with serious power outages. The primary power system is the one system that is needed to keep the plant operating in a non-emergency mode and cutting spending in this area can have serious consequences.

5. SYSTEM AGING, SPARE PARTS CONSIDERATIONS, AND LONG TERM MAINTENANCE PHILOSOPHY

A. Discuss effects of system aging.

System 11 primary power equipment is showing signs of aging. The $115 \mathrm{KV} / 13.8$ $\mathrm{KV}$ transformers in $451 \mathrm{~A}$ and in $451 \mathrm{~B}$ have leaked oil periodically and one transformer at 451B has a very slow continuous oil leak. The equipment is in need of preventive maintenance to determine if there are other aging effects that can only be found when the equipment is inspected and tested.

B. Discuss the strategy for near term spare parts and their availability strategy.

There are very few spare parts for system 11 equipment. The equipment is large and it is very expensive to maintain any significant spare inventory. In case of a major failure, alternate power sources would have to be used until repairs are made or replacement equipment is obtained. 


\section{ANNUAL SYSTEM ASSESSMENT REPORT}

(Sheet 4 of 6 )

C. Standby Maintenance Plan: Discuss a plan which ensures essential system functions for standby are provided and minimizes equipment degradation. Assume the standby period extends for the next one to two years. Include in the plan, as a minimum: 1)the identification of hardware to be repaired, replaced, or upgraded; and 2)the frequency of routine field maintenance, ensuring material and spare parts are identified to support these activities.

To maintain system 11 over the next two years, the preventive maintenance items listed in the "Near Term Items" and "Long Term Items" must be completed. The work items listed are from recommendations in an administrative study entitled "Electrical Preventive Maintenance Administration Evaluation for FFTF/400 Area," work package 4F-97-247/A.

\section{CHECK OFF LIST}

A. Accessible parts of the entire system or component have been thoroughly walked down at least once in the past 30 days to view current performance, equipment status and condition. Yes $\underline{X}$ No

B. Are there any conditions which might require limitations different from operating limits as defined in the SDDs, the FSAR, or the Plant Technical Specifications? Yes__ No $\underline{X}$

C. Are there trip settings, set points, interlocks, etc., that should be changed from those currently established? Yes_ No $X$

D. Are there interface areas which have not performed acceptably, which require resolution? Yes_No $\underline{X}$

E. Are there temporary plant or procedural conditions which will and should remain in place? Yes No $\mathrm{X}$

F. Is any retesting or special testing (e.g., OSP) required? Yes_ No $\underline{X}$ 


\section{ANNUAL SYSTEM ASSESSMENT REPORT}

(Sheet 5 of 6 )

G. Are the current plant corrective maintenance, preventive maintenance, and calibration database items all properly identified and are planned actions acceptable? Yes_No $\underline{X}$

Preventive maintenance procedures for the 451A substation transformer, switches, and bus work are on an "As Requested" basis; therefore the procedures have no fixed periodicity to be done and there is no priority for them being performed. Some of the landlord preventive maintenance procedures are in the site wide procedure system which makes it virtually impossible for FFTF to make changes to them. They are not up to date and in some cases not correct. One solution would be to write and use our own procedures for the FFTF landlord preventive maintenance work. The landlord preventive maintenance procedures will be written for the FFTF preventive maintenance system if we receive a start up order from the DOE.

Preventive maintenance procedures will have to be written for the $13.8 \mathrm{KV}$ breakers in the $451 \mathrm{~B}$ substation and for the high voltage switches $\mathrm{S} 7, \mathrm{~S} 8$, and $\mathrm{S} 9$ in the 451A substation when this work is done.

H. Are all other action items (NCRs, IRs, etc.) properly identified and assigned? Yes No_ NA X $\mathrm{X}$

I. Are there any special operating considerations? Yes_ No $\mathrm{X}$

J. Are near term spare parts adequate? Yes $\underline{X}$ No

K. Have any safety issues (radiological, industrial) been identified that remain unresolved? Yes_ No _ NA X

L. Have all component data been entered into the Plant information database? Yes No $\mathrm{X}$

The breakers in switchgear $\mathrm{HIl}$ and $\mathrm{H} 12$ at $451 \mathrm{~B}$ will have to be added when the preventive maintenance procedures are written.

M. Have applicable SISI inspections been conducted? Yes_No_NA $\underline{X}$

N. Has a cleanliness evaluation been completed? Yes X No_ Are any issues still unresolved? Yes_No $\mathrm{X}$ 


\section{ANNUAL SYSTEM ASSESSMENT REPORT}

(Sheet 6 of 6 )

\section{REFERENCES}

Administrative study "Electrical Preventive Maintenance Administration Evaluation for FFTF/400 Area," work package 4F-97-247/A.

\section{ATTACHMENTS}

(Attach any CSRs, data sheets showing system performance, or other material demonstrating the substantive nature of this review).

None. 


\section{ANNUAL SYSTEM ASSESSMENT REPORT}

(Sheet 1 of 7)

Date of This Report January 27, 1998

Date of Previous Report January 20, 1992

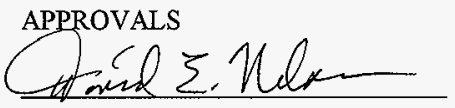

Cognizant Engineer

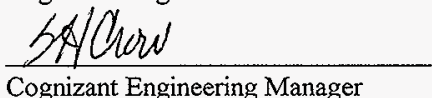

1. $\underline{\text { SCOPE }}$

System 12A/M, Battery \& 125 VDC Systems

System 12J, Zero Time Outage 120 VAC System

2. SUMMARY EVALUATION (Provide a general assessment of the overall health of the system. Include a discussion of the system's minimum operable equipment from plant procedure PN-7.)

The 125 VDC System consists of four separate battery banks, chargers, monitoring and power distribution systems which provides power to the $1 \mathrm{E}$ and non- $1 \mathrm{E}$ power systems. The $1 \mathrm{E}$ systems have been laid up with their loads connected to the non- $1 \mathrm{E}$ system and have had only routine surveillance performed on the batteries and chargers. The non-1E systems are currently functioning and routine surveillance is performed to maintain operability. Non-1E batteries D-101 and D-102 are listed as minimum operable equipment in PN-7. The overall health of the $125 \mathrm{VDC}$ system is good; however, preventive maintenance on the $1 \mathrm{E}$ system has not been kept up to date because of the plant being in either a shutdown or standby mode (with limited resources).

System 12J, the Zero Time Outage 120 VAC System, fed by the 125 VDC system is currently laid up for shutdown and will not be addressed until a restart order is given. 
HNF-2380

Rev. 0, Page 19

\section{ANNUAL SYSTEM ASSESSMENT REPORT}

(Sheet 2 of 7)

3. ITEMS REQUIRNNG ACTION (Items on PTS, Procedures, Software, etc.)

A. Near Term Items

$\underline{\text { Required By }}$

$1 \mathrm{E}$ battery banks $\mathrm{D} 1$ and $\mathrm{D} 2$ both have high levels of corrosion on the intercell connections. Work requests 4F-96-1065 and 4F-96-1461 address the corrosion and should be done the second and third quarters of 1998. D2 is the one with the most corrosion and should be done first. After the connections are cleaned, both battery banks should have a full seven to fourteen day equalizing charge to ensure that the specific gravity reaches the vendor recommended value of 1.215. D1 specific gravity checked during surveillance averaged around 1.210, which is low. D2 specific gravity checked during surveillance averaged around 1.200 , which is very low. Routine surveillance and equalizing charges should be performed as scheduled after the work orders for cleaning the corrosion and equalizing charges to restore the battery capacity are completed. The battery chargers D3 and D5 for $\mathrm{D} 1$ and D2 were last maintained in 1993. A routine inspection and calibration check of each charger should be done during the last quarter of 1998 . The rest of the $1 E$ distribution panels and motor starters had energized inspections performed between 1993 and 1995. The current frequency has been four years between inspections. It is recommend that the inspections continue to be deferred until the decision on startup is reached.

$\begin{array}{llr}\text { 4F-96-1461 } & \text { CLEAN CORROSION OF INTERCELL CONNECTIONS } & 98-2 \\ \text { 4F-96-1065 } & \text { CLEAN CORROSION OF INTERCELL CONNECTIONS } & 98-3 \\ \text { EQUALIZE D2 FOR 7 TO 14 DAYS PER SN-12-12 } & 98-3 \\ \text { EQUALIZE D1 FOR 7 TO 14 DAYS PER SN-12-12 } & 98-4 \\ \text { PERFORM PMP 12A/M-E03 ON D2 } & 98-4 \\ \text { PERFORM PMP 12A/M-E03 ON D1 } & 98-4\end{array}$

The non-1E battery banks D101 and D102 are both in excellent condition, showing no sign of corrosion. Battery chargers $\mathrm{D} 103$ and $\mathrm{D} 105$ both require the overcurrent charging circuits to be set to avoid the potential for equipment damage. D101 average specific gravity is 1.210 , which is low. D102 specific gravity is 1.212 , which is also low. This indicates that both battery banks require an extended seven to fourteen day equalize charge to return the specific gravity to the vendor recommended value of 1.215 . The rest of the non- $1 E$ system has had routine maintenance performed. 


\section{ANNUAL SYSTEM ASSESSMENT REPORT}

(Sheet 3 of 7)

A. Near Term Items (cont'd)

Required By

4F-97-1099/W

REPAIR CURRENT LIMIT ON D103 \& D105

98-3

D103 \& D105 battery chargers draw excessive current and trip their overcurrent protective breaker when placed back in service after maintenance or battery discharge tests.

4F-97-1201/P INSPECT PANELS D 106 \& D107

Maintenance inspection of main DC distribution panels per PMP-12A/M-E05.

4F-97-904

REPAIR LOOSE KNOCKOUTS ON D103

One of the electrical knockouts is loose in the top panel of battery charger D103.

If it falls into the charger a severe electrical short circuit could result.

4F-96-1143

REPLACE LOAD CIRCUIT BREAKER

98-2

A piece of the D-115 non-1E inverter load breaker case broke off while closing the breaker. This affects the integrity of the breaker during fault conditions.

4F-97-2152/W \& 4F-97-2575/M

98-3

INSTALL THE AC OUTLETS AND CABLES FOR THE PORTABLE EMERGENCY BATTERY CHARGER.

A portable emergency charger was purchased to provide backup for the $1 \mathrm{E}$, non-1E, and $451 \mathrm{~B}$ battery chargers in the event they fail. Outlets are required near the existing battery chargers to allow the portable unit to be plugged in. Cables will be attached to the portable unit to connect it to the outlet and the battery banks.

B. Long Term Items

Required By

Routine surveillance on D1 and D2, including the battery chargers, should be performed as scheduled. Equalize battery charges to the 1.215 specific gravity should be performed to ensure that batteries maintain the level of equipment readiness to support the standby mission and be prepared for restart. If a restart order is given, the battery banks D1 and D2 will require load testing to determine if any cells are failing and require replacement.

Routine maintenance should continue on D101 and D102 batteries, their chargers, and the non-1E distribution equipment. Equalize charge to the 1.215 specific gravity level should also be performed. Deferred inspections of the energized equipment should be completed. 


\section{ANNUAL SYSTEM ASSESSMENT REPORT}

(Sheet 4 of 7 )

B. Long Term Items (cont'd)

Required By

4F-96-1748 ENERGIZED INSPECTION OF D-114 PER PMP-12J-E14 99-2

4F-97-382 ENERGIZED INSPECTION OF D-115 PER PMP-12J-E14 99-3

4F-93-1595/A REPLACE CAPACITORS IN INVERTORS

D40,41,42,43,114,115

SU-1

4. TRENDS (Discuss trended parameters. See Appendix K for typical parameters which can be used for trending studies.)

There have not been any power failures in the $12 \mathrm{~A} / \mathrm{M} 125 \mathrm{VDC}$ power distribution system. The preventive maintenance procedures past due for the non- $1 E$ system are the energized inspections of the inverters. 1E system maintenance is deferred. The slippage in the maintenance efforts and completion dates is due to the facility being in a shutdown or standby mode. This trend needs to be reversed to prevent any unscheduled power outages or premature battery bank replacement.

5. SYSTEM AGING, SPARE PARTS CONSIDERATIONS, AND LONG TERM MAINTENANCE PHILOSOPHY

A. Discuss effects of system aging.

System aging in the battery chargers, inverters, and monitoring electronic and control circuit boards is primarily reflected in the failure of capacitors which then can cause major failures of the internal electronics and components making up this equipment. After about ten years, the larger electrolytic capacitors used in the UPS, inverters, and battery chargers are subject to failures which can cause longer term outages of the equipment while corrective maintenance is performed.

Terminals, battery bus and cable connector bolts may corrode and loosen up and cause a hot connection which can eventually cause a fire and fault condition. For example, high levels of corrosion on the $\mathrm{lE}$ battery intercell connections is due to aging and the lack of maintenance. Breakers, if not cycled, can become dirty and bind up so that they will not operate properly, failing to protect the downstream equipment. Battery banks, if not properiy maintained, charged, and load tested, will fail when called upon to perform their emergency backup function; thus placing the facility at risk. Cells will sulfate and stratify due to aging if not maintained. 


\section{ANNUAL SYSTEM ASSESSMENT REPORT}

\section{(Sheet 5 of 7 )}

B. Discuss the strategy for near term spare parts and their availability strategy.

The existing spare parts for the $1 \mathrm{E}$ and non- $1 \mathrm{E}$ systems are adequate. The battery cells are not stocked, but are standard manufactured items readily available. The capacitors and circuit boards having capacitors require inspection for age related failure if we receive a startup order.

C. Standby Maintenance Plan: Discuss a plan which ensures essential system functions for standby are provided and minimizes equipment degradation. Assume the standby period extends for the next one to two years. Include in the plan, as a minimum: 1)the identification of hardware to be repaired, replaced, or upgraded; and 2)the frequency of routine field maintenance, ensuring material and spare parts are identified to support these activities.

To maintain system 12A/M over the next two years, the corrective and preventive maintenance items listed in "Near Term Items" and "Long Term Items" should be completed.

\section{CHECKOFF LIST}

A. Accessible parts of the entire system or component have been thoroughly walked down at least once in the past 30 days to view current performance, equipment status and condition.

Yes $\underline{X}$ No

B. Are there any conditions which might require limitations different from operating limits as defined in the SDDs, the FSAR, or the Plant Technical Specifications? Yes_ No $\mathrm{X}$

C. Are there trip settings, set points, interlocks, etc., that should be changed from those currently established?

Yes_. No $\mathrm{X}$

D. Are there interface areas which have not performed acceptably, which require resolution?

Yes_No $\mathrm{X}$

E. Are there temporary plant or procedural conditions which will and should remain in place? Yes_ No $\mathrm{X}$ 


\section{ANNUAL SYSTEM ASSESSMENT REPORT}

(Sheet 6 of 7)

F. Is any retesting or special testing (e.g., OSP) required?

Yes_. No $\mathrm{X}$

G. Are the current plant corrective maintenance, preventive maintenance, and calibration database items all properly identified and are planned actions acceptable?

Yes_No $\mathrm{X}$

The preventive maintenance program needs to be evaluated to ensure that the resources are provided to perform the work. The electrical backlog for all systems impacts the response to the required maintenance on this system. There is a total of seventeen preventive maintenance line items in the $1 \mathrm{E} / 12 \mathrm{~A}$ system with $53 \%$ overdue. There is a total of ten preventive maintenance line items in the non- $1 E / 12 \mathrm{M}$ system with $20 \%$ overdue. The items listed in Section 3 should be performed to maintain system health.

H. Are all other action items (NCRs, IRs, etc.) properly identified and assigned? Yes_No_NA X

I. Are there any special operating considerations?

Yes_No No

J. Are near term spare parts adequate? Yes X No _

K. Have any safety issues (radiological, industrial) been identified that remain unresolved? Yes__ No $\mathrm{X}$

L. Have all component data been entered into the Plant information database?

Yes $\mathrm{X}$ No

M. Have applicable SISI inspections been conducted?

Yes_No_NA X

N. Has a cleanliness evaluation been completed? Yes_X No

Are any issues still unresolved? Yes_ No_ X

\section{REFERENCES}

None 


\section{ANNUAL SYSTEM ASSESSMENT REPORT}

(Sheet 7 of 7 )

\section{ATTACHMENTS}

None. 


\section{ANNUAL SYSTEM ASSESSMENT REPORT}

(Sheet 1 of 5 )

Date of This Report January 26, 1998

Date of Previous Report January 20, 1992
APPROVALS
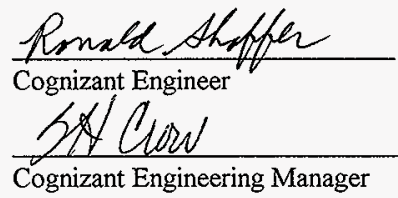

\section{SCOPE}

System 12B, 13.8KV Power Distribution System

\section{SUMMARY EVALUATION}

The 13.8KV power distribution system provides power to all the buildings in the 400 area from the $451 \mathrm{~A}$ and $451 \mathrm{~B}$ substations. There are three sources of $13.8 \mathrm{KV}$ power that feed FFTF, one from $451 \mathrm{~A}$, one from $451 \mathrm{~B}$, and one from the 300 area (alternate preferred). The $13.8 \mathrm{KV}$ is distributed throughout FFTF to transformers where it is transformed down to $480 / 277 \mathrm{VAC}$. The overall health of the $13.8 \mathrm{KV}$ system is good; however, preventive maintenance on this system has not been kept up to date because of the plant being in either a shutdown or standby mode with limited resources.

The backup $13.8 \mathrm{KV}$ power for switchgear $\mathrm{HI}$ and the alternate preferred $13.8 \mathrm{KV}$ power are listed as minimum operable equipment in procedure PN-7.

\section{ITEMS REOUIRING ACTION}

A. Near Term Items

Required By

PROTECTIVE RELAY CALIBRATION

The protective relays in the FFTF $13.8 \mathrm{KV}$ system need calibration. The protective relays provide the electrical protection for the $13.8 \mathrm{KV}$ system and prevent equipment damage, due to fault conditions. It is the set point on these relays that determine the current level that signals the breaker to open. These relays are normally calibrated every two years; the last preventive maintenance calibration on these relays was performed seven years ago. 


\section{ANNUAL SYSTEM ASSESSMENT REPORT}

(Sheet 2 of 5)

A. Near Term Items (cont'd)

$\underline{\text { Required By }}$

WORK PACKAGE 4F-90-181

$98-2$

This work package performs preventive maintenance on one breaker (11R)

in $\mathrm{H} 1$ switchgear and on the downstream load center and motor control centers.

BREAKERS MAINTENANCE AT 451B

Breakers at $451 \mathrm{~B}$ in switchgear $\mathrm{H} 11$ and $\mathrm{H} 12$ will be inspected, cleaned, and tested. There are no preventive maintenance procedures for these breakers. The work instructions will be in the work package and preventive maintenance procedures can then be written from the work package resolution.

B. Long Term Items

Required By

SWITCHGEAR H2 AND H3

$99-2$

Switchgear $\mathrm{H} 2$ and $\mathrm{H} 3$ will undergo preventive maintenance at the same time that $451 \mathrm{~A}$ substation is shut down for preventive maintenance. This work will involve inspecting, cleaning, and testing.

SWITCHGEAR H4 AND H5

Preventive maintenance will be performed on the breakers in emergency Switchgear $\mathrm{H} 4$ and $\mathrm{H} 5$.

\section{TRENDS}

There have not been any power failures in the $13.8 \mathrm{KV}$ power distribution system. The number of preventive maintenance procedures past due in this system has increased substantially, due to the facility being in a shut down or standby mode. This trend needs to be reversed to prevent any unscheduled power outages and damage to the PCB transformers. 
HNF-2380

Rev. 0, Page 27

\section{ANNUAL SYSTEM ASSESSMENT REPORT}

(Sheet 3 of 5)

The PCB transformer oil is tested yearly to determine the health of these transformers. There are a total of three tests performed on the oil: breakdown voltage, neutralization number (acidity), and oil screening (color, sediment). All of these tests show the transformers are in good health; however, there are a few where the neutralization number is approaching borderline. If the oil tests for 1998 on these transformers have a higher neutralization number, we may be faced with having the oil processed to reduce the acidity. The acid in mineral oil and in PCB oil can be removed with a Fuller's earth treatment. The mineral oil can be treated by Dyncorp Electrical Utilities, but the PCB oil would have to be treated by an outside service like S.D.Myers.

\section{SYSTEM AGING, SPARE PARTS CONSIDERATIONS, AND LONG TERM} MAINTENANCE PHILOSOPHY

A. Discuss effects of system aging.

As the system ages and when preventive maintenance is not performed, insulators become dirty and may short out the system causing a fault condition. Bus bar and cable connector bolts may loosen up and cause a hot connection which will eventually cause a fire and shorted fault condition. Breakers can become dirty and parts bind up such that they do not operate properly, failing to protect the downstream equipment. Protective relays that are not calibrated will eventually be out of calibration and fail to trip the breakers that are protecting downstream equipment. If we are not doing preventive maintenance on this equipment, the only way we know the equipment is deteriorating is when it fails.

One example of $13.8 \mathrm{KV}$ equipment deterioration due to aging is in work package 4F-96-2186 which describes breaker H1-12R being difficult to close. This breaker will be repaired when the equipment it powers can be arranged to be shut down.

B. Discuss the strategy for near term spare parts and their availability strategy.

The existing spare breakers for the $13.8 \mathrm{KV}$ switchgear are adequate at the present time. The remaining equipment (i.e., transformers, high voltage switches, switchgear, and cables) are not kept in spares. In case of a major equipment failure, this material could be readily purchased to avoid an extended outage. 


\section{ANNUAL SYSTEM ASSESSMENT REPORT}

(Sheet 4 of 5 )

C. Standby Maintenance Plan: Discuss a plan which ensures essential system functions for standby are provided and minimizes equipment degradation. Assume the standby period extends for the next one to two years. Include in the plan, as a minimum: 1) the identification of hardware to be repaired, replaced, or upgraded; and 2) the frequency of routine field maintenance, ensuring material and spare parts are identified to support these activities.

To maintain system 12B over the next two years the preventive maintenance items listed in "Near Term Items" and "Long Term Items" should be completed. The work items listed are from recommendations in an administrative study entitled "Electrical Preventive Maintenance Administration Evaluation for FFTF/400 Area" (Work Package 4F-97-247/A).

\section{CHECKOFF LIST}

A. Accessible parts of the entire system or component have been thoroughly walked down at least once in the past 30 days to view current performance, equipment status and condition.

Yes $\mathrm{X}$ No -

B. Are there any conditions which might require limitations different from operating limits as defined in the SDDs, the FSAR, or the Plant Technical Specifications? Yes_ No $\underline{X}$

C. Are there trip settings, set points, interlocks, etc., that should be changed from those currently established?

Yes_No No $\mathrm{X}$

D. Are there interface areas which have not performed acceptably, which require resolution?

Yes_No N X

E. Are there temporary plant or procedural conditions which will and should remain in place? Yes_ No $\mathrm{X}$

F. Is any retesting or special testing (e.g., OSP) required?

Yes_No $\mathrm{X}$ 


\section{ANNUAL SYSTEM ASSESSMENT REPORT}

(Sheet 5 of 5)

G. Are the current plant corrective maintenance, preventive maintenance, and calibration database items all properly identified and are planned actions acceptable?

Yes_No $\mathrm{X}$

The preventive maintenance program needs to be changed to have the procedures released on a realistic fixed schedule and the resources need to be provided to perform the work. There are approximately 350 preventive maintenance line items that are overdue for this system.

H. Are all other action items (NCRs, IRs, etc.) properly identified and assigned? Yes_No__NA $\underline{X}$

I. Are there any special operating considerations?

Yes_No $X$

J. Are near term spare parts adequate? Yes $\underline{X}$ No_

K. Have any safety issues (radiological, industrial) been identified that remain unresolved? Yes_ No $\underline{X}$

L. Have all component data been entered into the Plant information database?

Yes_ No $\underline{X}$

The landlord equipment is not all in the JCS database.

M. Have applicable SISI inspections been conducted?

Yes_No_NA $\mathrm{X}$

N. Has a cleanliness evaluation been completed? Yes $\mathrm{X}$ No

Are any issues still unresolved? Yes_ No $\mathrm{X}$

\section{REFERENCES}

Administrative study "Electrical Preventive Maintenance Administration Evaluation for FFTF/400 Area" (Work Package 4F-97-247/A).

\section{8. $\quad$ ATTACHMENTS}

None. 


\section{ANNUAL SYSTEM ASSESSMENT REPORT}

(Sheet 1 of 5)

Date of This Report January 26, 1998

Date of Previous Report January 20, 1992

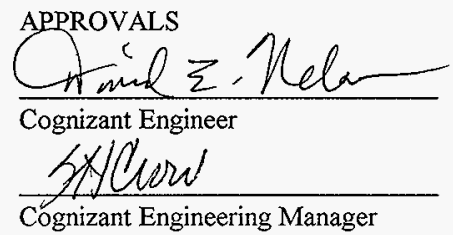

1. SCOPE

System 12C, 2.4KV Power Distribution System.

2. SUMMARY EVALUATION (Provide a general assessment of the overall health of the system. Include a discussion of the system's minimum operable equipment from plant procedure $\mathrm{PN}-1$.)

The 2.4KV power distribution system consists of switchgear units $\mathrm{A} 1, \mathrm{~A} 2, \mathrm{~A} 3, \mathrm{~A} 4 \mathrm{~A}$, and $\mathrm{A} 4 \mathrm{~B}$. Each one of the switchgear units $\mathrm{A} 1, \mathrm{~A} 2$, and $\mathrm{A} 3$ have identical loads tied to them consisting of one of the three Primary Pumps P1, P2, P3; one of the secondary pumps P4, P5, P6, and four DHX fan motors. The primary pump pony motors are fed from the $480 \mathrm{~V}$ system and not covered here. A1 has the additional primary feeder to the CRDM MG set D17 tied to its bus. Currently, only the secondary pumps P4, P5, and P6 are operational during standby. Switchgear lineups A4A and A4B provide power to ECCW chillers E20A, E21A, E22A, and E23A which are operational during standby. The overall health of the $2.4 \mathrm{KV}$ system is good; however, preventive maintenance on this system has not been kept up to date because of the plant being in either a shutdown or standby mode (in conjunction with limited resources).

Note: P4, P5, P6, E20, E22, and E23 are listed in PN-7 as minimum operable equipment. Without switchgear $\mathrm{Al}, \mathrm{A} 2, \mathrm{~A} 3, \mathrm{~A} 4 \mathrm{~A}$, and $\mathrm{A} 4 \mathrm{~B}$ being available to provide power, none of the equipment listed will be operable. 


\section{ANNUAL SYSTEM ASSESSMENT REPORT}

(Sheet 2 of 5)

3. ITEMS REQUIRING ACTION (Items on PTS, Procedures, Software, etc.)

A. Near Term Items

$\underline{\text { Required By }}$

Switchgear units $\mathrm{A} 1, \mathrm{~A} 2$, and $\mathrm{A} 3$ have all experienced problems with the racking motors, coupling for the racking motors, and mechanical alignments. Switchgear protective relay calibrations were last completed in phase 94-2. Switchgear Al was last inspected and maintained in phase 91-4. Switchgear A2 was last inspected and maintained in phase 88-2. Switchgear A3 was last inspected and maintained in phase $87-4$. Al individual $2.4 \mathrm{KV}$ breakers were inspected and maintained in phase 91-4. A2 individual 2.4KV breakers were inspected and maintained in phase 91-3. A3 individual $2.4 \mathrm{KV}$ breakers were inspected and maintained in phase $90-4$. Switchgear unit A4A was inspected and maintained in phase 94-1. Switchgear unit $\mathrm{A} 4 \mathrm{~B}$ was last inspected and maintained in phase 88-4. National Fire Code (NFC) $70 \mathrm{~B}$ recommends that relays be calibrated every two years, indoor switchgear be inspected and maintained on a three to six year cycle, and outdoor switchgear be inspected and maintained on a three year cycle. The above records show that we are long overdue for maintenance on the majority of system $12 \mathrm{C}$ equipment. The following items require near term action.

\section{F-97-245 RELIABILITY OF SWGR RACKING MOTORS A1,A2,A3}

The racking motors and mechanisms are difficult to operate due to worn parts and possible misalignment of mechanisms.

4F-98-44 CUBICLE RACKING MTR COUPLINGS LOOSE A1,A2,A3 98-3 The couplings for the breaker racking mechanisms have become loose and slip when the racking motor is engaged to rack in the breaker.

PERFORM PROTECTIVE RELAY CALIBRATION PER PMP-12C-E06 ON SECONDARY PUMP CIRCUITS

PERFORM PMP-12C-E04 BREAKER MAINTENANCE ON SECONDARY PUMP BREAKERS

PERFORM PMP-12C-E05 BREAKER AND SWITCHGEAR MAINTENANCE

ON A4B 
HNF-2380

Rev. 0, Page 32

\section{ANNUAL SYSTEM ASSESSMENT REPORT}

(Sheet 3 of 5 )

\section{B. Long Term Items}

Required By

The results of the short term work items will be used to determine if there are potential failures in the other components of the A1, A2, A3, and A4A switchgear lineups that require immediate corrective action. Although beyond the scope of this assessment, the following items must be done prior to startup.

PERFORM PMP-12C-E04 ON REMAINING Al, A2, \& A3 BREAKERS SU-1 PERFORM PMP-12C-E06 ON REMAINING PROTECTIVE RELAYS ON AI, A2, A3, A4A, AND A4B SWITCHGEAR

4. TRENDS (Discuss trended parameters. See Appendix $\mathrm{K}$ for typical parameters which can be used for trending studies.)

There have not been any power failures in the $2.4 \mathrm{KV}$ power distribution system; however, the problems with the racking mechanisms is an indicator that the deferred maintenance is contributing to the problem. The preventive maintenance has been deferred in this system due to the facility being in a shutdown or standby mode. This trend needs to be reversed to prevent any unscheduled power outages.

\section{SYSTEM AGING, SPARE PARTS CONSIDERATIONS, AND LONG TERM} MAINTENANCE PHILOSOPHY

A. Discuss effects of system aging.

As the system ages and when preventive maintenance is not performed, operating mechanisms loosen up and become misaligned, lubrication dries out causing binding, dirt accumulates which can cause operational malfunctions, and insulation breakdowns cause catastrophic failures and system burn downs due to short circuits and system fault conditions. These types of problems have been experienced with the switchgear unit $\mathrm{A} 1, \mathrm{~A} 2, \mathrm{~A} 3$ racking motors, couplings for racking motors, and mechanical alignments. Bus bar and cable connector bolts may loosen up and cause a hot connection which will eventually cause a fire and shorted fault condition. Breakers can become dirty and parts bind up such that they do not operate properly, failing to protect the downstream equipment. Protective relays that are not calibrated will eventually be out of calibration and fail to trip the breakers that are protecting downstream equipment. Routine maintenance is critical to maintain operation of higher voltage equipment. 


\section{ANNUAL SYSTEM ASSESSMENT REPORT}

(Sheet 3 of 5)

B. Long Term Items

Required By

The results of the short term work items will be used to determine if there are potential failures in the other components of the $\mathrm{A} 1, \mathrm{~A} 2, \mathrm{~A} 3$, and $\mathrm{A} 4 \mathrm{~A}$ switchgear lineups that require immediate corrective action. Although beyond the scope of this assessment, the following items must be done prior to startup.

PERFORM PMP-12C-E04 ON REMAINING A1, A2, \& A3 BREAKERS SU-1

PERFORM PMP-12C-E06 ON REMAINING PROTECTIVE RELAYS ON A1, A2, A3, A4A, AND A4B SWITCHGEAR SU-1

PERFORM PMP-12C-E05 ON A4A

SU-1

4. TRENDS (Discuss trended parameters. See Appendix K for typical parameters which can be used for trending studies.)

There have not been any power failures in the $2.4 \mathrm{KV}$ power distribution system; however, the problems with the racking mechanisms is an indicator that the deferred maintenance is contributing to the problem. The preventive maintenance has been deferred in this system due to the facility being in a shutdown or standby mode. This trend needs to be reversed to prevent any unscheduled power outages.

5. SYSTEM AGING SPARE PARTS CONSIDERATIONS, AND LONG TERM MAINTENANCE PHILOSOPHY

A. Discuss effects of system aging.

As the system ages and when preventive maintenance is not performed, operating mechanisms loosen up and become misaligned, lubrication dries out causing binding, dirt accumulates which can cause operational malfunctions, and insulation breakdowns cause catastrophic failures and system burn downs due to short circuits and system fault conditions. These types of problems have been experienced with the switchgear unit A1, A2, A3 racking motors, couplings for racking motors, and mechanical alignments. Bus bar and cable connector bolts may loosen up and cause a hot connection which will eventually cause a fire and shorted fault condition. Breakers can become dirty and parts bind up such that they do not operate properly, failing to protect the downstream equipment. Protective relays that are not calibrated will eventually be out of calibration and fail to trip the breakers that are protecting downstream equipment. Routine maintenance is critical to maintain operation of higher voltage equipment. 


\section{ANNUAL SYSTEM ASSESSMENT REPORT}

(Sheet 4 of 5)

B. Discuss the strategy for near term spare parts and their availability strategy.

The existing spare parts for the $2.4 \mathrm{KV}$ switchgear are adequate at the present time.

C. Standby Maintenance Plan: Discuss a plan which ensures essential system functions for standby are provided and minimizes equipment degradation. Assume the standby period extends for the next one to two years. Include in the plan, as a minimum: 1) the identification of hardware to be repaired, replaced, or upgraded; and 2) the frequency of routine field maintenance, ensuring material and spare parts are identified to support these activities.

The preventive maintenance items listed in Near Term Items should be completed to maintain system $12 \mathrm{C}$ over the next two years. The Long Term Items are required for start up only.

\section{CHECKOFF LIST}

A. Accessible parts of the entire system or component have been thoroughly walked down at least once in the past 30 days to view current performance, equipment status and condition.

Yes $\mathrm{X}$ No

B. Are there any conditions which might require limitations different from operating limits as defined in the SDDs, the FSAR, or the Plant Technical Specifications? Yes__ No $\mathrm{X}$

C. Are there trip settings, set points, interlocks, etc., that should be changed from those currently established?

Yes_ No $\mathrm{X}$

D. Are there interface areas which have not performed acceptably, which require resolution?

Yes_No $\mathrm{X}$

E. Are there temporary plant or procedural conditions which will and should remain in place? Yes_No N X

F. Is any retesting or special testing (e.g., OSP) required?

Yes_No N X 


\section{ANNUAL SYSTEM ASSESSMENT REPORT}

(Sheet 5 of 5 )

G. Are the current plant corrective maintenance, preventive maintenance, and calibration database items all properly identified and are planned actions acceptable? Yes_ No $\underline{X}$

The preventive maintenance program needs to be evaluated to ensure that the resources are provided to perform the work. There are approximately 67 preventive maintenance line items for system $12 \mathrm{C}$ with $100 \%$ that are overdue for this system. The items listed in Section 3 should be performed to maintain system health.

H. Are all other action items (NCRs, IRs, etc.) properly identified and assigned? Yes__No__NA X

I. Are there any special operating considerations?

Yes No $\underline{X}$

J. Are near term spare parts adequate? Yes $\underline{X}$ No

K. Have any safety issues (radiological, industrial) been identified that remain unresolved? Yes _ No $\underline{X}$

L. Have all component data been entered into the Plant information database?

Yes $\mathrm{X}$ No

M. Have applicable SISI inspections been conducted?

Yes_No_NA X

N. Has a cleanliness evaluation been completed? Yes $\mathrm{X}$ No

Are any issues still unresolved? Yes_ No X X

\section{REEERENCES}

None.

\section{ATTACHMENTS}

None. 


\section{ANNUAL SYSTEM ASSESSMENT REPORT}

(Sheet 1 of 5 )

Date of This Report January 26, 1998

Date of Previous Report January 20, 1992.

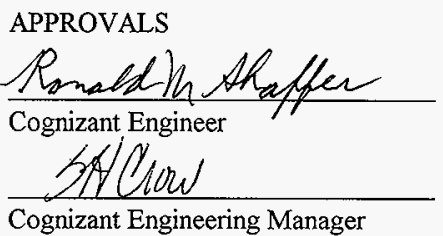

1. $\quad$ SCOPE

System 12D, 480 VAC Load Centers

System 12E, 480 VAC Emergency Load Centers

2. SUMMARY EVALUATION (Provide a general assessment of the overall health of the system. Include a discussion of the system's minimum operable equipment from plant procedure $\mathrm{PN}-7$.)

System 12D provides 480 VAC electrical power to all systems and equipment in FFTF. There are twelve 480 VAC load centers with sixty-six 480 VAC breakers in the normal power system. These load centers distribute power and provide overcurrent protection to all plant electrical power panels, motor control centers, lighting transformers, and to various plant equipment. The load centers receive their power from transformers that reduce the $13.8 \mathrm{KV}$ voltage they receive from switchgear $\mathrm{H} 1$ down to $480 \mathrm{VAC}$.

The emergency power system $12 \mathrm{E}$ distributes $480 \mathrm{VAC}$ power and provides overcurrent protection to selected critical systems in FFTF. The secondary power transformers that reduce the $13.8 \mathrm{KV}$ power to the $480 \mathrm{VAC}$ for the load center have a backup $13.8 \mathrm{KV}$ power source from turbine generator $\mathrm{G} 3$ and from the $13.8 \mathrm{KV}$ alternate preferred. There are five emergency load centers and twenty-eight $480 \mathrm{VAC}$ breakers feeding critical loads.

The $480 \mathrm{VAC}$ power distribution equipment is needed to power the equipment specified in PN-7 to maintain the plant in minimum operating condition. The overall health of this system is good; however, the equipment is in bad need of preventive maintenance being performed on it. 


\section{ANNUAL SYSTEM ASSESSMENT REPORT}

(Sheet 2 of 5)

3. ITEMS REQUIRING ACTION (Items on PTS, Procedures, Software, etc.)

A. Near Term Items

Required By

WORK PACKAGE 4F-90-181

The outdoor load center $B 113$ should have preventive maintenance performed on it during the $\mathrm{H} 1-11 \mathrm{R}$ breaker outage and maintenance. If this preventive maintenance work package is worked the 480 VAC breakers will all be cleaned, lubricated, and tested. The switchgear cubicle will be cleaned, insulators meggered, and bus bolts will be torqued. The $13.8 \mathrm{KV} / 480 \mathrm{~V}$ transformer will have preventive maintenance performed on it at the same time.

B. Long Term Items

Required By

OUTDOOR LOAD CENTERS B190 AND B195

The 480 VAC breakers in load centers B 190 and B 195 should all be cleaned, lubricated, and tested. The breaker cubicles should be cleaned, insulators cleaned, insulators meggered, and bus bolts torqued. The $13.8 \mathrm{KV} / 480 \mathrm{~V}$ transformer should have preventive maintenance performed on it at the same time.

4. TRENDS (Discuss trended parameters. See Appendix K for typical parameters which can be used for trending studies.)

There have been numerous problems with $480 \mathrm{VAC}$ breakers, most of them have been with mechanical mechanisms on racking the breakers in and out of their compartments. There have not been any electrical failures with 480 VAC Load Center breakers.

The breakers in all the 480 VAC Load Centers are long overdue for preventive maintenance being performed on them. Some load centers do not have records of preventive maintenance being performed on the breakers for the past fifteen years. The National Fire Protection Association (NFPA) recommends preventive maintenance be performed on this type of equipment at a maximum of every three to six years for indoor equipment and once every three years for outdoor equipment. The trend to not have preventive maintenance performed on $480 \mathrm{VAC}$ breakers needs to be reversed. 


\section{ANNUAL SYSTEM ASSESSMENT REPORT}

(Sheet 3 of 5)

\section{SYSTEM AGING, SPARE PARTS CONSIDERATIONS, AND LONG TERM MAINTENANCE PHILOSOPHY}

A. Discuss effects of system aging.

As the load centers age without any preventive maintenance being performed, insulators become dirty and may cause a shorted fault condition. Bus bar and cable connector bolts may loosen up and cause a hot connection which will eventually cause a fire and shorted fault condition. Breakers can become dirty and parts bind up so that it does not operate properly, failing to protect the downstream equipment. Protective relays that are not calibrated will eventually be out of calibration and fail to trip the breakers that are protecting downstream equipment.

Outdoor equipment is exposed to a lot more dirt and weathering conditions than indoor equipment; therefore, outdoor $480 \mathrm{VAC}$ Load Centers need a lot more preventive maintenance then indoor equipment.

B. Discuss the strategy for near term spare parts and their availability strategy.

The existing spare breakers for the 480 VAC Load Centers are adequate at the present time.

C. Standby Maintenance Plan: Discuss a plan which ensures essential system functions for standby are provided and minimizes equipment degradation. Assume the standby period extends for the next one to two years. Include in the plan, as a minimum: 1)the identification of hardware to be repaired, replaced, or upgraded; and 2)the frequency of routine field maintenance, ensuring material and spare parts are identified to support these activities.

To maintain Systems 12D and 12E over the next two years, the preventive maintenance items listed in "Near Term Items" and "Long Term Items" should be completed. Most of these motor control centers are outdoors and are therefore the dirtiest and the most likely to fail if not cleaned and inspected.

\section{CHECKOFF LIST}

A. Accessible parts of the entire system or component have been thoroughly walked down at least once in the past 30 days to view current performance, equipment status and condition.

Yes $\mathrm{X}$ No 


\section{ANNUAL SYSTEM ASSESSMENT REPORT}

(Sheet 4 of 5 )

B. Are there any conditions which might require limitations different from operating limits as defined in the SDDs, the FSAR, or the Plant Technical Specifications? Yes_No $X$

C. Are there trip settings, set points, interlocks, etc., that should be changed from those currently established?

Yes_No $\underline{X}$

D. Are there interface areas which have not performed acceptably, which require resolution?

Yes_No $\mathrm{X}$

E. Are there temporary plant or procedural conditions which will and should remain in place? Yes_ No $\mathrm{X}$

F. Is any retesting or special testing (e.g., OSP) required?

Yes_No No $\mathrm{X}$

G. Are the current plant corrective maintenance, preventive maintenance, and calibration database items all properly identified and are planned actions acceptable? Yes No $\underline{X}$

There are approximately 350 preventive maintenance line items that are overdue for this system. See Section 4.0 for additional discussion.

H. Are all other action items (NCRs, IRs, etc.) properly identified and assigned? Yes_No_NA X

I. Are there any special operating considerations?

Yes_No $\mathrm{X}$

J. Are near term spare parts adequate? Yes_X No

K. Have any safety issues (radiological, industrial) been identified that remain unresolved? Yes No $\underline{X}$ 


\section{ANNUAL SYSTEM ASSESSMENT REPORT}

(Sheet 5 of 5)

L. Have all component data been entered into the Plant information database?

Yes_ No $\underline{X}$

The landlord equipment is not all in the JCS database.

M. Have applicable SISI inspections been conducted?

Yes_No_NA $\underline{X}$

N. Has a cleanliness evaluation been completed? Yes_ $X$ No

Are any issues still unresolved? Yes__ No_X

7. REFERENCES

Administrative study "Electrical Preventive Maintenance Administration Evaluation for FFTF/400 Area," Work Package 4F-97-247/A.

8. ATTACHMENTS

(Attach any CSRs, data sheets showing system performance, or other material demonstrating the substantive nature of this review)

None. 


\section{ANNUAL SYSTEM ASSESSMENT REPORT \\ for \\ SYSTEM 12F AND 12G}

Date of This Report $1 / 16 / 98$

Date of Previous Report _ 1/23/92

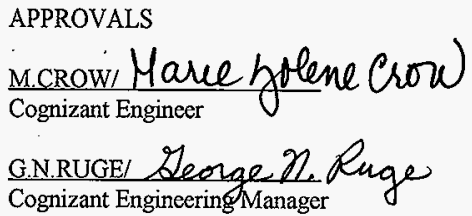

1. SCOPE

System/Component Title

$12 \mathrm{~F}$

$12 \mathrm{G}$
LIGHTING SYSTEM

REGULATED AND NON REGULATED 120V AC.

2. SUMMARY EVALUATION (Provide a general assessment of the overall health of the system. Include a discussion of the system's minimum operable equipment from plant procedure PN-1.)

\section{SYSTEM $12 F$}

The health of system $12 \mathrm{~F}$ is in good shape. There are four new projects to improve the existing system: Installing a new dimming system for the lights in the IEM cell galleries. Installing new fluorescent lights in the control room and removing the dimmers which are no longer needed. Performing a functional test for the emergency lights located in FSF stairwell per the requirements of NFPA 101 section 5-9. Installing new emergency lights for the deficient areas in FSF.

\section{SYSTEM $12 \mathrm{G}$}

System $12 \mathrm{G}$ is functioning properly. The new project for system $12 \mathrm{G}$ is to replace the three existing voltage regulators that are failing after nearly twenty years of continuous use with new voltage regulators.

3. ITEMS REOUIRING ACTION (Items on PTS, Procedures, Software, etc.)

A. Near Term Items

$\underline{\text { Required By }}$

SYSTEM $12 \mathrm{~F}$

4F-97-1249/M: Install new dimming system for the IEM cells galleries.

The existing dimming system in the IEM cell galleries is nearly twenty years old and replacement parts are no longer manufactured. 


\section{A. Continued}

4F-97-2633/M: Remove the existing control room dimming system

which is no longer needed and replace it with a new lighting system.

Perform test of the emergency lights in FSF stairwell and install new

$12 / 98$

lights for the deficient areas.

SYSTEM $12 \mathrm{G}$

4F-97-1978/M: Install a new voltage regulator to replace the existing X-110 which is failing after twenty years of continuous use.

4F-97-1977/M: Install a new voltage regulator to replace the failing voltage regulator X-180.

$6 / 98$

4F-97-1980/M: Install a new voltage regulator to replace the failing voltage

$9 / 98$ regulator X-22.

B. Long Term Items

$\underline{\text { Required By }}$

None

\section{TRENDS}

The existing Sola voltage regulators which have been in use for nearly twenty years are exhibiting a common failure mode with indications of voltage output less than $120 \mathrm{~V}$. This problem is being addressed by the installation of new voltage regulators to replace the failing ones.

5. SYSTEM AGING, SPARE PARTS CONSIDERATIONS, ANDLONG TERM MANTENANCE PHILOSOPHY

A. Discuss effects of system aging.

The Sola regulators which have been in use for more than twenty years are aging and failing. They are in the process of being replaced with new ones.

The existing dimming systems for the IEM cells galleries and the control room are nearly twenty years old and parts for both systems are failing at a higher rate than before. With replacement parts no longer manufactured, the solution is to install a new dimming system for the IEM cells galleries and to remove the control room dimming system which is no longer needed.

B. Discuss the strategy for near term spare parts and their availability strategy.

Existing spare parts are adequate and will be replenished as minimum levels are reached.

C. Standby Maintenance Plan: Discuss a plan which ensures essential system functions for standby are provided and minimizes equipment degradation. Assume the standby period extends for the next one to two years. 


\section{C. Continued}

Include in the plan, as a minimum: 1) the identification of hardware to be repaired, replaced, or upgraded; and 2) the frequency of routine field maintenance, ensuring material and spare parts are identified to support these activities (i.e., refurbish pumps, etc,).

See discussion above under section $5 \mathrm{~A}$.

\section{CHECKOFF LIST}

A. Accessible parts of the entire system or component have been thoroughly walked down at least once in the past 30 days to view current performance, equipment status and condition. Yes $\underline{\mathrm{X}}$ No_.

COMMENTS (exceptions): None

B. Are there any conditions which might require limitations different from operating limits as defined in the SDDs, the FSAR, or the Plant Technical Specifications? Yes_ No X

COMMENTS (exceptions): None

C. Are there trip settings, set points, interlocks, etc., that should be changed from those currently established? Yes__No_X

COMMENTS (exceptions): None

D. Are there interface areas which have not performed acceptably, which require resolution? Yes_ NoX

COMMENTS (exceptions): None

E. Are there temporary plant or procedural conditions which will and should remain in place? Yes X No

Attach list of $M O D(L) / E C N(L) s$, and OSPs that are currently active. Provide justification for continuing temporary MOD $(\mathrm{L}) \mathrm{s}$ and $\mathrm{ECN}(\mathrm{L}) \mathrm{s}$.

COMMENTS (exceptions): It could be stated that though the lighting in Lower Containment is not in compliance with NEC requirements Article 305-3 section d, it has been reviewed by Engineering and Safety personnel and deemed acceptable for current plant status. No changes will be made while we remain in Standby or return to Deactivation. Modifications to bring the lighting in Lower Containment into conformance with the NEC requirements would wait until we received a Startup order.

F. Is any retesting or special testing (e.g., OSP) required? Yes_No $\mathrm{X}$

COMMENTS (exceptions): None 


\section{Continued}

G. Are the current plant corrective maintenance, preventive maintenance, and calibration database items all properly identified and are planned actions acceptable? Yes $\underline{X}$ No

COMMENTS (exceptions): A Preventive Maintenance Procedure (PMP) will be written for the new voltage regulators.

H. Are all other action items (NCRs, IRs, etc.) properly identified and assigned?

Yes X_No_ (attach the summary of needed actions not in the data base)

COMMENTS (exceptions): None

I. Are there any special operating considerations? Yes_ No $\mathrm{X}$

List or Reference: None

J. Are near term spare parts adequate? Yes $X_{\text {_ No_ }}$

COMMENTS (exceptions): None

K. Have any safety issues (radiological, industrial) been identified that remain unresolved? Yes_ No X

COMMENTS (exceptions): None

L. Have all component data been entered into the Plant information database?

Yes $\mathrm{X}$ No

COMMENTS (exceptions): None

M. Have applicable SISI inspections been conducted? Yes_ No X

COMMENTS (exceptions): None

N. Has a cleanliness evaluation been completed? Yes X No_

Are any issues still unresolved? Yes_No $\mathrm{X}$

COMMENTS (exceptions): None

\section{REFERENCES}

None

8. ATTACHMENTS

None 


\section{ANNUAL SYSTEM ASSESSMENT REPORT}

(Sheet 1 of 6)

Date of This Report January 26, 1998

Date of Previous Report January 20, 1992

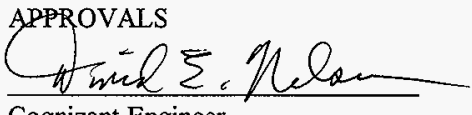

Cognizant Engineer

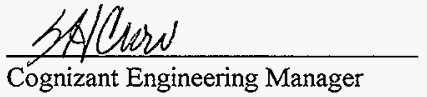

1. $\quad$ SCOPE

System 12H, Emergency Diesel Generators

System 12T, Gas Turbine Generator

2. SUMMARYEVALUATION (Provide a general assessment of the overall health of the system. Include a discussion of the system's minimum operable equipment from plant procedure $\mathrm{PN}-7$.)

\section{System 12H, Emergency Diesel Generators}

This system is currently shutdown with no maintenance being performed other than turning the crankshaft periodically to keep it from taking a set or warping.

\section{System 12 1 , Gas Turbine Generator}

Gas Turbine Generator $\mathrm{G} 3$ provides power at $13.8 \mathrm{KV}$ to buses $\mathrm{H} 4$ and $\mathrm{H} 5$ upon the loss of alternate preferred power. G3 is listed as minimum operable equipment in PN-7. The $13.8 \mathrm{KV}$ is distributed throughout FFTF to transformers where it is transformed down to 480/277VAC to provide power to loads that are necessary for normal plant operation and essential to avoid significant equipment or plant damage in the event of loss of offsite power. The overall health of system $12 \mathrm{~T}$ is good due to extensive repair and maintenance work performed during 1997; however, the turbine generator controls system is obsolete and is scheduled for extensive retrofit and replacement work during the second quarter of 1998. 


\section{ANNUAL SYSTEM ASSESSMENT REPORT}

(Sheet 2 of 6 )

3. ITEMS REQUIRING ACTION (Items on PTS, Procedures, Software, etc.)

A. Near Term Items

$\underline{\text { Required By }}$

The major work being performed on System 12T in 1998 is the replacement of the existing analog controls system with a new digital microprocessor based system during the second quarter of 1998 . Several other minor repair jobs will also be performed to ensure that the turbine generator continues its reliable emergency power function. Routine surveillance will continue as scheduled.

4F-97-2211 NEW CONTROLS SYSTEM

The existing turbine controls system is an obsolete analog modular controls system that is difficult to maintain and requires long lead times to obtain spare parts for replacement. A new digital microprocessor based system has been ordered and will replace the existing system in the second quarter of 1998.

4F-97-1565 BREAKER CONTROL SWITCH STICKS ON C1402

$98-3$

The breaker control switch for alternate preferred power breaker H52-43 sticks in the "pull to lock" position. This affects the restoration of alternate preferred power to the $\mathrm{H}-4$ bus. The switch requires rebuild or replacement.

4F-97-1375 G3 LUBE OIL SYSTEM TEMP ALARM REPAIR The temperature switch TSH-73139 indicated an alarm condition while the turbine generator was running with a lube oil temperature of $128^{\circ} \mathrm{F}$. The alarm point is set at $135^{\circ} \mathrm{F}$. The switch requires calibration or replacement.

4F-97-1109 G3 BATTERY MAINTENANCE PROCEDURE

98-1 Inactive G3 battery PMP-12E-E04 will be restored to the PMP system during the first quarter of 1998.

4F-97-1393 G3 BATTERY CABLE ID TAGS

98-1

Battery cable ID tags will be fabricated and installed during PMP-12E-E04 when it is scheduled.

4F-97-117 T303 NEEDS LEAK DETECTION

The $\mathrm{T}-303$ fuel oil tank leak detection system, which will satisfy the Washington State regulatory requirements, is in the design phase and is scheduled for installation during the last quarter of 1998 . 


\section{ANNUAL SYSTEM ASSESSMENT REPORT}

(Sheet 3 of 6 )

B. Long Term Items

Required By

Continue to maintain $\mathrm{G} 3$ in readiness as the emergency backup power source for the plant. In the event of a restart order, the following work packages will need to be addressed.

Calibration of protective relays on system 12T per PMP-12E-E05 \& E12 99-4

4F-84-94 RELOCATE THE G3 BATTERIES

SU-1

The G-3 control power and start diesel batteries will be moved to improve safe access for maintenance.

4F-97-1108 REQUALIFY G3 TO SES1

SU-1

The seismic qualification of G-3 will be evaluated.

4. TRENDS (Discuss trended parameters. See Appendix K for typical parameters which can be used for trending studies.)

Several major failures in the G3 controls system required extensive repair work and vendor support. It became evident during the progress of the repairs and the long lead time to obtain spare parts that the G3 controls system would have to be upgraded if it were to remain a reliable source of emergency power. The system upgrade work document is scheduled as a $98-1 \mathrm{C}$; but, due to procurement delays, may not be accomplished until 98-2. The turbine was mechanically checked out and overhauled by a vendor during the last quarter of 1997 . It currently is performing its emergency role very capably. 
HNF-2380

Rev. 0, Page 48

\section{ANNUAL SYSTEM ASSESSMENT REPORT}

(Sheet 4 of 6 )

\section{SYSTEM AGING, SPARE PARTS CONSIDERATIONS, AND LONG TERM MAINTENANCE PHILOSOPHY}

A. Discuss effects of system aging.

As the system ages and when preventive maintenance is not performed, insulators become dirty and may short out the system causing a fault condition. Bus bar and cable connector bolts may loosen up and cause a hot connection which will eventually cause a fire and shorted fault condition. Breakers can become dirty and parts bind up so that it does not operate properly, failing to protect the downstream equipment. Protective relays that are not calibrated will eventually be out of calibration and fail to trip the breakers that are protecting downstream equipment. The older technology control systems used electronics parts and circuit boards that age, even on the shelf as spares, and break down causing failures when installed in the operating systems. Several of the control modules in the G3 controls system failed in this manner during 1997 at a high maintenance and repair cost, which also caused G3 to be unavailable for service for extensive periods of time. On circuit board capacitors were contributory to this failure mode as was the lack of battery maintenance and ultimate failure of the system batteries in early 1997.

B. Discuss the strategy for near term spare parts and their availability strategy.

The existing spare parts for the G3 are adequate at the present time. The new controls system will have currently manufactured and vendor stocked spares readily available. In case of a power failure this equipment would have to be purchased.

C. Standby Maintenance Plan: Discuss a plan which ensures essential system functions for standby are provided and minimizes equipment degradation. Assume the standby period extends for the next one to two years. Include in the plan, as a minimum: 1) the identification of hardware to be repaired, replaced, or upgraded; and 2) the frequency of routine field maintenance, ensuring material and spare parts are identified to support these activities.

To maintain system 12T over the next two years the preventive maintenance items listed in "Near Term Items" must be completed. 


\section{ANNUAL SYSTEM ASSESSMENT REPORT}

(Sheet 5 of 6 )

\section{CHECKOFF LIST}

A. Accessible parts of the entire system or component have been thoroughly walked down at least once in the past 30 days to view current performance, equipment status and condition.

Yes $X$ No

B. Are there any conditions which might require limitations different from operating limits as defined in the SDDs, the FSAR, or the Plant Technical Specifications? Yes__ No $\mathrm{X}$

C. Are there trip settings, set points, interlocks, etc., that should be changed from those currently established?

Yes__No X

D. Are there interface areas which have not performed acceptably, which require resolution?

Yes__No $\mathrm{X}$

E. Are there temporary plant or procedural conditions which will and should remain in place? Yes_ No $\mathrm{X}$

F. Is any retesting or special testing (e.g., OSP) required?

Yes__ No $\mathrm{X}$

G. Are the current plant corrective maintenance, preventive maintenance, and calibration database items all properly identified and are planned actions acceptable?

Yes_No $\underline{X}$

There are eighteen preventive maintenance line items dealing with the fuel and lube instrumentation that are $100 \%$ overdue for this system

H. Are all other action items (NCRs, IRs, etc.) properly identified and assigned?

Yes_No_NA X

I. Are there any special operating considerations?

Yes__ No $X$

J. Are near term spare parts adequate? Yes X No 


\section{ANNUAL SYSTEM ASSESSMENT REPORT}

(Sheet 6 of 6 )

K. Have any safety issues (radiological, industrial) been identified that remain unresolved? Yes__ No $\underline{X}$

L. Have all component data been entered into the Plant information database? Yes $X$ No

M. Have applicable SISI inspections been conducted?

Yes_No_NA_ X

N. Has a cleanliness evaluation been completed? Yes_X_No_

Are any issues still unresolved? Yes No $\mathrm{X}$

\section{7.}

None

8. ATTACHMENTS

None. 


\section{ANNUAL SYSTEM ASSESSMENT REPORT}

(Sheet 1 of 5)

Date of This Report January 27, 1998

Date of Previous Report January 20, 1992

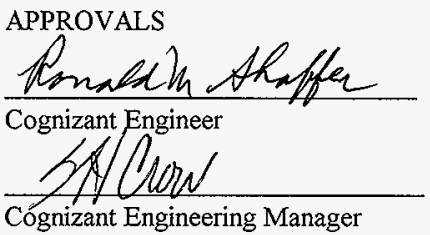

1. SCOPE

System 12K, 480 VAC Motor Control Centers

2. SUMMARYEVALUATION (Provide a general assessment of the overall health of the system. Include a discussion of the system's minimum operable equipment from plant procedure $\mathrm{PN}-7$.)

The 480 VAC motor control centers play an important role in the FFTF power distribution system. The motor control centers contain individual compartments for 480 VAC motor starters and compartments for breakers which power $480 / 277 \mathrm{VAC}$ loads. The motor starters provide a means for starting and stopping motors and a means of providing electrical protection for the motors they control. There are some motor controls centers that are in the emergency power system that are critical to the plant's operation.

The general health of the system is good; however, all the motor control centers are in need of preventive maintenance performed on them.

3. ITEMS REQUIRING ACTION (Items on PTS, Procedures, Software, etc.)

A. Near Term Items

Required By

WORK PACKAGE 4F-90-181

This work package performs preventive maintenance on one breaker (11R) in $\mathrm{H} 1$ switchgear and on downstream load center and motor control centers. Motor control centers MCC-B25, MCC-B26, and MCC-B131 are the motor control centers that should be cleaned, meggered, and inspected for tight connections.

OUT DOOR MOTOR CONTROL CENTERS

Motor control centers MCC-B130, MCC-B95A, MCC-B96B, and MCC-B231 should have preventive maintenance performed on them. 
HNF-2380

Rev. 0, Page 52

\section{ANNUAL SYSTEM ASSESSMENT REPORT}

(Sheet 2 of 5)

B. Long Term Items

$\underline{\text { Required By }}$

OUT DOOR MOTOR CONTROL CENTERS

99-1

Motor control centers MCC-B96A, MCC-B188, and MCC-B95A should have preventive maintenance performed on them.

4. TRENDS (Discuss trended parameters. See Appendix $K$ for typical parameters which can be used for trending studies.)

There have been occasional power failures in the 480 VAC motor control center systems with about one failure every twelve months over the past five years. In all the cases, the failures were in the individual motor starters or in breakers that feed systems. In one case, the breaker failed and burned out the entire pan assembly. In another case, one of the pony motors failed to start because of a loose power connection in a motor starter which resulted in a burned out overload relay. The failure rate in this system has not increased dramatically over the past five years; however, it will increase as time goes on without preventive maintenance being performed. The last time any motor control centers were cleaned was in 1993 when two outdoor motor control centers were cleaned; since that time no other motor control centers have been cleaned and inspected. The trend for the number of preventive maintenance procedures past due in this system has increased substantially because of the facility being in a shutdown or standby mode and reduced emphasis on preventive maintenance due to limited resources. The National Fire Protection Association recommends preforming major preventive maintenance once every three to six years for indoor equipment.

5. SYSTEM AGING, SPARE PARTS CONSIDERATIONS, AND LONG TERM MAINTENANCE PHILOSOPHY

A. Discuss effects of system aging.

As the motor control centers age and when preventive maintenance is not being performed, insulators become dirty and may short out the system causing a fault condition. A fault condition, if not cleared by the breaker, can cause severe and serious damage to electrical equipment. Bus bar and cable connector bolts may loosen up and cause a hot connection which will eventually cause a fire and shorted fault condition. Breakers can become dirty and parts bind up so that they do not operate properly, failing to protect the downstream equipment. The failures that we have had did not leave enough evidence behind to investigate what caused the failure. 
HNF-2380

Rev. 0, Page 53

\section{ANNUAL SYSTEM ASSESSMENT REPORT}

\section{(Sheet 3 of 5)}

B. Discuss the strategy for near term spare parts and their availability strategy.

The existing motor control centers were manufactured by two companies, Allis Chalmers and ITE Imperial, that are no longer in existence. The present way we are handling this problem is to use existing Allis Chalmers spares out of the equipment in the plant and some from the warehouse spares. The spares in the warehouse do not provide a great variety of motor starters sizes for all our needs. The Allis Chalmers spare issue can be handled this way for the next two years. The ITE Imperial motor starters pan assemblies can be replaced with motor starters manufactured by Square D Company. When the entire pan assembly is replaced, the door assembly must also be replaced because of the breaker lock out mechanism is not made exactly like the ITE Imperial starter lock out mechanism.

C. Standby Maintenance Plan: Discuss a plan which ensures essential system functions for standby are provided and minimizes equipment degradation. Assume the standby period extends for the next one to two years. Include in the plan, as a minimum: 1)the identification of hardware to be repaired, replaced, or upgraded; and 2)the frequency of routine field maintenance, ensuring material and spare parts are identified to support these activities.

To maintain system $12 \mathrm{~K}$ over the next two years, the preventive maintenance items listed in "Near Term Items" and "Long Term Items" should be completed.

\section{CHECKOFF LIST}

A. Accessible parts of the entire system or component have been thoroughly walked down at least once in the past 30 days to view current performance, equipment status and condition.

Yes $\underline{X}$ No

B. Are there any conditions which might require limitations different from operating limits as defined in the SDDs, the FSAR, or the Plant Technical Specifications? Yes__ No _ X

C. Are there trip settings, set points, interlocks, etc., that should be changed from those currently established?

Yes_No No X 


\section{ANNUAL SYSTEM ASSESSMENT REPORT}

(Sheet 4 of 5)

D. Are there interface areas which have not performed acceptably, which require resolution?

Yes No $\mathrm{X}$

E. Are there temporary plant or procedural conditions which will and should remain in place? Yes_ No $\underline{X}$

F. Is any retesting or special testing (e.g., OSP) required?

Yes__ No $\mathrm{X}$

G. Are the current plant corrective maintenance, preventive maintenance, and calibration database items all properly identified and are planned actions acceptable?

Yes_ No $\underline{\mathrm{X}}$

The preventive maintenance program needs to be changed to have the most important procedures released on a realistic fixed schedule and the resources needed to perform the work. Preventive maintenance on motor control centers should be done once every three to six years, many of our motor control centers have not been done for well over fifteen years.

H. Are all other action items (NCRs, IRs, etc.) properly identified and assigned? Yes_No_NA X

I. Are there any special operating considerations?

Yes_No $\mathrm{X}$

J. Are near term spare parts adequate? Yes X No_

K. Have any safety issues (radiological, industrial) been identified that remain unresolved? Yes_ No $\underline{\mathrm{X}}$

L. Have all component data been entered into the Plant information database? Yes_ No $\underline{X}$

The landlord equipment is not all in the JCS database.

M. Have applicable SISI inspections been conducted?

Yes_No_NA $\mathrm{X}$ 


\section{ANNUAL SYSTEM ASSESSMENT REPORT}

(Sheet 5 of 5 )

N. Has a cleanliness evaluation been completed? Yes $\mathrm{X}$ No_

Are any issues still unresolved? Yes _ No X X

\section{REFERENCES}

Administrative study "Electrical Preventive Maintenance Administration Evaluation for FFTF/400 Area," Work Package 4F-97-247/A.

\section{ATTACHMENTS}

(Attach any CSRs, data sheets showing system performance, or other material demonstrating the substantive nature of this review).

None. 


\section{ANNUAL SYSTEM ASSESSMENT REPORT}

(Sheet 1 of 4)

Date of This Report January 16, 1998

Date of Previous Report January 20, 1992

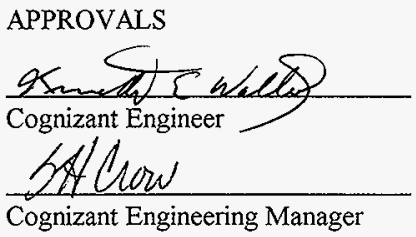

1. $\quad \underline{\mathrm{SCOPE}}$

System 12L, Freeze and Cathodic Protection

\section{SUMMARYEVALUATION}

The extent of the cathodic protection system was greatly reduced by removal of three diesel fuel oil storage tanks. These tanks serviced emergency power generators DG-1 and DG-2 and diesel fire water pump P-28. The three remaining underground fuel storage tanks are for the DHX preheaters. Due to the use of the fuel for heating purposes, these tanks are currently exempt from cathodic protection requirements. An attempt was made in 1997 to restore cathodic protection to these tanks, but the electrodes and rectifiers were found to be unserviceable. The electrode cables to DHX-S preheater fuel oil storage tank $\Upsilon-20$ were cut during excavation for the Sodium Storage Facility and would need to be replaced to restore protection. The electrodes for DHX-E preheater fuel oil storage tank $\mathrm{T}-19, \mathrm{DHX}-\mathrm{W}$ fuel oil storage tank $\mathrm{T}-21$ and $\mathrm{T}-20$ are deteriorated beyond use and need to be replaced. Rectifier units D-35 and D-37 are unserviceable due to age and corrosion from being out in the weather. The cathodic protection system was declared Out of Service and laid up by work package 4F-97-470/W.

The freeze protection system, though extensive, is simple in that the variety of I\&C components is small. All above ground water piping and DHX preheater fuel oil pipe lines are heat taped and insulated. The system is generally in good operating condition with the exception of two circuits on fuel oil pipes in DHX-E (circuit FP-101, 4F-97-1956/W) and DHX-S (circuit FP-108, 4F-97-2489/W). These packages are currently in WCC hold. There is no immediate need to work these packages due to cloud point lowering additive placed in the DHX fuel storage tanks.

Water system altitude valve pit heaters were installed in 1996. These infrared temperature controlled heaters preclude the use of extension cords to provide power for portable heaters placed in the pits as was the past practice.

There is no PN-7 required equipment in this system. 


\section{ANNUAL SYSTEM ASSESSMENT REPORT}

(Sheet 2 of 4 )

\section{ITEMS REOUIRING ACTION}

\section{A. Near Term Items}

Several heat taped and insulated DHX fuel oil pipe lines have insulation removed or have wet insulation on them. A decision needs to be made regarding continued use of the fuel oil cloud point lowering additive. If the additive's use is to be continued, then the remaining wet insulation should be removed to prevent further rusting of the pipes. Also the freeze protection circuits should be laid up. If the fuel additive is not going to be used in the future, then the defective freeze protection circuits need to be repaired and new pipe insulation installed where needed. This decision needs to be made by second quarter to allow time for repair work prior to freezing weather.

\section{B. Long Term Items}

The $\mathrm{H}-4$ drawings for the freeze protection system are out of date and are in need of extensive work. Work package 4F-96-808/A has been generated for this effort. This will be a SU1 priority item.

Restoration of the cathodic protection system may be required for the DHX fuel storage tanks in the event of a startup order. This will be a SU1 issue.

\section{TRENDS}

The trend will probably be toward increased failure of heat tape and temperature switches due to length of service. Pipe insulation and heat tape in the DHXs are degrading due to incursion of moisture.

5. SYSTEM AGING, SPARE PARTS CONSIDERATIONS, AND LONG TERM MAINTENANCE PHILOSOPHY

\section{A. SYSTEM AGING:}

Heat tape wire insulation is degrading due to age and exposure to wet condition of pipe insulation in some areas.

\section{B. SPARE PARTS:}

Spare parts are readily available in spares, shop stock, or local suppliers. 
HNF-2380

Rev. 0, Page 58

\section{ANNUAL SYSTEM ASSESSMENT REPORT}

(Sheet 3 of 4 )

\section{STANDBY MAINTENANCE PLAN:}

A standby I\&C maintenance plan is not necessary for this system. Routine failures will be repaired as they occur using readily available materials.

\section{CHECKOFF LIST}

A. Accessible parts of the entire system or component have been thoroughly walked down at least once in the past 30 days to view current performance, equipment status and condition.

Yes $\underline{X}$ No

B. Are there any conditions which might require limitations different from operating limits as defined in the SDDs, the FSAR, or the Plant Technical Specifications? Yes__ No $\mathrm{X}$

C. Are there trip settings, set points, interlocks, etc., that should be changed from those currently established?

Yes_ No X

D. Are there interface areas which have not performed acceptably, which require resolution?

Yes_No $\mathrm{X}$

E. Are there temporary plant or procedural conditions which will and should remain in place? Yes_No $\mathrm{X}$

F. Is any retesting or special testing (e.g., OSP) required?

Yes_ No X

G. Are the current plant corrective maintenance, preventive maintenance, and calibration database items all properly identified and are planned actions acceptable?

Yes_X No

COMMENTS: Outstanding CMs for the Cathodic Protection system were cancelled when the system was declared inoperable and laid up. Scheduled PMs were suspended for the $\mathrm{CP}$ rectifiers. Only two $\mathrm{CMs}$ are outstanding for the Freeze Protection system. They are in WCC HOLD designated phase SU1. These are the $C M$ packages referenced in Item 2 SUMMARY EVALUATION. There are no components in the Freeze Protection System requiring scheduled PMs. 


\section{ANNUAL SYSTEM ASSESSMENT REPORT}

(Sheet 4 of 4 )

H. Are all other action items (NCRs, IRs, etc.) properly identified and assigned?

Yes_No _ NA

I. Are there any special operating considerations?

Yes_ No $\underline{X}$

J. Are near term spare parts adequate?

Yes. $\mathrm{X}$ No

K. Have any safety issues (radiological, industrial) been identified that remain unresolved? Yes__ No $\mathrm{X}$

L. Have all component data been entered into the Plant information database?

Yes X No

M. Have applicable SISI inspections been conducted?

Yes_No _ NA X

N. Has a cleanliness evaluation been completed?

Yes $\mathrm{X}$ No

Are any issues still unresolved? Yes_ _ No X

\section{REFERENCES}

None.

\section{ATTACHMENTS}

None. 


\section{ANNUAL SYSTEM ASSESSMENT REPORT}

(Sheet 1 of 5)

Date of This Report January 27, 1998

Date of Previous Report January 20, 1992

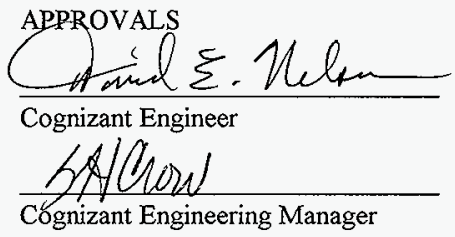

1. SCOPE

System 12Z, FSF Electrical Distribution System

2. SUMMARYEVALUATION (Provide a general assessment of the overall health of the system. Include a discussion of the system's minimum operable equipment from plant procedure PN-7.)

The System $12 Z$ electrical distribution system provides power to all of FSF. The B900 substation located outside FSF transforms power from $13.8 \mathrm{KV}$ down to $480 / 277$ VAC and distributes it to two motor control centers inside FSF. The overall health of the system is good; however, preventive maintenance on this system has not been kept up to date because of the plant being in either a shutdown or standby mode. FSF has equipment listed on PN-7 that is powered from system $12 \mathrm{Z}$, but the system is not on the minimum operable equipment list. System $12 \mathrm{Z}$ is powered by a single $13.8 \mathrm{KV}$ feeder from the $451 \mathrm{~B}$ Substation. There is no redundancy in the power supply to this facility. Any failure in the 451B Substation affecting this feeder puts FSF out of power as does a single failure in the B900 substation. FSF will also have to be shutdown to perform maintenance or repairs to the $\mathrm{B} 900$ substation. The other FFTF facilities have redundancy in power supplies. The single power source is the weak link in maintaining FSF operational and will have to be addressed when FFTF starts up. The risk involved in operating, as we have for years, is the potential for sodium freezing in the storage vessel due to a long term power outage caused by equipment failure in the single power source. 


\section{ANNUAL SYSTEM ASSESSMENT REPORT}

(Sheet 2 of 5)

3. ITEMS REOUIRING ACTION (Items on PTS, Procedures, Software, etc.)

A. Near Term Items

Required By

All the preventive maintenance on the $\mathrm{B} 900$ substation has been deferred during the transition to shutdown and standby operation mode and will have to be addressed on the outdoor substation during 1998. Maintenance and repair work on D904 and D905 is the primary outstanding work currently in the system for FSF and will be cancelled. D904 and D905 were switched off line in the bypass mode in 1996. If the order to restart FFTF is given, both inverters will be replaced by a single, reliable, easily maintainable unit with a low maintenance battery bank.

$\begin{array}{llr}\text { 4F-96-2100 } & \text { D904 INVERTER BREAKER TRIPS } & \text { To be cancelled } \\ \text { 4F-96-839 } & \text { D905 INVERTER BREAKER TRIPS } & \text { To be cancelled } \\ \text { 4F-97-2733 } & \text { BREAKER 10 INTERLOCK BROKEN } & 98-3\end{array}$
The mechanical interlock door latch is broken or missing and needs replacement. 4F-97-0270 BREAKER 15 WON'T CLOSE 98-3 The breaker will not latch or stay closed. It is broken and needs replacement. 4F-96-2344 TRANSFORMER TEST \& INSPECTION Maintenance inspection and testing is required per PMP-12B-E02. INSPECT \& MAINTAIN B900 SWITCHGEAR \& BREAKERS (PMP-12Z-E02 $\& \mathrm{E} 03)$

B. Long Term Items Required By

Long term items deal with the maintenance and inspection of the motor control centers in FSF. The breaker failures listed in the work orders above indicate that inspection and maintenance should be carried out on the motor control centers as a minimum. Other long term work depends upon the receipt of a start up order which will then allow the replacement of the FSF inverters and battery systems with a more reliable option. Also the single feeder to FSF needs addressing when the order is received. A second feeder and substation would increase the overall long term reliability of the FSF facility power system.

PERFORM MAINTENANCE AND INSPECTION OF MCC B910 \& MCC B9l1 99-3 INSTALL NEW SECOND FEEDER AND SUBSTATION FOR FSF INSTALL NEW INVERTER 
HNF-2380

Rev. 0, Page 62

\section{ANNUAL SYSTEM ASSESSMENT REPORT}

(Sheet 3 of 5)

4. TRENDS (Discuss trended parameters. See Appendix K for typical parameters which can be used for trending studies.)

There have not been any power failures in the $13.8 \mathrm{KV}$ power distribution feeder and substation B900. There have been some minor breaker failures in the $480 \mathrm{~V}$ motor control centers internal to FSF which may indicate potential wear and future failures if not addressed. The inverter systems have failed and are operating in the bypass mode due to the hazards of working on them with parts of the circuitry exposed and energized. The preventive maintenance procedures are past due in this system due to the facility being in a shutdown or standby mode. This trend needs to be reversed to prevent any unscheduled power outages.

\section{SYSTEM AGING, SPARE PARTS CONSIDERATIONS, AND LONG TERM MAINTENANCE PHILOSOPHY}

A. Discuss effects of system aging.

As the system ages and when preventive maintenance is not performed, insulators become dirty and may short out the system causing a fault condition. Bus bar and cable connector bolts may loosen up and cause a hot connection which will eventually cause a fire and shorted fault condition. Breakers can become dirty and parts bind up so that it does not operate properly, failing to protect the downstream equipment. Protective relays that are not calibrated will eventually be out of calibration and fail to trip the breakers that are protecting downstream equipment. Inverters that have electronic components and large capacitors experience aging and failures due to the capacitors failing. Deferred preventive maintenance has not allowed the opportunity to test and inspect switchgear. The effects of system aging cannot be fully characterized without inspection.

B. Discuss the strategy for near term spare parts and their availability strategy.

The existing spare parts for the System $12 Z$ are adequate at the present time. The transformers are not kept in spares. In case of a power failure they would have to be purchased. 


\section{ANNUAL SYSTEM ASSESSMENT REPORT}

(Sheet 4 of 5)

C. Standby Maintenance Plan: Discuss a plan which ensures essential system functions for standby are provided and minimizes equipment degradation. Assume the standby period extends for the next one to two years. Include in the plan, as a minimum: 1) the identification of hardware to be repaired, replaced, or upgraded; and 2) the frequency of routine field maintenance, ensuring material and spare parts are identified to support these activities.

To maintain system $12 Z$ in standby over the next two years, the corrective and preventive maintenance items listed in "Near Term Items" and "Long Term Items" should be completed. The modification work will be deferred to startup

\section{CHECKOFF LIST}

A. Accessible parts of the entire system or component have been thoroughly walked down at least once in the past 30 days to view current performance, equipment status and condition.

Yes $\underline{X}$ No

B. Are there any conditions which might require limitations different from operating limits as defined in the SDDs, the FSAR, or the Plant Technical Specifications? Yes_ No $\mathrm{X}$

C. Are there trip settings, set points, interlocks, etc., that should be changed from those currently established?

Yes__ No _ X

D. Are there interface areas which have not performed acceptably, which require resolution?

Yes_No_X

E. Are there temporary plant or procedural conditions which will and should remain in place? Yes_ No $\mathrm{X}$

F. Is any retesting or special testing (e.g., OSP) required?

Yes__ No_ $X$ 


\section{ANNUAL SYSTEM ASSESSMENT REPORT}

(Sheet 5 of 5 )

G. Are the current plant corrective maintenance, preventive maintenance, and calibration database items all properly identified and are planned actions acceptable?

Yes_No No X

The preventive maintenance program needs to be changed to have the procedures released on a realistic fixed schedule and the resources need to be provided to perform the work. There are currently ten preventive maintenance line items for FSF that are $100 \%$ overdue for this system.

H. Are all other action items (NCRs, IRs, etc.) properly identified and assigned? Yes__. No__ NA X

I. Are there any special operating considerations?

Yes__ No $\mathrm{X}$

J. Are near term spare parts adequate? Yes $\underline{\mathrm{X}}$ No

K. Have any safety issues (radiological, industrial) been identified that remain unresolved? Yes__ No $X$

L. Have all component data been entered into the Plant information database?

Yes $\mathrm{X}$ No

M. Have applicable SISI inspections been conducted?

Yes_No_NA $X$

N. Has a cleanliness evaluation been completed? Yes_ $\mathrm{X}$ No

Are any issues still unresolved? Yes__ No X

\section{REFERENCES}

None.

\section{ATTACHMENTS}

None. 


\section{ANNUAL SYSTEM ASSESSMENT REPORT}

(Sheet 1 of 11)

Date of This Report March 11, 1998

Date of Previous Report January 13, 1992
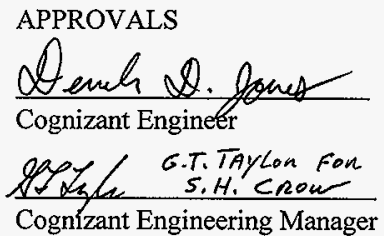

1. $\underline{\text { SCOPE }}$

System 15A, FFTF Communications Systems, which includes the following subsystems: FFTF Private Automated Exchange (PAX)

General Plant Telephones (GPT)

400 Area Public Address System (PA)

FFTF Plant Radio System (Radio)

IEM Cell Interior Communictions System (IEMC)

System M34. MASF Interior Communications System (MASF-IC)

\section{SUMMARYEVALUATION}

No System 15A and M34 equipment is listed as Minimum Operable equipment in PN-7. However, it is used for coordinating work in the plant and is required by Emergency Response procedures, and needs to be maintained during the standby period.

\section{PAX and GPT Telephone Systems}

These systems are fully operational and can continue to be maintained through the replacement of telephone sets as they fail. US West performs these maintenance activities for us at this time.

\section{$\underline{\mathrm{PA}}$}

This system is operational even though it has exceeded its design lifetime. PA.speakers are available from many distributors. The amplifiers in this system are obsolete and no longer vendor supported. But, they can be replaced with new commercially available equipment. This maintenance is performed by plant electricians. This is General Service equipment and system maintenance is constrained by limited resources, coupled with the increasing failure rate of component parts will continue to limit the full reliability of this system. 


\section{ANNUAL SYSTEM ASSESSMENT REPORT}

(Sheet 2 of 11)

\section{$\underline{\text { Radio }}$}

The plant radio system is maintained by LMSI network maintenance. This equipment is performing as designed and LMSI keeps a sufficient supply of spare parts on hand to repair all of the equipment failures to date. It is anticipated that this equipment will continue to operate effectively over the next two years.

\section{IEMC and MASF-IC}

This equipment is also maintained by plant electricians. It is just beginning to experience late in life component failures. Parts are available from the Original Equipment Manufacturer (OEM) and therefore can continue to be maintained by on site personnel.

\section{ITEMS REQUIRING ACTION}

A. Near Term Items

Required By

4F-95-1070/M

BLDG. 4710 PA GARBLED IN THE SOUTH BATHROOMS

There are no fire alarm chimes in these locations, therefore the PA is the only way that personnel in this building can be informed of an emergency requiring evacuation. The regulatory requirement for performing this work is 29 CFR 1910.165 (a)(3).

4F-94-359/M REMOVE D-33 \& INSTALL DC POWER SUPPLY 98-2 D-33 is the backup power supply for the PA system. It is failed and needs to be replaced with a DC power supply. The regulatory requirement for performing this work is 29 CFR 1910.165 (d)(3).

Last year the rear doors on the PA cabinets were reinstalled. This causes a corresponding increase of the temperature inside the cabinets. Installing cooling fans would increase the air flow through the cabinets and extend the life of the amplifiers inside the cabinets. 


\section{ANNUAL SYSTEM ASSESSMENT REPORT}

(Sheet 3 of 11)

A. Near Term Items (cont'd)

Required By

4F-96-2466/M

IMPROVE THE ABILITY TO UNDERSTAND

$98-3$

PA ANNOUNCEMENT ON THE 550' LEVEL OF

CONTAINMENT

While there are a large number of existing speakers on the Containment

Mezzanine, this is a high noise area, even with the lube oil skids shut down, and there is also a significant echo problem. Another attempt to correct this problem needs to be made, as emphasized by the last FEB team audit.

4F-97-2434/A

EVALUATE REPLACING THE PA OVERRIDE

98-3

HANDSETS

An increasing number of problems with the old telephone sets has prompted a search for replacement components. This administrative package will list the options available for replacing these handsets.

4F-96-165/M

4713A \& B BLDGS NEED ADDITIONAL PA

$98-4$ SPEAKERS

An audit of PA speakers conducted by FFTF Operations Crew A revealed that there are about a dozen locations in these buildings where there is a need to install new speakers.

4F-96-701/M

MOVE 4713B PA SPEAKERS TO OVERRIDE CKT

$98-4$

The 4713B lunchroom is now used as a location to conduct training and work control meetings. At the present time all speakers in the 4713B building are supplied from an In-Plant (Zone 1) amplifier, therefore all of the pages from any of the PAX telephones are heard throughout the building. This is not in keeping with chapter \# 4 of the Conduct of Operations manual. Plant pages are being ignored because of the high usage of this In-Plant page. However, personnel still need to be informed of an emergency. Changing the input of this system to the override circuit would minimize the number of pages that are heard in the 4713B lunchroom and continue to allow routine pages to be passed through out the shops. If a supervisor needs to page with-in the building there is a separate amplifier with speakers in the lunchroom that can be used, to get a worker to report back to the shop. 


\section{ANNUAL SYSTEM ASSESSMENT REPORT}

(Sheet 4 of 11)

B. Long Term Items

Required By

Replace five amplifiers in the PA system cabinet $\mathrm{C}-1328$ with

$99-1$ commercially available Public Address Amplifiers which have either Underwriters Laboratories (UL) or Factory Mutual (FM) listings.

Begin the PA system upgrade by replacing the override handsets $99-2$ and the alarm tone generators in $\mathrm{C}-1332$ with a commercially available UL listed Interior Communications systems similar to the IEMC and MASF-IC systems.

Increase the number of available paging zones from two to seven, to try to minimize routine use of the all page.

\section{TRENDS}

\section{$\underline{\text { PAX }}$}

Individual telephone sets have lasted as long nineteen years in the plant. Telephones are continuing to be replaced with new sets at a rate of four per quarter.

GPT

The observed trends indicate that this equipment will operate virtually maintenance free for the next two years. This equipment is all relatively new.

$\underline{P A}$

There are approximately 420 speakers tied into this system. Over $90 \%$ are still original equipment. The failure rate for speakers in this system is approximately one every twenty days. The failure rate for amplifiers is approximately one every seven months. Engineering assists plant electricians with almost every one of these adjustments because adjusting even one speaker in a line of twenty affects the volume and amplifier loading on every other speaker connected to the line. This problem is not present on newer systems where line loading is adjusted once and volume is adjusted with a signal mixer/preamplifier connected between the microphone and the individual power amplifiers in the system. 


\section{ANNUAL SYSTEM ASSESSMENT REPORT}

(Sheet 5 of 11)

\section{$\underline{\text { RADIO }}$}

The battery failures or frequency shift for transceivers in this system requires LMSI personnel to be called out about every five months. FFTF Engineering provides technical assistance or escorts workers on each of these trouble calls.

\section{IEMC \& MASF-IC}

The failure rate on equipment in this area is approximately one station per year. Previous to 1995 there were no failures. So equipment aging is now just beginning to become a problem.

\section{SYSTEM AGING, SPARE PARTS CONSIDERATIONS, AND LONG TERM MAINTENANCEPHILOSOPHY}

A. Discuss effects of system aging.

\section{$\underline{\mathrm{PAX}}$}

It is anticipated that approximately 24 telephone sets will fail in the next two years and be replaced by US West personnel under contract.

It is anticipated that up to seven new paging output cards may be added to the PAX switch to support the upgrade of the PA system. There are still twenty four spare lines on the PAX switch. It is not anticipated that any cards in the switch will fail during the next two years.

\section{GPT}

All of the GPT telephone sets were replaced as part of the site wide telephone upgrade in 1995 and are maịntained by US West.

The Merlin ${ }^{\circledR}$ II telephone system in the ECC and Control Room has operated for the last two years without any failures. This Key System is also the maintenance responsibility of US West. 


\section{ANNUAL SYSTEM ASSESSMENT REPORT}

(Sheet 6 of 11)

\section{$\underline{\mathrm{PA}}$}

The PA system has operated well beyond its twenty year design life. The amplifiers and tone generators are obsolete and spares parts are depleted. After the PA-IC was shut down spare parts were scavenged from that system, repaired once and are now depleted. The PA-IC was an FFTF interior communications system that was supposed to be redundant to the PAX and PA systems, but which was never very reliable. The time between failures for amplifiers continues to decrease and timely replacement of the amplifiers in this system, is prudent before major portions of the system become inoperable.

\section{$\underline{\text { RADIO }}$}

In 1992 the time between failures was insignificant. Today it is measurable and the time period between failures will continue to decrease. The system is now obsolete, but spare parts are still available and so it should be operable for the next two years. Maintenance will continue to be performed by LMSI Network Maintenance. LMSI also handles the stocking of ready spares. Replacing this radio network should be considered for reactor restart.

\section{IEMC \& MASF-IC}

The time between failures is now measurable and decreasing. But, the system is still state of the art and replacement parts are available from the original vendor.

B. Discuss the strategy for near term spare parts and their availability strategy.

Over the next two years the components of all of these system can continue to be procured as Off the Shelf Commercial Grade Equipment. Some parts for the PA system should be purchased under either a sole source justification or a QA Clause requiring that the equipment to be UL or FM listed, so that it can later be certified to meet OSHA standard 29 CFR 1910.165. This will put the facility in a better position for restart, but will not significantly increase the cost of the components. 


\section{ANNUAL SYSTEM ASSESSMENT REPORT}

(Sheet 7 of 11)

C. Long term maintenance plan.

\section{$\underline{\text { PAX \& GPT }}$}

This equipment should continue to be maintained by US West. It is anticipated that US West may discontinue maintenance on individual telephone sets and just be responsible for the lines in the plant. If that happens we need to budget about $\$ 500$ per year for replacement telephone sets.

\section{$\underline{\text { RADIO }}$}

The existing equipment should continue to be maintained by LMSI. If a major system failure necessitates an upgrade prior to the year 2002, then a capital expenditure of about $\$ 20,000$ is anticipated to upgrade the Bravo and Sierra Nets to digital transceivers.

\section{PA}

The details of the PA system upgrade are to be finalized by the Engineering Study on the 400 Area Public Address System, Document number HNF-2066. This study will be completed by April 30, 1998.

Replacement of the override handsets and the first five amplifiers is estimated to cost less than $\$ 15,000$, not including labor. Labor costs can be minimized by using existing PA-IC wiring.

\section{IEMC \& MASF-IC}

Continue to replace equipment as it fails and increase the number of components maintained in spares. Spare parts costs from last year indicate the we still need to budget about $\$ 2,000$ per year for maintenance of these systems.

\section{CHECKOFF LIST}

A. Accessible parts of the entire system or component have been thoroughly walked down at least once in the past 30 days to view current performance, equipment status and condition. Yes X No - . 


\section{ANNUAL SYSTEM ASSESSMENT REPORT}

(Sheet 8 of 11)

B. Are there any conditions which might require limitations different from operating limits as defined in the SDDs, the FSAR, or the Plant Technical Specifications? Yes X No _

\section{COMMENTS (exceptions):}

Sections 9.7 and 13.3.7.2 of the FSAR are out of date and need to be re-written for restart. Conditions are evaluated as necessary through the USQ process, using a graded approach. It may be prudent to update the FSAR during standby just to remove the need to perform USQ evaluations on this system. The out-of-date information is acceptable during the standby period. The system 15 SDD is also out of date and needs to be rewritten.

C. Are there trip settings, set points, interlocks, etc., that should be changed from those currently established? Yes__ No X $\mathrm{X}$

D. Are there interface areas which have not performed acceptably, which require resolution? Yes $\mathrm{X}$ No

\section{COMMENTS (exceptions):}

The PA system interfaces with the PAX system. Two zones for paging are not optimal. The PAX system is capable of providing nine paging zones. It is proposed that at least five more page output ports be added to the PAX system and that several locations be separated from the two existing zones. The In-plant page should have zones for CTMT, HTS, and the Service System buildings. The over-reliance on the all page can be alleviated by separating Zone 2 into separate zones for the maintenance buildings, OSB, MASF, the pump houses, the training building and the protected area yard.

E. Are there temporary plant or procedural conditions which will and should remain in place? Yes_ No

Attach list of $\mathrm{MOD}(\mathrm{L}) / \mathrm{ECN}(\mathrm{L}) \mathrm{s}$, and OSPs that are currently active. Provide justification for continuing temporary MOD (L)s and ECN (L)s.

COMMENTS (exceptions):

There are no temporary modifications to the system at this time and all upgrades 


\section{ANNUAL SYSTEM ASSESSMENT REPORT}

(Sheet 9 of 11)

should be performed to make permanent improvements to these systems.

F. Is any retesting or special testing (e.g., OSP) required? Yes_No No $\mathrm{X}$

G. Are the current plant corrective maintenance, preventive maintenance, and calibration database items all properly identified and are planned actions acceptable? Yes X No

The PAX, GPT, IEMC \& MASF-IC systems have no preventative maintenance requirements.

The PMPs on the radio system were deferred for standby, there has only been two battery failures that can be attributed to one of the deferred PMP procedures. This is not excessive, and was detected and repaired in a timely manner because of the functional testing performed by Operations per SI-15-1.

Preventive maintenance on D-33 has been discontinued since 1994 when it was determined to be failed. Maintenance will not be required after $4 \mathrm{~F}-94-359 / \mathrm{M}$ is field work complete.

H. Are all other action items (NCRs, IRs, etc.) properly identified and assigned? Yes X No_ (attach the summary of needed actions not in the data base)

I. Are there any special operating considerations? Yes__ No $\mathrm{X}$

List or Reference: None.

J. Are near term spare parts adequate? Yes_ No $\underline{X}$

COMMENTS (exceptions):

No more repaired amplifiers for the PA system exist. The company that used to repair them for us was sold and their new subsidiary no longer performs this type of service. We will now try to repair the four remaining chassis on site.

New spare parts for the IEMC and MASF-IC systems will be ordered by April 1998, to account for the recent increase in component failures. 


\section{ANNUAL SYSTEM ASSESSMENT REPORT}

(Sheet 10 of 11)

K. Have any safety issues (radiological, industrial) been identified that remain unresolved? Yes.X No

COMMENTS (exceptions):

The PA system, as originally designed, does not meet the OSHA requirements set forth in 29 CFR 1910.165. This is an industrial safety standard that applies to any industrial facility, and is included in the FFTF S/RID's documentation.

The power supply to the PA system is not reliable, and needs to be upgraded as required by work package $4 \mathrm{~F}-94-359 / \mathrm{M}$. There are also components installed in the PA system that were not designed for use as an employee warning system. Specifically, the override telephones, which are modified GTE telephones, use amplifiers and relays designed for local office telephone systems and are not UL or FM listed. The alarm tone generators are also not UL or FM listed.

L. Have all component data been entered into the Plant information database?

Yes_ No $\underline{X}$

COMMENTS (exceptions):

JCS only contains information to the cabinet level. As a minimum, individual amplifiers should be identified in JCS, but this effort can not be justified during standby.

M. Have applicable SISI inspections been conducted? Yes $\underline{X}$ No_

COMMENTS (exceptions):

There are no SISI inspections needed for this system.

N. Has a cleanliness evaluation been completed? Yes X No_

Are any issues still unresolved? Yes X No

COMMENTS (exceptions):

All communication distribution cabinets are long overdue for cleaning, inspection, and documentation of their respective wiring configuration. This effort.can wait until a restart order is issued. 


\section{ANNUAL SYSTEM ASSESSMENT REPORT}

(Sheet 11 of 11)

\section{REFERENCES}

HNF-2066 Engineering Study of the 400 Area Public Address System

8. ATTACHMENTS

None. 


\section{COMPONENT STATUS REPORT \\ FOR}

Polar Crane (M-004) and RSB Crane (M-709)

Period Covered: December, 1995 to Present

Component: M-004 (Polar Crane) and M-709 (RSB Crane)

Cognizant Engineer(s): R.L. Olson

H.L. Anderson

Cognizant Manager(s): D.L. Polzin

G.N. Ruge

Date Reported: January 14, 1998

Approvais
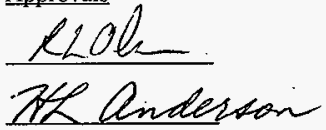

6).3. Pogin

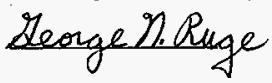

1. Summary of Component Status:

A. The polar crane is presently in operable status. Annual PMPs were performed in July, 1997 and January, 1998, with no problems found.

B. The RSB crane is presently in operable condition with exception of the use of the main hoist. A vibration was noted in the main hoist motor. A work package was written to evaluate the condition. The package has been phase marked as $98-2 \mathrm{M}$.

The annual PMP for the new radio controller has been completed, and the ofher PMPs are being performed at this time. Thus far, no problems have been found.

2. Trends Observed:

A. Polar Crane: During a monthly wire-rope inspection in September, 1997, the auxiliary hoist wire-rope was found to have a damaged lay. The hoist was immediately tagged out of service and the rope replaced in October, 1997.

During a monthly wire-rope inspection in October, 1997, the main hoist wire-rope was found to have an apparent opening of the wire-rope lays. Conversations with industry recognized wirerope experts resulted in recommendations to perform a thorough wire-rope inspection. A work package was written to evaluate the rope condition. The inspection indicated no safety related problems and confirmed the rope was "creeping" as described by the wire-rope experts. This "creeping" can occur on older, low duty cycle/low load wire rope. The hoist is operable with emphasis on the monthly rope inspections to inspect for degrading conditions.

B. RSB Crane: A control system upgrade consisting of a Control Chief, four motion, proportional radio controller, was added to the existing pendant control as of September 4, 1996. The upgrade reduced operator risk of repetitive use injuries that had occurred with the use of the high-force, pendant push buttons. The annual radio PMP had a major revision and was 
2.B. continued

performed December 5, 1997. Hoisting and rigging related findings during the 1997 Facility Evaluation Board (FEB) visit to FFTF, are tracked via administrative work packages. Work package 4F-97-1676/A (FEB Condition, FEB-97-FFTF-15) recommended performing a comprehensive review of bridge crane PMPs. The review has determine what and when changes will be made to the bridge crane (Polar, RSB, FSF, and MASF bridge cranes) PMPs . A new administrative package, 4F-98-165/A was issued to track and monitor the PMP revisions.

The crane continues to provide satisfactory service with exception as stated in Item I.B.

3. Component Aging and Spare Parts Considerations:

\section{A. Aging Parts}

1. Polar Crane: Parts, such as brake shoes and clutch discs are replaced as necessary during PMP performance and as found inspections. Typically, aging components are consumable items and are replaced as necessary. See above, Item 2, for wire-rope information.

2. RSB Crane: Same as above, except last statement.

B. Spare Parts Considerations

1. Polar Crane: All necessary and predictable spare parts are on hand. The Whiting Co. (crane manufacturer) remains in business, and should be capable of supplying unforeseen part needs.

Wire-rope is on hand for both hoists and if necessary, is readily available from wire-rope suppliers.

2. RSB Crane: All necessary and predictable spare parts are on hand. The crane manufacturer is no longer in business, however, most of the major components are made by companies that have remained in business.

Wire-rope for the main hoist is on hand. Wire-rope for the auxiliary hoist is not on hand, however, it is readily available through wire-rope suppliers.

Regarding Item $1, \mathrm{~B}$, a new main hoist motor is not on hand. A motor of this size and cost can be repaired if necessary.

4. Analysis, Conclusions, Followup:

A. Polar Crane: The polar crane should provide future satisfactory service. Normal wear and degradation of components is checked during PMP performance and monthly inspection to maintain the crane in operable condition.

B. RSB Crane: The RSB crane should provide future satisfactory service. Normal wear and degradation of components is checked during PMP performance and monthly inspection to maintain the crane in operable condition. See Item 1, B for main hoist condition. 
5. Items Requiring Action:

A. Near Term Items

Required By

1. Polar Crane radio PMP-27B-E13 will be revised with enhancements and reformatting. E13 will provide crane-specific information and call out the Control Chief radio tuning procedure PMP-27B-E14. (Engineering post review action on $4 \mathrm{~F}-97-2551 / \mathrm{P}$.)

2. Evaluate/repair RSB main hoist per $4 \mathrm{~F}-98-107 / \mathrm{W}$.

B. Long Term Items

Replace the polar crane main hoist wire-rope. This will be determined TBD by follow-up monthly wire-rope inspections. It is anticipated, replacement will be done sometime in 1999 .

\section{Checkoff List}

A. Are the current plant corrective maintenance, preventive maintenance, and calibration database items all properly identified and planned actions acceptable? Yes X No

COMMENTS (exceptions): See 5.A.1 above.

B. Are all other action items (IRs, NCRs, etc.) properly identified and assigned? Yes N/A No_ COMMENTS (exceptions): No other action items identified.

C. Are near term spare parts adequate? Yes $\mathrm{X}$ No

COMMENTS (exceptions): None.

D. Are trend analysis data acceptable for continued operation? Yes $\mathrm{X}_{\text {No_ }}$

COMMENTS (exceptions): None. 
HNF-2380

Rev. 0, Page 79

\section{ANNUAL SYSTEM ASSESSMENT REPORT \\ for \\ SYSTEMS 23A/B}

Date of This Report

$01 / 29 / 98$

Date of Previous Report

$01 / 27 / 92$
APPROVALS

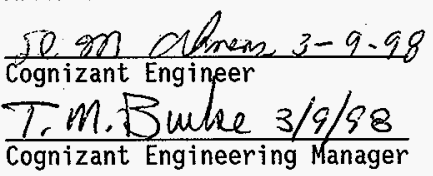

1. SCOPE

System/Component

Title

System 23 A/B - Sanitary Water for Fire and Domestic use for the entire 400 Area.

\section{SUMMARY EVALUATION}

The sanitary water system was able to satisfactorily supply water to the 400 Area during the past year. In August during the hot summer, the system demand peaked at about 1.4 milition gallons of water per week to the 400 area. During the cooler weather from September through March, the peak water demand was about 250,000 to 300,000 gallons per week.

The water storage tanks, $T-58, T-87$, and $T-330$ al so serve as storage for the Fire Protection Water Reserve. In order to meet the requirements for Fire Protection Water Reserve they must be inspected every two years per Fire Protection System Comp 1 iance Procedure FC-26.1-1. FC-26.1-1 was performed on a11 the tanks in 1997.

T-58 and T-87 tanks and coating were in excellent condition. T-58 and T-87 were originally elevated storage tanks (water towers) at "B" reactor built in circa 1944. Circa 1974 when FFTF was under construction, they were moved, modified, reconditioned, coated and placed in service in the 400 Area. They were modified slightly in 1984 per the V-749 Project. The Coal Tar Enamel coating was properly applied and is still in excellent condition.

$T-330$ was built in 1984 per $V-749$ project. When T-330 was inspected in 1991 the interior coating was beginning to show signs of failing but corrosion was not bad yet. Work Package 4F-91-2340/W was generated and dispositioned to re-coat the interior of the tank. The estimated cost was about $\$ 100,000$. Before the work was scheduled, FFTF got the shutdown order, so the work was canceled for economic reasons. The package is now in hold and will be re-activated if a startup order is received. The tank is beginning to corrode, but the integrity is not yet threatened. 
HNF-2380

Rev. 0, Page 80

Modifications during period (1992 through 1997)

4F-95-1030/M: Replaced T-14, the plant water heater, with two smaller units which are more dependable.

4F-94-0415/M: Trimmed impellers on P-467 and P-468 from 91" to $9 "$. In this application the pump runs at normal capacity and the pressure is controlled by bypassing the excess water back to the tank. The control valve had been repaired several times showing erosion to the interior of the valve. On 02/14/93 the control valve failed suddenly. The check valve did not operate properly and caused a severe water hammer. The check valve was replaced with an FM approved check valve and a new control valve was ordered with an orifice in the discharge to lower the $\triangle P$ across the control valve. The orifice did not help. The bypassed water was too much for the control valve. Tests indicated the pump was discharging over $600 \mathrm{gpm}$, the rating was supposed to be $480 \mathrm{gpm}$.

Examination of the pump curves indicated the impellers could be trimmed to $9^{\prime \prime}$ and still produce the desired $480 \mathrm{gpm}$.

4F-97-2110/M: 6" KHF-23826 and 6" KHF-23826 (Emergency Cooling Tower Makeup lines) were cut off at the main 7 ines and abandoned in place. KHF-23826 was leaking where it could not be repaired. There are other sources of emergency makeup. They cannot be used without installing backflow preventers, and they were dead legs which are not desirable in the drinking water system.

3. ITEMS REQUIRING ACTION (Items on PTS, Procedures, Software, etc.)

A. Near Term Items

Required By

4F-97-2007/W Repair FE-70031, P-467/468 discharge

98-2 meter

4F-97-0142/W: P-16 capacity is diminishing.

$98-2$

P-16 in well \#4 was installed in 1984 and has been the

main well water supply. It has run about 4,000 hours

per year for over 13 years so it has logged about

50,000 hours. It is still running, but the capacity

has dropped from $220 \mathrm{gpm}$ to $160 \mathrm{gpm}$. The pump needs to

be pulled and the pump bowls replaced with a spare set

of bowls.

B. Long Term Items

Required By

None

N/A 
4. TRENDS

Except for the well pump listed above, the water supply system is operating normally. Since the sanitary water pump impellers were trimmed, the pressure control valve has been operating normally with no sign of distress.

5. SYSTEM AGING. SPARE PARTS CONSIDERATIONS, AND LONG TERM MAINTENANCE PHILOSOPHY

A. Discuss effects of system aging.

The equipment is in good condition and does not appear to have any aging problems at this time.

The interior coating in T-330 is bad and the tank is beginning to corrode. If a startup order is received, it should be re-coated as soon as possible. If corrosion continues at the present rate it will be about 10 years before it is too bad to use.

B. Discuss the strategy for near term spare parts and their availability strategy.

An adequate supply of spare parts for the pumps and motors are available in the warehouse.

C. Standby Maintenance Plan:

The operational requirements of Systems $23 \mathrm{~A} \& 23 \mathrm{~B}$ have not changed due to shutdown or standby. The maintenance requirements have not changed. It is planned to continue the normal maintenance procedures and frequencies as required for system health.

\section{CHECKOFF LIST}

A. Accessible parts of the entire system or component have been thoroughly walked down at least once in the past 30 days to view current performance, equipment status and condition. Yes $\checkmark$ No

COMMENTS (exceptions): None

B. Are there any conditions which might require limitations different from operating limits as defined in the SDDs, the FSAR, or the Plant Technical Specifications? Yes No

COMMENTS (exceptions): None 
C. Are there trip settings, set points, interlocks, etc., that should be changed from those currently established? Yes No COMMENTS (exceptions): None

D. Are there interface areas which have not performed acceptably, which require resolution? Yes No $\checkmark$

COMMENTS (exceptions): None

E. Are there temporary plant or procedural conditions which will and should remain in $\mathrm{place}$ ? Yes No

Attach list of MOD(L)/ECN $(L) s$, and OSPs that are currently active. Provide justification for continuing temporary MOD $(L) s$ and $E C N$

(L)s.

COMMENTS (exceptions): None

F. Is any retesting or special testing (e.g., OSP) required? Yes

No 1

COMMENTS (exceptions): None

G. Are the current plant corrective maintenance, preventive maintenance, and calibration database items all properly identified and are planned actions acceptable? Yes \& No

COMMENTS (exceptions): None

H. Are all other action items (NCRs, IRs, etc.) properly identified and assigned?

Yes_ No No the data base) $N / A \&$ (attach the summary of needed actions not in COMMENTS (exceptions): None

I. Are there any special operating considerations? Yes No List or Reference: None

J. Are near term spare parts adequate? Yes $\_$No COMMENTS (exceptions): None 
K. Have any safety issues (radiological, industrial) been identified that remain unresolved? Yes No 1

COMMENTS (exceptions): None

L. Have all component data been entered into the Plant information database?

Yes $\mathcal{L}$ No

COMMENTS (exceptions): None

M. Have applicable SISI inspections been conducted? Yes No

N/A $\underline{G}$

COMMENTS (exceptions): None

N. Has a cleantiness evaluation been completed? Yes Are any issues sti11 unresolved? Yes No 1 No

COMMENTS (exceptions): None

\section{REFERENCES}

\section{ATTACHMENTS}

See the attached graph of 400 area water demand $01 / 94$ to $08 / 97$. 
HNF-2380

Rev. 0, Page 84

ASAR 23A7B

Page 6

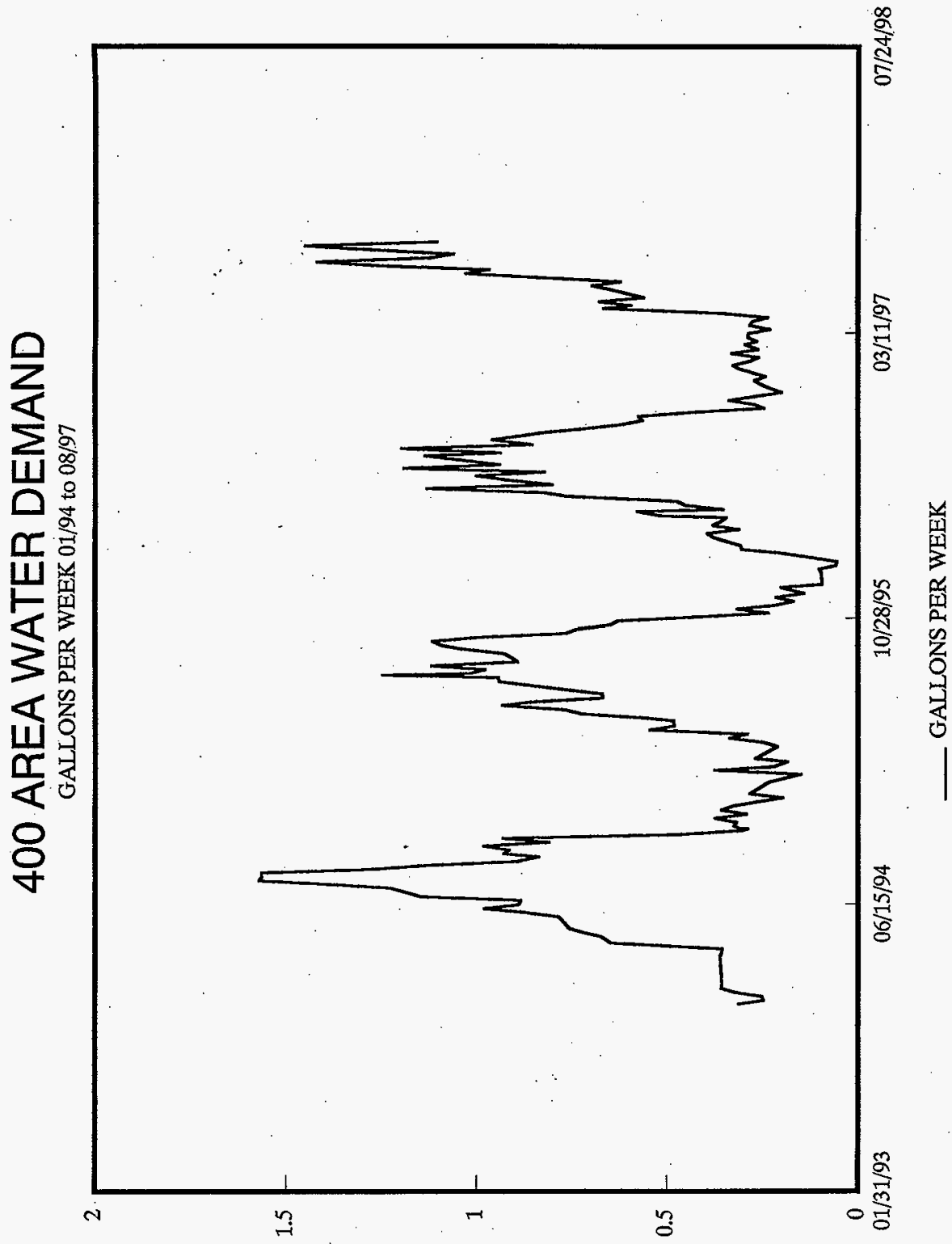




\section{ANNUAL SYSTEM ASSESSMENT REPORT for \\ SYSTEM 23C and 23D}

Date of This Report _ February 06, 1998

Date of Previous Report January 29, 1992

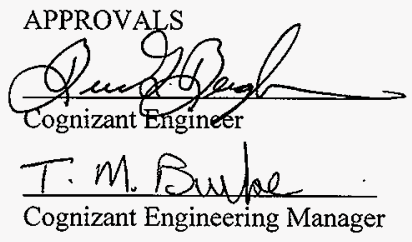

\section{$1.0 \quad$ SCOPE}

System/Component

System 23C/D
Title

Cooling Towers/Cooling Water

\subsection{SUMMARY EVALUATION}

The health of System $23 \mathrm{C}$ is improving while the health of System 23D continues to be good. Some improvements have been made with more planned to place System $23 \mathrm{C}$ in a condition to serve well throughout the standby period. System 23D continues to be good and will serve the system well throughout the standby period.

For purposes of discussion, the systems will be divided between System 23C (Cooling Towers) and System 23D (Cooling Water).

\section{Cooling Towers:}

Three of the eight cooling towers were laid up because of the reduced cooling loads during the transition to the shutdown period and will continue to be in the laid up condition because the cooling loads for the system have not changed for the standby period. The conductivity meters and the makeup water float valves have been removed from the laid up towers. Sheet metal covers have been recently installed to prevent further degradation during the standby period.

The five operating cooling towers continue to be maintained with three out of five being the minimum operable equipment requirement. Although the overall condition of the exterior of the cooling towers has degraded somewhat, they continue to provide adequate cooling capability. 
The conductivity meters have been replaced to adequately control cooling tower chemistry and minimize unnecessary blow downs. On August 1, 1996, the state waste discharge permit FT -4501 for the 400 Area process water effluent system went into effect. The permit required composite sample monitoring with a limit of $<500 \mu \mathrm{gms} / \mathrm{liter}$ of Total Dissolved Solids (TDS) on a 60 day cycle. This had never been monitored before. After a few monitoring periods, the TDS for the 400 Area effluent system exceeded the permit requirements. Various samples were taken from the well water and the water going in and out of the Cooling Towers. Two significant discoverys were made. First, the TDS of the water coming out of the 400 Area well (P-16) was approximately $250 \mu \mathrm{gms} / \mathrm{liter}$ and second, the Cooling Towers were the largest facility TDS contributor. The only way to reduce the TDS created by the Cooling Towers was to increase the cooling towers sump water cycling. This doubled the makeup water usage in the Cooling Towers but lowered the TDS for the 400 Area Process Sewer to keep from exceeding permit limits. Reportable exceedances to the state through DOE have been eliminated. In addition, the conductivity meters range resistors were replaced because control levels had been lowered to $\leq 1000 \mu$ mhos to address the TDS issue and to increase accuracy to $+/-50 \mu \mathrm{mhos}$. Conductivity is now controlled between the ranges of 600 and $700 \mu$ mhos with a high alarm at $800 \mu$ mhos. The new conductivity meters were essential in resolving these issues. The December 1996 sampling data result for the 400 area process sewer TDS was $420 \mu$ mhos.

The FT-4501 permit also included a Total Organic Halide (TOX) early warning value of $<$ $20 \mu \mathrm{gms} / \mathrm{liter}$. Additional Cooling Tower effluent problems were encountered with this value because the existing process sewer effluent was also exceeding the early warning value. It was found that the largest contributing cause was the chlorination of the sanitary water normally controlled between .4 and $1 \mathrm{ppm}$. Past records indicated that the chlorination level was normally controlled near $1 \mathrm{ppm}$. The chlorination levels were immediately dropped and reduced further to $.2 \mathrm{ppm}$ following approval of the Hanford Site Water purveyor. BetzDearborn 702 consists of $<2 \%$ magnesium chloride plus two organic constituents. When this biocide was concentrated to $.5 \mathrm{ppm}$, sampling tests revealed that TOX levels doubled. This proved that the BetzDearborn biocide 702 was the main contributor after chlorination. An engineering study was performed to evaluate replacing the current biocide with hydrogen peroxide. However, since the early warning TOX value did not relate to any organic halide limit in the process sewer effluent permit, the Washington Department of Ecology agreed to change the TOX values from an early warning value to an information only when the permit is revised in the near future. Recent TOX results have been below the early warning value during the winter months because of reduced cooling loads resulting in less makeup water usage to the cooling towers. It is expected that the new permit will be in place before the TOX levels rise above $20 \mu \mathrm{gms} / \mathrm{liter}$ again, so no further action is required to look for a cooling tower biocide replacement. The current BetzDearborn 702 will continue to control biological growth in the cooling towers.

A plan is in progress to repair the cooling tower sheet metal areas necessary to preserve them adequately for the standby period. Based on internal and external inspections by 
HNF-2380

Rev. 0, Page 87 .

Engineering, some sheet metal degradation has occurred and various sheet metal fasteners are missing. Many of the demisters appear to be degraded and thus require replacement in the near future. Twenty-nine new demisters are currently in spare parts and can be readily replaced.

The makeup water blowdown solenoid valves continue to fail in all seasons for various reasons. A work plan has been developed and is currently in the approval process to install $Y$-strainers upstream of the blowdown valves to minimize debris from plugging the valves; debris is known to have caused numerous failures. Also, the heat trace and insulation will be replaced to eliminate failures due to cold weather conditions.

The biocide and anti-scaling chemistry control in for the cooling tower in Building 611 has been improved dramatically since 1992. In 1993, a task team was formed by the Cognizant Engineer that included an Industrial Hygienist, Operator, Operations Support and the Cognizant Engineer. Improvements that were implemented as a result of the task team included; personnel protection equipment, procedure changes, installation of a proper safety shower, purchase of a chemical cabinet to perform sampling, purchase of a chemical storage cabinet, MSDS information booklet for all chemicals used in the building, proper labeling and many other miscellaneous items to improve the safety and efficiency for the personnel working with the cooling tower chemistry control procedures. Additional cooling tower chemistry improvements include: upgrading the makeup water flowmeter FQT-70928, installation of permanent piping from the chemical totes to the chemistry control pumps P-464, P-465 and P-466, replacement of the stationary biocide tank T-356 with a removable biocide tote to eliminate handling of chemicals by operations and installation of berms at the doorways and makeup water return pit to contain any chemicals that might spill within the building to eliminate leakage into the process sewer or outside of the building.

See the System 96-3 Annual System Assessment Report for issues and actions that involve electrical and Instrumentation and Control work packages.

\section{Cooling Water:}

The Cooling Water system continues to operate adequately for standby conditions. With the current priority planning phases, little operational annoyances continue to linger on. However, with the creation of the new Fix It Now team at the facility, some of these annoyances will be remedied in a timely manner without going through the normal scheduling and priority process.

In an effort to conserve resources, the decision was made early in the FFTF shutdown phase to decrease lubrication frequencies on the Cooling Water pumps and monitor performance via the vibration and bearing analysis program. The system is now beginning to experience increased motor and bearing failures as a result. All equipment frequencies have recently been increased to reflect health of the system requirements for the standby condition. 
The ongoing mechanical seal replacement program for all Cooling Water pumps continues as the old Borg Warner seals fail. This program continues to be successful in eliminating ethylene glycol leaks and the need to set the seal numerous times which required isolation and draining of the system.

\subsection{ITEMS REQUIRING ACTION}

A. Near Term Items

$\underline{\text { Required By }}$

Cooling_Towers

4F-93-1593/M-E-19 SUMP LEAK FLANGE;RECAULK ALL TOWERS. This package requires repairing and cold galvanizing portions of the degrading sheet metal, replacement of several mist eliminators and sealing of some external flanges.

(98-2R) June 1998

4F-97-211/M-IMPROVE TRACE HEAT/INSULATION ON CLG TWR VALVE. This work package will install $Y$ strainers upstream of the cooling tower sump blowdown solenoid valves to extend the life of the valve. In addition, insulation will be replaced with improved heat tracing to eliminate cold weather failures. The Y strainers should eliminate the failures of the solenoid valves being stuck open by debris.

(98-2R) June 1998

\section{Cooling Water}

4F-97-2248/M-COOLING WATER RELIEFS TO THE ENVIRONMENT. This package requires piping all the Cooling Water relief valves near the cooling towers to a containment system in the event a relief valve lifts again. This became an issue when one of the cooling tower legs was isolated during the summer months which resulted in thermal expansion causing a relief valve to lift expelling ethylene glycol/water mixture to the environment.

(98-3) Sept 1998

\section{$4.0 \quad$ TRENDS}

\section{Cooling Towers}

Trending of the Cooling Tower chemistry continues to be monitored. It was a key element in determining the conductivity meter replacement, the flow totalizer replacement and provided the data required to accurately calculate the decrease in the makeup water cycles through the cooling towers to come in compliance with the 400 Area Process Sewer Total Dissolved Solids limit of $500 \mu \mathrm{gms} / \mathrm{liter}$. 


\section{Cooling Water}

There are several pumps whose bearings show signs of wear. These units have been observed for years but they continue to respond to lubrication. The bearing analysis program has proven that there will generally be no sudden bearing failures or surprises.

\subsection{SYSTEM AGING, SPARE PARTS CONSIDERATIONS, AND LONG TERM MAINTENANCE PHILOSOPHY}

A. System aging:

\section{Cooling Towers}

The sheet metal of the cooling towers and the demisters have shown the greatest effect of system aging. As discussed earlier, plans are underway to extend the life of the cooling towers by repairing the necessary sheet metal and demisters this year to prevent continued degradation which will eliminate costly replacements in the future.

\section{Cooling Water}

There are no aging issues with the cooling water system. The ethylene glycol and demineralized water mixture coolant medium in the closed loop systems have demonstrated aging issues such as corrosion have not been detected. Recent vessel inspections of the expansion tanks also provided additional assurance for this determination.

B. Near Term Spare Parts:

There are no known major deficiencies in the System 23C and 23D spare parts inventory that would impact continued Standby operation.

C. Standby Maintenance:

\section{Cooling Towers}

Operating in standby for the next several years presents no maintenance challenges if we implement the near term standby maintenance improvement items listed stated in Section 3. The major components, especially the cooling towers, are industrial in nature and simple to repair with available spare parts or via ordered parts.

\section{Cooling Water}

Operating in standby for the next several years presents no major maintenance challenges. However, replacement of the old Borg Warner type mechanical seals 
with the new cartridge type should continue during the standby period. Some lower strainers have been removed from the air separators because of a baffle plate welding design deficiency causing the lower strainer to crumble. When this condition exists, the lower strainer often starts breaking apart ending up in the impeller of the pump. Preventative Maintenance on the pumps must continue to be a priority during the standby condition.

\subsection{CHECKOFF LIST}

A. Accessible parts of the entire system or component have been thoroughly walked down at least once in the past 30 days to view current performance, equipment status and condition. Yes X No _.

COMMENTS (exceptions): None

B. Are there any conditions which might require limitations different from operating limits as defined in the SDDs, the FSAR, or the Plant Technical Specifications? Yes_No $\underline{X}$

COMMENTS (exceptions): None

C. Are there trip settings, set points, interlocks, etc., that should be changed from those currently established? Yes_ No X

COMMENTS (exceptions): None

D. Are there interface areas which have not performed acceptably, which require resolution? Yes_ No _ X

COMMENTS (exceptions): None

E. Are there temporary plant or procedural conditions which will and should remain in place? Yes_NoX

Attach list of $M O D(L) / E C N(L) s$, and OSPs that are currently active. Provide justification for continuing temporary MOD $(\mathrm{L}) \mathrm{s}$ and $\mathrm{ECN}(\mathrm{L}) \mathrm{s}$.

COMMENTS (exceptions): None

F. Is any retesting or special testing (e.g., OSP) required? Yes_ No $\mathrm{X}$

COMMENTS (exceptions): None 
G. Are the current plant corrective maintenance, preventive maintenance, and calibration database items all properly identified and are planned actions acceptable? Yes_X No

COMMENTS (exceptions): None

H. Are all other action items (NCRs, IRs, etc.) properly identified and assigned? Yes X No_ (attach the summary of needed actions not in the data base)

COMMENTS (exceptions): None

I. Are there any special operating considerations? Yes__ No $\underline{X}$

List or Reference: None

J. Are near term spare parts adequate? Yes X No

COMMENTS (exceptions): None

K. Have any safety issues (radiological, industrial) been identified that remain unresolved? Yes_ No $\mathrm{X}$

COMMENTS (exceptions):

L. Have all component data been entered into the Plant information database?

Yes $\underline{X}$ No

COMMENTS (exceptions): None

M. Have applicable SISI inspections been conducted? Yes X No

COMMENTS (exceptions):Has a cleanliness evaluation been completed? Yes_No N X

Are any issues still unresolved? Yes_ No $\mathrm{X}$

COMMENTS (exceptions): None

\subsection{REFERENCES}

none

\subsection{ATTACHMENTS}

none 


\section{ANNUAL SYSTEM ASSESSMENT REPORT \\ for \\ SYSTEM 23F and 23G}

Date of This Report _ March 9.1998

Date of Previous Report January 29, 1992

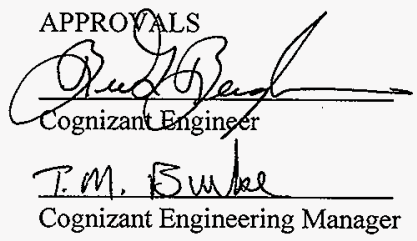

$1.0 \quad \underline{\text { SCOPE }}$

System/Component $\quad \underline{\text { Title }}$

System $23 F / G$

Ex-Containment Chilled Water (ECCW)/
In-Containment Chilled Water (ICCW)

\subsection{SUMMARY EVALUATION}

\section{ECCW and ICCW System Improvements}

The health of Systems $23 \mathrm{~F}$ and $23 \mathrm{G}$ is improving. Some chiller upgrades are in progress which are improving the reliability and lowering operational cost during the standby to restart period. Upgrades and improvements are discussed as follows:

Refrigerant conversions from the ozone depleting CFC-12 to the new HFC-134a are in progress on seven of the eight chillers. The one exception is discussed below under ECCW. All of the ICCW chillers have been converted to the new refrigerant with the ECCW chillers currently in the conversion process. One setback occurred on E-142 after the refrigerant conversion when it was determined that a different ratio gear had been installed to provide additional cooling ( 475 tons verses 400 tons for all of the other ICCW chillers) when the chiller was rebuilt in the early 1980 's. Although the E-142 cooling capacity is only about $70 \%$ of the other ICCW chillers, this is considered adequate for the standby period. However, pollution prevention money from the ROI program is being investigated as a source of funding to install the correct gear set. Scheduled completion for all refrigerant conversions is at the end of the 98-2 work phase. In addition, oil skimmers are being added to most of the chillers to assist in returning oil entrained in the refrigerant from the evaporator cooler to the oil sump to eliminate excessive oil entrainment in the refrigerant and to reduce oil sump drain and fill frequencies.

Upgrades of all the ICCW and ECCW chiller controls are also in progress. Six microprocessors were purchased and are currently in our possession. Originally, eight 
microprocessors were purchased, but the vendor sent the wrong microprocessors. When the wrong microprocessors were sent back, they claimed that the correct microprocessors cost $25 \%$ more, so it was agreed that six microprocessors be purchased due to limited funding. Three ICCW microprocessor controls have already been installed. Engineering is currently preparing for the first $\mathrm{ECCW}$ chiller microprocessor installation during the 98-2 work phase. Although documentation preparation for these upgrades is time consuming, immediate benefits have already been experienced with future benefits available should the facility be returned to operation. The immediate benefits of the new ICCW chiller microprocessor controls include decreased shutdowns from failed shutdowns protective circuits, elimination of $\mathrm{C}-1016$ panels agastat relay failures, chiller shutdown diagnostic codes to quickly determine problems and immediate access to chiller operating parameters to monitor chiller performance. The facility has already realized a large decrease in ICCW chiller shutdowns as a result of instrumentation and electrical failures. Future benefits include the capability of tying the ICCW chiller microprocessor to a central computer in the control room should this capability be required.

Investigations by the Cognizant Engineer recently determined that the chiller American Society of Mechanical Engineers (ASME) section VIII vessels and respective pressure relief valves (PRV) on the storage tanks and evaporator coolers had not been included in the System In Service Inspection (SISI) program required by the ASME code.

Documentation could not be located for history on evaporator cooler and storage tank vessel PRV testing and chiller ASME Section VIII vessel inspections. As a result, immediate action was undertaken to inspect all of the ICCW and ECCW chiller ASME Section VIII vessels and replace all of the PRV's. All of the ICCW chillers and two of ECCW chillers (E-21 and E-22) have had the Section VIII vessels inspected and PRV's replaced. The two remaining ECCW chiller vessel inspections and PRV replacements are being worked in parallel with the CFC-12 to HFC-134a refrigerant conversion work and are documented on the respective work packages. E-20 and E-23 chillers will receive the Section VIII vessel inspections and PRV replacements during the 98-2 work phase. Scheduled completion for replacement of all the PRV's is by June 30, 1998. A NCR was written and dispositioned to address the discrepancy with the ASME code.

For purposes of further discussion, the two systems will be divided between System 23F (ECCW and Secondary Chilled Water) and System 23G (ICCW).

\section{ECCW:}

In 1994 , the motor failed on the E-21 chiller requiring replacement at a cost of $\$ 25000$. Since the facility was in transition to shutdown with a reduced cooling load, it was determined that the chiller could be laid up. This consisted of pulling the thermal overloads on the main breaker, removing the refrigerant oil and transferring the CFC-12 refrigerant to the storage tank until needed for future use. In 1996, the facility status changed from shutdown to standby. This caused a need to put E-21 Chiller in a condition to preserve it for future operation. As a result, the $\mathrm{CFC}-12$ refrigerant was removed from the storage tank and the chiller oil cavities were drained of the original Mobil DTE 26 oil. VSI-32 Shell vaporizing oil was added with a 15 psig nitrogen cover gas and a lace of 
HFC-134a refrigerant. E-21 will continue to be monitored in this condition until the facility status changes again.

The ECCW chillers are still operated at varying cooling load conditions because of dependence upon the outside ambient temperature. The ECCW chilled. water header temperature limit is mainly controlled by the secondary sodium pump tower temperatures and has been raised from $45^{\circ} \mathrm{F}$ to $65^{\circ} \mathrm{F}$ because the secondary sodium system temperature is being maintained at $400^{\circ} \mathrm{F}$. Varying load conditions cause the oil in the chiller sump to transfer to the refrigerant during low cooling loads and precipitate back out of the refrigerant at high loads. This condition has occurred since the facility began operation. Over extended operating periods, the refrigerant becomes more and more saturated with oil. Abnormal operating characteristics begin to appear when the refrigerant is saturated with greater than $9 \%$ oil. The CFC-12 refrigerant removed from E-21 and E-22 is suspected to be saturated signicantly greater than $9 \%$. Chillers are designed to operate at full load conditions and the ECCW chillers have never been operated in this manner continuously. The plan to eliminate these undesirable operating conditions is to install hot gas bypass systems on the chillers so they can be falsely loaded under low load conditions. This work is scheduled to be completed before the end of the 98-3 work phase on three of the ECCW chillers.

All of the chilled water pumps mechanical seals have been replaced with the Duraseal cartridge type. As a result, ethylene glycol leakage has been drastically reduced. Some of these pumps are operated continuously even through the winter cooling mode so the chillers will only have to be operated when the ambient temperature is greater than $40^{\circ} \mathrm{F}$.

The MOE for the ECCW chillers has recently been changed from one to two out of three chillers because the facility is now in the standby condition.

\section{Secondary Chilled Water}

The secondary chilled water system was important during the fuel off-load process since it supplies chilled water for the sodium removal system. No problems with the system were experienced. One of the chilled water pumps mechanical seal has been replaced with a new cartridge type. One out of two secondary chilled water pumps are required for minimum operable equipment.

\section{$\underline{\mathrm{ICCW}}$}

As discussed earlier, three of the ICCW chillers have new microprocessor controls and all four ICCW chillers have been converted from the CFC-12 refrigerant to HFC-134a refrigerant. When FFTF entered the shutdown phase in 1994, it was decided that E-145 would be run in lead (or run to failure) until the other three ICCW chillers had their new microprocessor controls installed, then it would be shutdown and laid up. However, when the facility returned to the standby condition, this changed how things were operated and maintained but the budget did not change. Currently, three reliable ICCW chillers are available for operation with new microprocessor controls. Because of budget contraints, 
the decision was made not to upgrade the controls or overhaul E-145 chiller, but to use it for emergency backup only. Operations recently changed the MOE list for the ICCW chillers from one to two out of four.

Some of the chilled water pumps have the new cartridge type mechanical seal. As the old Borg Warner type mechanical seals fail, they are being replaced with the new type. P-98 is experiencing some high vibrations from the impeller end of the bearing housing, but the bearings are not going to be replaced on a high priority basis because E-145 Chiller will be used as a backup chiller only.

\subsection{ITEMS REQUIRING ACTION}

A. Near Term Items

Required By

\section{$\underline{\text { ECCW }}$}

4F-97-214/M-REFIT E-20 TO RUN ON R-134A REFRIGERANT. This replaces the $\mathrm{CFC}-12$ refrigerant with $\mathrm{HFC}-134 \mathrm{a}$ refrigerant, increases the speed of the compressor by changing the pinion and drive gear ratio to make up for the losses related to the new refrigerant, installs an oil skimmer to skim the oil on top of the refrigerant in the evaporator cooler back to the oil sump and incorporates the chiller ASME vessel inspection and pressure relief valve replacement to comply with ASME code requirements.

(98-2M) June 1998

4F-97-217/M-REFIT E-23 TO RUN ON R-134A REFRIGERANT. This work is identical to $4 \mathrm{~F}-97-214 / \mathrm{M}$

(98-2M) June 1998

4F-94-812/M-INSTALL NEW E-22 CONTROL PANEL. This work replaces the existing chiller control panel with a microprocessor type. In addition, the chilled water pumps and cooling water isolation valves can be operated from the $\mathrm{C}-1022$ chiller control panel.

(98-2R) June 1998

4F-93-947/M-INSTALL HOT GAS BYPASSES FOR ECCW CHILLERS. This work package installs hot gas bypass capabilities on all of the operable ECCW chillers. The hot gas bypass will eliminate the need to start and stop a chiller during low load conditions primarily in the winter months and eliminate oil transfer to and from the refrigerant and the oil sump. Over a period of time, it will keep the new HFC-134a refrigerant from becoming saturated with oil.

(98-3R) September 1998 
4F-94-810/M-INSTALL NEW E-20 CONTROL PANEL. This work is identical to 4F-94-812/M stated above.

(98-4R) December 1998

4F-94-814/M-INSTALL NEW E-23 CONTROL PANEL. This work is identical to 4F-94-812/M stated above.

(99-1) March 1999

\section{$\underline{\mathrm{ICCW}}$}

4F-97-1077/W-P-228 (E-25) MOTOR REPLACEMENT. This work package replaces the motor for the P-229 ICCW booster chilled water pump for E-25 Cooler.

(98-2R) June 1998

4F-97-2697/M-E-142 GEARING CHANGE FOR NEW REFRIGERANT. This work package replaces the pinion and drive gear to increase compressor speed to replace the loss of cooling tonnage because the new refrigerant is lower in density than the CFC-12 refrigerant it replaced. In addition, the new oil skimmers will be similar to that of E-143 and E-144 Chiller. Performance of this work in standby is contingent on receiving additional ROI funding from DOE.

(98-3) September 1998

\subsection{TRENDS}

\section{ECCW and ICCW}

The chillers continue to be overhauled and inspected on an 8000 hour rotational basis. Trending for the chillers is performed by tracking the use of spare parts used on each overhaul. The chilled water pumps continue to be monitored on the vibration and bearing analysis program that identify any significant changes that can be repaired before failure occurs.

5.0 SYSTEM AGING, SPARE PARTS CONSIDERATIONS, AND LONG TERM MAINTENANCE PHILOSOPHY

A. System aging:

ECCW

The chillers continue to age but recent and ongoing upgrades will significantly extend the life of the chillers far into the future. The upgrades planned for this year include installing new chiller controls, refrigerant conversion from $\mathrm{CFC}-12$ to $\mathrm{HFC}-134 \mathrm{a}$ and installation of the hot gas bypass systems. Upon failure of the existing Borg Warner mechanical seals in the chilled water pumps, new cartridge 
type Duraseals will be installed and are readily available in spare parts.

\section{ICCW}

There are very few aging issues with the ICCW system except for E-145 Chiller. Circumstances with the status of the facility assisted in creating this concern but careful consideration has been placed on how it is operated until the facility status is changed.

B. Near Term Spare Parts:

There are no known major deficiencies in the System $23 \mathrm{~F}$ and $23 \mathrm{G}$ spare parts inventory that would impact continued Standby operation. However, replacement spare parts for the new chiller controls and instrumentation still needs to incorporated into the program once all the chillers have new controls installed.

C. Standby Maintenance:

\section{$\underline{\mathrm{ECCW}}$}

ECCW components will continue to operate in standby for the next several years and present no maintenance challenges if we continue to implement the planned upgrades.

\section{$\underline{\mathrm{ICCW}}$}

Operating in standby for the next several years present no major maintenance challenges. However, replacement of the old Borg Warner type mechanical seals with the new cartridge type should continue during the standby period.

\subsection{CHECKOFF LIST}

A. Accessible parts of the entire system or component have been thoroughly walked down at least once in the past 30 days to view current performance, equipment status and condition. Yes X No_.

COMMENTS (exceptions): None

B. Are there any conditions which might require limitations different from operating limits as defined in the SDDs, the FSAR, or the Plant Technical Specifications? Yes_No_X

COMMENTS (exceptions): None 
C. Are there trip settings, set points, interlocks, etc., that should be changed from those currently established? Yes__ No $\underline{X}$

COMMENTS (exceptions): None

D. Are there interface areas which have not performed acceptably, which require resolution? Yes__ No _ X

COMMENTS (exceptions): None

E. Are there temporary plant or procedural conditions which will and should remain in place? Yes X No_

Attach list of $\mathrm{MOD}(\mathrm{L}) / \mathrm{ECN}(\mathrm{L}) \mathrm{s}$, and $\mathrm{OSP}$ s that are currently active. Provide justification for continuing temporary MOD (L)s and ECN (L)s.

COMMENTS (exceptions): The only MOD(L) in place is on the ECCW E-22 Chiller. 4F-97-2194/L "E-22 HAS FAILED MOTOR TEMPERATURE

SENSORS". Both existing motor sensors have failed and are imbedded into the windings of the motor. These sensors have been temporarily bypassed until the new chiller controls are installed. E-22 is scheduled to be the next chiller for installation of new microprocessor controls. The motor sensors for the new microprocessor controls are already installed on the motor and will be connected during installation of the new chiller controls during the $98-2$ work phase.

F. Is any retesting or special testing (e.g., OSP) required? Yes_ No $\mathrm{X}$

COMMENTS (exceptions): None

G. Are the current plant corrective maintenance, preventive maintenance, and calibration database items all properly identified and are planned actions acceptable? Yes_X No

COMMENTS (exceptions): None

H. Are all other action items (NCRs, IRs, etc.) properly identified and assigned? Yes_. No__ (attach the summary of needed actions not in the data base)

COMMENTS (exceptions):

1) An NCR has identified the failure of the original PRV's on the chiller evaporator coolers and storage tanks. Following removal, the PRV's did not lift after being pressurized significantly above the set pressure. The PRV seat was rubber and stuck to the valve seat inhibiting it from lifting. Six out of eight ECCW and ICCW chillers have received replacement PRV's with teflon seats. The two remaining chillers are scheduled for the 98-2 work phase. 
2) The Authorized Inspector also discovered after the inspections on the ICCW chillers that the U-1 form record indicates that the evaporator cooler chilled water tube maximum working pressure is $150 \mathrm{psig}$. The evaporator cooler ASME identification plates on the ICCW chillers indicate 150 psig for E-142 and 190 psig for E-143, E-144 and E-145. The ICCW chilled water pumps normally operate at $160-170 \mathrm{psig}$. The PRV's on the chilled water going through the evaporator coolers are set at $190 \mathrm{psig}$. A NCR is being written to document this discrepency.

I. Are there any special operating considerations? Yes X No

List or Reference: ECCW: E-21 is laid up with vaporizing oil and a nitrogen cover gas installed in the refrigerant boundary to preserve it during the standby period. ICCW: E-145 is in need of an overhaul for continued full time operation and should be operated in backup use only but remain operable.

J. Are near term spare parts adequate? Yes X No

COMMENTS (exceptions): None

K. Have any safety issues (radiological, industrial) been identified that remain unresolved? Yes_ No $\mathrm{X}$

COMMENTS (exceptions):

L. Have all component data been entered into the Plant information database? Yes_No N

COMMENTS (exceptions): This exercise was performed several years ago, but another hand over hand of the system needs to be performed to identify all of the specific components for each chiller to verify proper identification of the JCS data base and physically have identification tags on the equipment.

M. Have applicable SISI inspections been conducted? Yes_No_X

COMMENTS (exceptions):Has a cleanliness evaluation been completed?

Yes__No_.

Are any issues still unresolved? Yes X No _

COMMENTS (exceptions):

The secondary chilled water heat exchangers and inert gas cooler heat exchangers have recently been identified as ASME Section VIII vessels with greater than 15 psig and volume $25 \mathrm{ft}^{3}$ should be inspected by the Authorized Nuclear Inspector and have the vessel PRV's tested . 


\subsection{REFERENCES}

none

8.0 ATTACHMENTS

none

System 23F/G ASAR

Page 9 of 9 
HNF-2380

Rev. 0, Page 101

\section{ANNUAL SYSTEM ASSESSMENT REPORT \\ FOR \\ SYSTEM 23J}

Date of This Report January 30, 1998

Date of Previous Report January 28, 1998

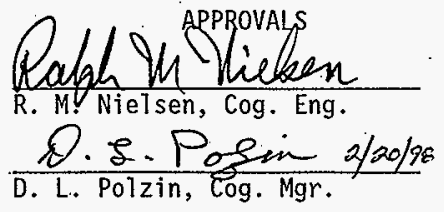

1. SCOPE

System/Component

$23 \mathrm{~J}$
Title

Instrument Air System

\section{SUMMARY EVALUATION}

The above system and its components are fully capable of meeting their requirements to support the $\mathrm{plant}$ during standby operations. The $R-1$ and R-2 instrument air compressors need new piston rings on the second stage pistons. $4 \mathrm{~F}-97-3638 / \mathrm{W}$ has been dispositioned to replace the second stage rings on R-1. This work started the last week of January. $A$ new J-1, 4F-98-39/W, has been written against $R-2$ which has 7000 hours on it since the last overhaul. This work should be performed in the second quarter of 1998 . The 7000 hour overhaul interval was established, through trending, as the hours the piston rings on the second stage will last before the rings start to fall apart, causing excessive vibration.

The instrument air dryers are fully functional, with the only discrepancy being that T-194 is marginal for carrying the drying load during high humidity days. This in not a major problem since we have another backup dryer, T-196. The T-196 dryer has a long term need to be hard piped into the system, so that the temporary hoses can be removed. $4 F-97-160 / \mathrm{W}$ and $4 \mathrm{~F}-97-161 / \mathrm{W}$ wi11 perform this work.

\section{ITEMS REQUIRING ACTION}

A. Near Term Items

$4 \mathrm{~F}-97-3638 / \mathrm{W}, \mathrm{R}-1$ Replace 2nd stage rings

$4 F-98-39 / W, R-2$ Replace 2nd stage rings

B. Long Term Items

4F--97-160/M T-196 Hard piping installation

4F-97-161/M Insta11 T-196 I\&C instatlation

after hard piping the dryer.
Required By

$1-30-98$

6-31-98

Required By

$12-30-98$

12-30-98 
HNF-2380

Rev. 0, Page 102

\section{SYSTEM $23 \mathrm{~J}$ ANNUAL SYSTEM ASSESSMENT REPORT (cont.)}

4. TRENDS

Trending of the maintenance history on the Instrument Air Compressors has led to establishing a 7000 hour interval for the replacement of piston rings on the second stage pistons. The teflon piston rings on the second stage were found to break apart after operating for over 7000 hours, allowing small sections of ring material to come between the head and piston causing excessive vibration. The first stage piston rings rarely are in need of replacement, which is the result of being vertical and the piston is light weight (aluminum) also it is tapered on both ends. The taper allows the piston to virtually float in the cylinder, with minimal wear to the piston rings. The second stage on the other hand is heavy (steel) and is horizontal, which creates more wear on the teflon rings.

5. SYSTEM AGING, SPARE PARTS CONSIDERATIONS, AND LONG TERM MAINTENANCE PHILOSOPHY

A. Aging problems have been observed in several components, primarily in the 0-rings and seals which lose their elasticity over time. other age related items would be bearing wear. Experience has shown that stocking a supply of bearings in the spares warehouse is not cost effective because usage is infrequent. Long term storage of bearings allows the factory applied lubricant to separate, leaving a varnish that then causes a rough sounding bearing and shorter life span. It is better to purchase fresh bearings from the local bearing distributor when new bearings are required.

B. All other hardware items for this system are readily replaceable from spares, and major components are attainable from the manufacturer. The spare parts for this system have been maintained in good order. Now and then manufacturing companies have changed hands and tracking down the new company provides a challenge, but we have been successful thus far.

C. Since trending has provided information that the second stage piston rings require replacement at or near 7000 hours., maintenance is now scheduled at or near that time. During the installation of the new control panels for the instrument air compressors, we installed an hour meter that can be reset. When major work has been performed on a compressor, the hour meter is reset to 0 hours. PMP 23J-R02, which inspected the piston to cylinder clearance on an annual basis, has been changed to a recall basis 3 "upon request." Now the hours are being tracked, and PMP-23J-R02 is called up only when the individual compressor has accumulated approximately 7000 hours.

D. The PMPs for this system are all active and have consistently been performed during the present standby period. These PMPs should continue to be performed for continued standby status. 


\section{SYSTEM 23J ANNUAL SYSTEM ASSESSMENT REPORT (cont.)}

\section{CHECKOFF LIST}

A. Accessible parts of the entire system or component have been thoroughly walked down at least once in the past 30 days to view. current performance, equipment status and condition. Yes $x$ No _-

COMMENTS (exceptions): An exception is the Instrument Air Piping System which is so large that it would be too time consuming to walk it down in it's entirety. This also would not yield a large dividend in that air is supplied to other systems, and a failure of any portion of the air system would soon be reported by others, and repairs administered immediately.

B. Are there any conditions which might require limitations different from operating Timits as defined in the SDD's, the FSAR, or the Plant Technical Specifications? Yes No $\mathrm{X}$

COMMENTS (exceptions): None

C. Are there trip settings, set points, interlocks, etc., that should be changed from those currently established? Yes__ No $\underline{X}$

COMMENTS (exceptions): None

D. Are there interface areas which have not performed acceptably, which require resolution? Yes__ No $X$

COMMENTS (exceptions): None

E. Are there temporary plant or procedural conditions which will and should remain in place? Yes No $X$

Attach 1 ist of $M O D(L) / E C N(L) s$, and OSPs that are currently active. Provide justification for continuing temporary MOD (L)s and ECN (L)s. COMMENTS (exceptions): None

F. Is any retesting or special testing (e.g., OSP) required? Yes_ No $X$ COMMENTS (exceptions): None

G. Are the current plant corrective maintenance, preventive maintenance, and calibration database items all properly identified and are planned actions acceptable? Yes $X$. No

COMMENTS (exceptions): None

H. Are all other action items (NCRs, IRs, etc.) properly identified and assigned? Yes_ No__ N/A

COMMENTS (exceptions): N/A 


\section{SYSTEM 23J ANNUAL SYSTEM ASSESSMENT REPORT (cont.)}

6. continued

I. Are there any special operating considerations? Yes No $X$ List or Reference: None

J. Are near term spare parts, adequate? Yes $X$ No

COMMENTS (exceptions): Attention must be paid to getting the air compressor valves rebuilt and put back into spares. The valves that are replaced on the compressors are rebuilt and tested in the FFTF shop, then returned to the spares inventory.

K. Have any safety issues (radiological, industrial) been identified that remain unresolved?. Yes No $x$

COMMENTS (exceptions): None

L. Have all component data been entered into the Plant information database? Yes $\underline{X}$ No

COMMENTS (exceptions): None

M. Have applicable SISI inspections been conducted? Yes $\underline{X}$ No

COMMENTS (exceptions): None

N. Has a cleanliness evaluation been completed? Yes $X$ No

Are any issues still unresolved? Yes_ NN_ No

COMMENTS (exceptions): None

7. REFERENCES

None

8. ATTACHMENTS

None 


\section{ANNUAL SYSTEM ASSESSMENT REPORT \\ for \\ SYSTEM(S) $24(A)$}

Date of This Report January 31, 1998

Date of Previous Report January 31, 1992
APPROVALS

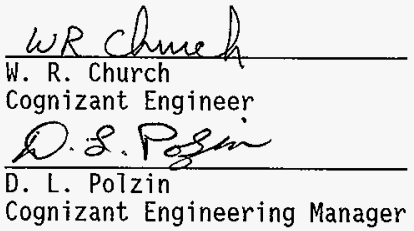

1. SCOPE

\section{System/Component}

$24(A)$

\section{Title}

Radioactive Waste

\section{SUMMARY EVALUATION}

The radioactive liquid waste system in the plant has performed very well since the last report. The system has no minimum operable equipment as defined in plant procedure PN-7.

We were recently notified that the Hanford Site Railroad will cease operation on September 30, 1998. This decision will impact FFTF in that we must excess the existing 8,000 gallon rail car (T-332) and develop another method of transporting our liquid waste for disposal. The IEM Ce1] Sodium Removal System (SRS) generates the majority of the FFTF waste water. Additional potential sources include the Radioactive Control Technician's personnel decon shower, sinks and floor drains, as we11 as equipment decontaminated in MASF.

\section{ITEMS REQUIRING ACTION}

A. Near Term Items

Required By September 30, 1998

The current Hanford Site raitroad operations will be shut down by September 30,1998 . We will have to excess our 8,000 gallon rail car (T-332) prior to this date. The railroad shutdown plan calls for shipping all contaminated cars to a siding north of the 200 West Area. The final disposition of the cars may not be accomplished for several years.

B. Long Term Items

Required By TBD

Based on the railroad shutdown plan, FFTF will be forced to identify an alternate method of transporting liquid waste, and facilities that can accept the discharge. The most promising 


\section{Annual System Assessment Report \\ System $24(A)$}

\section{B. continued}

scenario involves the 200 area Effluent Treatment Facility (ETF). We have submitted water sample analysis reports from the FFTF and MASF for their review. Initial feedback indicates that the ETF will be able to accept our waste water.

The biggest concern is the radionuclides that are present (i.e., $\mathrm{Na}-22, \mathrm{Mn}-54, \mathrm{Ta}-182, \mathrm{Cd}-109)$ but were not considered in the ETF safety analysis. The ETF safety analys is representative does not believe this is a problem. Additional characterization data has been sent to ETF so that an analys is can be done to show these four additional radionuclides will not effect their dose consequences.

The up side of using the 200 area ETF for disposal is they own three 5,000 gallon tanker trucks. We will have to modify the loadout facilities in MASF and FFTF to connect to the new tanker trucks. The modification may simply be construction of jumpers in the shop.

One additional requirement imposed by ETF requires the liquid waste be fittered prior to filling the tanker. The Ion exchange system in the SRS has a 25 micron prefilter which could satisfy this requirement. The MASF off load system may require modification.

Previous shipments of FFTF liquid waste went to the 204AR Facility in Tank Farms. This facility was only accessible by railroad which will no longer be an option. The IEM Cell SRS has been allowed to process fuel assemblies which were known gas leakers, however, fuel assemblies with known DNM signals should continue to be banned. The increased activity of the rinse water could create a problem with disposal at ETF.

4. . TRENDS

A substantial decrease in waste water has been realized by the installation of the Ion Exchange system. Approximately 115 assembi ies have been processed through the SRS which would have generated 58,000 gallons of contaminated water versus the 2,000 gallons currently in T-103. This equates to a reduction of approximately 56,000 gallons.

5. SYSTEM AGING, SPARE PARTS CONSIDERATIONS, AND LONG TERM MAINTENANCE PHILOSOPHY

A. Discuss effects of system aging.

There has been no observed degradation of the system due to aging. 


\section{Annua] System Assessment Report}

System $24(A)$

5. continued

B. Discuss the strategy for near term spare parts and their availability strategy.

This system witl remain in operation until the plant is shut down. The manufacturer's recommended spare parts for rotating equipment (i.e., pumps/agitator) will be maintained.

C. Standby Maintenance Plan: Discuss a plan which ensures essentia] system functions for standby are provided and minimizes equipment degradation.

The FFTF Radioactive Waste System is in fuTl operation with the exception of the Cel1 Atmosphere Processing System Liquid Waste Drainage tank, T-132, which has been deactivated. The existing PMP/ICRS program, along with the ASME Section VIII pressure vessel inspections, are current within their scheduling tolerance. Future PMP/ICRS programs will concentrate on the storage tank, T-103, level and pressure instrumentation only.

\section{CHECKOFF LIST}

A. Accessible parts of the entire system or component have been thoroughly walked down at least once in the past 30 days to view current performance, equipment status and condition. Yes $X$ No

COMMENTS (exceptions): None

B. Are there any conditions which might require limitations different from operating Timits as defined in the SDDs, the FSAR, or the Plant Technical Specifications? Yes No $X$

COMMENTS (exceptions): None

c. Are there trip settings, set points, interlocks, etc., that should be changed from those currently established? Yes_ No No $X$

COMMENTS (exceptions): None

D. Are there interface areas which have not performed acceptably, which require resolution? Yes No $X$

COMMENTS (exceptions): None 


\section{Annual System Assessment Report}

System 24(A)

6. continued

E. Are there temporary plant or procedural conditions which will and should remain in $\mathrm{place}$ ? Yes_. No $X$

Attach 1 ist of $\operatorname{MOD}(\mathrm{L}) / \mathrm{ECN}(\mathrm{L}) \mathrm{s}$, and OSPs that are currently active. Provide justification for continuing temporary MOD (L)S and ECN

(L)s.

COMMENTS (exceptions): None

F. Is any retesting or special testing (e.g., OSP) required? Yes_. No $\underline{X}$ COMMENTS (exceptions): None

G. Are the current plant corrective maintenance, preventive maintenance, and calibration database items all properly identified and are planned actions acceptable? Yes_X No

COMMENTS (exceptions): None

H. Are all other action items (NCRs, IRs, etc.) properly identified and assigned? Yes $X$ No___ (attach the summary of needed actions not in the data base)

COMMENTS (exceptions): None

I. Are there any special operating considerations? Yes No $\underline{X}$

List or Reference: None

J. Are near term spare parts adequate? Yes_ $X$ No

COMMENTS (exceptions): None

K. Have any safety issues (radiological, industrial) been identified that remain unresolved? Yes_ No $X$

COMMENTS (exceptions): None

L. Have all component data been entered into the Plant information database? Yes No $\mathrm{X}$

COMMENTS (exceptions): The JCS data base is incomplete for this system. The data base should be updated if the facility receives a startup order. JCS work package number 4F-98-00155/A.

M. Have applicable SISI inspections been conducted? Yes $X$ No

COMMENTS (exceptions): None. 


\section{Annual System Assessment Report}

System 24(A)

6. continued

N. Has a cleanliness evaluation been completed? Yes No $X$ Are any issues still unresolved? Yes No $X$ COMMENTS (exceptions): None

7. REFERENCES

None

8. ATTACHMENTS

Attachment 1 is included for information only and presents a summary of the T-103 1 iquid waste sample results. 
Annual System Assessment Report

System 24(A) - Attachment 1

FFTF RLWS T-103 Sample Resu1ts $(\mu \mathrm{Ci} / \mathrm{ml})$

\begin{tabular}{|c|c|c|c|c|c|c|c|c|c|c|c|c|c|c|}
\hline (1) & \% & (2) & 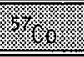 & 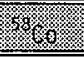 & row & 得: & (17.6. & (18) & 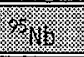 & the & rax. & 6 & 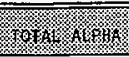 & 3. \\
\hline $04 / 02 / 82$ & & $6.7 E^{-5}$ & & $5.5 \mathrm{E}^{-4}$ & & & & $3.5 \mathrm{E}^{-5}$ & & & & & $1.8 E^{-6}$ & $9.5 E^{-4}$ \\
\hline $08 / 27 / 82$ & & $2.7 E^{-5}$ & & $5.5 \mathrm{E}^{-5}$ & & & & & & & & & $5.9 \varepsilon^{-7}$ & $1.4 E^{-4}$ \\
\hline $06 / 13 / 83$ & & $2.4 E^{-4}$ & & $2.4 E^{-4}$ & & & & $1.3 \mathrm{E}^{-4}$ & & & & & $2.3 E^{-6}$ & $2.8 E^{-4}$ \\
\hline $06 / 16 / 83$ & & $8.2 E^{-4}$ & & $9.3 E^{-4}$ & $3.5 \mathrm{E}^{-5}$ & & & $8.2 E^{-4}$ & & & & & $1.5 \mathrm{E}^{-5}$ & $1.5 E^{-3}$ \\
\hline $12 / 12 / 83$ & $1.6 \mathrm{E}^{-5}$ & $5.9 E^{-3}$ & & $2.6 \mathrm{E}^{-3}$ & $2.1 E^{-4}$ & & & $8.9 E^{-4}$ & $7.7 \mathrm{E}^{-5}$ & & & & $<2.9 E^{-6}$ & $2.6 \mathrm{E}^{-3}$ \\
\hline $06 / 28 / 84$ & & $9.0 \mathrm{E}^{-3}$ & $2.8 \mathrm{E}^{-5}$ & $4.5 E^{-3}$ & $5.0 E^{-4}$ & & & $4.1 E^{-4}$ & $6.5 E^{-5}$ & $6.4 E^{-5}$ & & & $<2.0 E^{-6}$ & $3.0 E^{-3}$ \\
\hline $02 / 12 / 85$ & $3.0 E^{-5}$ & $1.4 E^{-2}$ & $2.5 E^{-5}$ & $4.7 E^{-3}$ & $7.4 E^{-4}$ & & & $1.8 \mathrm{E}^{-3}$ & $2.8 \mathrm{E}^{-4}$ & & & & $<3.6 \mathrm{E}^{-6}$ & $5.8 E^{-3}$ \\
\hline $07 / 30 / 85$ & & $1.1 \mathrm{E}^{-2}$ & $2.9 \mathrm{E}^{-5}$ & $2.5 E^{-3}$ & $5.7 E^{-4}$ & & & $7.3 E^{-4}$ & $4.4 E^{-5}$ & & & & $<6.3 \mathrm{E}^{-7}$ & $2.1 \mathrm{E}^{-3}$ \\
\hline $04 / 22 / 86$ & & $2.1 E^{-2}$ & $5.8 \mathrm{E}^{-5}$ & $4.5 E^{-3}$ & $7.1 \mathrm{E}^{-4}$ & & & $7.3 \mathrm{E}^{-4}$ & $3.0 E^{-5}$ & & & & $<9.0 \mathrm{E}^{-7}$ & $5.6 E^{-2}$ \\
\hline $02 / 24 / 87$ & & $4.2 \mathrm{E}^{-3}$ & & $2.3 E^{-4}$ & $2.2 \mathrm{E}^{-4}$ & $4.5 \mathrm{E}^{-4}$ & $2.7 E^{-3}$ & & & & & & $<5.7 E^{-6}$ & $5.0 E^{-3}$ \\
\hline $08 / 26 / 87$ & & $4.95 \mathrm{E}^{-3}$ & . & $4.5 E^{-4}$ & $1.7 E^{-3}$ & $1.3 E^{-4}$ & $6.3 E^{-4}$ & & & & $2.7 E^{-3}$ & $5.9 E^{-4}$ & $<2.3 \mathrm{E}^{-7}$ & $4.46 \mathrm{E}^{-3}$ \\
\hline $09 / 01 / 88$ & Trace & $4.95 \mathrm{E}^{-4}$ & & & $2.3 \mathrm{E}^{-4}$ & $5.4 \mathrm{E}^{-5}$ & $2.9 E^{-4}$ & & & & & & $<3.6 \mathrm{E}^{-7}$ & $6.8 E^{-4}$ \\
\hline $12 / 21 / 88$ & Trace & $2.4 E^{-4}$ & & $1.8 E^{-4}$ & $7.7 E^{-5}$ & $1.98 \mathrm{E}^{-3}$ & $4.95 \mathrm{E}^{-3}$ & & & & & & $<3.2 \mathrm{E}^{-7}$ & $6.8 \mathrm{E}^{-3}$ \\
\hline $04 / 25 / 90$ & $3.8 \mathrm{E}^{-5}$ & $9.0 E^{-5}$ & & & $2.8 \mathrm{E}^{-5}$ & $2.4 E^{-4}$ & $1.2 \mathrm{E}^{-3}$ & & & & & & $<4.5 \mathrm{E}^{-7}$ & $1.7 \mathrm{E}^{-3}$ \\
\hline $02 / 19 / 91$ & & $4.5 E^{-5}$ & & & $9.4 E^{-6}$ & $3.2 E^{-4}$ & $2.4 \mathrm{E}^{-3}$ & & & & & & $<9.0 E^{-7}$ & $3.7 E^{-3}$ \\
\hline $12 / 12 / 91$ & $1.5 E^{-5}$ & $4.95 E^{-5}$ & & $6.3 E^{-6}$ & $1.4 \mathrm{E}^{-5}$ & $8.1 \mathrm{E}^{-5}$ & $8.1 E^{-4}$ & & & & & & $<4.7 \mathrm{E}^{-7}$ & $1.2 \mathrm{E}^{-3}$ \\
\hline $05 / 18 / 93$ & $1.6 \mathrm{E}^{-5}$ & $5.4 \mathrm{E}^{-5}$ & & & $1.0 E^{-5}$ & $2.9 \mathrm{E}^{-5}$ & $4.5 \mathrm{E}^{-4}$ & $1.4 \mathrm{E}^{-3}$ & & & & & $<9.0 E^{-7}$ & $2.2 E^{-3}$ \\
\hline $01 / 24 / 96$ & $1: 14 \mathrm{E}^{-5}$ & $1.1 \mathrm{E}^{-5}$ & & & $1.4 \mathrm{E}^{-4}$ & $5.63 E^{-5}$ & $2.64 \mathrm{E}^{-3}$ & $2.47 \mathrm{E}^{-6}$ & $4.1 E^{-7}$ & & & & $5.09 \mathrm{E}^{-7}$ & $3.06 \mathrm{E}^{-3}$ \\
\hline
\end{tabular}




\section{ANNUAL SYSTEM ASSESSMENT REPORT \\ for \\ SYSTEM 25}

Date of This Report _ February 6, 1998

Date of Previous Report January 29, 1992

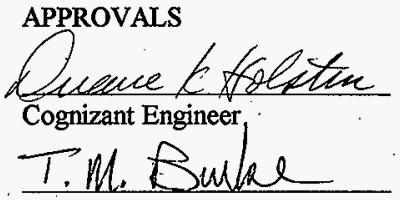

Cognizant Engineering Manager

1. SCOPE

System/Component

System 25
Title

Heating Ventilation and Air Conditioning

\section{SUMMARY EVALUATION}

The health of the System 25 continues to be good and the system will serve well throughout the Standby period.

For purposes of discussion, System 25 can be divided into two categories of equipment, the in-containment Inert Gas Cooling Systems and the more conventional HVAC systems.

Inert Gas Cooling Systems: Because of the tight working quarters in the lower cooler area in the containment and the overall cost and aggravation of having to replace a bearing in any Inert Gas Cooling System blower in that environment, these units continue to be the area where we focus attention to improve longevity. The three-month lubrication schedule for these units will forestall major wear and minimize the possibility of early overhaul in the next several years. In addition, we've gained more confidence in the bearing analysis program and its ability to warn us of impending bearing problems. However, it's also worth mentioning that some of the blowers have not had a bearing analysis run performed recently (shared redundant units, in particular, since they usually are not operating at the time the Crafts make their rounds with the instruments). See the more specific discussions relating to Minimum Operable Equipment in the TRENDS section that follows.

Conventional HVAC Systems: The more conventional portion of System 25 consists of units that are essentially industrial standard in construction. The health of this part of System 25 is also good. Because of the conventional nature of the equipment, we've 
experienced no difficulty in replacing fan and motor bearings, the motor itself and fan shafts.

In an effort to conserve resources, the decision was made early in the FFTF Standby phase to revise the computer database to prevent automatic recall of preventive maintenance procedures on certain selected units. Instead, we've been operating on the basis of repair/maintain as needed. This has been successful, especially since the units chosen are fairly innocuous in their cooling/heating duties and when problems do arise, they are easily rectified.

Historically, the conventional HVAC components were not given the same rigorous bearing analysis and attention as the Inert Gas Blowers when the plant was operating. This is the case in the FFTF Standby mode also. They receive special attention with the vibration and bearing analysis equipment as a troubleshooting aid only (not a regular scheduled bearing reading program).

See the System 96-3 Annual System Assessment Report for issues and actions that involve associated electrical and I\&C packages. Specifically, the programmable controllers in $\mathrm{C} 185$ and $\mathrm{C} 186$ in the Control Room are addressed in some detail there. These devices are old and continue to present recurring problems. The vendor is no longer in business and parts replacement has become a difficult issue. $\mathrm{C} 185$ and $\mathrm{C} 186$ are the panels that operate the Inert Gas Cooling Systems deemed to be important enough to require automatic transfer to the redundant unit when the operating unit fails.

\section{ITEMS REQUMRING ACTION}

Note: The following packages are in addition to those shown on the System 96-3 report (except 4F-97-1968, where additional information is supplied below):

A. Near Term Items

Required By

4F-97-2752/W E-530 FILTER D/P HIGH. E-530 serves the HVAC equipment room in AEB-East (Room 331/332). This is a simple filter changeout.

(3-blank) Mid 1998

4F-97-2627/W R-906 MOTOR AND FAN BEARING REPLACEMENT. This fan serving the FSF vestibule and rest rooms is operating but appears to have both fan and motor bearings that are failing.

(3-blank) Mid 1998 
HNF-2380

Rev. 0, Page 113

4F-97-1968/W E-565 BELTS ARE SLIPPING. This unit serves the HTS-East basement and the secondary cold trap and EM pump packages. While resolving the belt issue, the Crafts noticed roughness in the motor bearings. A WCN was written to allow replacement of the bearings.

(3-blank) Spring 1998

B. Long Term Items

Required By

See the $96-3$ report for packages relevant to the C-185 and C-186 controllers.

\section{TRENDS}

A trend in fractional horsepower motor failure had been reported in the two previous ASARs for System 25. This has tapered off somewhat. The worn out motors referred to were generally those in the roof exhaust fans scattered throughout the plant. Essentially all of these units have been put in layup. We also experienced a spate of pillow block bearing replacements in the conventional HVAC units. This trend has also leveled off, possibly because we've replaced most of the bearings whose lubrication had been inadequate at the beginning of operation of the plant.

There are several units (inert gas blowers) whose bearings show signs of wear. These units have been observed for years but they continue to respond to lubrication. They are discussed below. We have learned from the bearing analysis program that there will generally be no sudden bearing failures or surprises.

The System 25 Minimum Operable Equipment for Standby is listed below. Normally, this author's trend writeup would be general in nature. Since there have been no ASAR's released for a number of years, it was felt that unit-specific trend comments would be in order.

\section{A. E-201R and E-202R}

The Reactor Cavity and Upper Auxiliary Pipeway Cooling system blowers E-201R and E-202R, are in excellent condition and there are no adverse trends evident. In fact, a slight E-202R vibration condition mentioned in past ASAR's has even improved somewhat. The unit had indicated readings that peaked at approximately $3 / 4$ of the alarm level range in late 1995 and then gradually decreased with each successive reading to slightly below $1 / 2$ the alarm level range. At the time, it was thought that this vibration may be attributed to some looseness of the bearing in the end bells of the fan. With the improvement in the vibration readings, it isn't likely that there is an end-bell problem. However, should that be the case, there are spare end bells in stock. 
Because E-20IR has been shut down (not needed during Standby) no bearing analysis has been performed on it recently. But this is not viewed as a problem. It is still being lubricated on the quarterly schedule and the bearing analysis readings taken during power operation indicate that they are in excellent condition.

Unlike power operation of the plant, where both these units are required to operate to maintain temperatures below limits in the Reactor Cavity and pipeways, only one of the units needs to operate during the STANDBY phase of FFTF. Therefore these units should provide excellent service during the next several years of operation.

B. E-203R, HTS Cell \#1 (521) Cooling

This unit continues to draw attention since replacement of its bearings in November of 1989. It had suffered from lack of lubrication for some months following repair and we were concerned that it had suffered some permanent damage. This indeed is probably the case. However, with an attentive lubrication schedule, it appears not to be degrading further. The spike energy readings periodically cross the alarm limits but there is no degradation trend. The unit does respond well to lubrication and with the proper attention, it should continue to perform well throughout the next few years of FFTF Standby. E-204 (which shares redundancy with E-203 and E205) was in good condition when the last spike energy readings were taken and there is no reason to suspect it cannot assume the load should E-203 need to be shut down. The only factor that can be detrimental to the non-operating unit is brinelling of the bearing races that can happen as a result of vibration from the adjacent units. The periodic "bump" of E-204, as with the other Inert Gas Blowers that are not operating, is intended to distribute grease in the bearings to minimize the possibility of this kind of bearing damage when the unit is shut down.

\section{E-204R, HTS Cell \#1 and \#2 Shared Redundant Unit}

Since E-204R is a shared redundant unit and is not on line when the Crafts make their vibration analysis rounds, its readings have not recently been recorded. However, when last performed in late in 1989, the bearings were in excellent condition. And, the unit has been lubricated on the 3 month schedule (and bumped weekly).

\section{E-205R, HTS Cell \#2 Cooling System}

Previous ASARs reported that this unit was occasionally exceeding the spike energy alarm levels. We no longer see these levels being reached (presently in the range of $1 / 4$ the alarm level. 


\section{E. E-206R, HTS Cell \#3 (523) Cooling System}

This unit also is exhibiting excellent bearing conditions and much like E-202R, seems to be improving with age with spike energy readings at $1 / 4$ the alarm level.

\section{F. E-207R, HTS Cell \#3 and Miscellaneous Cells Redundant Unit}

E-207R serves as the shared redundant unit for E-206R and E-208R. Since the unit does not normally operate, there are no recent bearing readings available. However, when last recorded in 1992, there were no adverse trends. And with the 3-month lubrication schedule, the unit should be ready to serve in its redundant capacity throughout the Standby period.

\section{G. E-208R, Miscellaneous Cell Cooling System}

E-208R is in stable and excellent condition with both vibration and bearing noise readings. Spike energy readings are at $1 / 4$ the alarm level.

\section{H. E-222R, IDS Tank Cell Cooling System}

Excellent and stable condition with spike energy readings at $1 / 4$ the alarm level. No adverse trends.

\section{E-223R, IS Tank Cell \& Miscellaneous Cell Redundant Unit}

Since the unit does not normally operate, vibration and bearing noise readings are not as numerous as those of operating units. However, when last recorded in1996, the bearing spike energy readings were at or below $1 / 4$ of the alarm level. With the 3-month lubrication schedule and weekly bumping, the unit should be ready to serve in its redundant capacity throughout the Standby period.

\section{J. E-224, Miscellaneous Cell Cooling System}

There are no adverse trends in bearing condition. Spike energy readings are less than $1 / 4$ the alarm level.

See the System 96-3 ASAR for a low-flow shutdown package discussion.

\section{K. E-230R/E-231R, LLFM Cooling System}

Although not operating continuously during FFTF Standby, these units are functional but not without several concerns. The upper bearing in E-230 is indicating spike energy readings in excess of the alarm level. We believe there are 
some human factors involved in taking readings from these units because they are in an extremely crowded location on the mezzanine where the readings are awkward to take with repeatability. However, this upper bearing reading is likely valid.

Recently, when attempting to start E-231R for its weekly jog, its circuit breaker has been tripping. The worst case scenario would be that there is a problem with the motor, of course. The package is ready to work to troubleshoot the problem. See the System 96-3 ASAR for specific related comments.

Since only one of the units is required to operate and even then only intermittently during the FFTF STANDBY phase, we can expect satisfactory performance from them for the next several years, even with the questionable bearing in E-230R.

\section{R-816 and R-817, Outer Head Temperature Control System}

There are no known adverse trends with these units. They are axial flow fans with sealed bearings requiring no regular maintenance. They should provide adequate performance for the duration of FFTF STANDBY.

\section{E-232R and E-233R, Center Island Cooling System}

E-232R has exhibited periodic high spike energy readings over the last several years. The readings are so diverse from time to time (from 1.5 times the alarm level to less than 0.1 times the alarm level) that it leads one to suspect that there are also human factors involved with taking these readings. These blowers are almost as inaccessible as E-230R and E-231R making it difficult to take repeatable readings. The diversity may also simply be that the bearings are in fact noisy and that the low readings were taken immediately after lubrication. We've demonstrated that aspect many times with prime mover bearings, i.e., reducing the bearing spike energy levels by proper and periodic lubrication.

The top bearing in E-233 is also indicating an excessively high spike energy reading from time to time. However, in E-233, it appears that there is an increasing trend. This unit, like E-232R, a Spencer Turbine unit, will be difficult to repair because of its vertical orientation (shaft is vertical) and the bottom flange giving access to the fan end of the shat is near the floor. In order to repair this unit, it will very likely be necessary to cut the large piping in order to gain access. If E-233 continues to respond favorably to lubrication, it should still provide several years of service in a redundant mode. Only one of these two machines needs to operate and E-232 will provide the service needed during STANDBY. 


\section{N. E-68 and E-69, Containment HVAC Units}

These are conventional HVAC units, one the operating unit and the other a redundant unit, that continue to provide good service. Mechanically, they are relatively easy to repair. Spare parts, short of new motors, are on hand.

The E-68 low flow problem (loose belts) reported in 96-3 ASAR has been repaired.

The preheaters in these units continue to give reasonably good service. However, there are problems with the SCR controllers from time to time (see System 96-3 ASAR). The preheaters were provided as a design feature to maintain the inlet air temperature above 45 degrees to prevent hoar frost build-up on filters, cooling coils, etc. Other HVAC units in more exposed locations on the roof have seen frost buildup on the inlet bird screens - almost to the point of choking off fresh air flow; under the right atmospheric conditions. The inlet screens on E-68 and E-69, however, are located next to a maze of cooling water piping and have never exhibited frost buildup. It's conceivable that the containment $H \& V$ system could operate without these heaters, at the risk of lowering the temperature in areas directly served by E-68 and E-69, such as the IEM Cell gallery.

\section{O. R-3 and R-4, Containment Exhaust Fans}

These units are axial flow fans that continue to provide good service. The bearing analysis program indicates that the bearings are in excellent condition with spike energy readings at one tenth the alarm range.

\section{P. E-25 and E-26, Containment Recirculation Coolers}

These units provide local cooling for the operating elevation of the containment and for the lower cooler area. They are conventional HVAC units that are easily repaired.

See the discussion of condensed water in the CHECKOFF LIST section.

\section{Q. E-558, E-608 and E-609, Pump Tower HVAC Units}

E-608: There is some corrosion that has apparently caused a leak in the condensate pan of this unit that serves the Loop 3 secondary pump tower. Because of the construction of the unit and the difficulties in removing the cooling coil, the decision was made to simply place an auxiliary pan beneath the leaking unit rather than attempt repair of the pan. A separate drain hose connects the pan to a roof drain. Since this particular unit is the only one that has developed this problem (the problem surfaced over 10 years ago) and since none of the other units have shown 
this problem, there may have been a coating weakness in the pan allowing corrosion to occur. Should it become a problem with other units, there are other options including a special coating that can be applied to the pans. This is more of an esthetic issue rather than operational. The units will provide effective cooling even with large openings in the pan.

There are no other adverse trends noticed in these units and they will serve well for the FFTF STANDBY duration.

R. R-752, HTS-South Exhaust Fan

There are no problems with this fan. It seldom operates (and then only for periodic testing).

\section{S. E-525, Control Room Life Support HVAC}

This is a conventional unit that is part of the Life Support System for the Control Area. It is used only when the conventional HVAC for the Control Area is not operating. The bearings on this unit are external where they are easily examined and the unit is not normally one of those on the bearing vibration/analysis route.

\section{T. E-523 and E-524, Life Support Filter/Fans}

These units are also part of the Life Support System. They supply fresh air for the Control Area via HEPA filters and operate only when the Control Area is placed on the Life Support System. They are easily accessible for bearing vibration/analysis for troubleshooting purposes but are not on the normal route.

\section{U. E-565 and E-565, HTS-East HVAC Units}

These conventional units are easily repaired and are in good condition except for the motor bearing issue discussed in the Near Term Issues section above.

\section{R-701 and R-702, RSB Ventilation Fans}

These are axial flow units that serve the elevations of the RSB below the $550^{\prime}$ level. The bearing analysis program readings indicate that these units are in excellent condition with spike energy readings in the range of one tenth of the alarm level. 
HNF-2380

Rev, 0, Page 119

\section{SYSTEM AGING, SPARE PARTS CONSIDERATIONS, AND LONG TERM MAINTENANCE PHILOSOPHY}

A. System aging:

1) Inert Gas Cooling Systems There are two major components that present concern for longevity.

Blowers - Failure of the blower motors is the first threat to extended operation of these cooling systems. They are threatened by either bearing failure or winding degradation. The Vibration and Analysis program is an effective predictive tool for bearing degradation. We've proven that we can repair bearings in spite of the fact that the blowers are in cramped locations where maintenance is very difficult. Obviously, the bearing analysis program is more important for these units.

The winding degradation issue is directly related to heat and in the case of larger motors, to the number of starts placed on the motor. Heat is probably the most trying, especially for units where the return temperature is high. Since the plant is in Standby, all of the return temperatures are relatively low as compared to power operation. We have had only one electrical failure in these motors to date (E-220R discussed below). We do know that several of the motors have experienced high ambient temperatures due to inadvertent valve closures causing flow blockage while the motor continued to run. In each case, following the incident, megger readings of the windings indicated no sign of insulation degradation. The long term consequences of these incidents aren't fully known. Intuitively, they would seem to reduce the winding lifetime, much as would the number of starts of a motor.

We have had only one motor winding failure due to heat (E-220R second stage motor, IEM Cell Subassembly Cooling System). There are two motors within one housing in these units. The E-220 failure is a special case because the second stage motor is subjected to the heat of compression of the first blower (approximately 190 degrees F). After this failure (and replacement of the motor) we determined that the higher suction pressure supplied by two blowers in series was not needed to adequately cool an assembly in the IEM Cell. As a result, the mode of operation was changed such that only the one stage is used when assemblies requiring forced cooling are being processed. However, during FFTF Standby, there are no assemblies that require forced cooling and the Subassembly Cooling System has not been used.

It's generally agreed that windings in larger motors can suffer degradation during starts because of the physical forces and stresses induced in the windings, which can lead to insulation wear and breakdown. And of course, the starting current introduces extra heat. In general, because of the continuous duty needs of the inert 
HNF-2380

Rev, 0, Page 120.

gas cooling systems, this is not viewed as a large contributor to motor failure, especially in this horsepower range. And we can expect continued service from these machines in the future.

Heat Exchangers - The second concern with assuring that these Inert Gas Cooling Systems can continue to operate is the welfare of the heat exchangers. These tube and shell counterflow units were intended for inert gas operation. After they were manufactured and prior to their installation in the piping systems, they were monitored very closely to verify that they remained inerted and at a positive nitrogen gas pressure. However, once installed and placed in operation with chilled water on the shell side and ambient containment air flowing through the tube side, they were subject to corrosion during the startup phase of the plant. Once the systems were inerted, any corrosion that started earlier probably halted, except in the case of the Head Compartment Coolers, E-226 and E-227 which operate with containment air passing through the tubes.

However, during FFTF Standby, the sodium cells in the containment have been deinerted. The cells are maintained in the closed position and they have been deliberately allowed to warm up (to minimize heat loss from the sodium piping) which should minimize the potential of condensing water and continuing the corrosion process. In addition, the instrument air header has been cross-tied to the low pressure nitrogen header. This provides a source of dry gas which will tend to keep the dewpoint of the gas flowing through the Inert Gas Cooler below the coil temperature of the heat exchanger to minimize the possibility of further condensation. Instrument air has a much lower dew point than ambient air but not as low as nitrogen.

The prospect of replacing any of the inert gas cooling system heat exchangers is not palatable. Even minimal tube repair will be painful, requiring cutting of large pipe to gain access.

2) Conventional HVAC Systems - None of these units appear to present any major problems in assuring longevity through Standby. They consist mainly of sheet metal enclosures and conventional bearings, shafts, motors, belts, etc and do not represent great challenges in maintenance. See the pan corrosion issue discussed above (E-608).

Subsequent to the ASAR 90 report, an inspection was performed on E-670 and E-671 in the AEB-West CRDM Cabinet Room. The units proved to be in excellent condition with no apparent degradation of the sheet metal. The condensate pans apparently are protected by a special rust-resistant process. The only rust observed in the pans was a very small amount of loose material that had been transported by the condensate from other sources in the unit. This is comforting as these units are 
some of the most threatening with respect to concern for dripping water on electrical equipment below. It should also be noted that these units, like essentially all of the other recirculating coolers within the plant (i.e., not on the roof or handling outside air directly), do not condense a large amount of water or do so only during a few months in the spring and summer, lessening the threat even more.

\section{B. Near Term Spare Parts:}

There are no known major deficiencies in the System 25 spare parts inventory that would impact continued Standby operation. A number of units have been laid up and others are operating at lower stress levels with the lower temperatures encountered in the plant.

There are no spare motors for the Inert Gas Cooling System blowers other than E-201R and E-202R (Reactor Cavity and Upper Auxiliary Pipeway Cooling system), which is the one system where a motor failure would be problematic during power operation. They are both required to operate while the plant is at power but only one needs to operate during Standby.

Installed redundance will allow operation of all the Inert Gas Cooling Systems through the Standby period. Repair of a failed bearing can take place while the redundant unit is in operation. Since the majority of the in-containment cells are presently de-inerted, the repair is easier.

C. Standby Maintenance:

System 25 operating in Standby for the next several years presents no maintenance challenges. The major components, especially in the conventional HVAC portion of the system, are industrial standard in nature and simple to repair with available spare parts or via ordered parts (which are locally available for the most part). The Inert Gas Cooling System blowers' health continues to be good and there are no Standby maintenance improvements being considered.

\section{CHECKOFF LIST}

A. Accessible parts of the entire system or component have been thoroughly walked down at least once in the past 30 days to view current performance, equipment status and condition. Yes X No

COMMENTS (exceptions): None

B. Are there any conditions which might require limitations different from operating limits as defined in the SDDs, the FSAR, or the Plant Technical Specifications? 
Yes_NoX

COMMENTS (exceptions): None

C. Are there trip settings, set points, interlocks, etc., that should be changed from those currently established? Yes_ No X

COMMENTS (exceptions): None

D. Are there interface areas which have not performed acceptably, which require resolution? Yes_No N $\underline{X}$

COMMENTS (exceptions): None

E. Are there temporary plant or procedural conditions which will and should remain in place? Yes_No $\underline{\text { X }}$

Attach list of MOD(L)/ECN(L)s, and OSPs that are currently active. Provide justification for continuing temporary MOD (L)s and ECN (L)s.

COMMENTS (exceptions): None

F. - Is any retesting or special testing (e.g., OSP) required? Yes_ No $\mathbf{X}$ COMMENTS (exceptions): None

G. Are the current plant corrective maintenance, preventive maintenance, and calibration database items all properly identified and are planned actions acceptable? Yes $\mathrm{X}$ No COMMENTS (exceptions): None

H. Are all other action items (NCRs, $\mathbb{R} s$, etc.) properly identified and assigned? Yes X No_ (attach the summary of needed actions not in the data base) COMMENTS (exceptions): None

I. Are there any special operating considerations? Yes No $X$ List or Reference: None

J. Are near term spare parts adequate? Yes $\underline{X}$ No COMMENTS (exceptions): None 
K. Have any safety issues (radiological, industrial) been identified that remain unresolved? Yes_ No $\mathrm{X}$

\section{COMMENTS (exceptions):}

Recently, chemical analysis of the condensation collected in the in-containment recirculating air cooler E-26 indicated levels of lead ( $>15,000$ PPM) that required the water to be disposed of as mixed waste. ("mixed waste" because the water also contains tritium that has migrated from the cells that are normally inerted but are now de-inerted during the Standby phase). Following the lead discovery, the condensate collection pans in the operating coolers, E-25 and E-26, were cleaned. Sample results from the E-26 condensate following cleaning shows the lead level $(<50$ PPM) to be substantially below the mixed waste level. Since E-25 has only recently been cleaned and because the units do not condense water in the winter, we have no sample results on E-25. Based on the success of cleaning the E-26 pan, we see no reason to expect less success with E-25. The present plan is to clean the remaining 3 units, E-24, E-27 and E-28, prior to restart of the plant.

There are no components in these recirculating coolers that contain lead. The mechanical joints in the heat exchanger tubing are brazed rather than soldered (because of the System 23 seismic boundary issue). It is thought that since these units have not been cleaned since the plant was constructed, the lead in the dust/mud debris in the pan must have accummulated during painting inside the containment or from lead cutting operation when shielding was being placed during construction. The water had not been analyzed for lead until recently when the lead constituent was discovered.

L. Have all component data been entered into the Plant information database?

Yes X No

COMMENTS (exceptions): None

M. Have applicable SISI inspections been conducted? Yes_X No _

COMMENTS (exceptions):Has a cleanliness evaluation been completed?

Yes_No_X

Are any issues still unresolved? Yes_ No $\underline{X}$

COMMENTS (exceptions); None

\section{REFERENCES}

8. ATTACHMENTS 
ANNUAL SYSTEM ASSESSMENT REPORT

for

SYSTEMS $26 \mathrm{~A}, 26 \mathrm{~B}$, and $26 \mathrm{C}$

Date of This Report

$02 / 03 / 98$

Date of Previous Report

$01 / 29 / 92$
APPROVALS

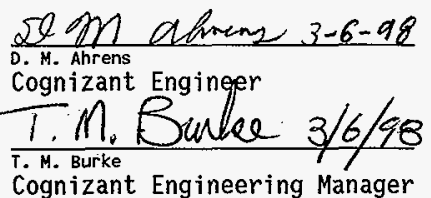

1. SCOPE

System/Component

$26 \mathrm{~A}$

26B

$26 \mathrm{C}$
Title

Fire Protection Water Supply

Fire Sprink1er Systems

Gas Systems

\section{SUMMARY EVALUATION}

The Plant Fire Protection System provides fire protection for the entire 400 area, including structures and equipment, nuclear safety and safety to 1 ife. System 26 consists of the Fire Protection Water supply system (Fire Pumps and the Main Fire Protection Water Supply Loop), al1 branch lines from the main fire protection water supply loop, the Automatic Gas B T anketing System, the Automatic Sprinkler Systems, the Inert Gas Flooding Systems, the Aqueous Film Forming Foam System (AFFF), all Fire Hose Stations and Portable Fire Extinguishing Units.

System 26A: Includes 3 Fire pumps, each rated at $1500 \mathrm{gpm}$. One of the pumps is Electric Motor driven and the other two are Diesel Engine driven. System $26 \mathrm{~A}$ also includes the underground distribution system and the fire hydrants. The underground distribution system also serves as the sanitary water distribution system (23B). In normal operation, the sanitary water pumps (23B) maintain the system pressure and provide the water for normal demand. If the Sanitary pumps cannot maintain the system pressure; a Fire Pump starts automatically. The Diesel Pumps also start on loss of electric power to the control panel.

System 26B: Includes the wet pipe sprinkler systems, preaction systems, a deluge system, Hose Connections and AFFF. The AFFF system has been taken out of service and laid up during standby. 
System $26 \mathrm{C}$ includes the Inert Gas Flooding system and the Automatic Gas Blanketing System (Halon). The inert gas flooding system uses nitrogen fed manually through patch panels to extinguish liquid metel fires by oxygen depletion. The inert gas flooding system has passed its required flow tests without problems.

System 26D is the fire alarm system. The fire alarm system and the Halon systems are covered in the ASAR for system 93-7.

Overal1, System 26A/B is in good operating condition. The only major deficiency at this time is the lack of backflow preventers between the fire protection and sanitary water systems. A program is in place and working to correct this deficiency by the end of FY-2001.

\section{Modifications since last report}

Replaced the flowmeter on P-61 Fire Pump. The existing flowmeter was unsatisfactory and inaccurate. It was replaced with a Barco venturi meter identical to the flowmeter used to test both P-27 \& P-28 Fire Pumps. The flow capability of each fire pump must be tested annually with a calibrated flowmeter that reads out the flow directly in gallons per minute. Previously the instruments on each flowmeter had to be calibrated individually prior to the flow test. The annual flow test for a 17 the Fire Pumps can now be performed with one calibrated instrument.

Replaced T-24, the underground fuel tank for P-28. The tank was changed out to meet the existing WAC standards for buried tanks. Also National Fire Protection Association (NFPA) requirements for fuel tanks had been changed since the unit was installed. The tank now has to be in a heated area and higher than the fuel transfer pump. Both problems were solved by relocating the new tank inside the pumphouse.

The DC generator on P-28 was no longer working. It was replaced with a more modern alternator.

Wet pipe sprinkler systems were added to several rooms throughout the plant.

Rooms 320,322 , and the decon shower were added. It appears the rooms were omitted from the original sprinkler coverage to mitigate spreading radioactive contamination if a sprinkler were to discharge. Room 322 was originally to be the Rad Tool Room and was subsequently converted to general occupancy as the lunch room. Room 320, the Personnel Decontamination Room, has combustibles stored in it, so sprinklers were added at the same time.

Sprinklers were extended to room 603 in building 481 . Room 603 is an office that was built inside the 481 pumphouse after the building was in service.

Room 135 in the control building was converted from the computer room to office space for the FIN Team. The existing Halon system was taken out of service and wet pipe sprinklers were added. 
The Hanford Fire Department will not use fire hoses from hose racks in a building. To avoid unnecessary maintenance and testing costs, the hoses were removed from all FFTF and MASF hose racks except Hose Rack 16 in cel1 446. HR-16 was kept because it is used as a jumper to supply water to the containment in an emergency.

Washington Department of Health $(\mathrm{DOH})$ now requires that backflow preventers be installed on wet pipe sprinkler systems connected to drinking water systems. A plan was developed to install 22 backflow preventers in the 400 Area buildings by 2001 . The Hanford Site Water Purveyor agreed with the plan. Three of the 22 backflow preventers have been installed.

3. ITEMS REQUIRING ACTION (Items on PTS, Procedures, Software, etc.)

A. Near Term Items

4F-96-0600/M: Install a backflow preventer in building 481 A (Auxitiary Pumphouse) fire sprinkler system.

4L-96-0087/M: Insta11 backflow preventer in building 4713A (Drivers Building) fire sprinkler system.

4F-96-0601/M: Install backflow preventer in building 481 (Pumphoue) fire sprinkler system.

41-96-0090/M: Install backflow preventer in building 436 (Training Building) fire sprinkler system.

4A-96-0042/M: Install backflow preventer in building 437 (MASF) fire sprinkler system.

B. Long Term Items

Install backflow preventers in all 400 Area Fire Sprinkler systems.
Required By

Required By

98-1

$98-1$

98-2

98-2

$98-3$

$9 / 30 / 2001$

4. TRENDS (Discuss trended parameters. See Appendix $K$ for typical parameters which can be used for trending studies.)

There were 8 fire protection system restrictions and impairments corrected during 1997, and none carried over. This does not include minor repairs to the fire pumps or sprinkler systems. 


\section{SYSTEM AGING, SPARE PARTS CONSIDERATIONS, AND LONG TERM MAINTENANCE} PHILOSOPHY

A. Discuss effects of system aging.

The Fire Pumps passed the weekly and annual tests with no problems. There is no indication of the capacity diminishing.

The required 10 year internal pipe inspections on the sprinkler systems was performed in 1994. There was no indication of corrosion or aging of the piping in the sprinkler systems.

The fire protection water dedicated reserve is stored in System 23 tanks T-58 and T-330. The condition of the tanks is discussed in the System 23 ASAR.

B. Discuss the strategy for near term spare parts and their availability strategy.

An adequate supply of spare parts is available in the warehouse. other parts are available from local suppliers.

C. Standby Maintenance Plan:

The operation and maintenance requirements for most of the fire suppression systems has not changed for standby. They are being maintained and tested to the Hanford Standards and Factory Mutual requirements.

The AFFF system was laid up when the Mobiltherm was drained since it was no longer needed. This entailed draing and venting the system to preclude overpressurization. The venting was accomplished by removing the safety valves and installing maze filters to prevent dirt from entering the system. All parts were saved so the system could be re-activated if needed for restart of the plant.

\section{CHECKOFF LIST}

A. Accessible parts of the entire system or component have been thoroughly walked down at least once in the past 30 days to view current performance, equipment status and condition. Yes $\{$ No - . COMMENTS (exceptions): None

B. Are there any conditions which might require 1imitations different from operating limits as defined in the SDDs, the FSAR, or the Plant Technical Specifications? Yes No $J$ 
C. Are there trip settings, set points, interlocks, etc., that should be changed from those currently established?. Yes No COMMENTS (exceptions): None

D. Are there interface areas which have not performed acceptably, which require resolution? Yes No

COMMENTS (exceptions): None

E. Are there temporary plant or procedural conditions. which will and should remain in place? Yes No 1

Attach list of $M O D(L) / E C N(L) s$, and OSPs that are currently active. Provide justification for continuing temporary MOD (L)s and ECN (L)s.

COMMENTS (exceptions): None

F. Is any retesting or special testing (e.g., OSP) required? Yes No 1

COMMENTS (exceptions): None

G. Are the current plant corrective maintenance, preventive maintenance, and calibration database items all properly identified and are planned actions acceptable? Yes_ No

COMMENTS (exceptions): None

H. Are all other action items (NCRs, IRs, etc.) properly identified and assigned? the data base)

COMMENTS (exceptions): None

I. Are there any special operating considerations? Yes_ No $\mathfrak{j}$ List or Reference: None

J. Are near term spare parts. adequate? Yes $\checkmark$ No COMMENTS (exceptions): None

K. Have any safety issues (radiological, industrial) been identified that remain unresolved? Yes No 1

COMMENTS (exceptions): None 
L. Have all component data been entered into the Plant information database?

Yes $\checkmark$ No

COMMENTS (exceptions): None

M. Have applicable SISI inspections been conducted? Yes No.

COMMENTS (exceptions): None

N. Has a cleanliness evaluation been completed? Yes $\checkmark$ No Are any issues still unresolved? Yes No

COMMENTS (exceptions): None

\section{REFERENCES}

$\mathrm{PN}-\mathrm{O}$

\section{ATTACHMENTS}

(Attach any CSRs, data sheets showing system performance, or other material demonstrating the substantive nature of this review). 


\section{ANNUAL SYSTEM ASSESSMENT REPORT \\ for \\ SYSTEM 31}

Date of This Report _ January 30. 1998

Date of Previous Report January 31, 1992

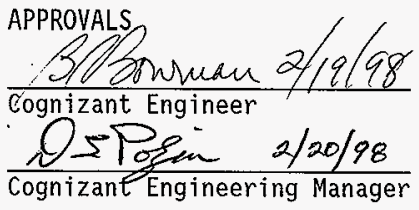

1. SCOPE

System/Component

31

\section{Titie}

Reactor Internals including:

- Instrument Trees

- Low Level Flux Monitors (Mech)

- Control Rod Drive Disconnects

- Structural Core Components

- Functional Core Components

\section{SUMMARY EVALUATION}

The Reactor Internals system is grouped into three areas of component usage: Functional Core Components, Structural Core Components and Other Functional Components.

The Functional core Components are.those components that function as part of the nuclear reactor function such as fuel assemblies, open test assemblies, control rod absorber assemblies, material test assemblies and radial reflector assemblies. Since all of the fuel assembljes have been removed from the core for shutdown and a new core design would be required for a tritium mission, these components are not evaluated at this time.

The Structural Core Components are passive metal structures required to support and maintain the core configuration and to provide the flow of sodium through the core. These components also would require evaluation for startup for a tritium mission when the neutronics of the new core design would be available. Some limited information has indicated a reduction in flux to the core basket and radial shield. Therefore, estimates for lifetime of these components have been increased from the 30 years previously published to satisfy requests for information from various sources. These components have not aged or deteriorated substantially since the last report in 1992 just prior to shutdown. With defueling and a constant $400^{\circ} \mathrm{F}$ sodium environment, no mechanisms for thermal or radiation damage have occurred. Therefore, no further evaluation of these components is required. 


\section{2. continued}

The other Functional Components include the Low Level Flux Monitor (mechanical only), the Control Rod Drive Mechanism and Disconnect Actuator, and the Instrument Trees.

The Low Level Flux Monitors (LLFM) have remained inserted fully into the thimbles in the outer core region with the electrical and electronics deactivated and layed-up. When FFTF restart was first considered, the immediate action to maintain the health of these units was to restore the cooling system pressure and gas flow to the detectors. No other activation has occurred and therefore monitoring to determine the detectors' actual 'health' conditions is not possible. The cooling system was also converted to instrument air from nitrogen as part of the modification to eliminate all nitrogen from containment for shutdown (now standby) conditions. An assessment was made of the effect of oxygen leakage into sodium, which concluded that the effect would be minimal. In addition, the thermal annulus, which contains mostly nitrogen, acts as a buffer to leakage from the cooling system. The LLFM will remain in this minimal operational status for at least the next two years. Testing of the drive functions is not considered prudent since those components have failed in the past and the components are relatively easy to replace. The detectors are the most concern since their life was stated at three years and pressure transients in the cooling system have caused signal problems. The detectors cannot be tested without a neutron source, which cannot be provided until restart is actually planned and reactor integrity for operations is reestablished. The spare detectors will have to be tested and the equipment needed to replace a detector will have to be expedited through fabrication and testing.

The Control Rod Drive Mechanisms (CRDM) have been restored to an operational status after three years of deactivation for shutdown. The reconnects of the drivelines through the Instrument Trees was very successful with no indications of binding or sodium frost buildup. Control Rod Drop Testing was completed in January 1998. Although flow through the reactor was from pony motors on the pumps versus main motor flow, the insertion times were consistent with similar testing performed in 1989. Stationary and rotating dropout currents and release times were within the acceptable range and in line with historical data. The electrical system (90) components (MG sets, ALPHA regulators, control drawers, ARPI and RRPI) all performed satisfactorily during the testing in January 1998. For further details of the CRDM assessments see the attached CSR.

The Instrument Trees (IT) were exercised and rotated over core in July 1997 satisfactorily with improved rotational torques. The seals were tested in July 1997 satisfactorily with the inflatable seals showing increased leakage of the inflation gas, but the overall boundary is maintained. The ASME check valves have not been tested since the ASME boundary is not required in standby. The Instrument Trees will remain immersed in sodium and rotated over the core, with no further testing or movement planned until a new core would be loaded prior to a restart. The Instrument Trees also provide the support over the core for the Control Rod Driveline Disconnects, which have been reconnected, and the Flow Temperature Reactor Instrument Assemblies. For further details on the Instrument Tree status, see the attached Component Status Report. 
HNF-2380

Rev. 0, Page 132

3. ITEMS REQUIRING ACTION

A. Near Term Items

Required By

Investigate implementation of procedure change

to deflate inflatable seals during reactor

operation including, redesign of gas control

console.

Test spare Source Range Detectors

(LLFM replacements).

September 30,1999

Restore temporary modification for power to

December 31, 1998

CRDM control (4F-97-413/L).

Restore temporary modification for CRDM alarms December 31, 1998 $(4 \mathrm{~F}-97-1700 / \mathrm{L})$.

B. Long Term Items

Test equipment for LLFM detector changeout

See individual CSRs for CRDM/CRDD and IT long term items

4. TRENDS

With the standby configuration of the reactor, everything was essentially non-operational and no trends were recorded. However, there were two noteworthy trends observed during the reactivation and testing of the Instrument Trees and Control Rod Mechanisms. The Instrument Tree rotational torques decreased on two units with the third approximately the same, which indicates some improvement, however slight. The Control Rod insertion times (time from segment arm release to 27 inches inserted) increased slightly (444 ms average versus $439 \mathrm{~ms}$ average) from the previous data in 1979/1980 when the system was new. This trend is not significant, but it should be watched.

5. SYSTEM AGING, SPARE PARTS CONSIDERATIONS, AND LONG TERM MAINTENANCE PHILOSOPHY

A. Discuss effects of system aging.

Very little aging of the reactor internals has occurred since the last report in 1992 . Mechanical operation was limited to the final configuration for standby and the recent testing of control rod drives and rotation of instrument trees. The LLFM's remained inserted. No radiation damage mechanisms for the internal portions of the equipment or thermal transients were experienced in the last six years. No further significant aging is expected since the thermal and radiation environment will not change. No further mechanical operations of the LLFM or IT are antjcipated prior to actual fuel load and testing for restart of a new mission. The CRDM's will be disconnected, reconnected and drop tested at least every 18 months. 
5. continued

B. Discuss the strategy for near term spare parts and their availability strategy.

Since additional operations are not planned, the use of spare parts is not anticipated and any spares still in existence will be adequate for the near term. If a new mission becomes a reality, spare parts for all components will have to be reevaluated and ordered as required.

C. Standby Maintenance Plan: Discuss a plan which ensures essential system functions for standby are provided and minimizes equipment degradation.

Significant maintenance during the next two years of standby is not anticipated to be extensive due to the non-operational character of the plant. As stated above, the maintenance activities would drastically increase if restart of the FFTF is imminent.

\section{CHECKOFF LIST}

A. Accessible parts of the entire system or component have been thoroughly walked down at least once in the past 30 days to view current performance, equipment status and condition. Yes $x$ No

COMMENTS (exceptions): A considerable portion of this system is unaccessible inside the reactor is bathed in sodium.

B. Are there any conditions which might require limitations different from operating limits as defined in the SDDs, the FSAR, or the Plant Technical Specifications? Yes No

COMMENTS (exceptions): Not applicable at present time.

C. Are there trip settings, set points, interlocks, etc., that should be changed from those currently established? Yes No

COMMENTS (exceptions): Not applicable at present in standby.

D. Are there interface areas which have not performed acceptably, which require resolution? Yes__ No $\mathrm{X}$

COMMENTS (exceptions): None

E. Are there temporary plant or procedural conditions which will and should remain in place? Yes $\underline{x}$ No

COMMENTS (exceptions): Two temporary modifications listed in 3.A. $(4 \mathrm{~F}-97-413 / \mathrm{L}$ and $4 \mathrm{~F}-97-1700 / \mathrm{L})$ are to remain in $\mathrm{place}$ until startup when they will be replaced with the original equipment or new mods.

F. Is any retesting or special testing (e.g., OSP) required? Yes No $\mathrm{x}$ 
6. continued

G. Are the current $p l a n t$ corrective maintenance, preventive

maintenance, and calibration database items all properly identified and are $p l a n n e d$ actions acceptable? Yes_ $\mathrm{x}$ No

COMMENTS (exceptions): None

H. Are all other action items (NCRs, IRs, etc.) properly identified and assigned? Yes $x$ No

COMMENTS (exceptions): None

I. Are there any special operating considerations? Yes_ No $\mathrm{x}$

List or Reference: None

J. Are near term spare parts adequate? Yes $x$ No

COMMENTS (exceptions): None

K. Have any safety issues (radiological, industrial) been identified that remain unresolved? Yes No $x$

COMMENTS (exceptions): None

L. Have al1 component data been entered into the P1ant information database? Yes $x$ No

COMMENTS (exceptions): None

M. Have applicab1e SISI inspections been conducted? Yes___ No_ $x$

COMMENTS (exceptions): These inspections will only be reactivated if the plant approaches active startup conditions.

N. Has a cleanliness evaluation been completed? Yes $\mathrm{x}$ No

Are any issues still unresolved? Yes No $x$

COMMENTS (exceptions): None

\section{REFERENCES}

None

8. ATTACHMENTS

CSR for Instrument Trees dated January 28, 1998.

CSR for Control Rod Drive Mechanisms (CRDM) dated February 3, 1998. 


\section{COMPONENT STATUS REPORT \\ FOR \\ INSTRUMENT TREES / SYSTEM 31}

Period Covered:1/27/92-1/28/98

Date Reported:1/28/98

Component: Instrument Trees

\section{Approvals}

Cognizant Engineer(s): D. C. Johnston

\section{J. B. Logan}

Cognizant Manager(s):

\begin{tabular}{l} 
S. W. Hiller \\
G.N. Ruge \\
\hline
\end{tabular}

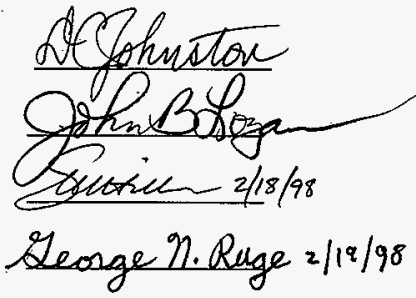

1. Summary of Component Status:

The plant is in hot standby, and as verified by the exercising (4F-97-615 and 4F-97-404) completed 7/30/97, the Instrument Trees are fully operational and capable of supporting all planned plant operations.

2. Trends Observed: (Attach graphs and tables as necessary)

A) The last instrument tree \#3 rotational torque was 19,000 in-lbs. when moved from the storage to overcore position during exercising performed in July 1997. This is an improvement from 37,500 in-lbs. when normally last moved at the end of the last outage.

B) The rotational torque on Instrument Tree \#1 has decreased to 12,000 in-lbs from the 46,500 in-lbs range. The lower torques are believed to be the result of the lower temperatures which result from not seeing the higher power cycle operating temperatures.

C) Instrument Tree $\# 2$ continues to operate in its normal range of 4,000 to 8,000 inlbs.

D) Leak testing was performed during the last year resulting in the following:

- All seals are presently operable.

- The inflatable seals show an increase in inflation gas leakage, but they still provide acceptable face seals. Additional testing was done to verify the condition 
of the inflatable seals. On Trees \#1 \& \#2, two of the three inflatable seals isolating the lower bonnet area from the reactor cover gas were verified as maintaining their complete integrity when isolated, and the remaining seal is fully functional as long as normal gas supply is maintained. All the inflatable seals on Tree \#3 were leaking, but the seals are fully functional as long as normal gas supply is maintained. When the buffers between the inflatable seals were tested with the seals inflated, the buffer pressure was maintained above atmospheric pressure when the buffers were isolated. This confirmed the inflatable seals are providing the isolation between the reactor cover gas and the lower bonnet area as intended when in the plant is in the refueling configuration.

- Leakage of the bellows on Instrument Tree \#2 was repaired in May 1992 by replacing the bellows per F1-3080.

-The check valves at the ASME boundary have not been maintained. As part of a startup order these would need to be removed, calibrated, and then installed. There are a total of five of these on each Instrument Tree.

3. Component Aging and Spare Parts Considerations: (Discuss effects of system aging, long term maintenance, and spare parts availability strategy)

A. Spare parts are adequate and available for all drive components, and gas control components should replacement be required. The chance of failure of the structural components is very small, but if required, spares are not readily available from the spare unit. The original order for the spare tree was changed to use the boundary parts from the prototype Mast and Support structure. These items were not obtained as ASME coded items. An attempt was made to locate the original manufacturing data which would have included the material and process control records only to discover these records no longer exists. Therefore if these parts are to be used they must be recertified per the ASME code or reordered.

The In-reactor portion of the instrument tree which was in the 200 area warehouse was nearly sold as excess equipment. It is currently being stored at the Port of Pasco. This unit will require thorough inspection and checkout prior to use. Spare inflatable seals have been checked for usability per F1-3035. The useable seals were installed into the seal housing as part of the bellows replacement. New inflatable seals will be required to replace those used when the bellows was repaired. Spare seals will only be reordered if a restart order is given. (See item 5.B)

B. During the checkout of the electrical controls for the Instrument Tree Rotational Drive (4F-97-404), it was discovered that all six of the drive system circuit breakers were damaged. Three available spares and three new breakers were installed to support the exercising of head mounted equipment. These breakers are equipped with an under voltage trip coil. Attempting to close the breaker without 
energizing the coil can result in damage to the breaker. Individual breakers have failed in the past for this reason. No short term action is required under the present standby order. New spare breakers were procured and are available should they be needed. In the event a restart order is given this system should be evaluated for a modification to use a more reliable breaker or the quantity of spares should be increased to six.

Several position and load displays on the instrument tree rotation control panels have failed. This did not prevent exercising the instrument trees as alternate readout devices are available. In the event this equipment is required to support a long term mission these displays will require replacement with more reliable substitutes. Some replacement meters have been procured but no design work is currently planned. (Ref 4F-97-1260/M) No short term action is required to preserve the system from further degradation.

C. To support all projected plant requirements for the next $20+$ years the following items must be considered in addition to normal maintenance and minor repair.

Approx Cost Target

Completion

Date

Prepare spare Instrument Tree

(See item 3.A)

Develop procedures and tooling to replace the guide tube inflatable seals (See item 3.A)

Develop procedures and qualify existing tooling and Segmented Maintenance Cask to replace an Instrument Tree

Develop procedures and upgrade tooling to replace the Flow Temperature Reactor Instrument Assemblies.
$\$ 100 \mathrm{~K} \quad$ When needed

$\$ 1,100 \mathrm{~K}$

Required for restart

$\$ 1,000 \mathrm{~K}$ When needed

$\$ 500 \mathrm{~K}$ When needed

4. Analysis, Conclusions, Follow up:

A. The torque required to rotate the instrument trees is highly dependent on the temperature of the sodium and length of the power cycles when the plant is at the maximum operating temperature. This is because the vapor pressure of the sodium increases as the temperature increases, and the temperature is at its maximum when operating. This sodium vapor can plate out in the cooler annuli 
areas of the guide tube. The less the buildup of frozen sodium, the less the sodium requiring to be sheared to rotate resulting in lower rotational torques.

B. The failure of the bellows was a horizontal crack along an internal convolute and perpendicular to a longitudinal weld. The crack was most likely the result of the stress which resulted when stretching the assembly during installation. The forming of the crack is cause for concern if it initiated in the heat affected zone of the weld, but there are many places where this set of conditions existed that did not fail. Therefore this is most likely not a generic problem, and the damaged bellows unit may be repaired.

5. Items Requiring Action: (Items on PTS., Procedures, Software, etc.)

A. Near Term Items

$\underline{\text { Required By }}$

Investigate implementation of Restart procedure change to deflate inflatable seals during reactor operation. This may require some redesign of the gas control console. (F1-219/A)

Install missing sheet metal cover Restart onto the upper bonnet of IT\#1 which was originally documented on F1-1073. This package was deemed unnecessary for $\mathrm{S} / \mathrm{D}$, and therefore was cancelled.

B. Long Term Items

Required By

See item 3. A

Restart

6. Checkoff List

A. Are the current plant corrective maintenance, preventive maintenance, and calibration database items all properly identified and planned actions acceptable? Yes X No-

COMMENTS (exceptions):

Spares action depends upon the future of the FFTF. 
B. Are all other action items (IRs, NCRs, etc.) properly identified and assigned? Yes_. No_ (Attach the summary of needed actions not in the database.) COMMENTS (exceptions):

C. Are near term spare parts adequate? Yes $\mathrm{X}$ No COMMENTS (exceptions):

D. Are trend analysis data acceptable for continued operation? Yes_X_No COMMENTS (exceptions): 
Period Covered: 1-1-92 thru 1-30-98 Date Reported: $2-20-98$

Component: Control Rod Drive Mechanisms (CRDM) (31B)* Cognizant Engineer(s):

D. J. Gerkensmeyer G. T. Taylor

Cognizant Manager(s):
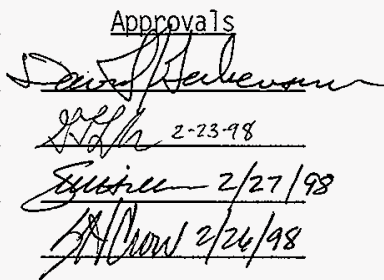

* System 90 electrical and instrumentation components which support CRDM operation are also discussed in this report.

1. Summary of Component Status:

\section{SYSTEM 31B}

A7though present7y powered down for standby, a 77. 9 CRDM's are operational with no known deficiencies.

\section{SYSTEM 90}

System 90 is normally powered down for standby. Various deficiencies, documented within this report, were found during preparation for and the conducting of CRDM functional testing under $4 \mathrm{~F}-97-403 / \mathrm{W}$. The deficiencies did not prevent completion of the CRDM testing, but would require resolution prior to startup.

2. Trends Observed:

NORMAL OPERATING CONDITIONS

During the report period, only one complete set of CRDM insertion times at normal temperature and flow $\left(440^{\circ} \mathrm{F}\right.$ at $100 \%$ flow) were measured. That timing was performed in January of 1992 . Those times were normal as shown on the attached Figure 1.

There was no indication of self welding between the CRDM and CRDD Position Indicator (PI) rods during the four disconnect operations performed between 11-91 and 3-94. The history of P.I. rod self welding is presented in Table 1. 


\section{COMPONENT STATUS REPORT (cont'd)}

\section{HOT STANDBY TESTING OF CRDM'S, DRIVELINES AND CONTROL RODS}

\section{SYSTEM 31B}

CRDM drivelines were reconnected in September of 1997 after having been in a disconnected and retracted state since March of 1994 . The reconnects went pretty much as planned with very few exceptions, which are discussed below:

CRDM Extension Shaft Loads were monitored during the reconnect and compared with the CRDM Extension Withdrawa7. Forces from 1994. The loads are not normally monitored during reconnects. The plots showed that the average SCRAM spring fully compressed force decreased $100 \mathrm{lb}$., the average SCRAM spring fully extended force decreased $83 \mathrm{lb}$. and the average knee of the curve value shifted 1 in. The changes in values are probably due to a combination of the load indicator presently in use which has a much better accuracy than those used in the past and system hysteresis. Review of earlier plots of CRDM Extension Withdrawal Forces indicates that the values seen in this reconnect are not out of line. The knee of the curves have not shifted significantly. The forces are consistent for all nine CRDM's.

The CRDD and lower disconnects functioned smoothly and showed no sign of binding or sodium frost buildup.

An alignment problem was noted when the DATR Drive Assembly was driving the PI rod down at position A-5. This problem was overcome by following normal procedural recovery actions. It appears that the PI rod in the CRDD did not align with the corresponding PI rod in the upper Instrument Tree coupling. The PI rod in the Instrument Tree may have also been pulled up during the last disconnect and caught on the ledge in the Instrument Tree coupling. The A-5 PI rod has had a history of self welding during previous refueling outages (see Table 1), but was not reported to be sticking during the last disconnect in 1994. When performing recovery actions on A-5 the DATR Drive Assembly was lifted by hand while attached to the actuation shaft. The feel of the actuation shaft was smooth and operated very easily, as well as extension shaft finger actuation.

DATR Drive Assembly actuation of the Extension Shaft Disconnect fingers in general occurred with very little force. Some slight sticking was noted when the safety interlock ring spreader tube was released and the driveline actuation shaft was restored just before the relatch verification test. The safety interlock ring spreader tube had to be pushed down into place with the DATR Drive Assembly tool by applying a slight downward force to complete the operation on all of the CRDM's.

DATR Holdup Mechanisms and Retractor Tubes installed in the Center Island were in very good shape. Seven out of nine Retractor Tubes were easily removed by hand indicating good alignment in the upper Motor Tube and smooth actuation of the Anti-Ejection Pawls. The Retractor Tubes which were installed in $A-1$ and A-4 were somewhat sticky but was removable by hand with some added effort. The resistance is probably due to the condition of the Retractor Tubes rather than the Motor Tubes or Anti-Ejection Pawls. 
HNF-2380

Rev. 0, Page 142

\section{COMPONENT STATUS REPORT (cont'd)}

CRDM instrumentation and cables in the Center Island looked to be in good condition with some wear evident. Center Island thermocouple wiring was in a more delicate condition and has been abused during the years of moving cables around in the tight Center Island areas. Some of the cabling and hoses are probably good candidates to be removed (MOTA for example).

A nitrogen cooling hose was found to be leaking during inspections and was subsequently replaced.

The argon buffer gas supplied to the CRDM Motor Tubes indicated that all the bellows are intact. Sector 3 flowmeter showed some slight leakage $(125 \mathrm{cc} / \mathrm{min}$ initially) but decreased $80 \mathrm{cc} / \mathrm{min}$ after 2 hours and down to $0 \mathrm{cc} / \mathrm{min}$ within two days.

No contamination was detected during the CRDM driveline reconnect operations. A17 work activity was conducted in a Contamination Area as a precaution, as is normally done. The lack of detectable contamination is another good

indication that the installed bellows on the ESD's are in good condition.

Control Rod Drop Testing was performed in January of 1998. Plant conditions for the rod drop testing were off-normal with reactor coolant flow at approx. $10 \%$ (pony motor flow) and average primary cold leg temperature of $404.3^{\circ} \mathrm{F}$. Normaliy the rod drops are performed at $100 \%$ flow and $440 \pm 10^{\circ} \mathrm{F}$ secondary cold $7 \mathrm{eg}$ temperature. Initial review of data reveals no indications of abnormalities with the Control Rod Drive Mechanisms (CRDM's). The specifics are discussed below:

Stationary and rotating dropout currents were within the acceptable range and in line with historical data.

CRDM release times (time from interruption of power to the stator to segment arm release) were in line with historical data.

The rod insertion times (time from segment arm release to the point at which the rods are 27 inches inserted) were in line with times which were obtained during similar testing performed in the 1979/1980 time period by TP-31-3A006 and reported in TRRT 31-X8. Those tests were performed at pony motor flow and reactor coolant temperature of $400^{\circ} \mathrm{F}$. Rod insertion times during TP-31-3A006 ranged from 430 to $448 \mathrm{~ms}$. Rod insertion times during the January 1998 testing ranged from 438 to 451 . ms. 


\section{SYSTEM 90}

Overal1 the System 90, REACTOR PLANT CONTROL, components which support CRDM operation performed we1] during the recent standby testing. The specifics are discussed below:

\section{CRDM Stators}

CRDM Stator checks conducted in October 1997 included:

Comparison between the temperature indicated by both thermocouples in each CRDM winding.

Insulation resistance measurement of al1 CRDM stator windings and CRDM motion sensor windings.

Resistance measurements of all CRDM stator windings and CRDM motion sensor windings.

Al1 data were within manufacturers recommendations except for the rod \#1 C1 to D winding resistance measurement which was .11 ohms higher than the manufacturers recommended 7 imit of 17.01 ohms. No reason was found for the increased resistance.

Stationary and rotating dropout current readings taken during rod drop testing were within the acceptable range and in line with historical data.

CRDM MG Sets. D-16/C-654 (Secondary) and D-17/C-653 (Primary)

Both MG sets performed satisfactori7y during the CRDM testing. A11 functional tests, including bearing noise level checks were satisfactory prior to CRDM testing. Post CRDM testing bearing noise level checks revealed high readings on the motor end bearing on D-16. Replacement of both bearings on $0-16$ prior to reactor startup is recommended.

ALPHA Regulators C-1367-A (Primary) and C-1368-A (Secondary)

No adjustments were required during initial alignment of the regulators. The regulators performed satisfactorily during CRDM testing.

CRDM Control Drawers

Approximately half of the controller drawers required replacement of one or more sub assembly boards in order to operate satisfactorily during calibration and alignment. A7l drawers operated satisfactorily during CRDM testing, except Rod 9 speed was out of spec low. 


\section{COMPONENT STATUS REPORT (cont'd)}

CRDM Control Panels C-651 (Primary) and C-652 (secondary)

A11 components of the control panels were satisfactorily aligned during calibration except for the secondary beta 24 VDC power supply. The secondary 24 VDC beta power supply immediately trips its input breaker, whenever that breaker is closed.

Absolute Rod Position Indication (ARPI)

A11 detectors performed satisfactorily. Nine ARPI transmitters were successfully calibrated. Two transmitters could not be calibrated. One transmitter failed during CRDM testing.

Relative Rod Position Indication (RRPI)

Al1 detectors performed satisfactorily. Nine RRPI transmitters were checked prior to CRDM testing. The output waveforms of 4 transmitters were distorted, and would have required adjustment of the transmitters during normal operations. Several RRPI indicators would count up one unit then count down two units when the expected action was to count down only one unit. Adjustment of the units would be required prior to continued use. One RRPI failed during testing. The unit could not be powered due to some internal defect.

CRDM Temperature Monitoring

The system was repaired and calibrated prior to CRDM testing. The system performed satisfactorily during testing.

3. Component Aging, Spare Parts Considerations and Long Term Maintenance Philosophy:

a. Component Aging:

SYSTEM 31B

Norma 1. wear of moving parts and exposure to radiation are the principal aging parameters. (Although the radiation exposure component has not been a concern as of late). The CRDM components appear to be holding up rather we11 from a11 outward indications.

The Motor Tube and Rotor Assembly and CRDM Leadscrew wear has been monitored by periodic inspections. The next inspection was scheduled for late 1994 but was deferred due to placing FFTF in standby. Based on the fall 1989 inspection, the plan to refurbish the Motor Tube and Rotor Assemblies has been deferred unti? the next inspection because the inspected unit was in excellent condition. It is probable that the units can be used an additional 20 years without any refurbishment. 


\section{COMPONENT STATUS REPORT (cont'd)}

Design life of the Stator is dependent primarily on the Stator insulation life which is influenced by the temperature of the windings and the length of time the Stator is energized. Based on the current Stator operating temperature and the hours it has been energized, the design life should easily meet an additional 20 year extension.

The CRDM design life was originally specified at 20 years. To extend the design life re-evaluation of the CRDM components and the criteria must be performed.

The 30 Year Life Evaluation for the FFTF Control Rod Driveline Disconnect, WHC-SD-FF-DA-011, was completed in 1989. The ECN which authorizes extension of the Control Rod Driveline Disconnects from 10 years to $30+$ years, ECN-108897, was approved and released in 1991.

CRDM components are being evaluated based on rod insertion times, extension shaft withdrawal forces, and problems experienced during the disconnect operations. To date, no evidence exists that any degradation of the components has occurred. The one risk that exists is the potential for the Position Indicator Rod to freeze up due to the formation of sodium reaction products, should the annuli around the Position Indicator Rod become contaminated. Position Indicator Rod freeze up did occur early in plant life. Should this recur, the affected CRDM must be replaced. The possibility of contaminating these annuli has been greatly reduced by maintaining an argon atmosphere in the Motor Tube cavity during the refueling activities and providing an argon purge during reactor operation. Since the argon atmosphere and argon purges have been instituted, a frozen Position Indicator Rod has not been encountered which would indicate that the problem may have been resolved. The freedom of the Position Indicator Rods will continue to be monitored.

\section{SYSTEM 90}

Heat in the region of the CRDM Motor Tubes seems to have taken its toll on the ARPI detector reed switch assemblies. The larger electrical components, such as the CRDM MG Sets and CRDM motor windings, have held up well over the years.

Component aging is suspected to be the cause of most deficiencies found in the rack mounted electronics and instrumentation during CRDM functional test preparations. Since failed subassemblies were replaced as a unit, the cause of the deficiencies was not determined.

b. Spare Parts Considerations:

For the near term spare parts are not an issue due to the standby status of the plant. If a startup order is received, many of the items listed under Spare Parts Considerations will need to be looked at closely and acted upon in a timely manner in order to make the CRDM's and support systems fully operational for reactor startup, as well as dependable enough to support continued plant operation. 
HNF-2380

Rev. 0, Page 146

\section{COMPONENT STATUS REPORT (cont'd)}

\section{SYSTEM 31B}

Currently, one Motor Tube and Rotor Assembly, four Stator Assemblies, one Control Rod Drive Mechanism (CRDM), and three Control Rod Driveline Disconnects (CRDD) are available in spares to support reactor operations. The two lead unit Motor Tube and Rotor Assemblies (previous test units, one located in the DATR Training Facility and the other in WSR storage) could be utilized, if necessary, for limited service in the reactor with minimal cleaning and preparation.

A second CRDM, which is in a state of partial disassembly, is in storage at 4713C. Refurbishment of that unit was started in 1986 and suspended in 1989. Some of the parts required for refurbishment are not available. Due to the lack of refurbishment parts, the amount of time that has lapsed since the work was suspended and retirement of key personnel that where involved in the work, it is uncertain how long it would take to complete the refurbishment at this time.

Receipt inspection of the replacement PI Rod for CRDM refurbishment was completed by $Q A / Q C$ in 1991 . Two concerns have been raised which need to be resolved before the rod can be considered for use. No volumetric test was performed on the material used for PI Rod manufacture. Radiographing of the finished PI Rod will most likely be required prior to acceptance. Also, during the research into the documentation for the original PI Rods it was discovered that the PI Rods supplied on the initial order were machined undersized in order to provide clearance for bellows which exhibited shrinkage during welding. . The design drawings did not reflect the undersized region. The new PI Rods were manufactured per the design drawings. The new PI Rod will have to be re-machined and chrome plated in the region of the bellows prior to acceptance.

\section{SYSTEM 90}

Limited spares exists for the system. since most spares were excessed during shutdown.

CRDM MG Sets D-16/C-654 (Secondary) and D-17/C-653 (Primary)

Al1 spare parts were excessed during shutdown.

ALPHA Regulators C-1367-A (Primary) C-1368-A (Secondary)

Al] spare parts were excessed during shutdown.

CRDM Control Drawers

A1] spare parts were excessed during shutdown. Some spare parts were recovered with the control drawer test panel. 
COMPONENT STATUS REPORT (cont'd)

CRDM Control Panels C-651 (Primary) and C-652 (secondary)

A11 spare parts were excessed during shutdown.

Actual Rod Position Indication system (ARPI)

Limited spare parts exist. There are spare ARPI detector reed switch assemblies, but none are operable. Refurbishment of those units are required.

Relative Rod Position Indicators (RRPI)

Limited spare parts exist.

CRDM Temperature Monitoring

Spare parts are satisfactory.

C. Standby Maintenance Plan

1. Hardware to be repaired, replaced or upgraded:

No hardware repair, replacement or updgrade is planned during the standby period. The two Near Term Items 1isted at 5. A need only be completed to restore the Rod Control System and Rod Control Alarms to their pre-functional test shutdown/disabled conditions.

2. Frequency of routine field maintenance:

No routine maintenance is planned during the standby period. Maintenance wi 17 be conducted just prior to any further CRDM functional testing or training which requires exercising the CRDMS.

3. Other considerations:

Although the CRDM's and supporting systems/components are not required to operate during the standby period, it is recommended that al1 9 CRDM's undergo driveline disconnect/reconnect followed by rod drop testing at least every 18 months during the standby period. This exercising of the CROM's and support systems is not believed to be required in order to maintain the health of the components, but is aimed at maintaining operations and maintenance personnel familiarity and training on the equipment at a level that would support a startup effort. A side benefit of the exercising would be early detection of any further degradation of the components. 


\section{COMPONENT STATUS REPORT (cont'd)}

4. Anatysis, Conclusions, Fol towup:

\section{SYSTEM 31B}

The CRDM's were functioning satisfactority in 1992 when the reactor was shut down and performed satisfactorily during the recent rod drop testing. There are no indications that the units have degraded in their performance capability. The CRDM's could support a reactor startup in their present condition.

\section{SYSTEM 90}

Although the System 90 components which support CRDM. operation performed much better than anticipated during the recent rod drop testing, several repairs are required and restocking of spare parts must be accomplished before they are ready to support a reactor startup.

A7though not part of System 90 , the PPS Scram Breakers, which are part of System 99 , require replacement in order to make the CRDM's fully functional.

5. Items Requiring Action (Items on PTS, Procedures. Software, etc.):
A. Near Term Items

SYSTEM 31B

NONE

SYSTEM 90

4F-97-413/L RESTORE POWER TO ROD CONTROL

$2 / 98-4$

A temporary modification was required to install SCRAM breakers which provide power to the Rod Drive System for support of Rod Drop Testing. Completion of this package is required in order to restore the system to it's former shutdown/disabled condition.

4F-97-1700/L ROD CONTROL ALARM RESTORATION $2 / 98-4$

A temporary modification was required to restore C-136 alarms for support of Rod Drop Testing. Completion of this package is required in order to restore the alarms to their former shutdown/disabled condition.
Required By/Target

PRIORITY \&

PHASE DESIGNATOR 
B. Long Term Items

SYSTEM 31B
Required By/Target

PRIORITY \&

PHASE DESIGNATOR
4F-86-1178/M REFURBISH CRDM LOWER MECHANISM

CRDM Lower Mechanism, H4-22947, Seria

Number R74-004, was removed from reactor, penetration A1 in June 1984 per PM-84-010 and PM-84-011. This package refurbishes the Lower Mechanism for return to spares. Refurbishment was started in 1986 and suspended in 1989. It is in a state of partial disassembly and in storage at $4713 \mathrm{C}$. Some of the parts required for refurbishment are not avai iable. The package is archived in a RETENT-INACTIVE status.

\section{F-87-1322/N NCR-23113 - REFURBISH CRDM IN MASF}

The non-conforming condition has to do with undersized baffle plates (too thin) which were manufactured by Tech Shops for CRDM R74-004 refurbishment per 4F-86-1178/M. The disposition requires verification of proper baffle plate stack up during reassembly of the CRDM. The NCR cannot be closed unt $i 1$ the CRDM is refurbished per 4F-86-1178/M.

4F-89-726/M DESIGN \& FABRICATE CRDM NOZZLE O-RING INSTALLATION TOOL

A special tool is needed to permit remote installation of an 0-ring on the CRS nozzle for sealing with the CRS shroud during CRDM removal and installation operations. This package was canceled in 1995 due to the apparent demise of the FFTF. If a startup order for FFTF is received this item needs to be resurrected in order to be prepared for. CRDM change out.
3/SU1

4/SU1

3/BLANK 
B. Long Term Items (cont'd)

SYSTEM 31B

\section{PLACE CRDM DRIVELINES IN SHUTDOWN CONDITION \\ CRDM drivelines need to be placed in their shutdown condition per WHC-SD-FF-SSP-028. This is considered part of the system 31B Tayup, the final condition of which is documented in 4F-95-291/D, including the STS for 31B. \\ $4 F-95-292 / D$ \\ CRDM MOTOR TUBE \& ROTOR DISASSEMBLY \& INSPECTION \\ SS-31-1 \\ The CRDM Motor Tube and Rotor Assembiy and Leadscrew inspection was scheduled for \\ late 1994, but was deferred due to placing \\ FFTF in standby. Performance of the surveillance should not be required until. approximately 2+ years after reactor startup.}

\section{SYSTEM 90}

4F-97-246/L PROVIDE POWER SOURCE TO D-16 SEC CRDM MG SET 2/SU1

A temporary modification was required to provide power to D-16 for support of Rod Drop Testing. The normal supply

transformer. PCB Transformer X-29, was removed from the plant as part of a commitment to environmental plans.

Temporary power is being supplied from MCC B-8 via a set of 480 VAC jumpers. Completion of this package is required in order to restore the affected portion of the power distribution to it's former shutdown/disabled condition.

4F-97-625/L RESTORE PRI \& SEC ROD CONTROL FOR STANDBY TEST 2/SU1

A temporary modification was required to supply SCRAM breaker hold-in coil voltage and bypass interlocks for support of Rod Drop Testing. Completion of this package is required in order to restore the system to it's former shutdown/disabled condition. 
B. Long Term Items (cont'd)

SYSTEM 90
Required By/Target

PRIORITY \&

PHASE DESIGNATOR
4F-97-2713/W C-652 24 VDC BETA SUPPLY FAILED 3/SU1

The C-652 24 VDC Beta power supply on/off breaker trips immediately when closed.

4F-98-114/W RRPI INDICATORS TRIPLE COUNTING AT LOW SPEEDS 3/SUI

While shimming at reduced speed ( 3 inches per minute) several RRPI indicators would count up one unit then courit down two units when the expected action was to count down only one unit. This problem was greatly reduced when rods were operated at normal ( 9 inches per minute) speed. Adjustment of the units will be required prior to continued use.

4F-98-115/W BAD ARPI SIGNAL CONDITIONING MODULE The ARPI signal conditioning module installed at rod 2 position has low sensitivity to ARPI detector input. ARPI should respond in $1 / 2$ inch increments, but when this module is installed, the display changes by 1 inch increments.

4F-98-116/W ROD 9 RRPI DIGITAL INDICATOR BLOWS FUSES

Rod 9 RRPI digital indicator is not working. It blows fuses when reset button is pushed, or after a short amount of rod motion.

4F-98-117/W RRPI-ARPI HEIGHT DIFFERENTIAL OUT OF SPEC

ARPI and RRPI differed by more than the 1.4 inch specification at various heights for rods $1,6,7$ and 8 . Calibration of indicators may fix this problem. Most rods start with ARPI at 1.0 or 1.5 when RRPI indicates 0.0 (rod bottom).
3/SU1

3/SU1

3/SU1 
B. Long Term Items (cont'd)

SYSTEM 90
Required By/Tarqet

PRIORITY \&

PHASE DESIGNATOR

$3 /$ SU1

Rod 9 speed was measured at 7.8 inches per minute at the max speed setting. The minimum specified speed is 8.2 inches per minute. Speeds were measured using ARPI versus RRPI (RRPI was inoperable) which may have contributed to uncertainty. Evaluation of speed control after RRPI is repaired is recommended.

4F-98-149/A EVALUATE CONTROL ROD DROP METHOD

2/SU1

Engineering needs to evaluate a modification to the CRDM test supply cabinets that would allow interruption of power at the test supply for performance of rod drop timing tests per SC-31-6. The current method of opening the MG set output breaker causes excessive wear on plant equipment that is critical for reactor operation (the output breaker itself, the alpha power supplies and the surge suppressors on the 3 phase to 6 phase transformer). The modification would also result in more efficient performance of the SC.

4F-98-182/W CRDM MG SET D-16 MOTOR END BEARING NOISE LEVEL HIGH

Post CRDM Rod Drop Testing bearing noise level checks revealed high readings on the motor end bearing on D-16. Replacement of both bearings on D-16 prior to reactor startup is recommended. 
6. Checkoff List

A. Are the current plant corrective maintenance, preventive maintenance, and calibration database items all properly identified and planned actions acceptable? Yes X No

COMMENTS (exceptions): NONE

B. Are all other action items (IRs, NCRs, etc.) properly identified and assigned? Yes $X$ No (Attach the summary of needed.actions not in the database.)

COMMENTS (exceptions): NONE

C. Are near term spare parts adequate? Yes $X$ No

COMMENTS (exceptions): The reason near term spare parts are adequate is that the CRDM's and support systems/components are not needed while the plant is in the standby condition. If a startup order is received, the answer to this question is NO.

D. Are trend analysis data acceptable for continued operation?

Yes $\mathrm{X}$ No

COMMENTS (exceptions): NONE 
COMPONENT STATUS REPORT (cont'd)

TABLE 1

POSITION INDICATOR ROD SELF WELDING HISTORY

OUTAGE DATE

S8A Jan. 86

S9B Feb. 87

S9C Jun. 87

S10C-1 Oct. 88

S11A-3 Jun. 89

S11B-1 Sep. 89

S12B-1a Sep. 91
LOCATION REMARKS

A5 \& A9

First indication of self welding. CRDM P.I. rod tip in location A9 was chrome carbide coated.

A5

Easily detached.

A5 \& A6

P.I. rod in location A6 did not move freely making self welding detection difficult.

A5

Easily detached.

A5

Easily detached.

A5

Easily detached.

A5

Easily detached. 
HNF-2380

Rev. 0, Page 155

Rod Lattlee Rod'Drop

Number Positlon TIme (ms) **

Cyclo No.

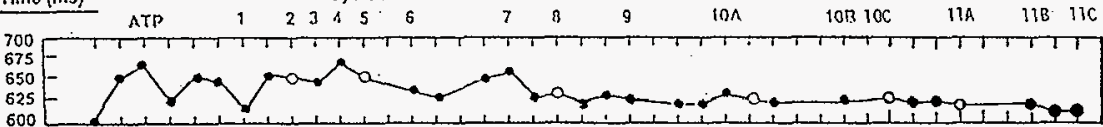

2-A1 2302

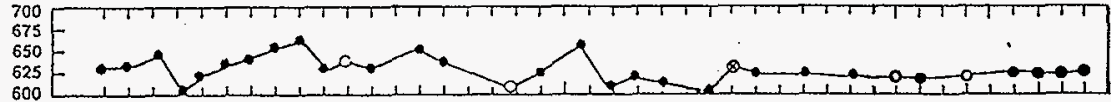

$3-\wedge 2$

3302

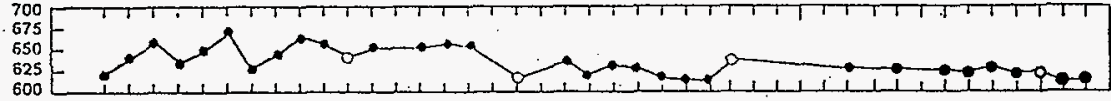

$4-\wedge 8 \quad 1502$

** 7

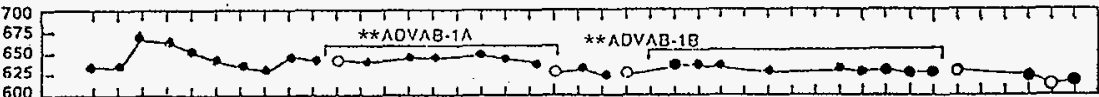

5.A9 1504

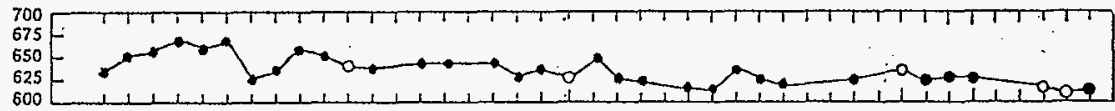

6-AS 2502

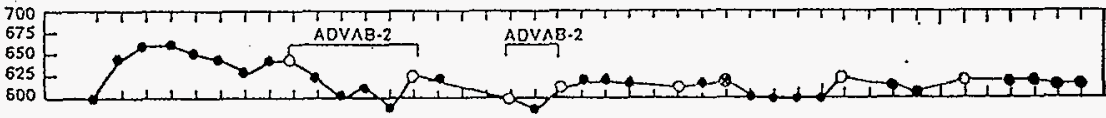

$7-\wedge 6$

2504

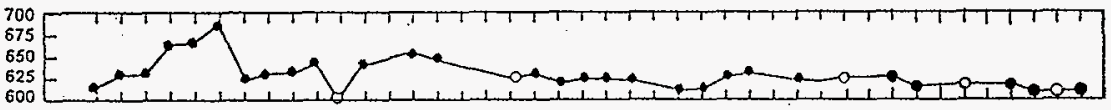

B.A4

3502

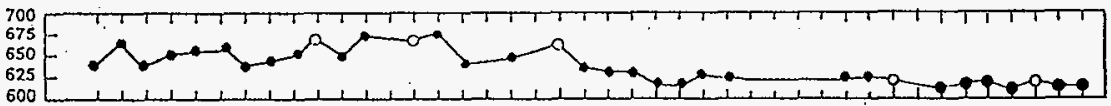

$9-A 7$

$\begin{array}{rr}* * & 700 \\ 67504 & 675 \\ 625 \\ 600\end{array}$

700
675
625
600

다유

啰

- Tech Specs Limit is $836 \mathrm{~ms}$.

- Indicates Control Rod Replacement.

Indicates Control Rod Exchange.

** Insertion Times for ADVAB-1A \& -7B use Rod Drop Time Scale at Right.

Figure 1 Control Rod Insertion Time.

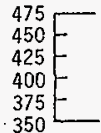


$1-\mathrm{A} 3 \quad 1302$

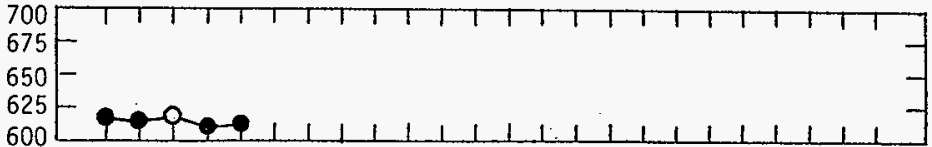

$2-A 1 \quad 2302$

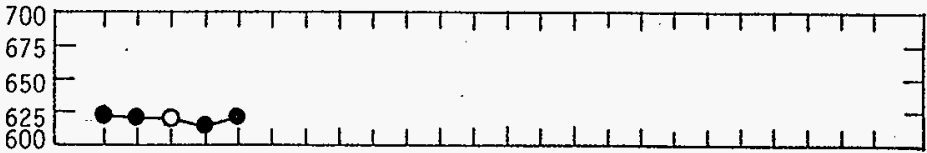

3-A2 3302

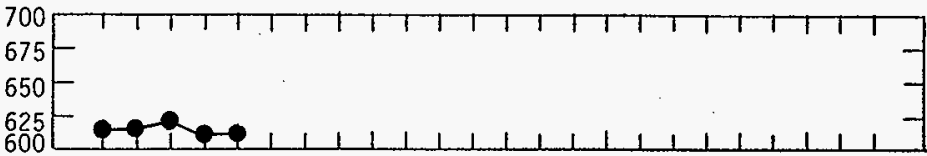

4-A8 1502

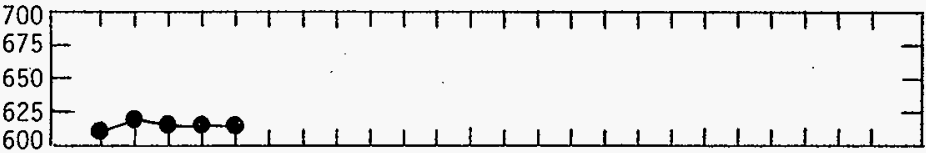

5-A9 $\quad 1504$

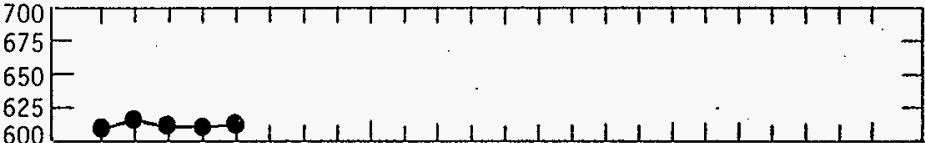

6-A5 2502

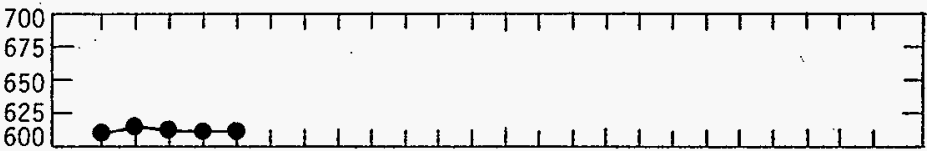

7-A6 2504

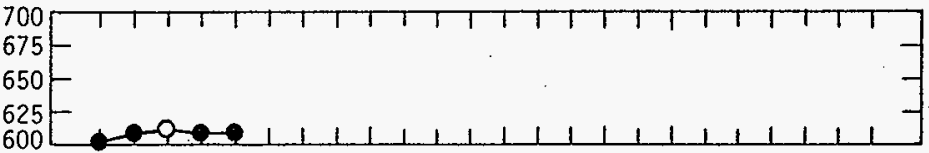
600

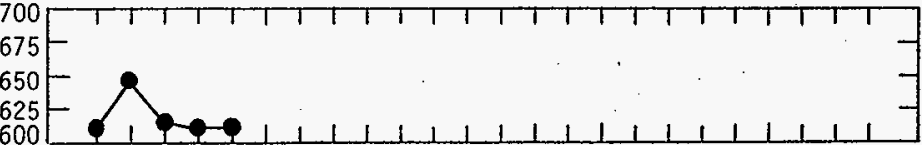

8-A4 3502

9-A7 $\quad 3504$

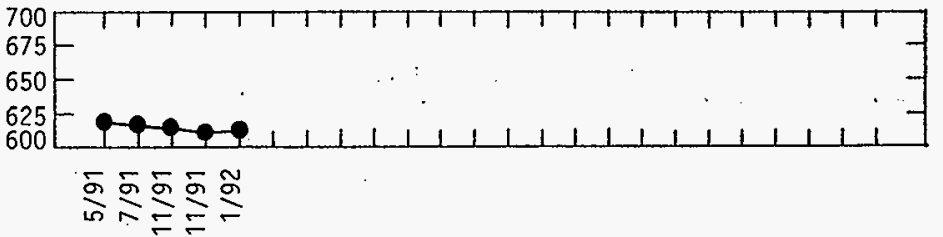




\section{ANNUAL SYSTEM ASSESSMENT REPORT \\ SYSTEM 32 \\ REACTOR ENCLOSURE \\ CI AND OH HEATING/COOLING}

Date of This Report $1 / 30 / 98$

Date of Previous Report $1 / 31 / 97$

APPROVALS:

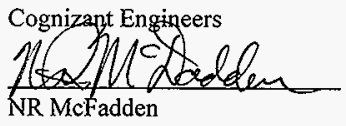

Cognizant Engineering Managers

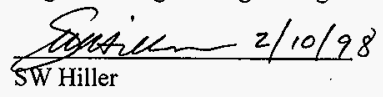

1. SCOPE
System/Components
32/ T32, T33, U519/20/21, M213A/B, $\mathrm{U} 292, \mathrm{C} 883, \mathrm{C} 852$

Title

\author{
REACTOR ENCLOSURE \\ Cl \& OH HEATING/COOLING
}

2. SUMMARY EVALUATION (Provide a general assessment of the overall health of the system. Include a discussion of the system's minimum operable equipment from plant procedure PN-7.)

The Reactor Enclosure system consists primarily of passive, inaccessible components such as the vessel, head, supports, guard vessel and shielding. The active portions are the head heating/cooling system, fuel/test transfer ports, and visual inspection equipment for the vessel. This assessment focuses on the head heating/cooling system which is required to be functional in standby. A number of assessments have been made for improvements and activities required for all system elements if a plant restart is authorized. Those plans will not be discussed in this assessment. All problems, with one exception, are identified in JCS and have appropriate phase/admin designations.

The head heating/cooling system is operating acceptably for standby conditions. PMP-32A-E02 was recently performed to check the condition of all head heater circuits (4F-97-194). Out of the 40 circuits, 6 were not operating and 6 were of questionable status.

One of the dead circuits was designated for immediate repair since it was in the Center Island. The circuit provides heat in the same Center Island sector where a low, but acceptable for standby, temperature has existed since $9 / 6 / 96$. After repairing the failed power controller (4F-97-2681), the low alarm cleared for the adjacent zone. This confirmed that there is enough interaction between the two adjacent zones that both have to be operational to maintain the temperature.

One of the drivers for performing the PMP was the fact that there was a significant temperature shift in one of the Outer Head zones. PMP results confirmed the suspicion that this circuit is not functioning. Discovery of the Center Island circuit not operating confirms the usefulness of the PMP, especially for circuits like it with no direct temperature indication. A package is being written to troubleshoot the remaining 11 problem zones. It is believed that most are not functioning due to failed power controllers, not failed heaters. 
HNF-2380

Rev. 0, Page 158

Page 2

3. ITEMS REQUIRING ACTION (Items on PTS, Procedures, Software, etc.)

A. Near Term Items

Required By

Diagnosis and repair of failed $\mathrm{OH} / \mathrm{CI}$ heater circuits.

Not assigned

Based on PMP-32A-E02 performance there are 11 of the 40 circuits that need additional troubleshooting and repairs performed. At this time, head temperatures are acceptable for the standby. This work is not a high priority item.

B. Long Term Items

Required By

Determine courses of action for Outer Head heater failures.

HSB

A significant system aging concern is Outer Head heater failure. Replacement of these heaters is expected to be a major plant work activity with the potential for long down time. Accessing the heaters requires major disassembly of head mounted equipment. An assessment needs to be performed to determine the work scope and costs to replace these heaters or identify an alternate method of maintaining head temperatures. This assessment is a restart activity that will be worked on a time available basis during standby.

4. TRENDS (Discuss trended parameters. See Appendix K for typical parameters which can be used for trending studies.)

There are no parameters trended in a formal manner for the Outer Head and Center Island temperature control systems. The cognizant engineer periodically reviews the operators logs, system temperatures and control set points. The trace heat temperature monitoring system includes the ability to review historical data and make hardcopy data printouts. This information is very useful for making comparisons that will detect and diagnose problems. The JCS system reports are also reviewed for repeat problems that would indicate a trend.

Performance of the diagnostic PMP is requested based on trending evaluations by the cognizant engineer. The discussions of heater circuit problems elsewhere in this assessment, reflect the results of trending evaluations.

5. SYSTEM AGING, SPARE PARTS CONSIDERATIONS, AND LONG TERM MAINTENANCE PHULOSOPHY

A. Discuss effects of system aging.

A major aging concern for a restart mission is the condition and longevity of the Outer Head heaters. As discussed under long term action items, replacement of these heaters is expected to be a major plant work activity with the potential for long down time. An assessment needs to be performed to determine the work scope and costs to replace these heaters or identify an alternate method of maintaining head temperatures. This assessment does not include the System 93-15 power supply/control systems which are also deteriorating and will need replacement for a restart mission. 
B. Discuss the strategy for near term spare parts and their availability strategy.

Over the years of operation, the spare parts inventory has been refined by actual usage. There are no zero balance items of significance.

C. Standby Maintenance Plan: Discuss a plan which ensures essential system functions for standby are provided and minimizes equipment degradation. Assume the standby period extends for the next one to two years. Include in the plan, as a minimum: 1) the identification of hardware to be repaired, replaced, or upgraded; and 2) the frequency of routine field maintenance, ensuring material and spare parts are identified to support these activities (i.e., refurbish pumps, etc.).

Since the head heating/cooling system must be functional during standby, routine preventive maintenance and calibrations will continue to be performed. A recent review of PMP's and ICRS's found that items to be performed were correctly identified and that actual performance and planned performance dates were acceptable.

\section{CHECKOFF LIST}

A. Accessible parts of the entire system or component have been thoroughly walked down at least once in the past 30 days to view current performance, equipment status and condition. Yes X No

\section{COMMENTS (exceptions): NONE}

B. Are there any conditions which might require limitations different from operating limits as defined in the SDDs, the FSAR, or the Plant Technical Specifications? Yes_ No _

COMMENTS (exceptions): NONE for standby

C. Are there trip settings, set points, interlocks, etc., that should be changed from those currently established? Yes_ No $\mathrm{X}$

\section{COMMENTS (exceptions): NONE for standby}

D. Are there interface areas which have not performed acceptably, which require resolution? Yes_No_

COMMENTS (exceptions): NONE for standby

E. Are there temporary plant or procedural conditions which will and should remain in place? Yes_No No $\mathrm{X}$

Attach list of $\mathrm{MOD}(\mathrm{L}) / \mathrm{ECN}(\mathrm{L})$ s, and OSPs that are currently active. Provide justification for continuing temporary MOD $(L) s$ and ECN $(L) s$. 
F. Is any retesting or special testing (e.g., OSP) required? Yes_ No $\mathrm{X}$

COMMENTS (exceptions): NONE

G. Are the current plant corrective maintenance, preventive maintenance, and calibration database items all properly identified and are planned actions acceptable? Yes X No

COMMENTS (exceptions): NONE

H. Are all other action items (NCRs, IRs, etc.) properly identified and assigned?

Yes X No__ (attach the summary of needed actions not in the data base)

COMMENTS (exceptions): NONE

I. Are there any special operating considerations? Yes_ No $\mathrm{X}$

List or Reference: NONE

J. Are near term spare parts adequate? Yes_. No _

COMMENTS (exceptions): NONE

K. Have any safety issues (radiological, industrial) been identified that remain unresolved?

Yes_No $\mathrm{X}$

COMMENTS (exceptions): NONE

L. Have all component data been entered into the Plant information database?

Yes_X No _

COMMENTS (exceptions): NONE

M. Have applicable SISI inspections been conducted? Yes X No

COMMENTS (exceptions): NONE

N. Has a cleanliness evaluation been completed? Yes X No _

Are any issues still unresolved? Yes_ No $X$

COMMENTS (exceptions): NONE

\section{REFERENCES}

PTS reports and searches for Work Documents and PMP/ICRS status.

Standby and Restart assessments performed since the last formal ASAR in 1992. 


\section{ATTACHMENTS}

(Attach any CSRs, data sheets showing system performance, or other material demonstrating the substantive nature of this review). 


\section{Revised 1/30/97 - Cog Engineer: McFadden}

The Reactor Enclosure system consists primarily of passive, inaccessible components such as the vessel, head, supports, guard vessel and shielding. The active portions are the head heating/cooling system, fuel/test transfer ports, and visual inspection equipment for the vessel.

\section{A. Head Heating/Cooling System}

This system is operating acceptably. Both the Outer Head and Center Island temperatures are being maintained above the $250^{\circ} \mathrm{F}$ minimum average for plant operation.

A1. The $\mathrm{C} 600$ Center Island Head Temperature monitoring system, including alarm reflash to the control room, was removed. For restart, there must be an evaluation of requirements (e.g. Tech Spec) and probably installation of a similar system. Prior to restart.

A2. A significant system aging concern is Outer Head heater failure. Replacement of these heaters is expected to be a major plant work activity with the potential for long down time.

a. An assessment needs to be performed to determine the work scope and costs to replace these heaters or identify an alternate method of maintaining head temperature. Accessing the heaters requires major disassembly of head mounted equipment. Start assessment during HSB.

b. In the near term, there needs to be an evaluation of existing Outer Head heater condition. The head temperatures and controller set points are monitored with the intent of detecting when significant heater failures begin to occur. An attempt is made to minimize heater power levels to extend life. The last direct check of heater condition was made when the outer head zones were turned off for FTP \#2 repairs in 12/89. There was no significant degradation found in the zones checked at that time. Perform PMP or equivalent during HSB. (4F-97-194)

c. The head heater control system (Outer \& CI) needs to be replaced. This is addressed by system 93B. Prior to restart.

A2. Another region where aging will have an impact is the Center Island heating system elements. These heaters and gas supply hoses can be replaced as failures occur.

a. Repair procedures should be developed for quick implementation and the spare quantities should be increased. Prior to restart.

\section{B. Vessel \& Head}

There are no active elements related to the vessel and head. The life extension and coupon surveillance program status are covered by System 31 assessments.

\section{SISI Inspection}

Reactor vessel support arm weld inspections are covered by the SISI program and detailed in SS-32-2. Status of the SISI program is covered by other assessments. 


\section{Floor Valve Adapters}

The two FVA's used at the Fuel Transfer Ports and the Test Transfer Port adapter have no significant problems.

D1. As a long term item to improve refueling cycle time, it has been suggested that a third FVA be procured. Evaluate prior to restart.

\section{E. Fuel Transfer Ports}

The nozzle at port \#2 is tilted. This problem is documented in detail by SD-FF-TA-00002, WHC-SP0531 and Occurrence Report \#WHC-91-B002-FFTF(formerly WHC-U0-88-037). The nozzle tilt caused FVA sealing difficulties and plug removal problems. During S11B-1, the cause of the problem was determined. Depleted uranium shielding around the nozzle had oxidized and expanded. Repair activities during S11B-1(12/89) removed depleted uranium to arrest the problem.

E1. Acceptable Floor Valve Adapter mating plus occasional dimensional checks, have verified that nozzle tilt is no longer increasing.

a. All three Fuel Transfer Ports should be periodically monitored. Most nozzle movement was seen during power operation due to higher temperatures. Perform dimensional checks at least once prior to restart. 


\section{ANNUAL SYSTEM ASSESSMENT REPORT}

for

SYSTEM 41-2

Date of This Report $01 / 30 / 98$

Date of Previous Report__ $01 / 27 / 92$

1. $\underline{\text { SCOPE }}$

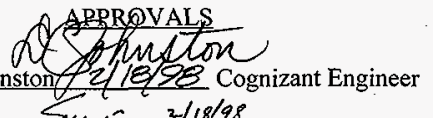

D. C. Johnstonf 2/18\%8 Cog

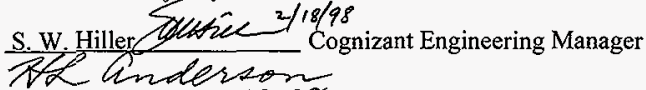

H. L. Anderson $0 z-78-98$ Electrical Cognizant Engineer

G.N. Ruge $29 R_{\text {uge }} \underset{2 / 18 / 98}{C o g n i z a n t . E l e c t r i c a l ~ E n g i n e e r i n g ~ M a n a g e r ~}$

System/Component . $\quad \underline{\text { Title }}$

41-2 In Vessel Handling Machine (IVHM)

2. SUMMARY EVALUATION (Provide a general assessment of the overall health of the system. Include a discussion of the system's minimum operable equipment from plant procedure $\mathrm{PN}-7$.)

As demonstrated by the Head Mounted Component Exercise, the IVHM is ready to initiate support for all normal activity that is required to either continue shutdown or pursue a restart order. Because the IVHMs had been idle for two years awaiting the final actions for shutdown, it was appropriate to show the IVHMs and their boundary integrity were still functional. By handling core components which represents the full range of those normally processed, through actions that represent the complete range of normal motions and measuring the forces required to do this, $4 \mathrm{~F}$ 97-402 successfully proved the IVHMs are fully functional with the boundaries properly maintained. This was proved by comparing these exercise results to those from past use and verifying there weren't any serious differences.

3. ITEMS REOUIRING ACTION (Items on PTS, Procedures, Software, etc.)

\section{A. Near Term Items}

Required By

1. None are required in the next year. When the IVHMs were exercised they $10 / 98$ proved a two year period of inactivity is tolerable, and that the IVHMs are properly prepared to initiate any normal activity within the next year.

2. Because of the success of the special method of initiating the RRP $10 / 98$ azimuth drives, it will be incorporated into the IVHM startup method to be used when the IVHMs are being activated after a minimum of one year of nonuse. 
HNF-2380

Rev. 0, Page 165

3. To maximize the availability of the IVHMs, the operating philosophy has Restart been to not fix what isn't broke. Therefore the inflatable seals have been useful far beyond their expected five year lifespan. The longer these seals are used, the more the concern over their failure increases. A fairly simple method of checking the seals for degradation was developed during the exercising, and it will be incorporated into the operating procedure as an interim check to be performed annually.

B. Long Term Items

Required By

Recommend replacing the inflatable seals.

Restart

To maximize support of a long term operation, most of the IVHM

Restart

subsystems should be overhauled as part of the dissassembly required when replacing the inflatable seals.

4. TRENDS (Discuss trended parameters. See Appendix $K$ for typical parameters which can be used for trending studies.)

One trend that was unknown prior to the exercising was the impact of long term Standby on the IVHMs. The machines appear to be minimally impacted by this mode. This was demonstrated by the lower than expected start up torques measured on all the azimuth drives. This made it easy to see that all the working forces to operate the machines through their full operating capability were also well within the normal range of what has been seen in the past.

\section{SYSTEM AGING, SPARE PARTS CONSIDERATIONS, AND LONG TERM} MAINTENANCE PHILOSOPHY

A. Discuss effects of system aging.

The biggest impact of system aging will be seen in all the seals. As they age, the seals will deteriorate and an increase will be seen in the amount of the argon used to maintain the buffers.

As the reactor cover gas activity increased, so did the potential of exposure to the upper portions of the IVHM gas system. This potential has decayed as the standby period lengthens. Therefore any needed maintenance in this area should be done prior to start up when cover gas activity will again increase. This applies to the part of the system that is guaranteed to need replacement- the inflatable seals.

B. Discuss the strategy for near term spare parts and their availability strategy.

Spare parts are available with the exception of the those which are age sensitive. These are the inflatable seals and most of the o-rings. With the exception of the very large o-rings, the o-rings are available as standard stock from the manufacturers and are immediately available.

Spares signal conditioners and absolute encoders are available but are becoming more expensive to maintain. For startup, the 15 signal conditioners and the 12 absolute encoders should all be upgraded, to regain ability to economically restock spares. 
C. Standby Maintenance Plan: Discuss a plan which ensures essential system functions for standby are provided and minimizes equipment degradation. Assume the standby period extends for the next one to two years. Include in the plan, as a minimum: 1) the identification of hardware to be repaired, replaced, or upgraded; and 2) the frequency of routine field maintenance, ensuring material and spare parts are identified to support these activities (i.e., refurbish pumps, etc.).

The most likley threat to the operation of the IVHMs would be the presence of sodium oxide compounds in the annular clearances of the machine and the annular interfaces of the head. Procedural checks were routinely done to confirm the buffers, in addition, the head mounted equipment exercise program has developed a method which permits a comparison to past inflatable seal performance. This method will be recommended in a standby check which will be recommended to be performed annually.

See 3.A.3

\section{CHECKOFF LIST}

A. Accessible parts of the entire system or component have been thoroughly walked down at least once in the past 30 days to view current performance, equipment status and condition: Yes $\mathrm{X}_{\text {NO }}$.

COMMENTS (exceptions):

B. Are there any conditions which might require limitations different from operating limits as defined in the SDDs, the FSAR, or the Plant Technical Specifications? Yes_No $\mathrm{X}$ COMMENTS (exceptions):

C. Are there trip settings, set points, interlocks, etc., that should be changed from those currently established? Yes _ No $\mathrm{X}$

COMMENTS (exceptions):

D. Are there interface areas which have not performed acceptably, which require resolution? Yes_No_X.

COMMENTS (exceptions):

E. Are there temporary plant or procedural conditions which will and should remain in place? Yes_No

Attach list of $\mathrm{MOD}(\mathrm{L}) / \mathrm{ECN}(\mathrm{L})$ s, and OSPs that are currently active. Provide justification for continuing temporary MOD $(\mathrm{L}) \mathrm{s}$ and $\mathrm{ECN}(\mathrm{L}) \mathrm{s}$.

COMMENTS (exceptions):

F. Is any retesting or special testing (e.g., OSP) required? Yes_ No X COMMENTS (exceptions): 
G. Are the current plant corrective maintenance, preventive maintenance, and calibration database items all properly identified and are planned actions acceptable? Yes X No COMMENTS (exceptions):

H. Are all other action items (NCRs, IRs, etc.) properly identified and assigned?

Yes_X_No_ (attach the summary of needed actions not in the data base)

COMMENTS (exceptions):

I. Are there any special operating considerations? Yes_ No _ $\mathrm{X}$

List or Reference: See 5C

J. Are near term spare parts adequate? Yes X No

COMMENTS (exceptions): See 5B

K. Have any safety issues (radiological, industrial) been identified that remain unresolved? Yes_No_

COMMENTS (exceptions):

L. Have all component data been entered into the Plant information database?

Yes X No

COMMENTS (exceptions):

M. Have applicable SISI inspections been conducted? Yes_No_X

COMMENTS (exceptions): The argon supply system has several check valves that are to prevent the backflow of irradiated cover gas. During the standby these have not been maintained because they are not needed. They will need to be restored to restart.

N. Has a cleanliness evaluation been completed? Yes X No

Are any issues still unresolved? Yes No X

COMMENTS (exceptions): For restart, the air flow into the head compartment carries rust particulate into the IVHM \#3 area. This problem has been documented on 4F-98-0058/M, and it has been forwarded to the cooling system engineer for resolution.

\section{REFERENCES}

HFS 2252, FFTF Head Mounted Equipment Exercising Report

8. ATTACHMENTS

(Attach any CSRs; data sheets showing system performance, or other material demonstrating the substantive nature of this review) 
HNF-2380

Rev. 0, Page 168

Page 1

\section{ANNUAL SYSTEM ASSESSMENT REPORT \\ SYSTEM 41-3 \\ CLEM}

Date of This Report $1 / 30 / 98$

Date of Previous Report $1 / 31 / 97$

APPROVALS:

Cognizant Engineers

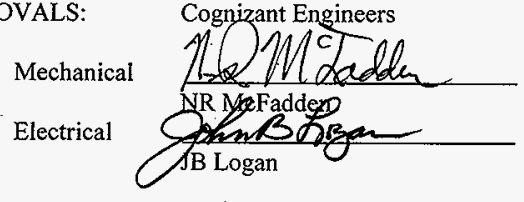

Cognizant Engineering Managers

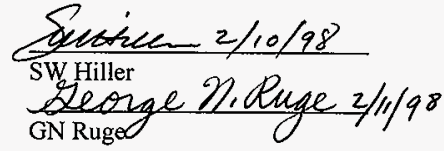

1. SCOPE

System/Components

41-3/M-9, M-13, C-698, C-699
Title

CLEM

2. SUMMARY EVALUATION (Provide a general assessment of the overall health of the system. Include a discussion of the system's minimum operable equipment from plant procedure $\mathrm{PN}-7$.)

CLEM is being maintained operable and is capable of performing planned component handling operations during the standby period. A number of assessments have been made for improvements and activities required if a plant restart is authorized. Those plans will not be discussed in this assessment. The major improvement being pursued during standby is replacement of the computer and related systems. Although the number of repairs required in the past several years has been low, the age related potential for failure of computer system components justifies this action, regardless of whether shutdown is continued or a restart is authorized. Both scenarios require handling large numbers of components.

Other than the computer, there are no significant problems for CLEM operability during standby. All problems are identified in JCS and have appropriate phase/admin designations.

3. ITEMS REQUIRING ACTION (Items on PTS, Procedures, Software, etc.)

A. Near Term Items

Drip pan encoder position shifts.
Required By

Phase 98-2R

(4F-97-1879)

The problem is due to intermittent gear tooth disengagement in the ratio reducer for the encoder. A new reducer has been ordered. The design is slightly different to eliminate future potential for the same problem. A modification package will be written. 
HNF-2380

Rev. 0, Page 169

Page 2

B. Long Term Items

Required By

Determine backup to coldwall heaters in case of failure.

HSB

(4F-97-195)

Tubular type heaters are installed directly on the back side of the coldwall pipe. If some of these fail, it will affect the ability to maintain coldwall temperatures. Heater replacement would require removal of the 40 foot long coldwall assembly. This is a major activity that borders on being impractical. A test was performed which demonstrated that the coldwall air preheaters and blowers could maintain acceptable temperatures with the coldwall heaters off. To reliably use this method will require modifications to increase the capacities and control flexibility. This design activity is designated for hot standby with no specific phase designator.

Evaluate options for slip correction of load limiter position encoder

HSB

(4F-97-196)

Due to drive wheel slippage during operation, occasionally the CLEM operator has to reset the encoder drive to the correct position. The problem potentially can be resolved by redesign of the drive mechanism or by computer auto check and reset of the encoder relationship. Resolution will be determined as part of the computer upgrade design task

Design replacement computer control system.

HSB

This upgrade to ensure future operability is in the design phase. Incorporation on CLEM is dependent on funding availability. The scope includes a new operator interface, analog and digital $\mathrm{I} / \mathrm{O}$, programmable controller, and a new trolley/gantry speed control system. Also addressed will be the oxygen analyzer, load cell signal conditioner and encoders for grapple, load limiter and drip pan positions. This upgrade will also resolve the Year 2000 date incompatibility problem.

4. TRENDS (Discuss trended parameters. See Appendix $\mathrm{K}$ for typical parameters which can be used for trending studies.)

There are no specific parameters trended in a formal manner on CLEM. The cognizant engineers periodically review the operators logs and the operating data printouts. The operating procedures require that most machine parameters including loads, be recorded at specific points in grapple drives during component handling. This information is very useful for making comparisons that will detect problems. The JCS system reports are also reviewed for repeat problems that would indicate a trend. At this time, CLEM is operating well, with the exception of items such as the computer system that are addressed elsewhere in this assessment. 
HNF-2380

Rev. 0, Page 170

Page 3

5. SYSTEM AGING, SPARE PARTS CONSIDERATIONS, AND LONG TERM MAINTENANCE PHILOSOPHY

A. Discuss effects of system aging.

Actions for computer system replacement and coldwall heater backup are due to anticipation of failures from system aging. Some items such as heaters and electronics are subject to aging due to continuous "on" time, but most items age primarily based on usage. These include grapple drive elements, moveable closure valve/drip pan drive elements, inflatable seals, and trolley/gantry drive systems. For the most part, repairs are made when failures occur. The real usage factor is low. These systems will require special attention to ensure availability with a restart mission but are acceptable as-is for standby or continuation of off-load.

B. Discuss the strategy for near term spare parts and their availability strategy.

Over the years of operation, the spare parts inventory has been refined by actual usage. There are no zero balance items of significance. Replacement of the BLTC computer system provided spares that should be adequate until the CLEM system is replaced.

C. Standby Maintenance Plan: Discuss a plan which ensures essential system functions for standby are provided and minimizes equipment degradation. Assume the standby period extends for the next one to two years. Include in the plan, as a minimum: 1) the identification of hardware to be repaired, replaced, or upgraded; and 2) the frequency of routine field maintenance, ensuring material and spare parts are identified to support these activities (i.e., refurbish pumps, etc.).

During the Standby period the CLEM control system upgrade will be actively pursued. The intent is to have all hardware design and software development complete to a point where the installation can be accomplished with the least impact to scheduled plant activities. Since CLEM's usage will vary depending on the FFTF Mission decision, the installation schedule will remain flexible. Installation will be a priority regardless of the direction of the decision.

Since CLEM will still see limited use during the Standby period, routine preventive maintenance and calibrations will continue to be performed.'A recent review of CLEM PMP's and ICRS's found that items to be performed were correctly identified and that actual performance and planned performance dates were acceptable. 


\section{CHECKOFF LIST}

A. Accessible parts of the entire system or component have been thoroughly walked down at least once in the past 30 days to view current performance, equipment status and condition. Yes X No

\section{COMMENTS (exceptions): NONE}

B. Are there any conditions which might require limitations different from operating limits as defined in the SDDs, the FSAR, or the Plant Technical Specifications? Yes_ No X

COMMENTS (exceptions): NONE for standby

C. Are there trip settings, set points, interlocks, etc., that should be changed from those currently established? Yes_ No _X.

COMMENTS (exceptions): NONE for standby

D. Are there interface areas which have not performed acceptably, which require resolution? Yes_. No X

COMMENTS (exceptions): NONE for standby

E. Are there temporary plant or procedural conditions which will and should remain in place? Yes_. No $X$

Attach list of $\mathrm{MOD}(\mathrm{L}) / \mathrm{ECN}(\mathrm{L}) \mathrm{s}$, and OSPs that are currently active. Provide justification for continuing temporary MOD (L)s and ECN (L)s.

COMMENTS (exceptions): NONE

F. Is any retesting or special testing (e.g., OSP) required? Yes_ No $\mathrm{X}$

COMMENTS (exceptions): NONE

G. Are the current plant corrective maintenance, preventive maintenance, and calibration database items all properly identified and are planned actions acceptable? Yes_X No

COMMENTS (exceptions): NONE

H. Are all other action items (NCRs, IRs, etc.) properly identified and assigned?

Yes_ X No__ (attach the summary of needed actions not in the data base)

COMMENTS (exceptions): NONE

l. Are there any special operating considerations? Yes_ No $X$

List or Reference: NONE 
HNF-2380

Rev, 0, Page 172

Page 5

J. Are near term spare parts adequate? Yes $\underline{X}$ No_

COMMENTS (exceptions): NONE

K. Have any safety issues (radiological, industrial) been identified that remain unresolved?

Yes_No No X

COMMENTS (exceptions): NONE

L. Have all component data been entered into the Plant information database?

Yes $\mathrm{X}$ No

COMMENTS (exceptions): NONE

M. Have applicable SISI inspections been conducted? Yes $\underline{X}$ No_

COMMENTS (exceptions): NONE

N. Has a cleanliness evaluation been completed? Yes $\underline{\mathrm{X}}$ No

Are any issues still unresolved? Yes_No $\mathrm{X}$

COMMENTS (exceptions): NONE

\section{REFERENCES}

PTS reports and searches for Work Documents and PMP/ICRS status.

Standby and Restart assessments performed since the last formal ASAR in 1992.

\section{8. $\quad$ ATTACHMENTS}

(Attach any CSRs, data sheets showing system performance, or other material demonstrating the substantive nature of this review).

A. JCS report of CLEM work items dated 1/28/98.

B. Hot Standby For Startup Assessment documentation of review meeting dated 2/4/97 including JCS report for CLEM work items dated 1/29/97. 
Revised 2/4/97 based on review meeting - Cog Engineers: McFadden/Logan

CLEM is presently operable, performing offload handling operations.

1. Over the years, there have been several Trolley and Gantry wheel bearing failures. In all cases, the axial thrust surfaces were broken, however, the main load bearing race surfaces were undamaged and capable of supporting the CLEM loads. It is not believed that wheel bearing failures will be a significant problem.

A. Ensure that procedures and repair equipment are available to minimize down time when failures occur. Prior to restart.

2. During investigation of a Closure Valve inflatable seal problem, it was determined that significant sodium compounds residue exists in the bottom seal region. This condition, coupled with the fact that there are seals and buffers with high leak rates, indicates that removal of the Closure Valve Assembly for cleaning and seal replacement will eventually be required.

A. MCV refurbishment. Prior to restart or right after first core load.

3. The existing air compressor is a high maintenance item.

A. Replace compressor with a new unit and make provision for temporary, portable compressor connection. Prior to restart.

4. An evaluation needs to be performed of CLEM operating conditions including temperatures to minimize vapor deposition and sodium spilled inside while handling full CCP's, especially for higher decay heat assemblies. Lowering the temperature below the nominal $400^{\circ} \mathrm{F}$ to contract the sodium may be useful.

A. Evaluation to minimize sodium spilled inside CLEM. Prior to restart. Have in place before CLEM use after MCV refurbishment.

5. An assessment of operating conditions needs to be done with the goal of maximizing cold wall heater life. Replacement of this assembly is a task that requires not only disassembly of the

- MCV assembly but also the grapple drive including load limiter carriage. It may be that an acceptable heating method can be determined using external heaters, thus eliminating the need for the cold wall heaters.

A. Recent test showed that modification of easily accessible air preheaters should allow acceptable CLEM heatup without cold wall heaters. Installation of modifications would allow turning off cold wall heaters to save for special beneficial operations. Design and install preheater modifications prior to restart but desirable to do as soon as possible. $4 \mathrm{f}-97-195 / \mathrm{M}$ 
6. The PDP-14/35 Controller and PDP-8E Computer do not have adequate spares on hand. The vendor no longer supplies spare components. Failed I/O modules are repaired when possible to extend an ever diminishing supply of actual spares. Replacement of the computer system is a major identified need. The existing computer is functionally in poor shape and contributes significantly to CLEM down time. The program can not be' reliably changed to accommodate altered operating requirements, which has necessitated the use of override keys and out-ofnormal sequence, push button fakeout techniques. This modification should include load cell and instrument signal conditioning systems plus the push button control panels. A permanent oxygen monitor should be installed and connected to the computer for operation and remote readout.

A. Computer replacement. Prior to restart but extension of standby increases justification to do as soon as possible to ensure CLEM is able to support defueling if shutdown is directed. Engineering for detailed program requirements must begin now.

7. There are no qualified spares for the trolley and gantry drive speed control systems. The equipment is obsolete.

A. Replace drive speed control systems. Perform as part of computer upgrade.

8. The battery system for the grapple auxiliary (backup) drive should be removed. CLEM on the emergency power supply system is adequate. If the batteries are retained, they need to be load tested and replaced as required.

A. Replace or eliminate grapple drive battery backup. Resolve prior to restart. Emergency power available at CLEM. Backup should not be required for low decay heat assemblies. Perform as soon as possible to eliminate hazardous batteries. Per review meeting, suspend PMP via ECN.

9. The drip pan drive unit needs to be modified to permit positive locating of the rotor at intermediate positions.

A. Modify drip pan drive for positive indication of intermediate positions. Perform prior to restart. Ideally should be done to coordinate with computer upgrade and possibly MCV refurbishment.

10. Depending on decisions made to decrease cycle time for tritium handling, it will probably be necessary to modify the grapple change box to allow it to remain permanently in place. The grapple wash process in the IEMC will also have to be refined.

A. Refine grapple change and cleaning process. Prior to restart.

11. Procedures and equipment need to be developed to repair the grapple drive system.

Procedures and a computer program should be prepared that would allow continued temporary operation if the load limiter assembly failed to operate.

A. Develop procedures and equipment related to recovery from failure of grapple drive system. Prior to restart. 
12. Procedures and tooling need to be developed to repair or replace trolley wheels. The shrink fit on the southeast trolley wheel apparently was not adequate. The wheel has moved and intermittently rubs on the housing. The condition has not worsened since first observed in 1985.

A. Ensure that procedures and equipment are available for trolley wheel repair. Prior to restart.

13. An in depth review needs to be made of the spares inventory for all potentially age degraded items (e.g. lip seals, lube in gearboxes, bearings, capacitors). Some testing, refurbishment and replacement may be required. There is presently no maintenance or inspection program.

A. Spares condition evaluation. Prior to restart.

14. A filter needs to be installed on the gas outlet going to CAPS. This will prevent contamination of the CAPS system.

A. CAPS line filter installation. Prior to restart.

15. Radiation detection system on CLEM needs to be defined and replaced.

A. Determine need and install detection equipment. Prior to restart. Coordinate with computer upgrade.

16. Determine fix for load limiter encoder slippage. During HSB. $4 F-97-196 / A$

17. Clean long grapple in IEMC. During HSB. 
HNF-2380

Rev. 0, Page 176

Page 1

\section{ANNUAL SYSTEM ASSESSMENT REPORT \\ SYSTEM 41-5 \\ DS}

Date of This Report $1 / 30 / 98$

Date of Previous Report _ 1/31/97

APPROVALS: $\quad$ Cognizant Engineers

Mechanical

Electrical

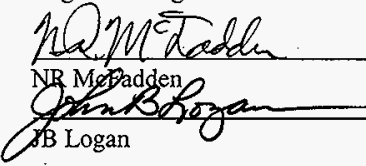

Cognizant Engineering Managers

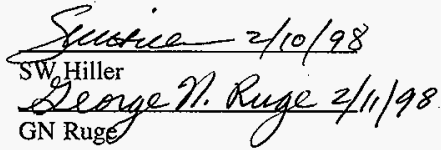

1. SCOPE

System/Components

41-5 / T-62, T182, C-625
Title

IDS

2. SUMMARY EVALUATION (Provide a general assessment of the overall health of the system. Include a discussion of the system's minimum operable equipment from plant procedure PN-7.)

IDS is being maintained operable and is capable of performing planned component handling operations during the standby period. There are two problems which have been designated as startup mission issues but which will be pursued on a time available basis during standby. They are: 1) inoperability of one of the two sodium level sensors and 2)inoperability of the visual index viewing system. All problems are identified in JCS and have appropriate phase/admin designations.

A number of assessments have been made for improvements and activities required if a plant restart is authorized. Those plans will not be discussed in this assessment. There are no major improvements being pursued during standby. The indexing control system was replaced in 1995 and is expected to be reliable for either a shutdown or restart mission.

3. ITEMS REQUIRING ACTION (Items on PTS, Procedures, Software, etc.)

A. Near Term Items

Required By

NONE

B. Long Term Items

Required By

Indexing control software does not support Year 2000 dates..

HSB

This will not impact operation of IDS. The date is displayed on the control screen but is not used for any activity or report. No action will be taken unless a revision is made to the software for other reasons. At that time the date will be removed from the display screen. 
HNF-2380

Rev. 0, Page 177

Page 2

One of the two sodium level sensors is inoperable.

HSB

(4F-87-468)

One operable sensor is acceptable during standby. Repairs will be initiated if other failures occur. A modified shield plug has been fabricated to facilitate the work.

Visual index viewer is not useable:

HSB

(4F-97-193)

The visual index mark viewer for basket position is no longer useable due to sodium frost build up. The unit needs to be removed, cleaned, modified and replaced. Due to the reliability of the encoder system and since there are two encoders, this problem has been designated as startup mission issue but will be pursued on a time available basis during standby.

4. TRENDS (Discuss trended parameters. See Appendix K for typical parameters which can be used for trending studies.)

There are no specific parameters trended in a formal manner on IDS. The cognizant engineers periodically review the operators logs. The JCS system reports are also reviewed for repeat problems that would indicate a trend: At this time, IDS is operating well.

\section{SYSTEM AGING, SPARE PARTS CONSIDERATIONS, AND LONG TERM MAINTENANCEPHILOSOPHY}

A. Discuss effects of system aging.

Replacement of the computer eliminated that as an aging concern. Most IDS active items age primarily based on usage. These include the basket rotational drive elements and encoders. The drive elements and encoders can also age due to the radiation field. The visual index viewer is not useable due to sodium frost deposition. For the most part, repairs are made to IDS when failures occur. These systems will require special attention to ensure availability with a restart mission but are acceptable as-is for standby or continuation of off-load.

B. Discuss the strategy for near term spare parts and their availability strategy.

Over the years of operation, the spare parts inventory has been refined by actual usage. Adjustments were made to spares inventory following completion of the computer upgrade. There are no zero balance items of significance. 
C. Standby Maintenance Plan: Discuss a plan which ensures essential system functions for standby are provided and minimizes equipment degradation. Assume the standby period extends for the next one to two years. Include in the plan, as a minimum: 1) the identification of hardware to be repaired, replaced, or upgraded; and 2) the frequency of routine field maintenance, ensuring material and spare parts are identified to support these activities (i.e., refurbish pumps, etc.).

There are no mandatory repairs or upgrades for IDS during the standby period. Two issues which will be pursued on a time available basis during standby are: 1) inoperability of one of the two sodium level sensors and 2)inoperability of the visual index viewing system.

Since IDS will still see limited use during the standby period, routine preventive maintenance and calibrations will continue to be performed. A recent review of IDS PMP's and ICRS's found that items to be performed were correctly identified and that actual performance and planned performance dates were acceptable.

\section{CHECKOFF LIST}

A. Accessible parts of the entire system or component have been thoroughly walked down at least once in the past 30 days to view current performance, equipment status and condition. Yes X No

\section{COMMENTS (exceptions): NONE}

B. Are there any conditions which might require limitations different from operating limits as defined in the SDDs, the FSAR, or the Plant Technical Specifications? Yes_ No $\mathrm{X}$

COMMENTS (exceptions): NONE for standby

C. Are there trip settings, set points, interlocks, etc., that should be changed from those currently established? Yes_ No $\mathrm{X}$

COMMENTS (exceptions): NONE for standby

D. Are there interface areas which have not performed acceptably, which require resolution? Yes_No No X

COMMENTS (exceptions): NONE for standby

E. Are there temporary plant or procedural conditions which will and should remain in place? Yes_No $\mathrm{X}$

Attach list of $\mathrm{MOD}(\mathrm{L}) / \mathrm{ECN}(\mathrm{L}) \mathrm{s}$, and OSPs that are currently active. Provide justification for continuing temporary MOD (L)s and ECN (L)s. 
F. Is any retesting or special testing (e.g., OSP) required? Yes_No $\mathrm{X}$

COMMENTS (exceptions): NONE

G. Are the current plant corrective maintenance, preventive maintenance, and calibration database items all properly identified and are planned actions acceptable? Yes_X No

COMMENTS (exceptions): NONE

H. Are all other action items (NCRs, IRs, etc.) properly identified and assigned?

Yes X No_ (attach the summary of needed actions not in the data base)

COMMENTS (exceptions): NONE

I. Are there any special operating considerations? Yes _ No $\mathrm{X}$

List or Reference: NONE

J. Are near term spare parts adequate? Yes $\mathrm{X}$ No_-

COMMENTS (exceptions): NONE

K. Have any safety issues (radiological, industrial) been identified that remain unresolved? Yes_No No X

COMMENTS (exceptions): NONE

L. Have all component data been entered into the Plant information database?

Yes_X No

COMMENTS (exceptions): NONE

M. Have applicable SISI inspections been conducted? Yes X No_

COMMENTS (exceptions): NONE

N. Has a cleanliness evaluation been completed? Yes X No

Are any issues still unresolved? Yes__NoX.

COMMENTS (exceptions): NONE

\section{REFERENCES}

PTS reports and searches for Work Documents and PMP/TCRS status.

Standby and Restart assessments performed since the last formal ASAR in 1992. 


\section{Page 5}

\section{ATTACHMENTS}

(Attach any CSRs, data sheets showing system performance, or other material demonstrating the substantive nature of this review).

A. JCS report of IDS work items dated 1/28/98.

B. Hot Standby For Startup Assessment documentation of review meeting dated 2/4/97 including JCS report for IDS work items dated 1/23/97. 
Revised 2/4/97 based on review meeting - Cog Engineers: McFadden/Logan

IDS is operable. The indexing control system has recently been upgraded and should be capable of supporting restart and long term operation.

1. The indexing system position encoders are the original units. These are subject to failure at any time. Due to the work to access the encoders, the existing old spares should not be used.

A. New design encoders should be procured and the installation package prepared. Prior to restart.

2. One of the two level indication sensors is inoperable.

A. The repair package needs to be performed (4F-87-468 \& 4F-87-1699). During HSB.

3. The visual index method is no longer useable should the electronic system fail. Sodium frost has built up the point that viewing through the window/mirror assembly is no longer possible. The unit needs to be removed and cleaned. A modification needs to be made at the same time to add an internal wiper/cleaner for the mirror and a functional cover.

A. Repair visual index. During HSB since backup to encoders (4F-97-193).

4. The vessel design life is 20 years. This will require reevaluation and probably some analysis.

\section{A. Prior to restart.}

5. Spares are available for the basket rotational drive system. Of the active components, the major uncertainty concerns the basket support bearing. Its real expected life is unknown. Replacement has not been scoped, but will probably be prohibitively difficult.
A. Do further research on bearing issue. Prior to restart.

6. An in depth review needs to be made of the spares inventory for all potentially age degraded items (e.g. lip seals, lube in gearboxes, bearings). Some testing, refurbishment and replacement may be required. There is presently no maintenance or inspection program.

A. Spares condition evaluation. Prior to restart. 


\section{ANNUAL SYSTEM ASSESSMENT REPORT \\ FOR \\ 41C/CCCS-S\&N \\ TACS \& SPSS $-1 \& 2$}

Date of this Report

$1-30-98$

APPROVALS

Date of Previous Report:

$1-24-92$

\section{Cognizant Engineer}

Mechanical:

Electrical:

Cognizant Engineering Manager

Mechanical:

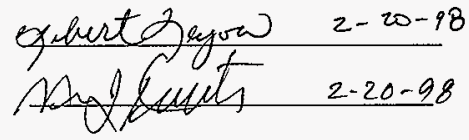

Electrical:

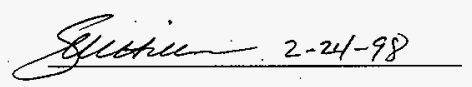

Electrical:

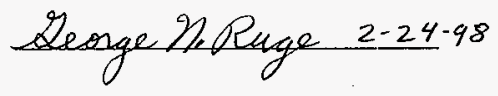

1. $\underline{\text { SCOPE }}$

\section{System/Component}

$41-6 /$ Conditioning Stations $\underline{\text { Title }}$

Core Component Conditioning Station South and North (CCCS S\&N), Test Assembly Conditioning Station (TACS), and Shield Plug Storage Station 1\&2 (SPSS 1\&2)

2. SUMMARY EVALUATION (Provide a general assessment of the overall health of the system. Include a discussion of the system's minimum operable equipment from plant procedure $\mathrm{PN}-7$ )

CCCS $-S$ is conditionally operational. At the present time, engineering does not forecast this equipment to be used during standby, but has been identified as an equipment that needs to be maintained for a potential startup. The limiting parameters of this station are that the blower needs to be inspected for noise and the temperature controller work package (F9-810/M) needs to be completed. Work package, $\mathrm{F} 9-810 / \mathrm{M}$, is presently in retention. BLTC and/or CLEM will be used, as needed, to preheat core component assemblies. The cells can be used to inert (feed and bleed) an assembly prior to BLTC or CLEM interface. The mentioned repairs were placed on hold due to the plant status (shutdown) at that time. During the next two years Engineering is recommending that as 
a minimum, to maintain the health of this equipment, we perform the pressure relief valve calibration (4F-94-660/1). Since the pressure relief valves are located in cell 512A (CCCS-S piping vault, located immediately east at the end of the BLTC tracks in the Reactor Containment Building (RCB)), which is not easily accessible, we should inspect and possibly repair the blower which is also located in the same cell.

CCCS $-N$ is nonoperational. Since early 1980 's, CCCS $-N$ has never been used due to the inaccessibility of the cells by CLEM. There is also, no existing operating procedure.

TACS is operational to inert a $40 \mathrm{ft}$. assembly, but not to preheat; the preheating of the assembly is accomplished in CLEM. During the next two years Engineering is recommending that we perform the pressure relief calibration (4F-94-661/ $)$. In addition, we should petform $4 \mathrm{~F}-91-584 / \mathrm{W}$ to maintain the system operable and clean.

SPSS -1 is operational. During the next two years, Engineering is not anticipating any PM's to be performed on the regulators and pressure relief valve. We should perform $4 \mathrm{~F}-94-480 / \mathrm{W}$ to maintain the system operable and clean.

SPSS -2 is nonoperational. This station does not have an approved operating procedure.

3. ITEMS REQUIRING ACTION (Items on PTS, Procedures, Software, etc.)

\section{$\underline{\text { Near Term Items } \quad \text { Required By }}$}

a. $4 \mathrm{~F}-91-584 / \mathrm{W}, \mathrm{TACS} \& \mathrm{SPSS}-2$ Port Opening need paint removed from sealing surfaces.

b. $4 \mathrm{~F}-94-480 / \mathrm{W}$, Remove Paint Drippings From Sealing Surfaces of SPSS-1.

c. $\quad 4 \mathrm{~F}-94-660 / \mathrm{I}, \mathrm{CCCS}-\mathrm{S}$ Pressure Relief Valve Calibration.

d. $4 \mathrm{~F}-94-661 / \mathrm{I}$, TACS Pressure Relief Valve Calibration.

e $\quad 4 \mathrm{~F}-97-2595 / \mathrm{W}$, Restore TACS Labeling.

f. $4 \mathrm{~F}-96-567 / \mathrm{W}$, Transfer Cell Pressure Indication low at $\mathrm{C}-1302$.

g. $4 \mathrm{~F}-97-061 / \mathrm{M}$, Permanently Disable The TACS Heaters at B-106 and B-18.

h. $4 \mathrm{~F}-94-783 / \mathrm{W}, \mathrm{CCCS}-\mathrm{S}$ Blower, B-081, Sounds bad.
As resources become available.

As resources become available.

As resources become available.

As resources become available.

As resources become available.

As resources become available.

As resources become available.

As resources become available. 


\section{Long Term Items $\quad$ Required By}
a. 4F-92-1941/W, SV-362 Leaks By.
Startup
b. 4F-86-2190/M, TACS Blower piping modification.
Startup
c. $4 \mathrm{~F}-97-610 / \mathrm{W}$, TACS New Storage $\mathrm{PE}-375$ $(\mathrm{P}-8)$, pressure transmitter, does not work.
Startup
d. $4 \mathrm{~F}-95-34 / \mathrm{W}$, Layup CCCS $-\mathrm{S} \& \mathrm{~N}$
Shutdown

4. TRENDS (Discuss trended parameters. See Appendix $K$ for typical parameters which can be used for trending studies.)

None

5. SYSTEM AGING, SPARE PARTS CONSIDERATIONS, AND LONG TERM MAINTENANCE PHILOSOPHY

CCCS $-S$, TACS and SPSS -1 have used minimal spare parts since the last reporting period, mostly due to the infrequent use of the systems. There is sufficient supply of spare parts to support any FFTF operation with the exception of a heater assembly. There is a viable replacement which is located in $\mathrm{CCCS}-\mathrm{N}$, although this has not been confirmed. The present backup for a failed heater is to preheat the assembly in CLEM. At the present time, we do not have any plans to preheat any components.

Sterer manufactured valves are used quite intensively in all the conditioning stations to regulate, relieve and control the flow and pressures for these components. These valves are unique only to FFTF's Conditioning Stations. Very minimal repairs (minimal spare parts impact) are expected on these valves since they have demonstrated good reliability; e.g., minor lapping of seats and changing out of o-rings.

Engineering's assessment and recommendation is to continue performing preventive maintenance on the blower and, continue pressure relief and regulator valve calibrations. The PM on the blower should only be performed in conjunction with valve calibrations since the cell is not easily accessible, i.e. plan as much of the work in cell 512A, $\mathrm{CCCS}-\mathrm{S}$ piping vault, as possible.

\section{CHECKOFF LIST}

A. Accessible parts of the entire system or component have been thoroughly walked down at least once in the past 30 days to view current performance, equipment status and conditions. Yes X No

COMMENTS (exceptions): None 
B. Are there any conditions which might require limitations different from operating limits as defined in the SDDs, the FSAR, or the Plant Technical Specifications? Yes_ No

COMMENTS (exceptions): None

C. Are there trip settings, set points, interlocks, etc., that should be changed from those currently established? Yes No $\mathrm{X}$

COMMENTS (exceptions):

D. Are there interface areas which have not performed acceptably, which require resolution? Yes No $\mathrm{X}$

COMMENTS (exceptions): None

E. Are there temporary plant or procedural conditions which will and should remain in place? Yes__No $\mathrm{X}$

Attach list of MOD(L)/ECN(L)s, and OSPs that are currently active. Provide justification for continuing temporary MOD (L)s and ECN (L)s.

COMMENTS (exceptions): NA

F. Is any retesting or special testing (e.g., OSP) required? Yes_ No X COMMENTS (exceptions): NA

G. Are the current plant corrective maintenance, preventive maintenance, and calibration database items all properly identified and are planned actions acceptable?

Yes_X No

COMMENTS (exceptions): None

H. Are all other action items (NCRs, Irs, etc) properly identified and assigned?

Yes X No___(attach the summary of needed actions not in the data base)

COMMENTS (exceptions): There is no outsanding NCRs, Irs, etc. at the present time.

I. Are there any special operating considerations? Yes___No $\mathrm{X}$ COMMENTS (exceptions): NA

J. Are near term spare parts adequate? Yes $\mathrm{X}$ No

COMMENTS (exceptions): See Item 5 above for explanation. 
K. Have any safety issues (radiological, industrial) been identified that remains untesolved? Yes__No_X

COMMENTS (exceptions): None

L. Have all components data been entered into the Plant information database? Yes X No

COMMENTS (exceptions):

M. Have applicable SISI inspections been conducted? Yes No

COMMENTS (exceptions): NA

N. Has a cleanliness evaluation been completed? Yes X No

Are any issues still unresolved? Yes No $\mathrm{X}$

COMMENTS (exceptions): None

\section{REFERENCES}

None

8. ATTACHMENTS

(Attach any CSRs, data sheets showing system performance, or other material demonstrating the substantive nature of this review). 
COMPONENT STATUS REPORT FOR

REFUELING FLOOR VALVES

Period Covered: $9-15-95$ through 1-31-98

Component: Refueling Floor Valves (41-7)

Cognizant Engineer(s):

$$
\text { Electrical: NJ Knuter }
$$

Cognizant Manager(s): Mechanical: SW Hiller

Electrical: GN Ruge
Date Reported: $2-20-98$

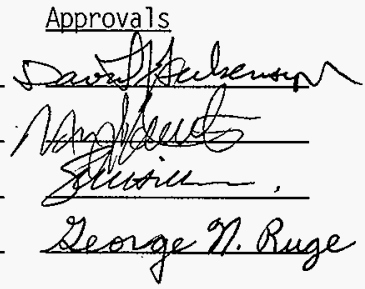

\section{Summary of Component Status:}

All Refueling Floor Valves, M-5, M-6, M-199, M-200 and M-247 are operational.

Floor Valve Controllers C-1148 and C-1149 are operational.

2. Trends Observed:

\section{A. Mechanical}

(Also see attached FLOOR VALVE MECHANICAL REPAIR HISTORY table).

Constant Purge System - Components in the Constant Purge System, which supplies make-up argon to the inflatable seal buffer spaces and the Thruport Cavity, were cleaned and/or replaced in FV's M-5, M-6 and M-247 during the past reporting periods. The work in M-5 and M-6 was required due to blockage. The work in M-247 was preventative. The same components were cleaned and/or replaced in FV's M-5, M-6 M-199 and M-200 this reporting period. The work in M-5 and M-199 was required due to blockage. The work in $M-6$ and $M-200$ was preventative. The Constant Purge System in M-247 was tested SAT twice in this reporting period. Cleaning of the check valves and orifices, and replacement of the filters in the system was required due to build-up of a fine black rubber-7ike powder. The source of this powder is unknown, but may be from the inside of the argon supple hoses. The purge solenoid valves (SV-36) in M-5, M-199 and M-247 were replaced during past reporting periods. The same valve in $M-200$ was replaced this reporting period. The purge solenoid valves generally develop a loud hum with age and eventualiy have to be replaced. 


\section{COMPONENT STATUS REPORT (cont'd)}

Argon Supply System Check Valves (CV-01, 07, 10, 15, 18 and 20) - During the previous reporting period (1-1-92 thru 9-15-95) the check valves in M-5, M-200 and $M-247$ required replacement/rebuild or repair. No work on these check valves has been required during this reporting period. The valves in M- 6 were functionally tested and found to be satisfactory. The cause of check valve failure in the past appears to have been due to aging of the check valve 0-rings (both internal and external 0-rings).

Vent System Check Valves ( $C V-25$ and 29) - During the previous reporting period (1-1-92 thru 9-15-95) no work on these check valves was performed. This was probably due to failure to detect a problem with them. In retrospect they have probably been bad for some time. Both valves in all five FV's were replaced this reporting period. Seven of the valves were actually leaking prior to replacement, the other three were replaced as a preventative measure during work on the companion valve. The cause of check valve failure in the past appears to have been due to aging of the check valve 0-rings (both internal and externa? 0 -rings).

Inflatable Seals - No inflatable seals required replacement this reporting period. The lower inner inflatable seal argon supply line on M-6 developed a leak which required removal of the bottom recess covers to repair.

Back Pressure Regulator (PCV-31) - Regulators in M-5, M-199 and M-200 were replaced during past reporting periods. The replacements in M-5 and M-199 were required due to leakage. The replacement in M-200 was preventative. The same regulators in $\mathrm{M}-200$ and $\mathrm{M}-247$ were replaced this reporting period. The replacement in $M-200$ was required due to leakage. The replacement in $M-247$ was preventative. The apparent cause of regulator failure is sodium frost build-up on the disc and seat.

Top Cavity Purge Solenoid Valves (SV-25 and 26) - The valves in M-200 and M-247 were rebuilt/replaced in past reporting periods. The same valves in $M-5, M-6$ and M-199 were rebuilt this reporting period. In addition to the standard rebuild. solenoid plungers were replaced in the valves in $M-5$ and $M-6$. Four of the valve rebuilds were required due to valve failures. Two of the rebuilds were preventative. Three of the solenoid plunger replacements were required due to failure to operate. One of the replacements was preventative. The need to rebuild the solenoid valves is a result of normal wear on the valve stems, discs, seats, actuating piston seals and manual opening devices. The solenoid plungers which have been replaced had become permanently magnetized which is a common occurrence with use over time.

There have been no repairs required on the Limitorque valve gate operators since 1990. 


\section{COMPONENT STATUS REPORT (cont'd)}

\section{B. Electrical}

Several FV batteries required replacement during this reporting period. The failures were either due to age, low FV usage during this time, failure to maintain the battery on a float charge when idle, or a combination of these factors. With the FV's sitting idle and the batteries on a trickle charge the batteries don't get cycled, which tends to shorten their lifetime. The batteries have been upgraded to units with higher amperage ratings, which may improve battery performance.

FV M-5 flow totalizer does not work. This problem is documented by 4F-97-1498.

4F-96-2099/M was prepared to modify the FV (al1 FV's) closing purge sequence. The purpose of this modification is to minimize the potential for an inadvertent spread of contamination following FV interface cavity purges. At present operators manually override SV-25 to depressurize the interface cavity prior to deflating FV interface seals. The modification adds a time delay to keep the top cavity purge vent solenoid valve (SV-25) open longer than the top cavity purge supply solenoid valve $(S V-26)$, therefore leaving the top cavity in a depressurized state automatically.

Periodic annunciator card replacement to resolve erroneous alarm indications continues to be a normal part of FV maintenance.

3. Component Aging and Spare Parts Considerations (Discuss effects of system aging, long term maintenance, and spare parts availability strategy):

A. FV components affected by aging are:

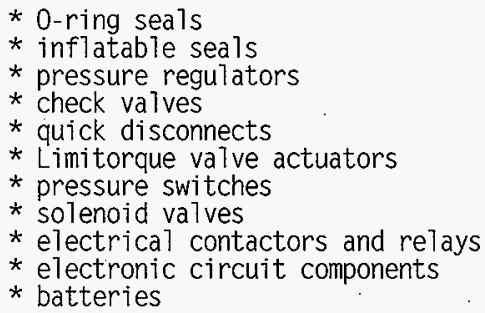

There are no plans to perform periodic replacement of the above listed items. For the most part, deterioration of the components is detectable using the established pre-operational checkout procedure. The components will be replaced when failure occurs or significant degradation is evident. The components are adequately backed up with facility spare parts, or are available from outside sources on a timely basis. 


\section{COMPONENT STATUS REPORT (cont'd)}

B. FV spare parts inventory is adequate, with the following exception:

Presently there is an adequate supply of inflatable seals in spares for the support of the FV. However, the condition of those seals is questionable since several seals withdrawn from spare parts inventory for both the Floor Valves and Plug Handling Fixture were found to be in a degraded condition. In addition to the available spare FV inflatable seals there are eight seals in a QA hold status, several of which may be usable after submitting them to visual inspection and pressure testing. The seals in QA hold were placed there due to various discrepancies found during receipt inspections performed between 1985 and 1989. The discrepancies range from physical flaws which exceed the acceptance criteria to documentation deficiencies. The seals in spares can be qualified for use on an as needed basis. Based on the available spares and a low inflatable seal failure rate, the floor valves are not considered highly vulnerable in the inflatable seal area.

\section{Standby Maintenance PTan}

1. Hardware to be repaired, replaced or upgraded:

The six work items (excluding the item which is to be canceled) listed below as Near Term Items at 5.A should be worked.

2. Frequency of routine field maintenance:

The FV electrical control cabinet inspection PMP is only performed when requested. There is presently no intent to perform that PMP during standby.

The electrical inspection PMP for FV Controllers is performed on a frequency of every 2 years. The intent is to continue that PMP through standby.

There are no other FV PMP's.

A significant preventative action, which will aid in extending $\mathrm{FV}$ battery life, is to ensure that the FV's are plugged into a 120 VAC outlet. at al1 times (except when in transit) and that the inverters are turned on. to provide a trickle charge on the batteries. This is being monitored by the Cognizant Engineer routinely on a monthly basis and also more frequently during unscheduled plant walk thru's. 
4. Analysis, Conclusions, Follow up:

A. Mechanical

Al1 of the mechanical failures during the reporting period appear to be due to normal wear and aging of the components. More failures of similar nature are expected in the future, but existing spare parts are adequate to support repairs.

B. Electrical

FV battery and annunciator failures tend to occur during times of low FV use. These failures are usually discovered during pre-operational checks.

- Failures that can be expected during times of high FV usage involve power cables, connectors, switches, alarm annunciator cards, and indicator and alarm lamps. Our spares inventory is usually adequate to support timely repair when these failures do occur. 
5. Items Requiring Action (Items on PTS, Procedures, Software, etc.):

A. Near Term Items

4F-91-516/M FV STORAGE CRIBS REQUIRE MODIFICATION

The steel and rubber FV storage cribs have a steel plate, mounted on top of the rubber mat. which compressed and sometimes damaged FV bottom seals. The modification package directed removal of the steel plates, but could not be accomplished due to very good adhesion between the steel and rubber. The steel and rubber cribs have been replaced by plywood pads. The modification package will be canceled and the steel and rubber storage cribs excessed.

4F-96-1007/W M-199 ANNUNCIATOR ACKNOWLEDGE PUSH BUTTON

The annunciator acknowledge (ACK) push button sticks whenever it is depressed. Also the ANNULR SPACES DEPRZD (annular spaces depressurized) annunciator light is not working and the annunciator lights do not stay locked in after releasing the TEST push button. The annunciator acknowledge push button needs to be replaced. Further troubleshooting and repairs are needed to fix the additional annunciator problems.

4F-96-1401/W M-199 INNER INFLATABLE SEAL PAL WON'T LIGHT WITH FVC

INNER SEALS DFLATD (inner inflatable seals deflated) alarms on M-199 and M-5 are not responding as expected when the FV's are operated from Floor Valve Controller (FVC) $\mathrm{C}-1148$. A problem with the FVC C-1148 wiring is suspected.

4F-96-1731/W M-247 ANNUNCIATOR ACKNOWLEDGE INOPERABLE

The annunciator acknowledge (ACK) push button is sticking at times and does not always make good contact. The push button needs to be replaced.
Required By/Target

PRIORITY \&

PHASE DESIGNATOR

4/BLANK

3/BLANK (NOTE 1)

3/BLANK (NOTE 1)

3/BLANK (NOTE 1) 
COMPONENT STATUS REPORT (cont'd)

A. Near Term Items (cont"d)

4F-97-932/W M-6 DRIVE SEAL ALARMING TOO LOW

DRIVE SEALS DFLATD (drive sea1s deflated) alarm is coming in at approx. 1.5 psig. Allowable setpoint range is 3.0 to 5.0 psig. Calibration of the pressure switch is required.

4F-97-1498/W M-5 FLOW TOTALIZER DOES NOT WORK

The flow counter is not indicating total flow. The problem could be with flow counter or totalizer.

4F-97-1591/W M-200 INNER INFLATABLE SEAL DEPRESSURIZED ALARM FAILING

The INNER SEALS DFLATD (inner inflatable seals deflated) alarm on M-200 is not clearing when seal pressure is raised above alarm setpoint. The audible alarm is responding as expected in both alarm and reset conditions.

B. Long Term Items

Required By/Target

PRIORITY \&

PHASE DESIGNATOR

4/SU1
4F-89-646/A REFUELING INFLATABLE SEAL QUALIFICATION PROGRAM

This administrative work item is to document the need to establish a program to periodically inspect and functionally test the refueling equipment inflatable seals in spare parts storage. This is necessary since some of the inflatable seals in storage have not been functionally tested on site. Periodic inspection and testing is desired in order to detect seal degradation due to aging.
PRIORITY \&

PHASE DESIGNATOR

3/BLANK (NOTE 1)

3/BLANK (NOTE 1)

3/BLANK (NOTE 1) 
B. Long Term Items (cont'd)

$4 F-95-41 / M$

$4 F-96-545 / W$

4F-96-2099/M
Required By/Target

PRIORITY \&

PHASE DESIGNATOR

4/BLANK (NOTE 2)

Replacement of the existing control cable plugs, CPP1 and CPP2, on the Floor Valve Controllers (FVC) with quick connect type plugs may improve the reliability of the mating receptacles. FVR1 and FVR2, on the Floor valves.

3/BLANK (NOTE 2)

Design and construction of a light weight FV bagging ring was initiated by Operations. The intent was to ease installation and removal of the bagging ring. The 400 area maintenance shop could not construct the ring as designed.

Additional design work by Engineering is required prior to resumption of work. At least two heavy (one steel and one aluminum) bagging rings are available for use, if needed.

MODIFY FV CLOSING PURGE SEQUENCE

3/BLANK (NOTE 2)

Floor Valve interface cavity (top cavity) pressure remains at 15 to 20 psig following interface cavity purges before and after FV gate opening. The retained pressure presents a risk of spreading contaminants when the interface seals are deflated. The control signal to purge the interface cavity simultaneously opens then closes both FV top cavity supply and vent valves. This results in trapping a pressurized gas volume. Presently the pressure is relieved by the Operator manually overriding SV-25 from the FV Control Panel. The mod adds a ten second delay to the SV-25 closure to al low the interface cavity pressure to be vented to CAPS.

NOTE 1 - Presentiy assigned a Phase Designator of BLANK. Should be upgraded and worked off during standby period.

NOTE 2 - Presently assigned a Phase Designator of BLANK. Should be designated SU1. 


\section{COMPONENT STATUS REPORT (cont'd)}

\section{Checkoff List}

A. Are the current plant corrective maintenance, preventive maintenance, and calibration database items all properly identified and planned actions acceptable? Yes_No No $X$

COMMENTS (exceptions): The presently assigned Phase Designators for the majority of work items in section 5.A above are a concern to Engineering and should be re-evaluated. The identified problems are not serious enough to make the FV's inoperable, but should be repaired to bring the FV's up to a higher level of operability. These minor problems have built up over the past two years. In most cases the effort involved in fixing the problem is not anticipated to be great.

B. Are all other action items (IRs, NCRs, etc.) properly identified and assigned? Yes $X$ No__ (Attach the summary of needed actions not in the database.)

COMMENTS (exceptions): NONE

C. Are near term spare parts adequate? Yes $\mathrm{X}$ No

COMMENTS (exceptions): See Item 3.B. for exceptions.

D. Are trend analysis data acceptable for continued operation? Yes X No

COMMENTS (exceptions): NONE 


\begin{tabular}{|c|c|c|c|c|c|}
\hline \multicolumn{6}{|c|}{$\begin{array}{l}\text { FLOOR VALVE MECHANICAL REPAIR HISTORY (1988 ON) } \\
\end{array}$} \\
\hline \multicolumn{4}{|c|}{ REVISED 2-4-98 } & \multicolumn{2}{|c|}{ PAGE 1 OF 4} \\
\hline COMPONENT & $M-5$ & $M-6$ & $M-199$ & $M-200$ & $M-247$ \\
\hline \multirow[t]{3}{*}{ SV-25 } & $\begin{array}{c}5-96 \\
\text { REBUILT } \\
\text { WITH VALVE } \\
\text { KIT \& } \\
\text { REPLACED } \\
\text { MANUAL } \\
\text { OPERATOR } \\
\text { 4F-94-1026 }\end{array}$ & $\begin{array}{c}9-96 \\
\text { REBUILT } \\
\text { WITH VALVE } \\
\text { KIT \& } \\
\text { REPLACED } \\
\text { MANUAL } \\
\text { OPERATOR } \\
\text { 4F-96-1398 }\end{array}$ & $\begin{array}{c}5-96 \\
\text { REBUILT } \\
\text { WITH VALVE } \\
\text { KIT \& } \\
\text { REPLACED } \\
\text { MANUAL } \\
\text { OPERATOR } \\
\text { 4F-95-1063 }\end{array}$ & $\begin{array}{c}6-91 \\
\text { REBUILT } \\
\text { WITH VALVE } \\
\text { KIT \& } \\
\text { REPLACED } \\
\text { MANUAL } \\
\text { OPERATOR } \\
\text { 4F-91-312 }\end{array}$ & $\begin{array}{c}6-90 \\
\text { REPLACED } \\
\text { MANUAL } \\
\text { OPERATOR } \\
\text { 4F-89-659 }\end{array}$ \\
\hline & \multirow{2}{*}{$\begin{array}{c}\text { 2-97 } \\
\text { REPLACED } \\
\text { SOLENOID } \\
\text { PLUNGER, } \\
\text { PILOT } \\
\text { VALVE STEM } \\
\text { ASSY. } \\
\text { PISTON ROD } \\
\text { LINK, } \\
\text { DISC, } \\
\text { SPRINGS \& } \\
\text { O-RING } \\
\text { 4F-96-1785 }\end{array}$} & $\begin{array}{c}11-96 \\
\text { REPLACED: } \\
\text { SOLENOID } \\
\text { PLUNGER, } \\
\text { PILOT } \\
\text { VALVE STEM } \\
\text { ASSY. \& } \\
0-\text { RINGS } \\
\text { 4F-96-1906 }\end{array}$ & & & \\
\hline & & $\begin{array}{c}\text { 4-97 } \\
\text { REPLACED } \\
\text { SOLENOID } \\
\text { PLUNGERS } \\
\text { (REMOVED } \\
\text { DC TYPE) } \\
\text { 4F-97-133 }\end{array}$ & & & \\
\hline
\end{tabular}


HNF-2380

Rev. 0, Page 197

\begin{tabular}{|c|c|c|c|c|c|}
\hline \multicolumn{6}{|c|}{ FLOOR VALVE MECHANICAL REPAIR HISTORY (1988 ON) } \\
\hline \multicolumn{4}{|c|}{ REVISED $2-4-98$} & \multicolumn{2}{|c|}{ PAGE 2 OF 4} \\
\hline COMPONENT & $M \cdot 5$ & $M-6$ & $M-199$ & $M-200$ & $M-247$ \\
\hline \multirow[t]{3}{*}{ SV -26} & $\begin{array}{c}5-96 \\
\text { REBUILT } \\
\text { WITH VALVE } \\
\text { KIT \& } \\
\text { REPLACED } \\
\text { MANUAL } \\
\text { OPERATOR } \\
\text { 4F-94-1026 } \\
\end{array}$ & $\begin{array}{c}\text { 9-96 } \\
\text { REBUILT } \\
\text { WITH VALVE } \\
\text { KIT \& } \\
\text { REPLACED } \\
\text { MANUAL } \\
\text { OPERATOR } \\
\text { 4F-96-1398 }\end{array}$ & $\begin{array}{c}5-96 \\
\text { REBUILT } \\
\text { WITH VALVE } \\
\text { KIT \& } \\
\text { REPLACED } \\
\text { MANUAL } \\
\text { OPERATOR } \\
\text { 4F-95-1063 }\end{array}$ & $\begin{array}{c}7-91 \\
\text { REBUILT } \\
\text { WITH VALVE } \\
\text { KIT \& } \\
\text { REPLACED } \\
\text { MANUAL } \\
\text { OPERATOR } \\
\text { 4F-91-312 }\end{array}$ & $\begin{array}{c}9-89 \\
\text { REBUILT } \\
\text { WITH VALVE } \\
\text { KIT } \\
\text { 4F-89-2427 }\end{array}$ \\
\hline & \multirow[t]{2}{*}{$\begin{array}{c}2-97 \\
\text { REPLACED } \\
\text { SOLENOID } \\
\text { PLUNGER, } \\
\text { PILOT' } \\
\text { VALVE STEM } \\
\text { ASSY. } \\
\text { DISC', } \\
\text { SPRINGS \& } \\
\text { 0-RING } \\
\text { 4F-96-1785 }\end{array}$} & $\begin{array}{c}11-96 \\
\text { REPLACED } \\
\text { SOLENOID } \\
\text { PLUNGER, } \\
\text { PILOT } \\
\text { VALVE STEM } \\
\text { ASSY. \& } \\
\text { 0-RINGS } \\
\text { 4F-96-1906 } \\
\end{array}$ & & \multirow[t]{2}{*}{$\begin{array}{c}4-93 \\
\text { REPLACED } \\
\text { VALVE } \\
\text { 4F-92-2143 }\end{array}$} & \\
\hline & & $\begin{array}{c}\text { 4-97 } \\
\text { REPLACED } \\
\text { SOLENOID } \\
\text { PLUNGERS } \\
\text { (REMOVED } \\
\text { DC TYPE) } \\
\text { 4F-97-133 }\end{array}$ & & & \\
\hline
\end{tabular}




\begin{tabular}{|c|c|c|c|c|c|}
\hline \multicolumn{6}{|c|}{ FLOOR VALVE MECHANICAL REPAIR HISTORY (1988 ON) } \\
\hline \multicolumn{4}{|c|}{ REVISED 2-4-98 } & \multicolumn{2}{|c|}{ PAGE 3 OF 4} \\
\hline COMPONENT & $M-5$ & $M-6$ & M-199 & $M-200$ & M-247 \\
\hline SV -36 & $\begin{array}{c}1-90 \\
\text { REPLACED } \\
\text { 4F-89-890 }\end{array}$ & & $\begin{array}{c}8-89 \\
\text { REPLACED } \\
4 \mathrm{~F}-88-3376 \\
\end{array}$ & $\begin{array}{c}6-96 \\
\text { REPLACED } \\
4 \mathrm{~F}-94-1360 \\
\end{array}$ & $\begin{array}{c}12-94 \\
\text { REPLACED } \\
4 \mathrm{~F}-94-49 \\
\end{array}$ \\
\hline \multirow[t]{3}{*}{$\begin{array}{l}\text { CONSTANT } \\
\text { PURGE } \\
\text { SYSTEM }\end{array}$} & $\begin{array}{c}5-94 \\
\text { REPLACED } \\
\text { FX-36 } \\
\text { PI }-18 \\
\text { CLEANED } \\
0-34 \\
0-36 \\
\text { CV-34 } \\
\text { CV-36 } \\
\text { 4F-94-426 }\end{array}$ & $\begin{array}{c}2-91 \\
\text { CLEANED } \\
\text { FX-36 } \\
0-34 \\
0-36 \\
\text { CAL'D } \\
\text { PI-18 } \\
4 \text { F }-90-2044\end{array}$ & \multirow[t]{3}{*}{$\begin{array}{c}5-96 \\
\text { REPLACED } \\
\text { FX-36 } \\
\text { CLEANED } \\
0-34 \\
0-36 \\
\text { CV-34 } \\
\text { CV-36 } \\
4 \text { F-95-1063 }\end{array}$} & \multirow[t]{3}{*}{$\begin{array}{c}6-96 \\
\text { REPLACED } \\
\text { FX-36 } \\
\text { CLEANED } \\
0-34 \\
0-36 \\
\text { CV-34 } \\
\text { CV-36 } \\
4 \text { F- }-94-1360\end{array}$} & $\begin{array}{c}12-94 \\
\text { REPLACED } \\
\text { FX-36 } \\
\text { CLEANED } \\
0-34 \\
0-36 \\
\text { CV-34 } \\
\text { CV-36 } \\
0-36 \text { BENT } \\
\text { 4F-94-49 } \\
\end{array}$ \\
\hline & \multirow{2}{*}{$\begin{array}{c}5-96 \\
\text { REPLACED } \\
\text { FX-36 } \\
\text { CLEANED } \\
0-34 \\
0-36 \\
\text { CV-34 } \\
\text { CV-36 } \\
4 \text { F- } 94-1026 \\
\end{array}$} & \multirow{2}{*}{$\begin{array}{c}9-96 \\
\text { REPLACED } \\
\text { FX-36 } \\
\text { CLEANED } \\
0-34 \\
0-36 \\
\text { CV-34 } \\
\text { CV-36 } \\
\text { 4F-96-1398 } \\
\end{array}$} & & & $\begin{array}{c}5-96 \\
\text { TESTED SAT } \\
\text { 4F-96-632 }\end{array}$ \\
\hline & & & & & $\begin{array}{c}\text { 6-97 } \\
\text { TESTED SAT } \\
\text { 4F-96-1121 }\end{array}$ \\
\hline \multirow[t]{3}{*}{ PCV-31 } & \multirow[t]{3}{*}{$\begin{array}{c}2-90 \\
\text { REPLACED } \\
4 F-89-3489\end{array}$} & \multirow{3}{*}{$\begin{array}{c}9-96 \\
\text { TESTED } \\
\text { SAT } \\
4 \mathrm{~F}-96-1398\end{array}$} & $\begin{array}{c}9-89 \\
\text { REPLACED } \\
\text { 4F-89-2336 } \\
\end{array}$ & $\begin{array}{c}6-91 \\
\text { REPLACED } \\
4 \mathrm{~F}-91-312\end{array}$ & $\begin{array}{l}\text { 7-92 } \\
\text { TESTED SAT } \\
\text { 4F-91-2992 }\end{array}$ \\
\hline & & & $\begin{array}{c}5-96 \\
\text { TESTED } \\
\text { SAT } \\
4 F-95-1063\end{array}$ & $\begin{array}{c}11-94 \\
\text { TESTED } \\
\text { SAT } \\
4 \mathrm{~F}-94-816\end{array}$ & $\begin{array}{l}5-96 \\
\text { TESTED SAT } \\
\text { 4F-96-632 }\end{array}$ \\
\hline & & & & $\begin{array}{c}\text { 6-96 } \\
\text { REPLACED } \\
\text { 4F-94-1360 }\end{array}$ & $\begin{array}{c}6-97 \\
\text { TESTED SAT } \\
\text { REPLACED } \\
\text { 4F-96-1121 } \\
\end{array}$ \\
\hline $\begin{array}{l}\text { LIMITORQUUE } \\
\text { DECLUTCH } \\
\text { LATCH SUB- } \\
\text { ASSEMBLY }\end{array}$ & $\begin{array}{c}2-90 \\
\text { REPLACED } \\
4 \mathrm{~F}-89-3501\end{array}$ & & $\begin{array}{c}\text { 8-88 } \\
\text { REPAIRED }\end{array}$ & & $\begin{array}{c}10-89 \\
\text { REPLACED - } \\
\text { NO FIX } \\
4 F-86-845\end{array}$ \\
\hline $\begin{array}{c}\text { COVER } \\
\text { PLATE } \\
\text { BOTTOM } \\
\text { SEAL ASSY }\end{array}$ & $\begin{array}{c}3-91 \\
\text { REPLACED } \\
\text { 4F-91-393 }\end{array}$ & & & & \\
\hline
\end{tabular}


HNF-2380

Rev. 0, Page 199

\begin{tabular}{|c|c|c|c|c|c|}
\hline \multicolumn{6}{|c|}{ FLOOR VALVE MECHANICAL REPAIR HISTORY (1988 ON) } \\
\hline \multicolumn{4}{|c|}{ REVISED 2-4-98 } & \multicolumn{2}{|c|}{ PAGE 4 OF 4} \\
\hline COMPONENT & $M-5$ & $M-6$ & M-199 & $M-200$ & $M-247$ \\
\hline \multirow[t]{2}{*}{$\begin{array}{l}\text { INFLATABLE } \\
\text { SEALS }\end{array}$} & & $\begin{array}{c}10-89 \\
\text { UPPER } \\
\text { INNER } \\
\text { REPLACED } \\
\text { 4F-89-2148 }\end{array}$ & & & \\
\hline & & $\begin{array}{c}\text { 9-96 } \\
\text { LOWER } \\
\text { INNER LINE } \\
\text { LEAKAGE } \\
\text { REPAIRED } \\
\text { 4F-96-1398 } \\
\end{array}$ & & & \\
\hline \multirow[t]{3}{*}{$\begin{array}{l}\text { CHECK } \\
\text { VALVES }\end{array}$} & \multirow{2}{*}{$\begin{array}{c}8-94 \\
\text { REPLACED } \\
\text { CV-01 } \\
\text { CV-07 } \\
\text { CV-15 } \\
\text { CV }-18 \\
\text { CV-20 } \\
\text { REPAIRED } \\
\text { CV-10 } \\
4 \text { F- } 94-844\end{array}$} & \multirow{2}{*}{$\begin{array}{c}9-96 \\
\text { TESTED SAT } \\
\text { CV }-01 \\
\text { CV-07 } \\
\text { CV-10 } \\
\text { CV-15 } \\
\text { CV-18 } \\
\text { CV-20 } \\
4 F-96-1398\end{array}$} & & \multirow{2}{*}{$\begin{array}{c}2-92 \\
\text { REBUILT OR } \\
\text { REPLACED } \\
\text { CV-01 } \\
\text { CV-07 } \\
\text { CV-10 } \\
\text { CV-15 } \\
\text { CV-18 } \\
\text { CV }-20 \\
\text { 4F-91-2095 }\end{array}$} & $\begin{array}{c}1-94 \\
\text { REPLACED } \\
\text { CV-01 } \\
\text { CV-07 } \\
4 F-92-704\end{array}$ \\
\hline & & & & & $\begin{array}{c}12-94 \\
\text { REPLACED } \\
\text { CV-10 } \\
\text { REPAIRED } \\
\text { CV-7 } \\
\text { SEALING } \\
\text { SURFACE } \\
\text { 4F-94-49 } \\
\end{array}$ \\
\hline & $\begin{array}{c}5-96 \\
\text { REPLACED } \\
\text { CV }-25 \\
\text { CV }-29 \\
4 F-94-1026 \\
\end{array}$ & $\begin{array}{c}9-96 \\
\text { REPLACED } \\
\text { CV }-25 \\
\text { CV-29 } \\
\text { 4F- } 96-1398 \\
\end{array}$ & $\begin{array}{c}5-96 \\
\text { REPLACED } \\
\text { CV }-25 \\
\text { CV-29 } \\
4 \text { F- } 95-1063\end{array}$ & $\begin{array}{c}6-96 \\
\text { REPLACED } \\
\text { CV-25 } \\
\text { CV-29 } \\
4 F-94-1360\end{array}$ & $\begin{array}{c}\text { 6-97 } \\
\text { REPLACED } \\
\text { CV }-25 \\
\text { CV-29 } \\
4 \text { F- } 96-1121\end{array}$ \\
\hline MISC. & & $\begin{array}{c}\text { 6-96 } \\
\text { BOTTOM } \\
\text { COVER } \\
\text { BUFFER } \\
\text { LEAKAGE } \\
\text { REPAIRED } \\
\text { 4F-96-948 }\end{array}$ & & $\begin{array}{c}6-96 \\
\text { REPLACED } \\
\text { ALL } 3 \\
\text { CAVITY } \\
\text { SAMPLE QD } \\
\text { 0-RINGS } \\
\text { 4F-95-666 }\end{array}$ & $\begin{array}{c}5-96 \\
\text { REPLACED } \\
\text { HV }-33 \\
4 F-96-632\end{array}$ \\
\hline
\end{tabular}

NOTE - SHADED BLOCKS INDICATE WORK TO BE DONE. 
COMPONENT STATUS REPORT

FOR

PLUG HANDLING FIXTURE

Period Covered: $9-22-95$ through 1-31-98

Date Reported: $\underline{2-19-98}$

Component: Plug Handling Fixture (41-8)

Approva?s

Cognizant Engineer(s): Mechanical: DJ Gerkensmeyer Electrical: MO Anglesey

Cognizant Manager(s): Mechanical: SW Hiller

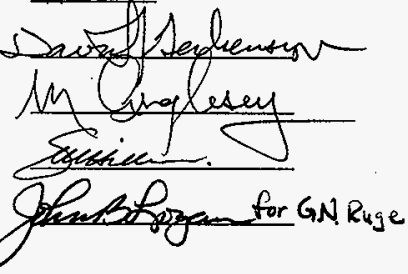

1. Summary of Component Status:

The Plug Hand7ing Fixture (PHF) M-66 is operational.

Control Panel C-697 is operational.

2. Trends Observed:

A. Mechanical

The PHF has been essentialiy trouble free during the reporting period. It has gone through approximately 100 plug cycles (plug retrieval into PHF thru plug discharge into a facility or storage location) in the 4 years since it's last major overhaul in March of 1994.

The back pressure regulator (PCV-03) is showing signs that it may be sticking and needs to be replaced.

The twelve 5/8-11UNC-2A hex head cap screws on the PHF Lifting Jig and two 1/2-13UNC-2A hex head cap screws at the top of the PHF access ladder were found to be suspect in May of 1997 . New hex head cap screws and hex nuts were procured and installed on the PHF Lifting Jig. New head cap screws were obtained from the 4713B Building shop stock and installed on the PHF access ladder.

An incident occurred in May of 1997 where a grapple drive was interrupted by an errant REEL EXTENDED shutdown. It was determined that the shutdown was probably due to a stack up of conditions in the grapple drive system components set off by an interrupted down ward drive of the grapple at an FTP port. The condition was corrected by performing a closely monitored up drive of the grapple. The REEL EXTENDED condition cleared when the weight of the shield collar was picked up near the top of the drive. The condition has not recurred. If it does, it can easily be recovered from. 


\section{B. Electrical}

The system has been operating incident free during this past reporting period. The batteries used for power supply backup wiTl no longer hold a charge and are scheduled to be replaced.

3. Component Aging and Spare Parts Considerations (Discuss effects of system aging, long term maintenance, and spare parts availability strategy):

A. PHF components affected by aging are: * 0-ring seals

* inflatable seals

* pressure regulators

* electrical contactors and relays

* hoist drive motors

* electronic circuit components

* batterjes

Deterioration of PHF 0-ring seals and inflatable seals is easily monitored using the existing procedural leak checks and normal visual inspections during use. There is no need to plan for a periodic replacement of seals. Replacement 0 -rings are readily available from facility spare parts.

The pressure regulators, electrical contactors and relays, hoist drive motors and electronic circuit components are all well backed up with on site spare parts and will be replaced when fajlure occurs or significant degradation is evident.

Batteries for the back up power supply are not carried in the on site spare parts inventory. Storage of the batteries in an inactive state has been unsuccessful. Replacement batteries can be obtained in a timely manner from outside suppliers when needed. Failure of the battery does not render the PHF inoperable.

B. The PHF spare parts inventory is adequate, with the following exceptions:

Presently there is an adequate number of inflatable seals in spares for the support of the PHF. However, the condition of those seals is questionable since several seals withdrawn from spare parts inventory for both the PHF and Floor Valves have been found to be in a degraded condition. Also the PHF Bottom Inner and Outer Inflatable Seals spares are not directly supported by PHF spare parts. Replacement seals can be obtained from the CLEM spares complement, but the balance on hand is marginal for supporting seal replacement in both machines. The seals in spares can be qualified for use on an as needed basis. Based on the available spares and a low inflatable seal failure rate, the PHF is not considered highly vulnerable in the inflatable seal area.

The spare grapple hoist drive motor brake, which was depleted during the 1994 overhauT, has not been replaced in spares yet. This should be done immediately.

The particular model of un-interruptable power supply used by the PHF is no longer being manufactured. There is stil1 one complete power supply in spare parts inventory at this time. 


\section{COMPONENT STATUS REPORT (cont'd)}

C. Standby Maintenance Plan

1. Hardware to be repaired, replaced or upgraded:

The PHF battery replacement work item listed below as Near Term Items at 5.A should be worked.

In addition, the spare grapple hoist drive motor brake discussed at $3 . \mathrm{B}$ above should be replaced.

2. Frequency of routine field maintenance:

There are no PHF PMP's. There is presently no intent to perform any preventative maintenance during standby.

4. Analysis, Conciusions, Followup:

A. Mechanical

The PHF mechanical components have been relatively trouble free during this reporting period. It is expected that the PHF will support standby/startup/shutdown with few mechanical problems.

\section{B. Electrical}

The PHF electrical components have been relatively trouble free during this reporting period. It is expected that the PHF wi11 support standby/startup/shutdown with few electrical problems. 
COMPONENT STATUS REPORT (cont' $d$ )

5. Items Requiring Action (Items on PTS, Procedures, Software, etc.):

A. Near Term Items

4F-90-2975/A PHF GRAPPLE POSITION INDICATION CAL PROCEDURE

This package is to be canceled. Future calibrations will be done using work package instructions, as they have been done in the past.

4F-97-1132/W PHF BATTERIES NEED REPLACEMENT

The PHF backup batteries have a low output voltage of $78 \mathrm{VDC}$. The acceptable range is 79 to 83 VDC. Replacement of the batteries is required.

B. Long Term Items

4F-89-646/A REFUELING INFLATABLE SEAL QUALIFICATION PROGRAM

This administrative work item is to document the need to establish a program to periodically inspect and functionally test the refueling equipment inflatable seals in spare parts storage. This is necessary since some of the inflatable seals in storage have not been functionally tested on site. Periodic inspection and testing is desired in order to detect seal degradation due to aging.
Required By/Target

PRIORITY \& PHASE DESIGNATOR

4/BLANK

$3 / 98-1$

Required By/Target

PRIORITY \&

PHASE DESIGNATOR

4/SUI 
B. Long Term Items (cont'd)

\section{F-92-1753/W ANALYZE INTERFACE OF PHF TO IEM CELL} 28" VALVE

An adapter plate which would allow the PHF to interface with the IEM Cel1 28-Inch Port for the purpose of transferring the BLTC Drip Cup Transfer Container (DCTC) into and out of the IEM Cell was needed. The PHF Adapter has been fabricated. This package provides instructions for the fit-up checks of the new PHF Adapter on the. IEM Cell 28-Inch Port.

4F-97-1197/W M-66 BACK PRESSURE REG PCV-03 NEEDS ADJ

The PHF back pressure regulator (PCV-03), which acts in conjunction with the argon supply regulator (PCV-01) to control shel1 pressure, is showing signs that it may be sticking and needs to be replaced. the check valve $(\mathrm{V}-08)$ downstream of $\mathrm{PCV}-03$ should also be replaced.

4F-97-1298/W PHF INDICATORS NEED LAMP TEST FEATURE

Presently the indicators located at the top of the PHF Control Cabinet (4 red indicators and 6 white indicators) have no 1 amp test feature. Typically a burnt out lamp is not discovered until the PHF is in the middle of plug moves. A lamp test feature is needed for the indicating lamps. Also consider replacing the existing incandescent lamps with longer lasting Tamps, such as LED's.
Required By/Target

PRIORITY \&

PHASE DESIGNATOR

3/SU1

3/SU1

3/SU1 
6. Checkoff List

A. Are the current plant corrective maintenance, preventive maintenance, and calibration database items all properly identified and planned actions acceptable? Yes $\times$ No

COMMENTS (exceptions): NONE

B. Are a 11 other action items (IRs, NCRs, etc.) properly identified and assigned? Yes X No__ (Attach the summary of needed actions not in the database.)

COMMENTS (exceptions): NONE

C. Are near term spare parts adequate? Yes $X$ No

COMMENTS (exceptions): See Item 3.B. for exceptions.

D. Are trend anajysis data acceptable for continued operation? Yes $X$ No

COMMENTS (exceptions): NONE 


\section{ANNUAL SYSTEM ASSESSMENT REPORT \\ for \\ SYSTEM 41-10 Sodium Removal System (SRS)}

Date of This Report $2 / 2 / 98$

Date of Previous Report N/A

Cognizant Engineer

Cognizant Engineering Manager
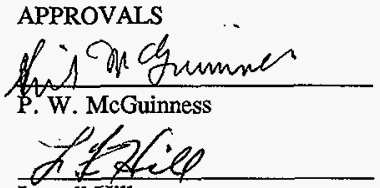

Lowell Hill
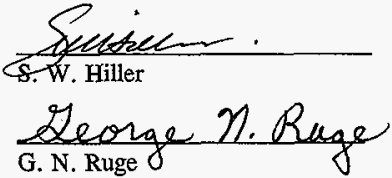

1. $\mathrm{SCOPE}$

System/Component

$41-10 / \mathrm{T}-100$

IEM Cell Sodium Removal System

2. SUMMARY EVALUATION (Provide a general assessment of the overall health of the system. Include a discussion of the system's minimum operable equipment from plant procedure $\mathrm{PN}-7$.)

The IEM Cell Sodium Removal System (SRS) is currently operable but administratively tagged out pending completion of work packages and the annual SRS Hydrostatic leak test required per operating procedure II-89-1. The sodium removal system washed 55 components, mostly Ident 69 pin containers, between January and September, 1997 to support FFTF fuel offload. The last assembly washed in 1997 was Ident $69-\mathrm{C} \# 24$ on 8/28/97.

The SRS Ion Exchange (IX) System operated flawlessly and removed sodium and contamination from the $126^{\text {th }}$ batch of wash water since it was installed and started in December, 1995. IX resin tanks \#1 and 2 and part of \#3 are depleted and can no longer remove sodium from the wash water. Resin tanks \#1 and 2 will be changed out in the Spring of 1998. The life expectancy of the resin tanks is better than expected (about 55 assembly washes per tank vs 40 expected).

In September, 1997, a high contamination area was found in cell 201 (ref. Section 5A). Also in September, water was discovered on the discharge side of the T-101 pressure relief valve (PSV677) during the annual A-I inspection. The SRS has been shut down for maintenance since September, 1997 and will continue to be shut down until PSV-677 relocation (4I-97-143/M) and HV-141 repair (4I-97-128) are completed during 98-1 work phase and the system is hydrostatically leak tested. Also, two IX system depleted resin tanks will be changed out during 98-2 work period 
HNF-2380

Rev. 0, Page 207

in preparation for operating the SRS again in July and/or August, 1998 to wash sheared OTA pieces.

Whether the FFTF proceeds with shutdown or startup, the Sodium Removal System is planned for further use. With the shutdown option, about $2 / 3$ of the fuel assemblies still need to be washed. With startup, the SRS will likely be used to support the increased number of assemblies that will be removed from the reactor plus tritium targets. Thus the system needs to be maintained in a fully working condition for at least several years to come.

3. ITEMS REOUIRING ACTION (Items on PTS, Procedures, Software, etc.)

\section{A. Near Term Items}

$\underline{\text { Require By }}$

- Replace HV-141; 4I-97-128/M

- Evaluate water in T-101 Pressure Relief Valve PSV-677; 4I-97-145/A

98-1R

- Flush new IX System Resin Tanks; 4F-97-254/W

98-1R

- Add HEPA Filters to IX Machine Dewatering Skid; 4I-95-083/W

98-1C

98-1C

- Re-evaluate dose rates in Cell 242 (for IX resin tank removal); 4I-96-059/A

$98-1 \mathrm{C}$

- HV-161 not operating properly; 4I-97-105/W

98-2M

- T-101 PSV relocation; 4I-97-143/M

$98-1 \mathrm{M}$

B. Long Term Items

Required By

Mechanical items

- Release new OMM for IX system, 4F-95-772/A

Res, Limited

(pri. 4-1)

- Improve pressure control for IX System; 4I-95-85-/M

- Improve SRS T-101/T-102 vent path to CAPS; $4 \mathrm{I}-96-15 / \mathrm{M}$

44

- Need tool to clean SRS T-100 Sealing Surface; $41-96-82 / W$

Res. Limited

- Down flow cooling hose needs handling tab; 4I-85-344/W

- SRS HV-25i leaks; 4I-97-67 (pri. 3-1)

Res. Limited (pri. TBD)

Control System Items:

4I-89-173, Need Alarm Overrides for Nuisance Alarms

Pri 3-blank 4I-95-99/M, Molytek Printer/Recorder failed

Pri 2-blank

4I-96-138/L, (Remove) Limited Mod for Ident-69 containers

Pri 3 blank

4I-96-1187, Correct Alarm window wording

Pri 2-blank

4. TRENDS (Discuss trended parameters. See Appendix $\mathrm{K}$ for typical parameters which can be used for trending studies.) See attached.

The back pressure flow characteristics of the Ametek solenoid operated valves continues to bother the EDS operators and results in work packages such as HV-141 (4I-97-019.W) in January and HV-251 (4I-97-067/W), in April of 1997. Also, the characteristic of the Ametek solenoid valves to jam when operated in a horizontal position cause these valves to occasionally stick. HV-181 stuck in April of 1996 and HV-251 (4I-97-67) in April of 1997, plus HV-161 in-cell in July of 1996 (4I- 
HNF-2380

Rev. 0, Page 208

96-119/W). A different problem which has arisen with one Ametek valve is a solenoid valve (HV-161) which overheats and stalls during operation (4I-97-105/W).

Another unexplained trend occurred on the IX system Resin Tank \#1 during late 1996 and early 1997. As expected, the dose rate measured on the exterior of Resin Tank \#1 read approximately zero before the $1^{\text {st }}$ assembly was washed for fuel offload and waste water was recycled through the IX system on $11 / 17 / 95$. As expected, the dose rate increased as more assemblies were processed and after Resin Tank \#1's sodium removal capacity was depleted after processing wash water from about 55 fuel assemblies in June of 1996, the dose rate at the top of Resin Tank \#1 had increased to about $13 \mathrm{mR} / \mathrm{hr}$ and the hottest spot was about $200 \mathrm{mR} / \mathrm{hr}$ near Resin Tank \#1 resin line.

Although resin tank \#1 remained on-line during continued fuel assembly washing, it was expected that the dose rates would level off because Resin Rank \#1 was not continuing to remove sodium. By October 1996, Resin Tank \#1 dose rates had increased to about $22 \mathrm{mR} / \mathrm{hr}$ at the top and 340 $\mathrm{mR} / \mathrm{hr}$ at the hot spot.

The Radiological Safety Group decided to make Cell 242 a High Radiation Area. Engineering decided to valve out Resin Tank \#1 inlet and outlet in October, 1996 to prevent water flow into or out of Resin Tank \#1. Resin Tank \#1 dose rates continued to increase into 1997 when in February the peak hot spot on Resin Tank \#1 reached $1.2 \mathrm{R} / \mathrm{hr}$ and the dose rate on top was $100 \mathrm{mR} / \mathrm{hr}$. It was verified that Resin Tank \#1 was indeed isolated and concluded that some unknown dynamic processes must be going on in Resin Tank \#1 to rearrange and concentrate the contamination. A high radiation cover was installed over resin tanks \#1, 2, and 3 in April of 1997 per work package 4F-96-2138/M so that the entire Cell 242 was no longer a High Radiation Area. In May of 1997, Resin Tank \#1 was "blown down" per work package 4I-97-43 to remove the water and stop whatever process was going on. The peak dose rate on Resin Tank \#1 was reduced to $850 \mathrm{mR} / \mathrm{hr}$ and the dose rate on top increased to $180 \mathrm{mR} / \mathrm{hr}$. The locked cover has remained in place since and the dose rate atop the cover over Resin Tank \#1 has remained at about $80 \mathrm{mR} / \mathrm{hr}$ to this date. Of course, the dose rate outside the IX Resin Tank shield in Cell 242 has always remained low (less than $5 \mathrm{mR} / \mathrm{hr}$ ).

5. SYSTEM AGING SPARE PARTS CONSIDERATIONS, AND LONG TERM MAINTENANCE PHILOSOPHY

A. Discuss effects of system aging.

Mechanical System

As discussed in Section 4.0 Trends, the SRS valves, especially the Ametek solenoid valves, continue to age and deteriorate.

Replacement of these valves should be considered necessary should FFTF restart occur.

It is also possible that all seals, gaskets and thread sealant need to be replaced in cells 201205. During a cell entry in September of 1997 to perform the annual Authorized Inspector examination of pressure relief valves, the RCT discovered much higher level of contamination on the floor of cell 201 (400,000 dpm vs. 1,000 dpm, Ref. RPR \# X-97-011). Although there appeared to be evidence of a dried water spot on the floor, no other indication of the leak location has been discovered, and leak tests performed showed the system was leak tight. 
It appears that some part of fuel assembly washing operation may have allowed a small leak to open up which wasn't evident during the normal SRS leak test. Troubleshooting will continue when core component washing continues in 1998.

\section{Control System}

The relays and operator switches are generally beginning to show symptoms of wearing out. Some relays have become "stuck", and many operator switches are difficult to operate, both of which are expectable "wear-out" indications.

B. Discuss the strategy for near term spare parts and their availability strategy.

\section{Mechanical System}

Most items required for normal maintenance are still available in FFTF Spare Parts.

Ametek no longer fabricates the types of valves we use on the SRS and new spares will not be available after/if our existing stock becomes depleted. If a spare part is required but not available, it will be evaluated on a case-by-case basis.

A spare SRS blower and spare water pump need to have PMP's written when the schedule directs so that the spares may be lubricated and verified operable.

\section{Control System}

Spares are readily available for the basic parts like operator switches, indicators and relays. The more complex components are less repairable, and spares may not be available. No spare is available for the failed Molytek Printer/Recorder, and the unit is no longer available. Replacement is being considered for inclusion in a more general upgrade discussed in $\mathrm{C}$ below.

C. Standby Maintenance Plan: Discuss a plan which ensures essential system functions for standby are provided and minimizes equipment degradation. Assume the standby period extends for the next one to two years. Include in the plan, as a minimum: 1) the identification of hardware to be repaired, replaced, or upgraded; and 2) the frequency of routine field maintenance, ensuring material and spare parts are identified to support these activities (i.e., refurbish pumps, etc.).

\section{Mechanical System}

The current plan is to continue to use exiting spares for SRS mechanical maintenance/repair throughout standby. Depleted spare parts will be replenished as required. Parts which cannot be replaced (e.g. Ametek Solenoid valves) will be evaluated on a use-by-case basis. If a restart order is given to FFTF, new, more current solenoid valves need to replace the existing welded-in-place Ametek valves.

A new PMP needs to be written and performed annually to lubricate and check the SRS spare blower(s) and water pump.

\section{Control System}

The control system work packages noted in section 3.B above, are indicative of a growing need to upgrade the control system. The failed Molytek recorder cannot be repaired or directly replaced; a modern solution would instead utilize computer-based Data Acquisition of the signals and would provide a general History and Trending capability. The other work 
HNF-2380

Rev. 0, Page 210

packages also point to a limited flexibility to adapt to changes. Panel meters do not stay in calibration and are difficult to read, and there have also been some failures of the control switches and relays. Repair is complicated by the numerous power sources that feed the cabinet and the need to literally get inside (a confined space) to perform the repair.

Heavy use over the past few years has also pointed out some ergonomic problems with the operator interface. Some operators take shifts longer to perform certain activities because of differences in interpreting the displays. In summary, an improved operator interface would appear to improve the consistency and integrity of the wash.

As a result of the above issues, a more general upgrade is being considered, which would include resolution of the open action items. The incremental cost above just trying to repair individual problems may make the more general upgrade actually the more cost effective solution.

\section{CHECKOFF LIST}

A. Accessible parts of the entire system or component have been thoroughly walked down at least once in the past 30 days to view current performance, equipment status and condition. Yes No $\underline{X}$.

COMMENTS (exceptions):

Only C-1167 has been walked down in the past 30 days. Cells 242,201 , and 205 have not been accessed by the engineer due to other higher priority work and other work ongoing (4I97-143).

B. Are there any conditions which might require limitations different from operating limits as defined in the SDDs, the FSAR, or the Plant Technical Specifications? Yes X No

\section{COMMENTS (exceptions):}

The ability to reliably provide backup cooling for washing a high heat assembly may be questionable at the present time. This is not presently an issue since there are no high heat assemblies which require washing. For restart, the need for backup cooling would be reassessed and may require some FSAR and system re-work.

C. Are there trip settings, set points, interlocks, etc., that should be changed from those currently established? Yes X No

COMMENTS (exceptions):

See 4I-89-173, Nuisance Alarms. . Disposition is being delayed pending a decision as to whether this can be included in a more general upgrade (reference discussion in section 5-C above). 
D. Are there interface areas which have not performed acceptably, which require resolution? Yes_X No

COMMENTS (exceptions):

See discussion in sections 3 and 5 .

E. Are there temporary plant or procedural conditions which will and should remain in place? Yes_ N No

Attach list of MOD(L)/ECN(L)s, and OSPs that are currently active. Provide justification for continuing temporary MOD (L)s and ECN (L)s.

COMMENTS (exceptions):

4I-96-138/L, which was installed for washing Ident-69 assemblies is still installed. Operations desires part of the Mod to be installed permanently. Disposition is being delayed pending a decision as to whether this can be included in a more general upgrade (reference discussion in section 5-C above).

F. Is any retesting or special testing (e.g., OSP) required? Yes $\mathrm{X}$ No

COMMENTS (exceptions):

Special testing in the form of an ESP or ATP will be required for washing of sheared OTA pieces in the SRS next year. The washing/drying cycle for these $5^{\prime}-0^{\prime \prime}$ to $11^{\prime}-1$ " long OTA's with pinched off ends may require changing and some of the first washed pieces will require visual examination inside and out to verify they are clean of sodium.

G. Are the current plant corrective maintenance, preventive maintenance, and calibration database items all properly identified and are planned actions acceptable? Yes $\mathrm{X}$ No

COMMENTS (exceptions):

New PMP's are still required for 2 spare parts (ref. Section 5).

H. Are all other action items (NCRs, IRs, etc.) properly identified and assigned?

Yes. $X$ No__ (attach the summary of needed actions not in the data base)

COMMENTS (exceptions):

NCR \#053938 will not be closed until PSV-677 modification is complete.

I. Are there any special operating considerations? Yes $\mathrm{X}$. No

List or Reference: :

SRS is currently tagged out pending completion of PSV-677 relocation and HV-141

replacement. Also, HV-161 operation is limited until it is repaired per 4I-97-105. 
J. Are near term spare parts adequate? Yes $\underline{X}$ No

COMMENTS (exceptions):

See Section 5B.

K. Have any safety issues (radiological, industrial) been identified that remain unresolved? Yes $\underline{\mathrm{X}} \mathrm{No}$

COMMENTS (exceptions):

- The source of the radioactive contamination cell $201 / 205$ has not yet been identified.

- Work on the Control System requires entry inside the cabinet, which is a confined space and does not meet NEC requirements for access clearance. Further, there are many different power sources that feed the cabinet. While there are methods to permit working on the system, it would be desirable to improve this situation.

- NCR - 053938 on PSV-677 must still be closed out.

L. Have all component data been entered into the Plant information database?

Yes $X$ No

COMMENTS (exceptions):

All presently known SRS equipment and instruments, including the Ion Exchange System, are on the component index. Some instrument recalibration bases require revision.

M. Have applicable SISI inspections been conducted? Yes_X No_

COMMENTS (exceptions):

ASME Code required bi-annual inspection of the SRS PSV's was successfully completed on PSV-678 (argon supply vent) and PSV-677 (T-101 vent). In-cell T-101 pressure relief valve PSV-623 was last tested in CY 1996 and will not require inspection until next year. An NCR written to document water found up stream of PSV-677 has been resolved.

ASME coded tanks T-101, T-102, and in-cell T-101 were successfully inspected this year, along with all of the Ion Exchange Resin Tanks (1-6) in Cell 242.

The SRS C.I.V. valves are on hold during shutdown and do not require inspections. 
N. Has a cleanliness evaluation been completed? Yes__ No X

Are any issues still unresolved? Yes No (TBD)

COMMENTS (exceptions):

Until the schedule permits a cleanliness evaluation to be performed, no items have or will be identified.

\section{REFERENCES}

RPR \#X-97-011

NCR \#053938.

\section{ATTACHMENTS}

(Attach any CSRs, data sheets showing system performance or other material demonstrating the substantive nature of this review).

RPR \#X-97-011

NCR \#053938. 
HNF-2380

Rev. O. Page 214

RADIOLOGICAL PROBLEM REPORT (RPR)

\begin{tabular}{|c|c|c|c|}
\hline \multirow{3}{*}{$\begin{array}{l}\text { Actionee: } \\
\text { D. W. Brown }\end{array}$} & & & Serial No.: \\
\hline & \multirow{2}{*}{$\begin{array}{l}\text { MSIN: } \\
\text { N2-30 }\end{array}$} & \multirow{2}{*}{$\begin{array}{r}\text { Org. Code: } \\
18110\end{array}$} & Issue Date: $09 / 23 / 97$ \\
\hline & & & ONC Report No:: N/A \\
\hline \multirow{6}{*}{$\begin{array}{l}\text { Distribution: } \\
\text { C. E. Alderson } \\
\text { P. S. Barajas } \\
\text { D. W. Brown } \\
\text { D. R. Burstad } \\
\text { S. V. Doebler } \\
\text { M. E. Eby } \\
\text { E. F. Loika } \\
\text { W. L. Marshat } \\
\text { L. A. Nelsen } \\
\text { B. OTdfield } \\
\text { R. E. Day-Phalen } \\
\text { P. R. Prevo } \\
\text { W. V. Witherspoon III }\end{array}$} & \multirow{6}{*}{$\cdot \cdot$} & \multirow{6}{*}{$\begin{array}{l}\text { MSIN: } \\
\text { B1-17 } \\
\text { G1-17 } \\
\text { N2-30 } \\
\text { N2-50 } \\
\text { N2-34 } \\
\text { N2-57 } \\
\text { N2-51 } \\
\text { N2-57 } \\
\text { N2-50 } \\
\text { R3-56 } \\
\text { G6-71 } \\
\text { N2-10 } \\
\text { N2-33 }\end{array}$} & Date Discovered: $\quad 09 / 18 / 97$ \\
\hline & & & Time Discovered: $\quad 1300$ \\
\hline & & & Type: $\quad E V-02-003-008$ \\
\hline & & & DOE Dir. Cause: IB \\
\hline & & & DOE Rt. Cause: $1 B$ \\
\hline & & & PPG Value: - - - \\
\hline
\end{tabular}

\begin{tabular}{|l|l|l}
\hline $\begin{array}{l}\text { Issuing Organization: } \\
400 \text { Area Radiological Controls, } \\
18500\end{array}$ & $\begin{array}{l}\text { Organization Point of Contact (OPOC): } \\
\text { D. R. Burstad }\end{array}$ & $\begin{array}{l}\text { Telephone No.: } \\
376-2180\end{array}$ \\
\hline $\begin{array}{l}\text { Location of Problem: } \\
\begin{array}{l}\text { Building/Cell Area/Reactor Service } \\
\text { Buld }\end{array}\end{array}$ & $\begin{array}{l}\text { References: } \\
\text { HSRCM-1, Articles 235.1, Radiation Survey Report } \\
255392\end{array}$ \\
\hline
\end{tabular}

Statement of Concern or Problem:

The HSRCM states areas shall be posted to alert personnel to contamination in accordance with Table 2-4.

During an entry into Cell 201 (Sodium Removal System, normally a Radiation Area/Contamination Area with a small High Radiation Area within) for a routine inspection by operations, the RCT performed the entry survey as required by the routine surveillance Iask Description. The contamination level near tank 101 has risen from less than $1000 \mathrm{dpm} / 100 \mathrm{~cm}$ to $400,000 \mathrm{dpm} /$ large area wipe. The RCT and operations employee immediately left the area, since the RWP did not address that level of contamination. No source was identified, no liquid was seen on the floor. This cell had not been entered since April 1997. Several evolution of sodium washing and tank pressurization had occurred during this time frame.

There had been no indication of teaks fron the pressurization.

Immediate Corrective Actions Taken: The cell entrance was posted as a High Contamination Area. Immediate notification was made to the RC Manager, SOM (Tim Lamberson)and EDS operations' management (Dave Brown). The facility point of contact (Mark Eby) was notified $(9 / 23 / 97,1430)$. As an added precaution air samples were taken in the cell; concentration was below $10 \%$ DAC.

Recomended Corrective Actions: Perform further radiological surveys of the area to determine the source. Take necessary action to stop the source of activity. Decontaminate the cell. 
HNF-2380

RADIOLOGICAL PROBLEM REPORT CORRECTIVE ACTION FORM (OAF)

Serial Number: $X-97-011$

Required Response Date: 10/6/97

Action taken or Planned (include date action completed or estimated date of completion):

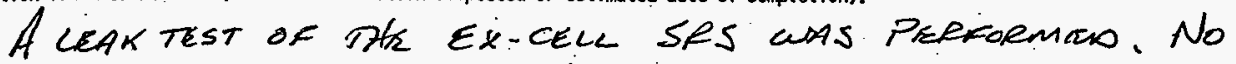
LEAKS WERT DETECTED. VISUAL INSPECTiON OF SYSTEM

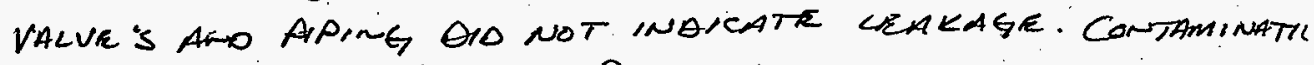
WAS MOST LELY ALE TO PREVIOUS SYSTEM MOdIFICATION WORK AND WENT UNDETECTED UNDER WATER TANK THIOL.

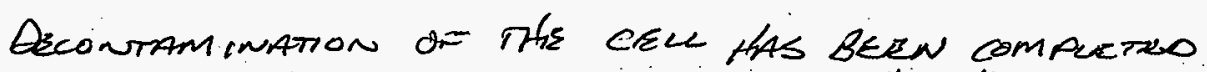
Hus att re ARER is Post en BACK TO $A$ "CA".

THK SPECIFIC AERA OF CONTAMINATION aha BEEN

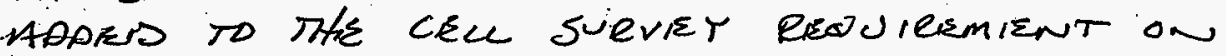
HEALTH PHYSICS ROUTINES.

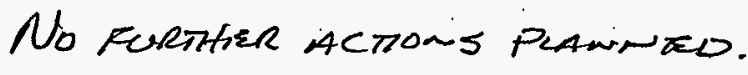

Aw Brown

DH $10-22-97$

Plan: Accepted Date: $10-6-97$

Rejected Date:

Actions:

Verified for closure

Date: 10/2apa> DR B

Comments:

Rejected for Closure Date:

Survey Repents 255394 i $255404,255418,255422$ confirm that senceyst. determine cortameriation some completed by $q / 26 / 47$.

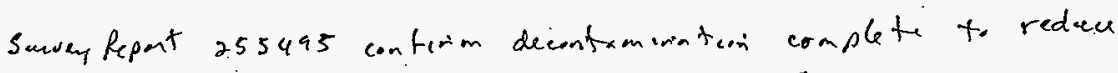

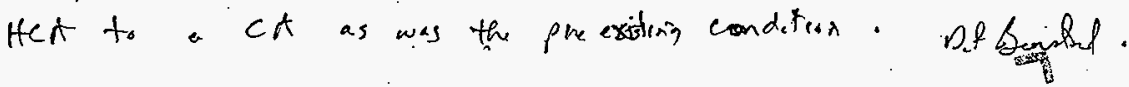

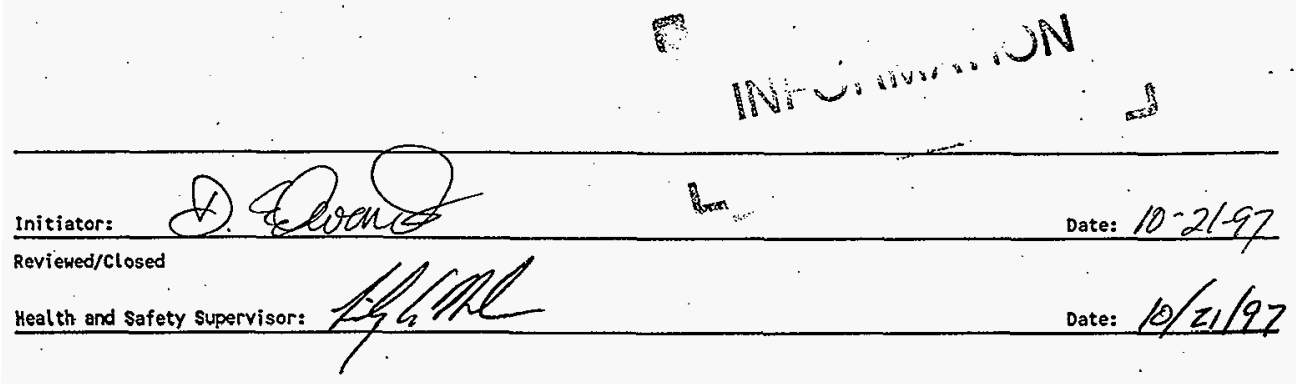

A-6000-644 (5/91) GEF072 


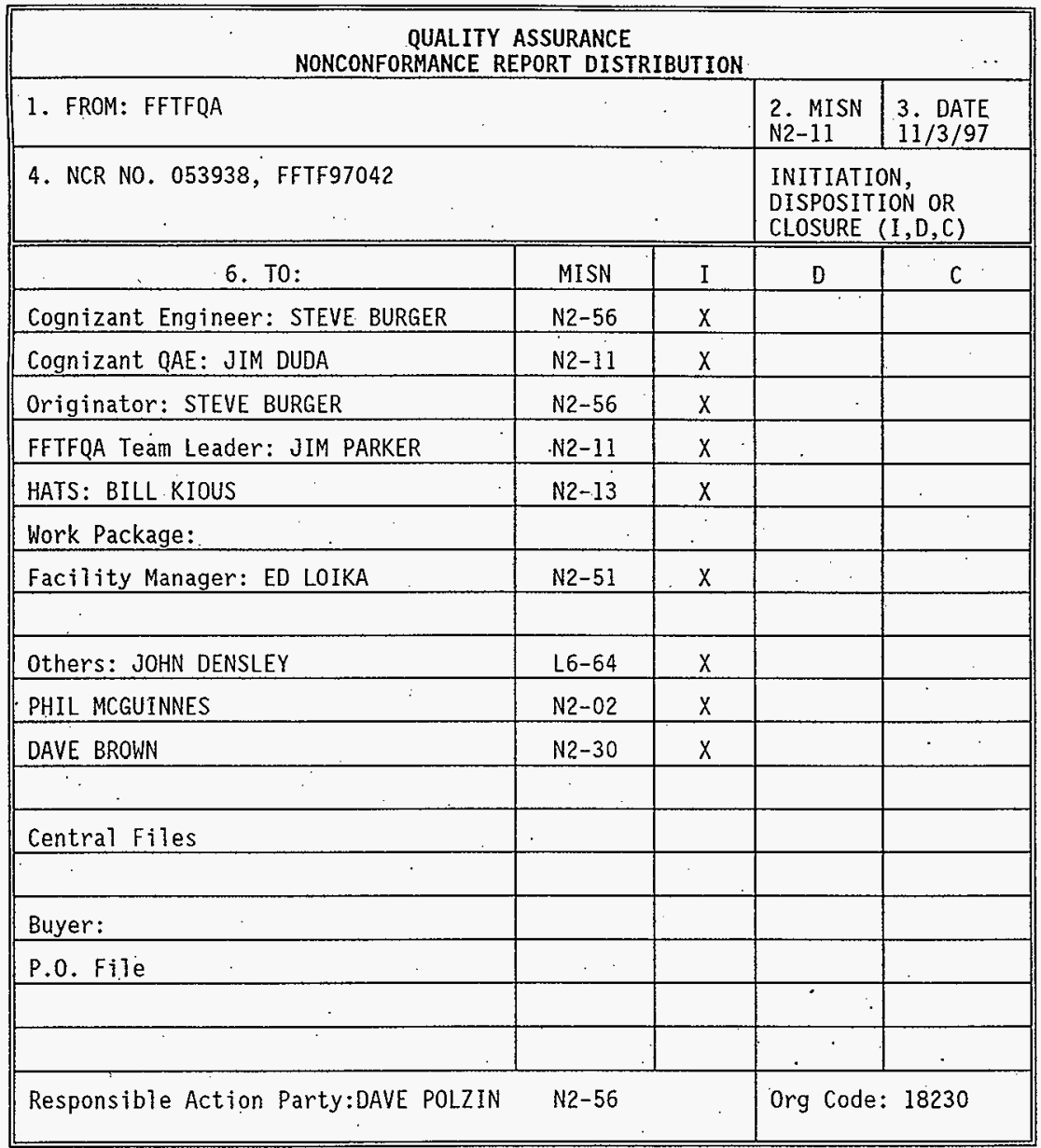




\begin{tabular}{|c|c|c|c|c|c|c|c|}
\hline $\begin{array}{l}\text { *ta. Orig. Document No. } \\
053938 \text {, FFTF97042 }\end{array}$ & \multicolumn{3}{|c|}{$\begin{array}{l}\text { *1b. Condition No. } \\
1\end{array}$} & & \multicolumn{3}{|c|}{$\begin{array}{l}\text { *2. Type } \\
\text { CONDITION. }\end{array}$} \\
\hline \multicolumn{4}{|c|}{$\begin{array}{l}\text { *3. Condition ritle ( } 65 \text { characters only) } \\
\text { PRESSURE RELIEF VALVE TESTING }\end{array}$} & & \multicolumn{3}{|c|}{ *4. View } \\
\hline \multicolumn{8}{|l|}{$\begin{array}{l}\text { *5. Owner/organization code } \\
\text { DAVE POLZIN/18230 }\end{array}$} \\
\hline \multicolumn{8}{|l|}{$\begin{array}{l}\text { *6. closure/organization code } \\
\text { FFTFQA/ } 18400\end{array}$} \\
\hline \multicolumn{8}{|c|}{$\begin{array}{l}\text { *7. Abstract Text ( } 250 \text { characters only) } \\
\text { FLUID IN DISCHARGE LINE. }\end{array}$} \\
\hline \multicolumn{4}{|l|}{$\begin{array}{l}\text { *8. Responsible Contractor } \\
\text { BWHC }\end{array}$} & \multicolumn{4}{|c|}{ 9. Root Cause Codes } \\
\hline \multicolumn{8}{|c|}{$\begin{array}{l}\text { 10. Detailed Text (Unlimited text field) } \\
\text { DURING REMOVAL OF PSV-677 FROM T-101, THE DISCHAREG LINE TO CAPS CONTAINED 1.5 GALLONS } \\
\text { OF RADIOACTIVE LIQUID. }\end{array}$} \\
\hline \multicolumn{3}{|l|}{ 11. PPG a, Responsible Contractor } & b. Evaluation Date & \multicolumn{3}{|c|}{ c. PPG Value } & d. Consequence Code \\
\hline \multicolumn{3}{|l|}{$\begin{array}{l}\text { 12. Condition Scope a. Facility } \\
\text { FFTF }\end{array}$} & \multicolumn{5}{|c|}{$\begin{array}{l}\text { c. Requirements/Reference Documents } \\
\text { PV }-030\end{array}$} \\
\hline
\end{tabular}

* Required fields on Initial Entry. 


\section{HATS CONDITION INPUT FORM}

*1a. Orig. Document No.

053938, FFTF97042

$\star 3$. Condition Title ( 65 characters only)

PRESSURE RELIEF VALVE TESTING *1b. Condition No.

$\cdot 2$
*2. Type CONDITION.

*5. Owner/Organization code.

DAVE POLZIN/18230

*6. Closure/Organization code

FFTFQA/18400

*7. Abstract Text (250 characters on (y)

SET PRESSURE FOUND TO BE HIGH

*8. Responsibte Contractor

9. Root cause codes

BWHC

10. Detailed Text (Untimited text field)

PSV-677 AS FOUND SET PRESSURE IS 100.5 PSIG. THIS IS OUTSIDE THE ALLOWABLE TOLERANCE OF $95 \pm 2.8$ PSIG.

\begin{tabular}{|l|l|l|l|}
\hline $\begin{array}{l}\text { 11. PPG a. Responsible Contractor } \\
\text { b. Evaluation Date }\end{array}$ & c. PPG Value \\
\hline $\begin{array}{l}\text { 12. Condition Scope a. Facility } \\
\text { FFTF }\end{array}$ & $\begin{array}{l}\text { b. Building Code (Name) } \\
\text { CELL 201 }\end{array}$ & $\begin{array}{l}\text { c. Requirements/Reference Documents } \\
\text { PV-030 }\end{array}$
\end{tabular}

* Required fields on Initial Entry. 


\section{HATS CONDITION INP.UT FORIM}

\begin{tabular}{|c|c|c|}
\hline $\begin{array}{l}\text { *1a. orig. Document No. } \\
053938 \text {, FFTF97042 }\end{array}$ & $\begin{array}{l}\star 1 \text { b. Condition No. } \\
3\end{array}$ & $\begin{array}{l}* 2 . \text { Type } \\
\text { CONDITION }\end{array}$ \\
\hline $\begin{array}{l}\text { *3. Condition ritle (65 characters only) } \\
\text { PRESSURE RELIEF VALVE TESTING }\end{array}$ & & $\star_{4}$. view \\
\hline
\end{tabular}

*5. Owner/Organization Code

DAVE POLZIN/18230

*6.' Clasure/organization code

FFTFQA $/ 18400$

*7. Abstract Text (250 characters only)

FLUID IN DISCHARGE LINE COULD HAVE ALLOWED AN OVER PRESSURE CONDITION.

*8. Responsible Contractor

9. Root Cause Codes

BWHC

10. Detailed Text (Unlimited text field)

THE STATIC HEAD OF $1 \frac{1}{2}$ GALLONS OF WATER PRESSURE, AS STATED IN CONDITION 1 ON THE DISCHARGE PIPING IS 1.6 PSI. THE MAXIMUM POSSIBLE WATER LEVEL IN THE ELEVATED DISCHARGE PIPING OVER THE LAST TWO YEARS EQUATES TO A PRESSURE OF 3.2 PSI.

PSV-677 AS FOUND SET PRESSURE OF 100.5 PSI AND THE MAXIMUM POSSIBLE DISCHARGE HEAD PRESSURE OF 3.2 PSI IS EQUAL TO 103.7 PSI. THIS ACCUMULATIVE PRESSURE IS ABOVE THE $T$ 101 MAXIMUM ALLOWABLE WORKING PRESSURE OF 100 PSIG.

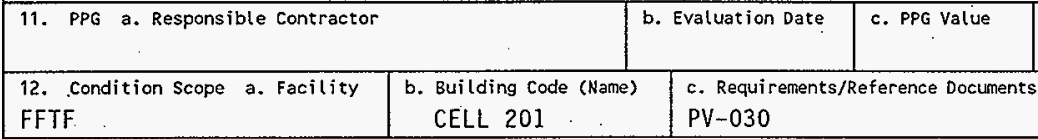

* Required Fields on Initial Entry. 
HNF-2380

Rev. 0, Page 220

\section{Westinghouse
Hanford Company NONCONFORMANCE REPORT}

P. O., W. O., or Job

antrol No.

$\frac{\text { N/A }}{\text { Program/Project/Other }}$

KUNKLE
5. Item/Material

VALVE/STAINLESS STEEL - - - PV-030
2. Preprinted No.
4. System/End Use

41/PRESSURE RELIEF

9. Safety Class 10. ASME Code ltems

FFTF

3

(If yes, notify authorized inspector)

12. Notification of Potential Occurence Required

$[$ Yes XX No

\section{Code: Lo
$N / A$}

8. Item
15. Sample

1 \begin{tabular}{lcc} 
16. Qty. Acc. \\
\hdashline & $\cdots$ & \\
$\cdots$ & 0 & $:$
\end{tabular}
17. Inspection Criteris

$\square$ Dwg. $\square$ spec. $\square$ Insp.:Plan

$\mathrm{XX}$ othe $\mathrm{PV}-030$

22. Disposition, Justification, and Instructions

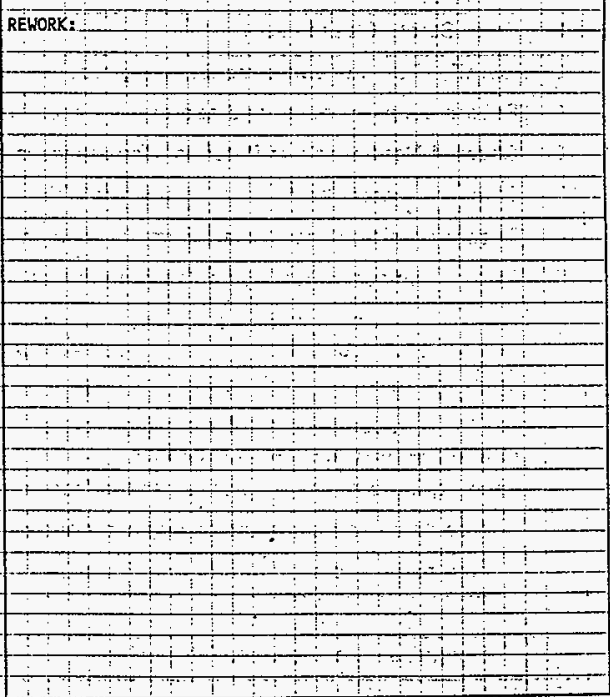

-o. Originator's Signature.

\begin{tabular}{l|l} 
Date ..... & 23. Design Document Change Required?
\end{tabular}

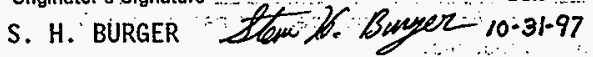

$\square$ Yes, Doc. No.

$5: 3)^{\circ}=\square$ No

7. Cognizant QA Manager's Signature Jibjed $\alpha_{.:}:$Q Date

QA Engineer

Date

Signature/Org.

$D$ Yes, No.

\begin{tabular}{c} 
Date \\
\hline
\end{tabular}

\begin{tabular}{l|l} 
Date ..... Signature/Org. & S
\end{tabular} 
HNF-2380

Rev. 0, Page 221

NONCONFORMANCE REPORT

(Continuation)
1. Page 2 2 2. Preprinted No.

of 2 QA Log No.
PSV- 677 AS FOUND SET PRESSURE IS 100.5 PSIG. THIS IS CUTSIDE THE ALLOWABLE TOLERANCE OF 95 ¿2.8 PSIG.

ICP-PV-030 (PRESSSURE RELTEF IVALVE CALIBRATION

PROCEDURE) SET PRESSURE TOLLERANCE IIS $\pm 3 \%$ OF SEI

PRESSURE THE ASHE CODE, SECTION VIII, UG-134, STATES

THAT ;SET PRESSURE TOLERANCES SHALL' NOT EXCEED $\pm 3 \%$ FOR - PRESSTURES - ABOVE 70 PSIG.
THE -STATIC HEAD OF - 1 \% GALLONS OF WATER PRESSURE, AS STATED IN ITEM 1 -ABOVE, ON PSV-677 DISCHARGE PIPING IS 1.6 PSI:- THE MAXIMUN POSSIBLE-WATER LEVEL-IN-THE ELEVATED DISCHARGE PIPING OVER THE LAST TWO YEARS EQUATES TO $A$ A PRESSURE OF $3-2$ - PSI

-PSV-677-AS SFOUND-SET-PRESSURE-OF-100.5-PSI-AKD -THE MAXIHUH POSSIBLE-DISCHARGE-HEAD PRESSURE OE 3.2_RSI IS EQUAL - 10!103.7-PSI - IHIS ACCUMULAIIVE_PRESSURE_IS

ABOVE JHE $J$-101 MAXIMUM ALLOWABLLE WORKING PRESSURE OF 100 PSIG

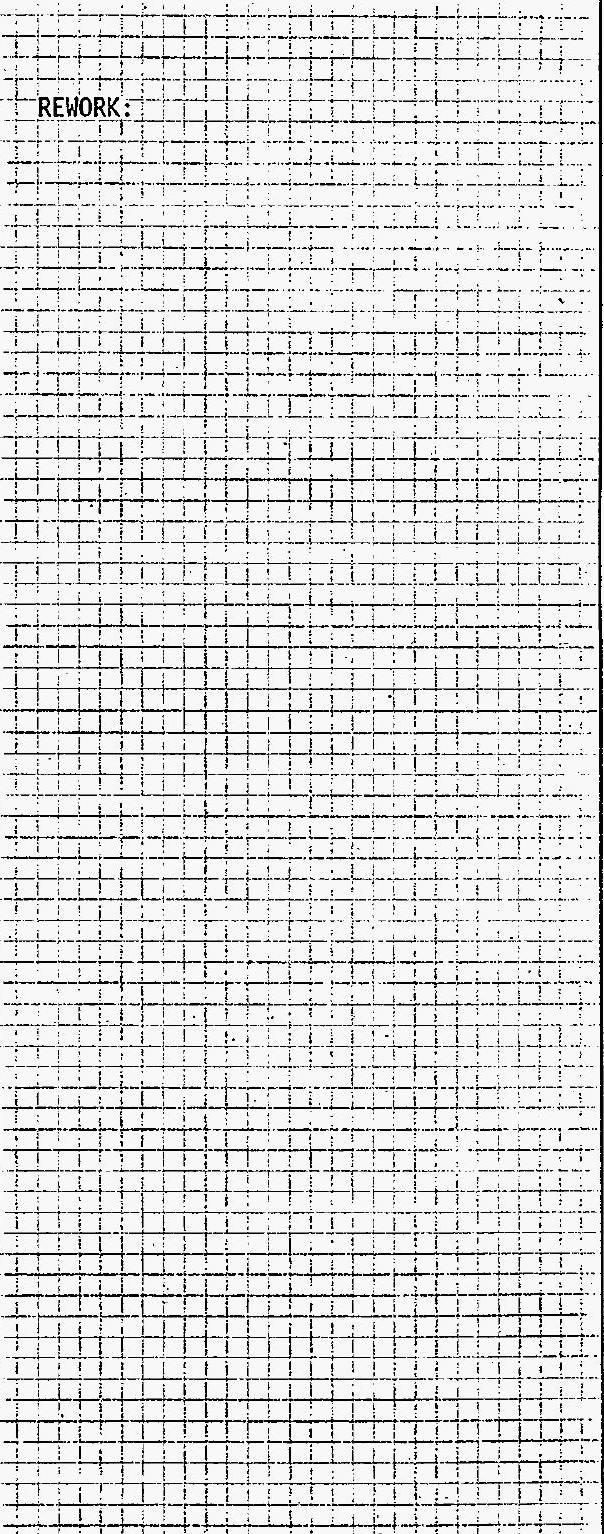


HNF-2380

Rev, 0, Page 222

\section{ANNUAL SYSTEM ASSESSMENT REPORT \\ FOR \\ 41D/PEDESTAL MOUNTED MANIPULATOR}

Date of this Report:

$1-30-98$

Date of Previous Report:

$1-24-92$

APPROVALS

Cognizant Engineer

Mechanical:

Electrical:

\section{Cognizant Engineering Manager}

Mechanical:

Electrical:

1. SCOPE

System/Component

41D/M-127
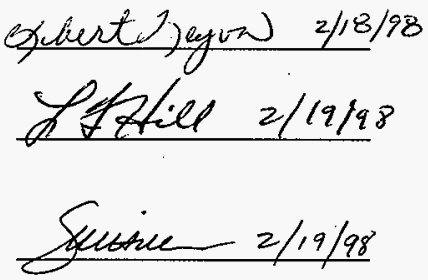

Deonge 27. Puge 2/20/98

2. SUMMARY EVALUATION (Provide a general assessment of the overall health of the system. Include a discussion of the system's minimum operable equipment from plant procedure $\mathrm{PN}-7$ )

PMM Arm \#1 is fully operational to support IEM Cell operations with the exceptions mentioned below. In the fouth quarter of 1995 the clutches for PMM Arm \#1 were adjusted to lift $300 \mathrm{lbs}$., i.e. the wrist extend, wrist pivot, elbow pivot and shoulder pivot clutches. Presently, the boom pivot has a lift capacity of $150 \mathrm{lbs}$. which limits the arm from lifting its design limit of $300 \mathrm{lbs}$. The other weak link is the shoulder rotate (present lift capacity is $165 \mathrm{lbs}$.) which requires the pivot joints (wrist, elbow and shoulder pivots) to be in a locked configuration to isolate the shoulder rotate which is not a common practice. However, the majority of the operations that have been experienced in the IEM Cell can be supported by the arm with the exception of changing out a Model 50 manipulator which weighs approximately $175 \mathrm{lbs}$. To this point, a Model 50 manipulator has never been removed with the arm fully extended. At the present time engineering is not planning a recovery scenerio; the recovery plan would require the use of the 4 ton crane. We have had experience removing a Model 50 from the $2 \mathrm{~A}$ and $3 \mathrm{~A}$ windows using the crane and a WMM. As a result, it was decided that 
removal of the PMM boom from the cell, to adjust the clutches for the boom pivot and the shoulder rotate, was not warranted.

At the present time all four hands are operational to support IEM Cell operations. There has been new information gathered about the operational interface between the clutch and the armature which affects the amount of grip force that the hand can generate. In summary, according to the vendor (Warner Electric) the hand (contains the armature) must go thru a run-in-period with the wrist (contains the clutch) to properly match the two faces together to obtain full electromagnetic strength. Before run in we can expect $30 \%-50 \%$ of the full design strength from the electromagnetic clutch. Experience has shown this to be true since we have had several documented (J-1's) problems in the past. The Cog. Engineer does not think performing a run-in-period would be beneficial since the particular hand/s would need to be matched with a particular wrist. Maintaining a matched set would not last long since the hand/s or wrist would inevitably be damaged due to remote operation. The two hands consist of one hook hand (design grip force of $0-1500 \mathrm{lbs}$.) and one jaw hand (design grip force of 0-500 lbs.). A hook hand not capable of gripping at the high end of the design grip force would not be detrimental since the hook hand only needs to close against the item being handled. Engineering has been able to measure approximately $480 \mathrm{lbs}$. of grip force from a hook hand (unmatched with the wrist); we will measure the grip force from a jaw hand early this year (98). The present stock of hands are operable to support IEM Cell operations.

There are two electrical problems where repair efforts require upper tower (boom) removal from the IEM Cell; the frayed arm cable and the crushed hoist conduit. The arm cable provides control and power to all of the PMM arm motions. The cable's outer jacket has been torn open, its retaining clamp ripped off of the boom and the connection to the boom loosened.. As a result, the individual conductors in the arm cable are exposed and chafe on the upper boom surface. If an electrical short were to occur, the PMM would lose operability of at least one motion. If the cable were to pull completely free from the boom connector all arm motions would be lost. In order to provide a method of recovery from this event, a Deutch connector was replaced with a Gulton connector, in late 1995 , on the back of the spare PMM arm whereby the modified drape cable could be used to recover from a failed arm and possibly eliminate the need for upper tower removal. The second significant electrical problem is the crushed metal conduit on the top of the PMM tower. This conduit houses the conductors that provide power to the main hoist motor and brake. The conduit sustained enough damage to expose individual conductors. If an electrical short were to occur in this area, the PMM is recoverable with the 4-ton crane. However, the crane would only be used to pull the boom assembly on to the upper PMM tower where it could be pinned in place for removal from the IEM cell. No action is planned to correct both of these problems since the recovery, as well as the repair, require removing the upper tower and boom assembly from the IEM Cell.

During shutdown, FFTF was processing spent fuel thru the Interim Examination and Maintenance (IEM) Cell in preparation for interim storage: The spent fuel being processed was being loaded into Core Component Containers (CCC) and then the cover installed and torqued. During this evolution we were experiencing more problems with the PMM Wrist Rotate which wasn't designed for this type of continuous screwing of the CCC bolts: At that time (shutdown) Engineering had planned to develop speed wrenches to alleviate the wear on the PMM Wrist Rotate. When we received the Standby order, Engineering reassessed that the need for speed wrenches was not as immediate due 
to the stoppage of processing of spent fuel. Recognizing that a speed wrench would still be needed in the future, engineering is still pursuing their fabrication.

3. ITEMS REQUIRING ACTION (Items on PTS, Procedures, Software, etc.)

\section{Near Term Items}

a. $4 \mathrm{I}-92-48 / \mathrm{W}, \mathrm{PMM}$ hand will not Open

b. $4 \mathrm{I}-96-61 / \mathrm{W}$, Refurbishment of the the Operator Control Panel.

Long Term Items

a. $4 \mathrm{I}-97-54 / \mathrm{W}$, Fabricate Power Tooling for the PMM and WMM.

b. 4I-91-140/W, EMM Parallel Jaw Hand

Grip Force Gage. Note: Grip Force Gage

for PMM is already built, but remains open

for WMM grip force gage which hasn't

been built (also ref. in WMM ASAR).
Required By

When resources are available

Work in progress.

Required By

Startup (Work will be started this year).

Startup

4. TRENDS (Discuss trended parameters. See Appendix K for typical parameters which can be used for trending studies.)

None

5. SYSTEM AGING, SPARE PARTS CONSIDERATIONS, AND LONG TERM MAINTENANCE PHILOSOPHY

PMM Arm \#2 was refurbished in 1996 and is ready to backup PMM \#1.

Engineering did not perform a spare part review for this equipment since a thorough review was performed during the refurbishment of PMM \#1. During this review process several difficient areas were identified; since that time these areas have been resolved. Continuous evaluations of spare parts are being performed as on going repairs are performed on the PMM. During these evaluations, Engineering has not noticed any appreciable depletion of spares parts during the last year.

The operator control panels have experienced some wear and adjustment problems with the finger switches. General refurbishment of these switches and their panels is currently being performed by work packages $4 \mathrm{I}-96-61 / \mathrm{W}$, and should extend their life. Problems with one of the T-bar relays was traced to excessive loads on the contacts from soldering directly to them and was alleviated by adding a relay socket. 


\section{CHECKOFF LIST}

A. Accessible parts of the entire system or component have been thoroughly walked down at least once in the past 30 days to view current performance, equipment status and conditions. Yes $\mathrm{X}$ No

COMMENTS (exceptions): None

B. Are there any conditions which might require limitations different from operating limits as defined in the SDDs, the FSAR; or the Plant Technical Specifications? Yes No $\underline{\mathrm{X}}$

\section{COMMENTS (exceptions): None}

C. Are there trip settings, set points, interlocks, etc., that should be changed from those currently established? Yes No $\mathrm{X}$

COMMENTS (exceptions): Refer to Section 2 above for limitation on the Boom Pivot and the Shoulder rotate. These limitations have already been accounted for in the applicable IN procedure.

D. Are there interface areas which have not performed acceptably, which require resolution? Yes No X

COMMENTS (exceptions): None

E. Are there temporary plant or procedural conditions which will and should remain in place? Yes No $\mathrm{X}$

Attach list of $\mathrm{MOD}(\mathrm{L}) / \mathrm{ECN}(\mathrm{L}) \mathrm{s}$, and OSPs that are currently active. Provide justification for continuing temporary MOD (L)s and ECN (L)s.

COMMENTS (exceptions): NA

F. Is any retesting or special testing (e.g., OSP) required? Yes_ No $\mathrm{X}$

COMMENTS (exceptions): NA

G. Are the current plant corrective maintenance, preventive maintenance, and calibration database items all properly identified and are planned actions acceptable?

Yes $\underline{X}$ No

COMMENTS (exceptions): None 
H. Are all other action items (NCRs, Irs, etc) properly identified and assigned? Yes_ X No _ (attach the summary of needed actions not in the data base)

COMMENTS (exceptions): There is no outsanding NCRs, Irs, etc. at the present time.

I. Are there any special operating considerations? Yes No No X

COMMENTS (exceptions): NA

J. Are near term spare parts adequate? Yes $\mathrm{X}$ No

COMMENTS (exceptions): See Item 5 above for explanation.

K. Have any safety issues (radiological, industrial) been identified that remains untesolved? Yes No N X

COMMENTS (exceptions): None

L. Have all components data been entered into the Plant information database?

Yes $\underline{\mathrm{X}}$ No

COMMENTS (exceptions):

M. Have applicable SISI inspections been conducted? Yes No

COMMENTS (exceptions): NA

N. Has a cleanliness evaluation been completed? Yes_No N N Are any issues still unresolved? Yes_ No X

COMMENTS (exceptions): A cleanliness evaluation cannot be performed on this equipment since it resides in a hot cell (contaminated and remotely operated).

\section{REFERENCES}

None

\section{ATTACHMENTS}

(Attach any CSRs, data sheets showing system performance, or other material demonstrating the substantive nature of this review). 


\title{
ANNUAL SYSTEM ASSESSMENT REPORT FOR \\ 41D/WALL MOUNTED MANIPULATOR
}

Date of this Report: $\quad 1-30-98$

\author{
APPROVALS
}

Date of Previous Report $1-24-92$

Cognizant Engineer

Mechanical:

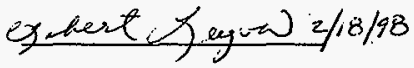

Electrical:

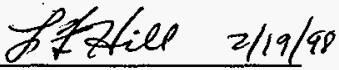

Cognizant Engineering Manager

Mechanical:

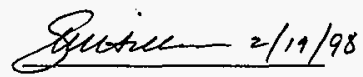

Electrical

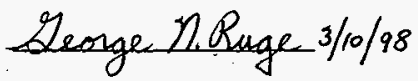

1. SCOPE

System/Component 41D/M-128
Title

Wall Mounted Manipulator

2. SUMMARYEVALUATION (Provide a general assessment of the overall health of the system. Include a discussion of the system's minimum operable equipment from plant procedure $\mathrm{PN}-7$ )

WMM Arm \#1 and Boom is fully operational and ready to support IEM Cell operations. In the latter part CY 1996, the clutches for the arm and boom were adjusted to lift 150 lbs., i.e. the wrist extend, wrist pivot, elbow pivot, shoulder pivot, shoulder rotate, boom extend/retract and boom. pivot clutches. Engineering recently located WMM \#2 and work instructions were prepared to inspect, repair and make any necessary adjustments to refurbish it, such that an operational spare WMM Arm is available when needed..

The present condition of the hands are acceptable, even though they have been heavily used in the 17 years of service. 
3. ITEMS REQUIRING ACTION (Items on PTS, Procedures, Software, etc.)

Near Term Items

a. $4 \mathrm{~A}-96-251 / \mathrm{W}$, WMM \#2 Inspection and Repair

b. 4I-89-167/M, WMM Grip Gauge OOC

c. 4I-97-18/W, Replace WMM Wrist \#2 Grip Clutch

d. $4 \mathrm{I}-98-2 / \mathrm{W}$, No Power to WMM Controller

e. 4I-96-61/W, Refurbishment of Operator Control Panel.

\section{Long Term Items}

a. 4I-97-82/W, Failure of WMM Boom Pivot \& Wrist Retract

b. 4I-91-140/W, EMM Parallel Jaw Hand Grip Force Gage. Note: Grip Force Gage for PMM is already built, but remains open for WMM grip force gage which hasn't been built (also ref. in PMM ASAR).

\section{Required By}

When resources are available

NA, the grip force gauge has been repaired. The work package is set up to support $4 \mathrm{I}-97-18 / \mathrm{W}$, before the work package can be closed.

When resources are available.

When resources are available.

Work in Progress.

Required By

Not required for standby, but needs to be evaluated for startup.

Startup

4. TRENDS (Discuss trended parameters. See Appendix K for typical parameters which can be used for trending studies.)

None observed since the refurbished spare (WMM \#1) has been in operation.

As mentioned in PMM's ASAR, new information had been gathered concerning the amount of grip force being found vs. the design limit that is expected when either or both, the clutch and/or armature are replaced. According to Warner Electric, the armature (located on the hand) and the wrist (contains the clutch) must go thru a run-in-period to properly match the two faces together to obtain full electromagnetic strength. We can expect $30 \%-50 \%$ of full design strength from the electromagnetic clutch prior to a run-in-period. The Cog. Engineer does not think performing a run-in-period would be beneficial since the particular hand/s would need to be matched with the particular wrist. It is difficult to maintain a matched set due to the nature 
of the remote operation and the resulting damages. This is new information and engineering has not received sufficient information to formulate a conclusion to obtain a optimum resolution.

5. SYSTEM AGING SPARE PARTS CONSIDERATIONS, AND LONG TERM MAINTENANCE PHILOSOPHY

WMM Arm \#2 has not been refurbished and awaiting for the necessary resources. WMM \#2 remains a relatively unused piece of IEM Cell equipment which we can expect at least the same amount of service time (at least 15 yrs.) that we have received from WMM \#1.

This reporting period, Engineering did not perform a spare part review for this equipment since a thorough review was performed during the refurbishment of WMM \#1 and continuous monitoring of spare parts has not identified a problem. When the spare parts review was performed, identical deficient areas in spare parts were noticed; since that time these areas have been resolved.

The operator control panels have experienced some wear and adjustment problems with the finger switches. General refurbishment of these switches and their panels is currently being performed by work package $4 \mathrm{I}-96-61 / \mathrm{W}$, and should extend their life.

Engineering has experienced constant repairs to all WMM appendages due to usage. During the inspection of the parts being repaired, we have noticed the following, mostly due to operation.

- Loose screws, nuts and bolts on moving pieces causing binding problems between moving parts.

- Binding bearings caused by dirt accumulation.

- Worn surfaces (e.g. clutches, armatures, bearing surfaces and poor manipulator design).

- Clutch settings wearing down to a lower load capacity.

Most of these symptoms are due to usage and are expected. The results of these inspections do not indicate a real condition of degradation to the WMM.

\section{CHECKOFF LIST}

A. Accessible parts of the entire system or component have been thoroughly walked down at least once in the past 30 days to view current performance, equipment status and conditions. Yes X No

COMMENTS (exceptions): None 
B. Are there any conditions which might require limitations different from operating limits as defined in the SDDs, the FSAR, or the Plant Technical Specifications? Yes_No $\mathrm{X}$

COMMENTS (exceptions): None

C. Are there trip settings, set points, interlocks, etc., that should be changed from those currently established? Yes_No_ $\mathrm{X}$

COMMENTS (exceptions): None

D. Are there interface areas which have not performed acceptably, which require resolution? Yes_No_ N

COMMENTS (exceptions): None

E. Are there temporary plant or procedural conditions which will and should remain in place? Yes_NoX

Attach list of MOD(L)/ECN(L)s, and OSPs that are currently active. Provide justification for continuing temporary MOD $(L) s$ and $E C N(L) s$.

COMMENTS (exceptions): NA

F. Is any retesting or special testing (e.g., OSP) required? Yes_No_X

COMMENTS (exceptions): NA

G. Are the current plant corrective maintenance, preventive maintenance, and calibration database items all properly identified and are planned actions acceptable? Yes_X_No_

COMMENTS (exceptions): None

H. Are all other action items (NCRs, Irs, etc) properly identified and assigned?

Yes_X No._. (attach the summary of needed actions not in the data base)

COMMENTS (exceptions): There is no outsanding NCRs, Irs, etc. at the present time.

I. Are there any special operating considerations? Yes_No $\mathrm{X}$

COMMENTS (exceptions): NA 
J. Are near term spare parts adequate? Yes_X_No__

COMMENTS (exceptions): See Item 5 above for explanation.

K. Have any safety issues (radiological, industrial) been identified that remains unresolved? Yes__No_.

COMMENTS (exceptions): None

L. Have all components data been entered into the Plant information database?

Yes X No

COMMENTS (exceptions):

M. Have applicable SISI inspections been conducted? Yes_No_

COMMENTS (exceptions): NA

N. Has a cleanliness evaluation been completed? Yes_NoN

Are any issues still unresolved? Yes__NoX_

COMMENTS (exceptions): A cleanliness evaluation cannot be performed on this equipment since it resides in a hot cell (contaminated and remotely operated).

\section{REFERENCES}

None

\section{ATTACHMENTS}

(Attach any CSRs, data sheets showing system performance, or other material demonstrating the substantive nature of this review). 
HNF-2380

Rev. 0, Page 232

Page 1

\section{ANNUAL SYSTEM ASSESSMENT REPORT \\ SYSTEM 41-11 \\ BLTC}

Date of This Report $\quad 1 / 30 / 98$

Date of Previous Report _ 1/31/97.

APPROVALS: Cognizant Engineers

Mechanical

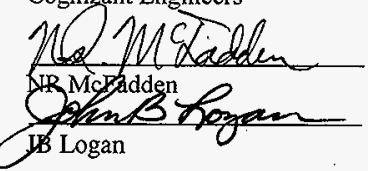

Cognizant Engineering Managers

Electrical

If Logan

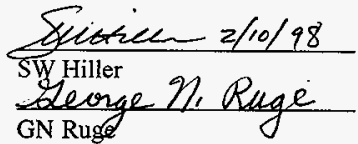

1. SCOPE

System/Components

41-11/M-50, M-51, C-696
Title

BLTC

2. SUMMARXEVALUATION (Provide a general assessment of the overall health of the system. Include a discussion of the system's minimum operable equipment from plant procedure PN-7.)

BLTC is being maintained operable and is capable of performing planned component handling operations during the standby period. There are no significant problems for BLTC operability during standby. All problems are identified in JCS and have appropriate phase/admin designations.

A number of assessments have been made for improvements and activities required if a plant restart is authorized. Those plans will not be discussed in this assessment. There are no major improvements being pursued during standby. The computer system was replaced in 1994 and is expected to be reliable for either a shutdown or restart mission.

3. ITEMS REQUIRING ACTION (Items on PTS, Procedures, Software, etc.)

A. Near Term Items

Required By

NONE

B. Long Term Items

Required By

Control software does not support Year 2000 dates..

HSB

This will not impact operation of BLTC, but will print erroneous data on reports unless some modifications are made. The software vendor is working on an update that will address the $\mathrm{Y} 2 \mathrm{~K}$ problem but it may require a hardware modification to implement. It is possible to manually input the date on the reports. The problem will be pursued with a permanent or temporary solution in place by 2000 . 
4. TRENDS (Discuss trended parameters. See Appendix $\mathrm{K}$ for typical parameters which can be used for trending studies.)

There are no specific parameters trended in a formal manner on BLTC. The cognizant engineers periodically review the operators logs and the operating data printouts. The operating procedures require that most machine parameters including loads, be recorded at specific points in grapple drives during component handling. This information is very useful for making comparisons that will detect problems. The JCS system reports are also reviewed for repeat problems that would indicate a trend. At this time, BLTC is operating well.

\section{SYSTEM AGING, SPARE PARTS CONSIDERATIONS, AND LONG TERM MAINTENANCE PHILOSOPHY}

A. Discuss effects of system aging.

Replacement of the computer eliminated that as an aging concern. Some items such as heaters and electronics are subject to aging due to continuous "on" time, but most items age primarily based on usage. These include grapple drive elements, closure valve/drip pan drive elements, inflatable seals, and elevator/dolly drive systems. For the most part, repairs are made when failures occur. The real usage factor is low. These systems will require special-attention to ensure availability with a restart mission but are acceptable as-is for standby or continuation of off-load.

Buildup of sodium compounds has historically caused problems with the drive systems internal to the cask. For off-load, operation was changed to include extended component removal times and cold BLTC operation. These actions reduced sodium drippage into BLTC to the point that sodium buildup has became insignificant. Issues of cleaning and repair will became important if operations return to the heated mode required for higher decay heat component transfers. Thus these drive systems will require special attention to ensure availability with a restart mission but are acceptable as-is for standby or continuation of off-load.

B. Discuss the strategy for near term spare parts and their availability strategy.

Over the years of operation, the spare parts inventory has been refined by actual usage. The only zero balance item of significance is an argon heater (4F-94-1172). The heater has no drawings or vendor so some design activity is required. BLTC heating is rarely used in the present cold operating mode, thus design and procurement of the spare have a low priority. The activity has a startup designator code but will be worked on a time available basis during standby.

Replacement of the BLTC computer system included procurement of spares for the new system. They have been conditionally received but are not accepted for use because the safety class assignment requires that a dedication procedure be performed. The dedication work activity (4F-94-534) has a startup designator code. If an item is needed for repair in the near term, individual part dedication will be performed by work package. 
C. Standby Maintenance Plan: Discuss a plan which ensures essential system functions for standby are provided and minimizes equipment degradation. Assume the standby period extends for the next one to two years. Include in the plan, as a minimum: 1) the identification of hardware to be repaired, replaced, or upgraded; and 2) the frequency of routine field maintenance, ensuring material and spare parts are identified to support these activities (i.e., refurbish pumps, etc.).

The Year 2000 computer software problem will be resolved. There are no other planned repairs of upgrades for BLTC during the standby period.

Since BLTC will still see limited use during the standby period, routine preventive maintenance and calibrations will continue to be performed. A recent review of BLTC PMP's and ICRS's found that items to be performed were correctly identified and that actual performance and planned performance dates were acceptable.

\section{CHECKOFF LIST}

A. Accessible parts of the entire system or component have been thoroughly walked down at least once in the past 30 days to view current performance, equipment status and condition. Yes X No..

COMMENTS (exceptions): NONE

B. Are there any conditions which might require limitations different from operating limits as defined in the SDDs, the FSAR, or the Plant Technical Specifications? Yes_ No $X$

COMMENTS (exceptions): NONE for standby

C. Are there trip settings, set points, interlocks, etc., that should be changed from those currently established? Yes__ No $\mathrm{X}$

COMMENTS (exceptions): NONE for standby

D. Are there interface areas which have not performed acceptably, which require resolution? Yes_No $\mathrm{X}$

\section{COMMENTS (exceptions): NONE for standby}

E. Are there temporary plant or procedural conditions which will and should remain in place? Yes_No No $\mathrm{X}$

Attach list of MOD(L)/ECN(L)s, and OSPs that are currently active. Provide justification for continuing temporary MOD (L)s and ECN (L)s. 
F. Is any retesting or special testing (e.g., OSP) required? Yes_ No _ $\mathrm{X}$

COMMENTS (exceptions): NONE

G. Are the current plant corrective maintenance, preventive maintenance, and calibration database items all properly identified and are planned actions acceptable? Yes_X No

COMMENTS (exceptions): NONE

H. Are all other action items (NCRs, IRs, etc.) properly identified and assigned?

Yes_X No__ (attach the summary of needed actions not in the data base)

COMMENTS (exceptions): NONE

I. Are there any special operating considerations? Yes_ No $\mathrm{X}$

List or Reference: NONE

J. Are near term spare parts adequate? Yes $\underline{\mathrm{X}}$ No

COMMENTS (exceptions): NONE

K. Have any safety issues (radiological, industrial) been identified that remain unresolved? Yes__ No _ $\mathrm{X}$

COMMENTS (exceptions): NONE

L. Have all component data been entered into the Plant information database?

Yes $\mathrm{X}$ No

COMMENTS (exceptions): NONE

M. Have applicable SISI inspections been conducted? Yes X No_-

COMMENTS (exceptions): NONE

N. Has a cleanliness evaluation been completed? Yes $\underline{X}$ No

Are any issues still unresolved? Yes_No_X

COMMENTS (exceptions): NONE

\section{REFERENCES}

PTS reports and searches for Work Documents and PMP/ICRS status.

Standby and Restart assessments performed since the last formal ASAR in 1992. 
HNF-2380

Rev. 0, Page 236

Page 5

\section{ATTACHMENTS}

(Attach any CSRs, data sheets showing system performance, or other material demonstrating the substantive nature of this review).

A. JCS report of BLTC work items dated 1/28/98.

B. Hot Standby For Startup Assessment documentation of review meeting dated 2/4/97 including JCS report for BLTC work items dated 1/23/97. 
Revised 2/4/97 based on review meeting - Cog Engineers: McFadden/Logan

BLTC is presently operable, performing offload handling operations.

1. Since all assemblies in the plant are less than $1.4 \mathrm{~kW}$, the decay heat verification test is not being performed. Assemblies are being drained by slow withdrawal and cooled before closing to minimize sodium deposits in BLTC. Restart actions for the plant will probably require a return to heated operation to preclude undesirable assembly thermal shock and decay heat verification. This will result in increased sodium deposits in BLTC. Related issues are: drip cup replacement/cleaning, periodic disassembly of BLTC for removal of sodium deposits that prevent operation of the closure valve and drip pan, plus grapple replacement and cleaning.

A. Develop methods and equipment for grapple cleaning and replacement. Prior to restart.

2. The issue of sodium drippage inside BLTC is a major concern because it can cause unpredictable maintenance outages to cleanup sodium in the drip cup region. Due to a design condition which can not reasonably be corrected, sodium drips from the grapple, assemblies and cask wall onto surfaces outside the drip cup. This leads to problems when trying to replace full cups with empties. Several dimensionally different cups are now required to accommodate sodium buildups around the cups. The sodium also gets onto other regions of the cup holding rotor, ultimately preventing rotation. The only recovery option when total jamming occurs, is to disassemble the cask. Sodium drippage has also been found to have channeled down into the closure valve region. It has caused leakage of the buffer between inflatable seals. It has the same potential for jamming this closure valve rotor as for the drip cup rotor. Steps taken for heated operation to minimize sodium drippage impact on rotor operation have been somewhat successful. Drip cup fill levels are closely monitored. Special handling and operating requirements are used for some items that have a high probability for excessive sodium drippage. The cold operating method for defueling has eliminated sodium deposits in the drip cups. The method can not continue to be used because of thermal shock for cold assemblies entering sodium pools and temperature control requirements for higher decay heat assemblies. It is probably possible to develop a hybrid handling method that lessens the amount deposited for heated handling but handling times would be increased. The area needs considerable brainstorming.

A. Determine if BLTC should be disassembled and cleaned of sodium deposits. Prior to restart. Need spare rotor bearing prior to actual work. - Bought

3. The issue of assembly identification verification should be revisited. The decay heat test in BLTC was done as a backup to the administrative inventory control system to ensure that handling limits for safety analyses were not exceeded. It added extra time to the heated handling evolution. If an increase in BLTC handling limit form $1.4 \mathrm{~kW}$ to $2.0 \mathrm{~kW}$ is desired, the basis for thermal discrimination would have to be redone. This would involve having assemblies in the $2.0 \mathrm{kw}$ plus range to use for characterizing BLTC temperature discrimination.

A. Resolve decay heat verification/assembly verification requirements. Prior to restart. 
4. The BLTC control system is operational and capable of supporting restart activities with little additional work. A recent upgrade to the computer system has significantly improved the reliability of the system. An adequate supply of spare parts is now available and additional parts are commercially available.

A. No action required.

5. A filter needs to be installed on the gas outlet going to CAPS. This will prevent contamination of the CAPS system.

\section{A. CAPS line filter installation. Prior to restart.}

6. The argon heater and piping assembly is being redesigned for installability. A spare needs to be procured. BLTC has only one heater and its use is mandatory for heated handling.

\section{A. Obtain spare heater. Prior to restart.}

7. Although the original argon blowers are still operating, they are expected to be difficult to replace. There are two spares of this blower model. They are no longer manufactured. Replacement blowers will require significant redesign to fit in the confined space.

A. Argon blower redesign and installation package needs to be developed and replacements purchased. Prior to restart.

8. The dolly drive coupling which periodically breaks needs to be redesigned.

\section{A. Redesign dolly drive. Prior to restart.}

9. Evaluations and orders need to be completed for PCV spares/replacements and sodium aerosol filter cores/spacers/0-rings.

\section{A. Prior to restart or repair actions which ever comes first.}

10. The drip cup transfer container equipment needs to be completed and tested. This provides a better method for sodium filled drip cup exchanges.

\section{A. Prior to restart.}

11. An in depth review needs to be made of the spares inventory for all potentially age degraded items (e.g. lip seals, lube in gearboxes, bearings). Some testing, refurbishment and replacement may be required. There is presently no maintenance or inspection program.

\section{A. Spares condition evaluation. Prior to restart.}

12. A new power cable should be added to BLTC to permit driving the entire distance from the Transporter to at least the equipment airlock with out performing a power transfer (cable reels on both ends). Elimination of power transfers will make machine operation safer.

\section{A. Prior to restart.}


13. A new load cell signal conditioner should be procured and installed. Although the existing unit works fine and has spares a newer model will be easier to maintain within the restrictions of a production schedule.

\section{A. Prior to restart.}

14. The variable speed controllers for the Dolly Drive, Primary blower, and Grapple Drive should be evaluated for adequacy of spares and upgraded as required to guarantee the machine is capable of supporting the required availability factor.

\section{A. Prior to restart.}




\section{COMPONENT STATUS REPORT FOR \\ MULTI PURPOSE RAIL TRANSPORTER}

Period Covered: $9-15-95$ through 1-31-98 Date Reported: 2-19-98

Component: Multi Purpose Rai1 Transporter (MPRT) M-605

Cognizant Engineer(s): Mechanical: DJ Gerkensmeyer

Cognizant Manager(s) Electrical: NJ Knuter

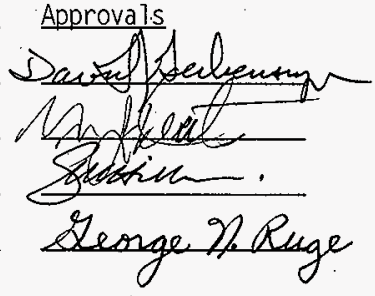

1. Summary of Component Status:

The MPRT is operationat.

2. Trends Observed:

A. Mechanical

1. In the past the MPRT has had problems with loss of drive wheel traction at various locations along the rails. Loss of MPRT drive wheel traction appears to be only a minor problem now, with no complaints received from Operations along those lines this reporting period.

2. A continuing problem over the years has been loosening of the lock nuts which hold the wheels on the axles. A permanent fix has not been found for this problem, however it happens infrequently and the nuts are easily tightened.

B. Electrical

1. Past electrical problems have usually been related to either the power cable, or electrical circuit interlocks.

During this past year work instruction $4 \mathrm{~F}-96-1768 / \mathrm{W}$ was implemented to simplify the MPRT control/interlock circuits. The intent was to improve MPRT operational reliability. 4F-96-1768/M eliminated the MPRT microprocessor control circuits, replacing them with simple relay logic. Since completion of the modification MPRT operational reliability has noticeably improved.

2. The MPRT power cable and cable reel assembly are subject to normal wear. It is anticipated that the power cable, and some cable reel components. may occasionally require repair and/or replacement. 
3. Component Aging and Spare Parts Considerations (Discuss effects of system aging, long term maintenance, and spare parts availability strategy):

\section{A. Mechanical}

1. It is expected that there will be very little degradation of the MPRT mechanical components over the next several years. The drive system and suspension components see relatively light duty due to the slow transport speeds and short travel distances.

2. The MPRT mechanical spares are adequate.

B. Electrical

1. The newly rebuilt MPRT electrical drive control circuitry has proven to be reliable during normal day to day operation. We expect that trend to continue.

2. The MPRT electrical spares are adequate.

C. Standby Maintenance Plan

1. Hardware to be repaired, replaced or upgraded:

The three work items listed below as Near Term Items at 5.A should be worked.

In addition to the identified work items, the recurring problem of loosening MPRT wheel lock nuts will be monitored and a long term fix pursued during standby.

2. Frequency of routine field maintenance:

There are no MPRT PMP's. There is presently no intent to perform any preventative maintenance during standby.

4. Analysis, Conclusions, Followup:

A. Mechanical

The MPRT mechanical components have been relatively trouble free during this reporting period. It is expected that the MPRT wi 17 be able to support FFTF standby/startup/shutdown activities with very little down time.

B. Electrical

MPRT electrical components have performed reliably since the control circuit modifications were performed. It is expected that the MPRT will be able to support. FFTF standby/startup/shutdown activities with very little down time. 


\section{COMPONENT STATUS REPORT (cont'd)}

5. Items Requiring Action (Items on PTS, Procedures, Software, etc.):

A. Near Term Items

$4 \mathrm{~F}-96-1298 / \mathrm{M}$

BUILD MPRT TOW BAR FOR FORKLIFT ASSIST

The MPRT needs a tow bar to facilitate using a fork lift to move the MPRT if the normal drive system is incapacitated. The present methods of attaching a sling between the MPRT and tow vehicle, or simply pushing the MPRT without attachment, do not provide enough control of the MPRT and can be dangerous to personnet.

4F-97-172/W [J-3] ADD SCH 40 PVC TO THREE LOCK OUT DEVICES

Shop fabricated lock out devices for the MPRT and BLTC need an additional one inch of schedule 40 PVC pipe added to the existing cap to prevent inadvertent removal of the devices from 480 VAC plugs.

4F-97-1374/W MPRT KEY STANDBY POSITION IS CAPTURED

The MPRT MODE control key switch captures the key when the switch is in the STANDBY position. The Operating procedure calls for placing the switch in the STANDBY position and removing the key at shutdown. The fix will either require switch replacement or switch plate label changes along with a procedure change.
Required By/Target

PRIORITY \&

PHASE DESIGNATOR

4/BLANK

$3 / 98-1$

4/BLANK 
HNF-2380

Rev. 0, Page 243

COMPONENT STATUS REPORT (cont'd)

B. Long Term Items

Required By/Target

PRIORITY \&

PHASE DESIGNATOR

4F-97-1501/A EVALUATE MPRT SUSPECT/COUNTERFEIT

2/SU1

\section{FASTENERS}

Inspection/evaluation of

suspect/counterfeit bolts on the MPRT

(documented by NCR-053889) wi 17 be

required if FFTF is given a restart

order. Existing fasteners are

acceptable for current standby status of

FFTF.

\section{Checkoff List}

A. Are the current plant corrective maintenance, preventive maintenance, and calibration database items a 11 properly identified and planned actions acceptable? Yes X No

COMMENTS (exceptions): There are no mechanical or electrical PMP's for the MPRT. PMP's on the majority of the components are not warranted due to the relatively low usage of the MPRT: . Mechanical and electrical drive component inspections and lubrication were performed per $4 \mathrm{~F}-96-1141 / \mathrm{W}$ in June of 1996. This was most likely the first inspection and lubrication performed since the MPRT was received at FFTF in the late 1970's. The only problem found was the oil level in the Boston Gear reductor which was 3/4" low. The reductor holds $31 / 2$ gallons. Based on this experience an inspection/lubrication every 10 years or so is probably adequate.

B. Are all other action items (IRs, NCRs, etc.) properly identified and assigned? Yes $X$ No__ (Attach the summary of needed actions not in the database.)

COMMENTS (exceptions): NONE

C. Are near term spare parts adequate? Yes $X$ No

COMMENTS (exceptions): NONE

D. Are trend analysis data acceptable for continued operation?

Yes X No

COMMENTS (exceptions): NONE 


\section{COMPONENT STATUS REPORT \\ FOR \\ RSB CASK LOADING STATION (M-52/M-53)}

Period Covered:

$9 / 95$ through $2 / 98$

Date Reported: 2/98

Component: FFTF Cask Loading Station

Cognizant Engineer(s): Mechanical: JA Lamendola

Electrical: NJ Knuter

Approvals

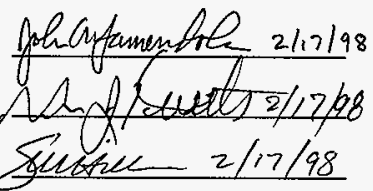

Cognizant Manager(s): Mechanical: SW Hiller

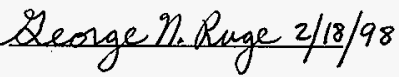

\section{Summary of Component Status:}

The Cask Loading Station is currently configured for $T-3$ operations. During this reporting period, the Phase II Fuel Offload ATP was completed, the first major fuel offload campaign (ISC Operations) was completed, the annual lubrication PMs were completed without any significant findings, and T-3 processing (along with required re-configuration of CLS) was completed. The Cask Loading Station, and supporting equipment, is fully operational with exception of the CLS Bag Sealer (repair is planned during this current work phase.)

\section{Trends Observed:}

Even during the current reporting period, which has seen a relatively high use for the Cask Loading Station, there has been minimal operation of the CLS elevator. During elevator operation, there has been no evidence of problems with the drive system. The periodic lube oil samples taken during the PMs have also shown no indication of problems. 


\section{Component Aging and Spare Parts Considerations:}

A. Effect of System Aging:

There are no components of the CLS for which system aging is a concern at this time. The portion of the CLS system most subject to aging (through the wear of components over time) is the elevator drive train. Since the jackscrews, drive motor, and gearing are only exercised during reconfiguration of CLS for the different casks, there has been very minimal drive operation. This situation is not expected to change unless FFTF receives a startup order.

\section{B. Long Term Maintenance:}

No long-term maintenance should be required other than the periodic lubrication and inspection of the elevator drive system. In the event of a startup mission in which the CLS sees more extensive use, a plan for periodic inspection of the jackscrew assemblies (similar in design to the BLTC jackscrews) should be developed. Due to infrequent use, the lubrication PM frequencies have been changed from an annual to a biennial requirement.

\section{Spare Parts Availability Strategy:}

A review indicates that spare parts for Cask Loading Station are available for all components where failure would be anticipated. As previously mentioned, due to minimal wear of system components, spare parts are not a concern for the Cask Loading Station.

4. Analysis, Conclusions, Follow up:

A. The Cask Loading Station is operational to support ISC, DSWC, and $\mathrm{T}-3$ processing. No major work is required during the standby period, and the CLS is ready for the increased use expected for a startup mission. 
5. Items Requiring Action:(Items on PTS, Procedures, Software, Etc.)

A. Near Term Items

Required By

4F-97-1506/W CLS Bag Sealer Will Not Work

Comments:

Although repair is planned for the bag sealer during the current quarter, a procedure change has allowed T-3 processing to proceed without the use of the bag sealer.

\section{B. Long Term Items}
4F-96-2544/M
Design and Fabricate DSWC / CLS Cask Restraints
$4 \mathrm{~F}-92-1489 / \mathrm{M}$
CLS Needs Additional Electrical Outlets
4F-96-0029/M
Design SWC Grapple Failure Recovery Equipment

\section{Comments:}

DSWC Cask restraints are required to support green fuel processing into the DSWC casks. Grapple failure recovery equipment is expected to be resolved through redesign of the SWC grapple system. Additional changes being considered include 1) using higher strength elevator support pins to prevent a CCC drop from initiating a drop of the elevator platform (along with the ISC) and 2) improving reliability of the overtravel limit switch system for the elevator.

6. Check off List

A. Are the current plant corrective maintenance, preventive maintenance, and calibration database items all properly identified and planned actions acceptable? Yes X No

B. Are all other actions (IR's, NCR's, etc.) properly identified and assigned? Yes X No (Attach summary of needed items not in database.)

C. Are near term spare parts adequate?

Yes $\mathrm{X}$

No

D. Are trend analysis data acceptable for continued operation?

Yes_X No 


\section{COMPONENT STATUS REPORT \\ FOR \\ SOLID WASTE CASK (SWC/M-57)}

Period Covered:

1/96 through 2/98

Component:

Solid Waste Cask (M-57)

Cognizant Engineer(s): Mechanical: JA Lamendola

Electrical: NJ Knuter

Cognizant Manager(s): Mechanical: SW Hiller

Electrical: GN Ruge
Date Reported: $\quad$ 2/98

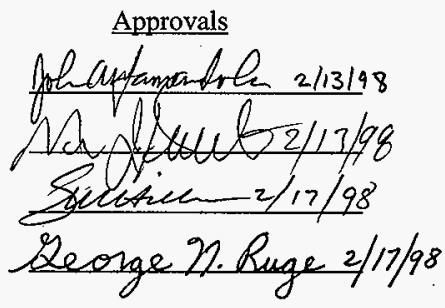

1. Summary of Component Status:

The Solid Waste Cask is not operational. During a CCC download at the Cask Loading Station, the hoist load chain jammed the drive sheave. During the event, the drive sheave was damaged, and during subsequent recovery efforts, the load chain was cut. The SWC hoist is partially disassembled with the upper hoist housing removed. Removal of the SWC hoist from the SWC, to allow further inspection, is expected to begin this month. Current plans are to not replace the drive components to restore the hoist to the current design. A major redesign of the SWC hoist/grapple system is expected to begin this quarter. The SWC is expected to be out of service for approximately 18 months during the redesign and modification of the SWC hoist/grapple system.

Also completed during the reporting period was installation of a new control console for the SWC. The new control console has worked without any significant problems. Some performance enhancing and system reliability enhancements are planned in the future. Additional changes may be required for the control system as a result of the planned hoist modification.

2. Trends Observed:

During the reporting period, the SWC was used to process $18 \mathrm{CCCs}$ into the Interim Storage Casks. The use during this two year period was significantly higher than in the past (prior to 1995, the SWC had been used to load only 5 DSWCs). Other than the hoist jam on the last CCC to be processed in this fuel offload campaign, there were only minor problems with the SWC. These problems included having difficulty in positioning the grapple at the grapple lock position, and excessive purge times at the IEM cell. 


\section{Component Aging \& Spare Parts Considerations:}

A. Component Aging: Component aging within the new control console is not expected to be a problem. With respect to the mechanical portions of the SWC, the hoist drive sheave (fabricated from gray cast iron) is an area of major concern. Excessive wear has been identified on the sheave teeth. At this time, the amount of wear is not known, but it is significant enough to cause a concern for the suitability of the cast iron sheave for such a critical use. This issue will be thoroughly investigated during the redesign of the SWC hoist.

B. Long Term Maintenance: There are currently no PMs done on the SWC. As part of the SWC hoist redesign, PMs and inspections required to support safe, reliable use of the SWC will be developed.

C. Spare Parts Availability Strategy: Spare parts for mechanical portions of the SWC are available where failure is anticipated: Electrical spare parts status is as follows:

The electrical spare parts inventory for the SWC is adequate.

SWC electrical spares can be presented in three categories; 1) the cask, 2) the cask / control console interface cable set, and 3) the control console.

Failure or wear prone electrical components for the cask itself are maintained in FFTF spares.

We have a spare SWC cable set. This cable set is now in the Electrical Shop to be modified for compatibility with the new control console per work document 4F-95-844/M. An ECN to correct a wiring configuration error on an existing $\mathrm{H}-4$ drawing must be written and incorporated into the work package before this work can continue.

Spares for microprocessor and computer components in the control console are maintained as "shop stock" in a common inventory with spares for the BLTC and other plant microprocessor based equipment.

The spares inventory for incidental electrical components in the control console is maintained by local electrical parts suppliers. For the most part, any component in the control console that fails can be replaced through normal procurement in a matter of days. A few long lead items are maintained in FFTF spares. There are also a few spare parts for the "old" SWC control console that can now be purged from FFTF spares. 
4. Analysis, Conclusions, and Follow-up:

A. Current plans are to remove the hoist assembly from the SWC and inspect the area of the hoist where the jam occurred. Results from this inspection will be used in evaluating requirements for the hoist redesign. Further conclusions on the status of the SWC hoist, along with the design changes required, will be included in an engineering study which will be completed prior to further SWC use.

5. Items Requiring Action:

The following work documents are the major items requiring resolution and are expected to be resolved as a result of the redesign of the SWC hoist/grapple system, or the item is expected to be completed during implementation period for this modification. At this time, due to the uncertainty in defining the scope of the SWC hoist/grapple redesign, specific need dates for these items have not been determined.

$4 \mathrm{~F}-97-2622 / \mathrm{W}$

4F-96-029/W

4F-96-028/W

$4 \mathrm{~F}-97-300 / \mathrm{W}$

$4 F-95-618 / W$

$4 \mathrm{~F}-96-2156 / \mathrm{M}$

$4 \mathrm{~F}-97-301 / \mathrm{M}$

$4 \mathrm{~F}-97-284 / \mathrm{M}$

4F-96-024/T

4F-97-1605/M

4I-97-0005/W
REPAIR SWC HOISTT

DESIGN SWC GRAPPLE FAILURE RECOVERY EQUIPMENT

PROVIDE MECH AND ELEC PMPS FOR SWC

CALIBRATE SWC PRESSURE TRANSMITTERS

REPAIR SPARE SWC GRAPPLE

NEW SWC CONTROL CONSOLE ENHANCEMENTS

UPGRADE SWC CONTROL SYSTEM SOFTWARE

SWC HARDWARE AND SOFTWARE WATCHDOG

TE-19 SWC FSAR TRANSIENT DOSE RATE DISCREPANCY

SWC SOFTWARE CHANGE FOR 28" PORT \& CLS

SWC ENCODER FOR GRAPPLE ELEV DRIFTED 
6. Check off List

A. Are the current plant corrective maintenance, preventive maintenance, and calibration database items all properly identified and planned actions acceptable? Yes $\underline{X} \quad$ No

Comments (exceptions): A need has been identified to develop PMs for the SWC. These will be provided during the SWC hoist redesign.

B. Are all other actions (IR's, NCR's, etc.) properly identified and assigned? Yes $\mathrm{X}$ No___ (Attach summary of needed items not in database.)

Comments (exceptions): None

C. Are near term spare parts adequate?

Yes X No

Comments (exceptions): None

D. Are trend analysis data acceptable for continued operation?

Yes No $\underline{X}$

Comments (exceptions):

See section on trends for further discussion of drive sheave wear indications. 


\section{ANNUAL SYSTEM ASSESSMENT REPORT \\ FOR \\ 41Z/FUEL STORAGE FACAITY}

Date of this Report:

$1-30-98$

APPROVALS

Date of Previous Report

1-24-92

Cognizant Engineer

Mechanical:

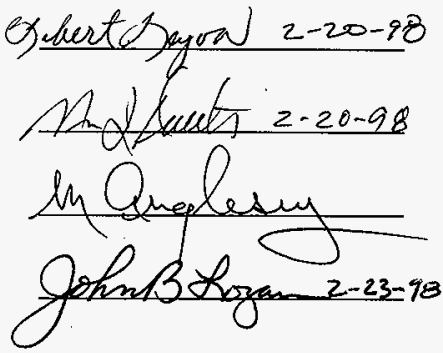

Cognizant Engineering Manager

Mechanical:

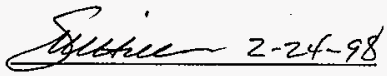

Electrical:

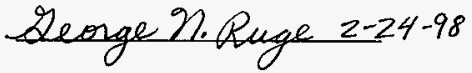

1. $\underline{\text { SCOPE }}$

System/Component
41-14/FSF Turntable Drive
PHF, FVA, Head \& Plugs,
FSF/FV and BLTC Transporter

Title

Fuel Storage Facility (FSF)

2. SUMMARY EVALUATION (Provide a general assessment of the overall health of the system. Include a discussion of the system's minimum operable equipment from plant procedure $\mathrm{PN}-7$ )

The FSF Turntable Drive and Basket Assembly remains operational. The turntable has been rotated approximately 145 times from 12/95-1/98 to access various ports. During these operations we have not encountered any notable problems.

The FSF Plug Handling Fixture (PHF) remains operational. The PHF has been used approximately 31 times from 12/95-1/98 to access various ports. During this period of time we have not encountered any major problems.

The FSF/FVA is operational. The FSF/FVA has been used to support the PHF during FFTF operations. The only area of concern noted on this equipment was the need for a replacement seal plate. The seal plate provides a seal boundary between FSF and the refueling equipment. 


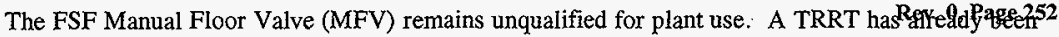
performed resulting in the safety concerns listed in section 3 (ITEMS REQUIRING ACTION). Initially the MFV was conceived to allow the other refueling floor valves to be dedicated to FFTF plant operations. This allowed greater flexibility for maintaining the refueling floor valves while allowing to efficiently operate the refueling floor valves during FFTF plant operations. Since that time the plant has changed its operating status to shutdown and now to hot standby. Either shutdown or standby, engineering is not going to pursue the qualification of the FSF MFV, unless the we were to receive orders to startup the plant.

The BLTC Transporter remains operational. The transporter PMP's (PMP-41C-14-M01 and PMP-41C-14-M02) are up to date. Since the last reporting period, the electrical receptacle for BLTC was relocated from the floor level to waist level, resolving a safety concern.

3. ITEMS REQUIRING ACTION (Items on PTS, Procedures, Software, etc.)

Near Term Items

\section{MECHANICAL}

a. $4 F-96-1311 / \mathrm{M}$, FSF/FVA Upper Seal can not be leak checked.

b. 4F-96-991/W, FSF Row "K" Buffer Pressure Anomally.

c. $\quad 4 \mathrm{~F}-97-319 / \mathrm{M}$, Manufacture a Spare FSF/FVA Seal Plate.

\section{ELECTRICAL}

a. 4F-96-779/W, BLTC Transporter Not Slow In the East Direction.

b . 4F-97-2557/W, BLTC Transporter Clean, Inspect And Lube.

\section{Long Term Items}

\section{MECHANICAL}

a. F8-1546/W, The FSF/MFV requires a vent path for deinert

b. F8-1547/W, Redesign the FSF/MFV control console to be more efficient. Present design is comprised of unreliable pressure switches to trigger the correct light indicator. Pressure gages must be installed to obtain a visual assurance.

c. F8-1548/W, Repair the Upper/Lower purge switch keyswitch for the FSF/MFV control console.

\section{$\underline{\text { Required By }}$}

As resources become available.

As resourses become available.

As resources become available.

"Old Intermittent Condition"

(Low Priority)

As resources become available.

Required By

Will be addressed at a later

date depending on the plant's status.

Will be addressed at a later date depending on the plant's status.
Will be addressed at a later date depending on the plant's status. 
d. F8-2550/W, Redesign the OPEN/CLOSE indication Will be addressed at a later date of the FSF/MFV. The gate status indications is not depending on the plant's status. located at a visually accessible location especially when BLTC is mated.

e. F8-2551/W, The FSF/MFV outer inflatable seal needsto be repaired. Inflatable seal was rolled out of its groove during the performance of the test procedure.

f. F8-2552/W, The FSF/MFV needs to be labeled so it can only be used at FSF.

Will be addressed at a later date depending on the plant's status.

Will be addressed at a later date depending on the plant's status.

Startup

g. $4 \dot{F}-97-320 / W$, Build a spare FSF Turntable

Drive Pendant. The drive control pendant needs periodic repair due to normal wear. A spare pendant would permit continued operation.

\section{ELECTRICAL}

a. None

4. TRENDS (Discuss trended parameters. See Appendix $\mathbf{K}$ for typical parameters which can be used for trending studies.)

\section{MECHANICAL}

The FSF Periscope remains visible. The lens has been cleaned in 1990 and again in 1994.

\section{ELECTRICAL}

1. The BLTC Transporter is generally reliable. Past rare electrical problems have usually related to either the power cable or electrical circuit interlocks. The transporter's power cable occasionally (approximately once/year) becomes tangled on it's take-up reel; then, while driving east it automatically disconnects itself from the wall mounted electrical supply source junction box. Operators typically monitor the power cable take-up reel during east drives. This action tends to preclude the manifestation of cable tangling problems.

2. The transporter power cable and cable reel assembly are subject to normal wear. It is anticipated that the power cable, and some cable reel components, may occasionally require repair or replacement.

5. SYSTEM AGING, SPARE PARTS CONSIDERATIONS, AND LONG TERM MAINTENANCE PHILOSOPHY

The FSF Turntable Drive and Basket Assembly have shown no signs of abnormalities since the last reporting period. During this period of time, there hasn't been any significant J-1's written against the turntable drive and basket assembly. The sytem was designed for a $20 \mathrm{yr}$. life. The only area of predictable repairs (in the area of available spare parts) is the turntable drive which is accessible from the $550 \mathrm{ft}$. level. At the present time, we do not have in stock a replacement motor, a 
reduction gearbox and the necessary shafts with meshing gears to quickly replace a failed item. It is difficult to predict failure of these items since we haven't had any problems. Engineering does not plan to procure these items for the present plant status based on frequency of usage, nonproblems with the turntable drive and the design life of the system. In the area of preventive maintenance, we should investigate the possibility of lifting the shield plates on the periphery of the storage vessel to lube the turntable bearing; and continue PMs on the transporter and PHF pressure relief calibration.

The FSF/PHF is operable to support FFTF operation in the next two years. The PHF has been relatively maintenance free since the last reporting period. An indepth evaluation of the spare parts inventory indicates that there are adequate spare parts to support any predictable major repair. Due to the infrequent usage of the FSF/PHF during normal operation, engineering accesses that this equipment should not be affected during this standby period.

FSF/FVA is operable to support any FFTF operation in the next two years. During the spare parts evaluation, engineering identified the seal plate as a potential spare part's problem. A J-1 has been initiated, a resolution already written and material has been ordered to cover this area. Engineering will request the $\mathrm{J}-1$ to be worked during the upcoming quarters.

The BLTC Transporter is operable to support any FFTF operation in the next two years. With the exception of the power cable, component aging should not be a factor for continued operation. There is presently a sufficient amount of electrical spares.

\section{CHECKOFF LIST}

A. Accessible parts of the entire system or component have been thoroughly walked down at least once in the past 30 days to view current performance, equipment status and conditions. Yes $\underline{X}$ No

\section{COMMENTS (exceptions): None}

B. Are there any conditions which might require limitations different from operating limits as defined in the SDDs, the FSAR, or the Plant Technical Specifications? Yes No X

\section{COMMENTS (exceptions): None}

C. Are there trip settings, set points, interlocks, etc., that should be changed from those currently established? Yes__. No _ X

COMMENTS (exceptions): Refer to Section 2 above for limitation on the Boom Pivot and the Shoulder rotate. These limitations have already been accounted for in the applicable IN procedure. 
D. Are there interface areas which have not performed acceptably, which require resolution? Yes___No X

COMMENTS (exceptions): None

E. Are there temporary plant or procedural conditions which will and should remain in place? Yes__No_X

Attach list of MOD(L)/ECN(L)s, and OSPs that are currently active. Provide justification for continuing temporary MOD (L)s and ECN (L)s.

COMMENTS (exceptions): NA

F. Is any retesting or special testing (e.g., OSP) required? Yes__No_X

COMMENTS (exceptions): NA

G. Are the current plant corrective maintenance, preventive maintenance, and calibration database items all properly identified and are planned actions acceptable? Yes_X No

COMMENTS (exceptions): None

H. Are all other action items (NCRs, Irs, etc) properly identified and assigned? Yes $\mathrm{X}$ No___ (attach the summary of needed actions not in the data base)

COMMENTS (exceptions): There is no outsanding NCRs, Irs, etc. at the present time.

I. Are there any special operating considerations? Yes__ No $\underline{X}$

COMMENTS (exceptions): NA

J. Are near term spare parts adequate? Yes $\underline{X}$ No

COMMENTS (exceptions): See Item 5 above for explanation.

K. Have any safety issues (radiological, industrial) been identified that remains unresolved? Yes No_X

COMMENTS (exceptions): None

L. Have all components data been entered into the Plant information database?

Yes X No

COMMENTS (exceptions): 
M. Have applicable SISI inspections been conducted? Yes No

COMMENTS (exceptions): NA

N. Has a cleanliness evaluation been completed? Yes_X_No_-

Are any issues still unresolved? Yes No $\underline{X}$

COMMENTS (exceptions): None

\section{REFERENCES}

None

8. ATTACHMENTS

(Attach any CSRs, data sheets showing system performance, or other material demonstrating the substantive nature of this review). 


\section{ANNUAL SYSTEM ASSESSMENT REPORT for \\ SYSTEM(S) 51A/B}

Date of This Report $02 / 12 / 98$

Date of Previous Report 01/28/92
APPROVALS

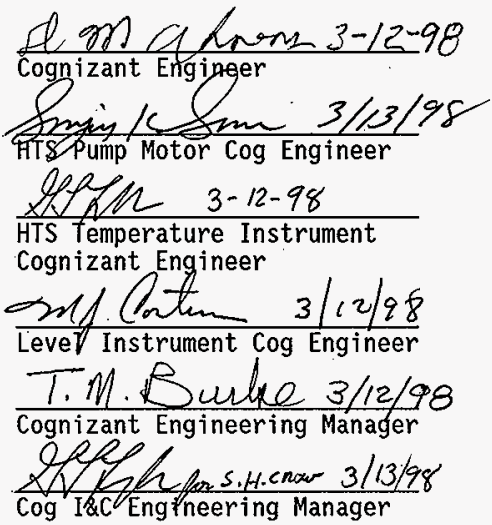

1. SCOPE

\section{System/Component}

51
Title

Reactor Heat Transport System

2. SUMMARY EVALUATION

The reactor was shut down on 03/19/92 and has not been re-started. System 51 was performing satisfactorily during reactor operation and has continued to do so during standby. No difficulties were identified in the assessment of the loop hydraulics from the previous power cycles, and the thermal transient usage continued to be very low. Transient usage at time of the shutdown is compared to the design allowances below:

Design Transient

Normal Startup - N4U

Normal Shutdown - N4D

Normal Scram - U1

$$
\text { No. Accumulated }
$$

88

75

82
Design Allowance

843

118

580

The effect of thermal transients on component groups to date is lower than the accumulated transients and is detailed in the cycle transient. reports. 
Since the time the reactor was shut down the Main Heat Transport System has been maintained at refueling temperature, $380^{\circ} \mathrm{F}$ to $420^{\circ} \mathrm{F}\left(193^{\circ} \mathrm{C}\right.$ to $216^{\circ} \mathrm{C}$ ) primarily using the energy supplied by the secondary sodium pumps.

When the standby order was received, preventive maintenance procedures. on the secondary pony motors were resumed. Performance of 51A/B-2-M02 (overrunning $c$ ] utch $0 i 7$ change) on $P-5$ revealed the sea 1 in the overrunning clutch was leaking oil. The clutch was changed out with a spare from spare parts. The existing clutch was rebuilt and placed in spare parts. The existing clutch appeared to be like new except for the leaking seal which was replaced.

The secondary sodium inventory remains constant which indicates there are no leaks in the IHX tubes.

The oil consumption through the sodium pump seals remains constant.

The FFTF SISI program, WHC-SD-FF-SISI-006, requires that normally accessible mechanical shock arresters (snubbers) on Seismic Category 1 pipe hangers be randomly tested on an annual basis. Because of the current plant configuration, the 1997 annual snubber inspections included testing of snubbers from primary system Cells 521 and 531 . The testing of snubbers from Cell 531, which included approximately ten percent of each snubber size, was completed without any failures. The testing of snubbers from Cell 521 resulted in failure of three of seven snubbers of the PSA $\frac{1}{4}$ and $\frac{1}{2}$ design size. Each of the snubbers that failed showed an increase in drag force, which was above the manufacturer's suggested allowable. The cause(s) of these failures cannot be determined until they are sent to the supplier for refurbishment. The most likely causes for the increased drag are infiltration of dust/rust into the working mechanism, construction damage to the snubber (someone stepped on it), or hardening of the grease from elevated ambient temperatures.

Further testing of primary system snubbers is planned in the future to gather additional data for potential reactor startup. This testing will only be done if a decision is made to proceed with an Environmental Impact Statement (EIS), which would suggest that a restart order may be forthcoming. Additional testing and evaluation will be needed to better understand failure rates, causes of the failures, and corrective actions needed to support startup. Risk to the system in the present standby condition is considered minimal because the piping is operating in an isothermal state at a reduced temperature $\left(\approx 400^{\circ} \mathrm{F}\right)$. Piping design calculations assumed that seismic reactions occur at operating temperatures $\left(>800^{\circ} \mathrm{F}\right)$, which are more severe than present conditions. Additionally, although a number of untested snubbers may also fail, the failures are expected to follow what we've seen to date. That is, the snubber exhibits increased drag forces, but does not "lock up" and become a rigid strut. Therefore, the present condition is considered acceptable for continued standby or shutdown, but further testing and evaluation will be necessary to support a reactor restart.

The sodium temperature instruments for the primary and secondary HTS loops and the sodium level instruments for the primary and secondary 
main sodium pumps and the secondary pump expansion tanks are operating acceptably for the standby condition. Calibration status of the sodium temperature and level instruments are current in accordance with the $\mathrm{PM} / \mathrm{S}$ requirements for maintenance of the instrumentation.

The condition of the primary sodium pump main motors is satisfactory. The primary sodium pumps are operating on pony motor, with the main motor brushes removed. The main motor heaters are energized to help keep moisture out of the motor. The secondary sodium pump main motors, associated controls, and liquid rheostats are operating satisfactorily. The main motor brushes have not been a problem. Operations and the Cognizant Engineer check the brushes weekly for wear. The brushes are replaced at Cognizant Engineer request using PMP-51A/B-2-E03 when required.

The sodium temperature from each DHX module is monitored by 4 instrument channels (thermocouples plus associated electronics). Since reactor shutdown, the instrument groups have been calibrated only on request, when comparison of the temperature channels indicated calibration was required. Calibration has recentiy been changed to a 2 year periodicity, based on an increased number of requests for calibration and instrument failures.

It is current7y planned to perform an OSP (0SP-97-02) to confirm the acceptability of operating for extended periods on two rather than three secondary main motors (as an energy/cost savings measure). All DHX outlet temperature instrument channels on the sodium loop with the main motor shut down during 0SP-97-02 should have a current calibration prior to conducting the OSP since an out of calibration or failed temperature instrument could defeat the group low temperature alarm.

\section{ITEMS REQUIRING ACTION (Items on PTS, Procedures, Software, etc.)}

\section{A. Near Term Items}

At this time there are no Corrective Maintenance (CM) items that require immediate priority on System 51 .

\section{B. Long Term Items}

0SP-97-02: Extended operation on two secondary main motors (to conserve energy and money).

Perform additional testing of primary system snubbers to gather data for potential reactor restart.

\section{TRENDS}

The oil consumption through the sodium pump seals remains constant. The coastdown time of the secondary pumps remains constant. 
HNF-2380

Rev. 0, Page 260

5. SYSTEM AGING, SPARE PARTS CONSIDERATIONS, AND LONG TERM MAINTENANCE PHILOSOPHY

A. Discuss effects of system aging.

There are no signs of major detrimental effect of age on the mechanical system components.

The overrunning clutch seal leak might be a sign that after 20 years the seals are aging. A lift fixture was designed, fabricated and tested so the secondary pony motors could be serviced without removing the hatch cover. If the others have to be replaced, it will now be a rather inexpensive job.

Random and age related failures of the electronic components within the sodium temperature and level instruments have occurred. As the systems age, additional failures are expected to occur.

No aging problems associated with the main sodium pump motors and controls have been noted, except there have been numerous problems with aging Lube 0il Skid controls (i.e., switches not working, relays fajling, wires breaking off).

Age related failures of the electronic components within the DHX outlet temperature instruments, particularly capacitors, are common place. An estimated $25 \%$ of the instruments have failed over the last three years. Instruments will be rebuilt or replaced as they fait.

B. Discuss the strategy for near term spare parts and their availability strategy.

Spare seals for the overrunning clutches were placed in spare parts.

A check of the spare parts for this ASAR indicated there were no sodium pump lube oil seals listed in spare parts. According to the warehouse personnel, they were excessed in May 1995 by document number W95D17011. They should not have been excessed. We will investigate how it happened. It is highly unlikely that there would be a seal problem at standby with the secondary cover gas pressure reduced. If a startup order is received, spare seals should be ordered as soon as possible for long term operation.

Sufficient spare parts exist for repair of sodium level and temperature instrumentation associated with system 51A/B.

Sufficient spare parts also exist for the main sodium pump motors and controls except that direct replacement parts for many of the Lube $0 i l$ Skid controls are no longer available. Substitute parts have to be identified, and purchased for spare parts. 
Sufficient spare parts exist for repair/replacement of the existing defective DHX outlet temperature instruments. Additional components will be required for future repairs.

C. Standby Maintenance P7an: Discuss a $p 7$ an which ensures essential system functions for standby are provided and minimizes equipment degradation. Assume the standby period extends for the next one to two years. Include in the plan, as a minimum: 1) the identification of hardware to be repaired, replaced, or upgraded; and 2) the frequency of routine field maintenance, ensuring material and spare parts are identified to support these activities (i.e., refurbish pumps, etc.).

\section{Primary Sodium Pumps:}

The PMPs (Preventive Maintenance Procedures) have been maintained on the primary pony motors since reactor shutdown. The main motor leads were disconnected to preclude any chance of starting the main motors. The lube oil skid check valves, were modified so there is an adequate supply of lube oil to the bearings and seals by gravity from the supply reservoir and the lube oil skids are shut down. The shutdown watch monitors the oil level in the supply reservoir. The motor space heaters are running to prevent moisture buildup.

The primary liquid rheostats are shut down. The sodium carbonate electrolyte has been left in because it acts as a rust inhibitor.

Secondary Sodium pumps:

When the shutdown order was received and draining of the secondary system was imminent the scheduled maintenance packages (PMPs) were discontinued on the secondary lube oil skids, pony motors and Tiquid rheostats. When the standby order was received, the PMPs were re-instated on this equipment.

\section{Snubbers:}

If a decision is made to begin the EIS process, additional snubbers from cel1 521 wi11 be tested to more accurately determine the failure rate, cause of faiTure and required corrective actions.

Electrical and Instrumentation \& Controls:

Preventive maintenance will be maintained to assure the sodium level instruments, sodium temperature instruments and main sodium pump motors and controls continue to support the standby condition. 


\section{CHECKOFF LIST}

A. Accessible parts of the entire system or component have been thoroughly walked down at least once in the past 30 days to view current performance, equipment status and condition. Yes $\&$ No COMMENTS (exceptions): None

B. Are there any conditions which might require. 1 imitations different from operating limits as defined in the SDDs, the FSAR, or the Plant Technical Specifications? Yes No $c$ COMMENTS (exceptions): None

C. Are there trip settings, set points, interlocks, etc., that should be changed from those currentiy established? Yes No

COMMENTS (exceptions): None

D. Are there interface areas which have not performed acceptably, which require resolution? Yes No

COMMENTS (exceptions):None

E. Are there temporary plant or procedural conditions which will and should remain in place? Yes No

Attach list of $M O D(L) / E C N(L) s$, and OSPs that are currently active. Provide justification for continuing temporary MOD (L)s and ECN (L)s.

COMMENTS (exceptions): None

F. Is any retesting or speciat testing (e.g., OSP) required? Yes No

COMMENTS (exceptions): None

G. Are the current p1ant corrective maintenance, preventive maintenance, and calibration database items all properly identified and are planned actions acceptable? Yes $\_$No COMMENTS (exceptions):

H. Are all other action items (NCRs, Irs, etc.) properly identified and assigned? Yes $d$ No data base) (attach the summary of needed actions not in the COMMENTS (exceptions): None 
I. Are there any special operating considerations? Yes No List or Reference: None

J. Are near term spare parts adequate? Yes_ No COMMENTS (exceptions): None

K. Have any safety issues (radiological, industrial) been identified that remain unresolved? Yes No $A$

COMMENTS (exceptions): None

L. Have all component data been entered into the Plant information database?

Yes $\downarrow$ No

COMMENTS (exceptions): None

M. Have applicable SISI inspections been conducted? Yes $\mathcal{G}$ No

COMMENTS (exceptions): None

N. Has a cleanliness evaluation been completed? Yes No 1

Are any issues still unresolved? Yes No $r$

COMMENTS (exceptions): None

\section{REFERENCES}

\section{ATTACHMENTS}

(Attach any CSRs, data sheets showing system performance, or other material demonstrating the substantive nature of this review).

Table of pump and seal operating time.

Plots of the secondary pump seal oil consumption 


\section{COMPONENT STATUS REPORT \\ FOR \\ (COMPONENT NAME/NUMBER)}

Period Covered: 02/01/92 through 02/15/98

Component: HTS pumps

Cognizant Engineer(s):

D. M. Ahrens

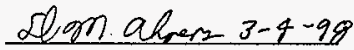

Cognizant Manager(s):
Date Reported:

Approvals

1. Summary of Component Status:

Primary Sodium Pumps; $\mathrm{P}-1, \mathrm{P}-2$, and $\mathrm{P}-3$

Since $03 / 19 / 92$ when the reactor was shut down, the primary pumps have been operating on pony motor to maintain circulation in the primary HTS.

Secondary Sodium Pumps; P-4, P-5, and P-6

Since the reactor was shut down the Main Heat Transport System has been maintained at refueling temperature, $380^{\circ} \mathrm{F}$ to $420^{\circ} \mathrm{F}\left(193^{\circ} \mathrm{C}\right.$ to $216^{\circ} \mathrm{C}$ ) primarily using the energy supplied by the secondary sodium pumps.

2. Trends Observed: (Attach graphs and tables as necessary)

The PDS (Plant Data System) was shut down soon after the reactor was shut down, therefore most of the trends that were evaluated during power operation are not available.

SC-51-5, the pump coastdown times are still performed on the secondary pumps and have remained constant. There is no discernable difference between the present coastdown time and the coastdown time when the pumps were new.

The $0 i 1$ consumption through the sodium pump seals remains constant. 
3. Component Aging and Spare Parts Considerations:

The seal in the overrunning clutch in P-5 began leaking oi1. The clutch was changed out with a spare from spare parts. The clutch appeared to be like new except for the leaking seal. The seal was replaced and the clutch was placed in spare parts. The overrunning clutch seal leak might be a sign that after 20 years the seals are aging. A lift fixture was designed, fabricated and tested so the secondary pony motors could be serviced without removing the hatch cover. If the others have to be replaced, it will now be a rather inexpensive job. Spare seals for the overrunning clutches were placed in spare parts.

A check of the spare parts indicated there were no sodium pump lube oil seals listed. According to the warehouse personnel1, they were excessed in May 1995 by document number W95D17011. They should not have been excessed. We will investigate how it happened. It is highly unlikely that there would be a serious seal problem at standby with the secondary cover gas pressure reduced. The $\Delta \mathrm{P}$ across the upper seal is the sum of the cover gas pressure and the lube oil skid pressure of about $35 \mathrm{psi}$. During operation the secondary cover gas pressure is $90 \mathrm{psi}$ so the $\Delta P$ is about $125 \mathrm{psi}$. During standby the cover gas pressure has been reduced to about $20 \mathrm{psi}$. reducing the $\Delta \mathrm{P}$ to about $55 \mathrm{psi}$. If a startup order is received, spare seals should be ordered as soon as possible for long term operation.

4. Analysis, Conclusions, Followup:

The overall reliability and performance of the pumps is excellent based on existing data and observations.

5. Items Requiring Action: (Items on PTS, Procedures, Software, etc.)

A. Near Term Items

None

B. Long Term Items

None
Required By

$$
\text { N/A }
$$

Required By

N/A

6. Checkoff List

A. Are the current $\mathrm{p} 7$ ant corrective maintenance, preventive maintenance, and calibration database items all properly identified and planned actions acceptable? Yes_ \& No

COMMENTS (exceptions): None 
B. Are all other action items (IRs, NCRs, etc.) properly identified and assigned? Yes $\checkmark$ No actions not in the database.) (Attach the summary of needed

COMMENTS (exceptions): None

C. Are near term spare parts adequate? Yes_ $\checkmark$ No

COMMENTS (exceptions): None

D. Are trend analysis data acceptable for continued operation? Yes $\_$ No

COMMENTS (exceptions): None 


\section{FIGURE 1}

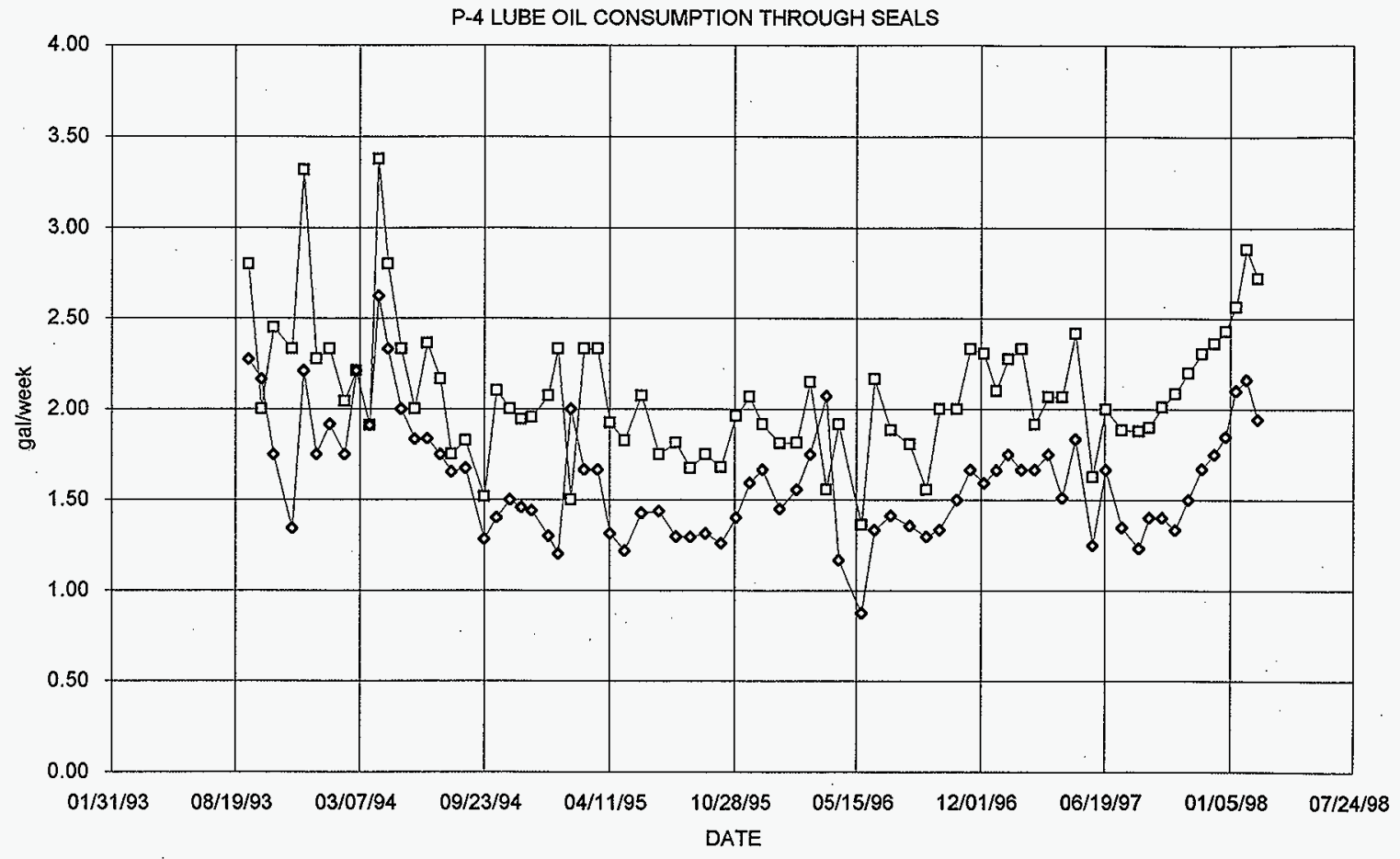

[- Upper Seal -o- Lower Seal 


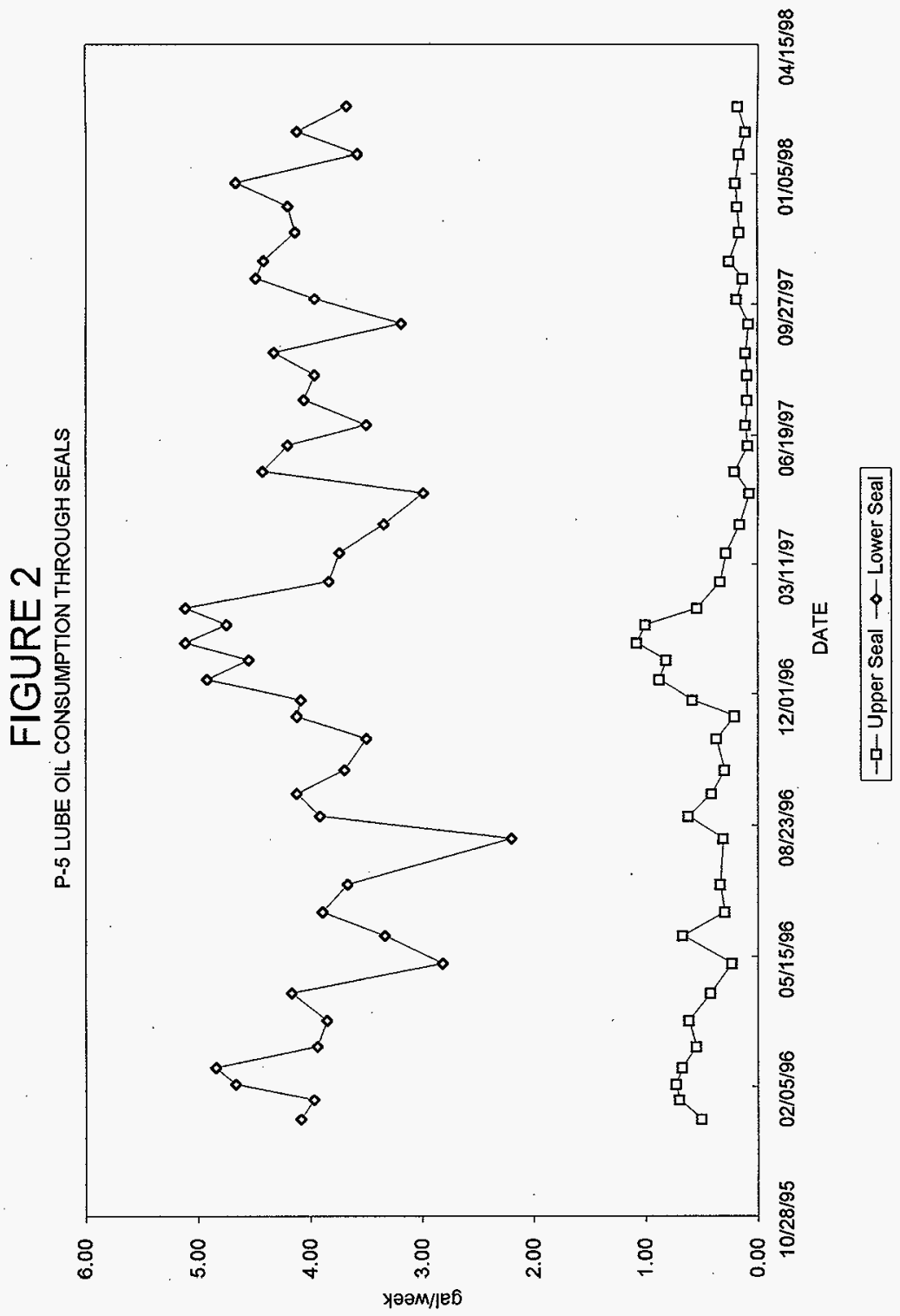




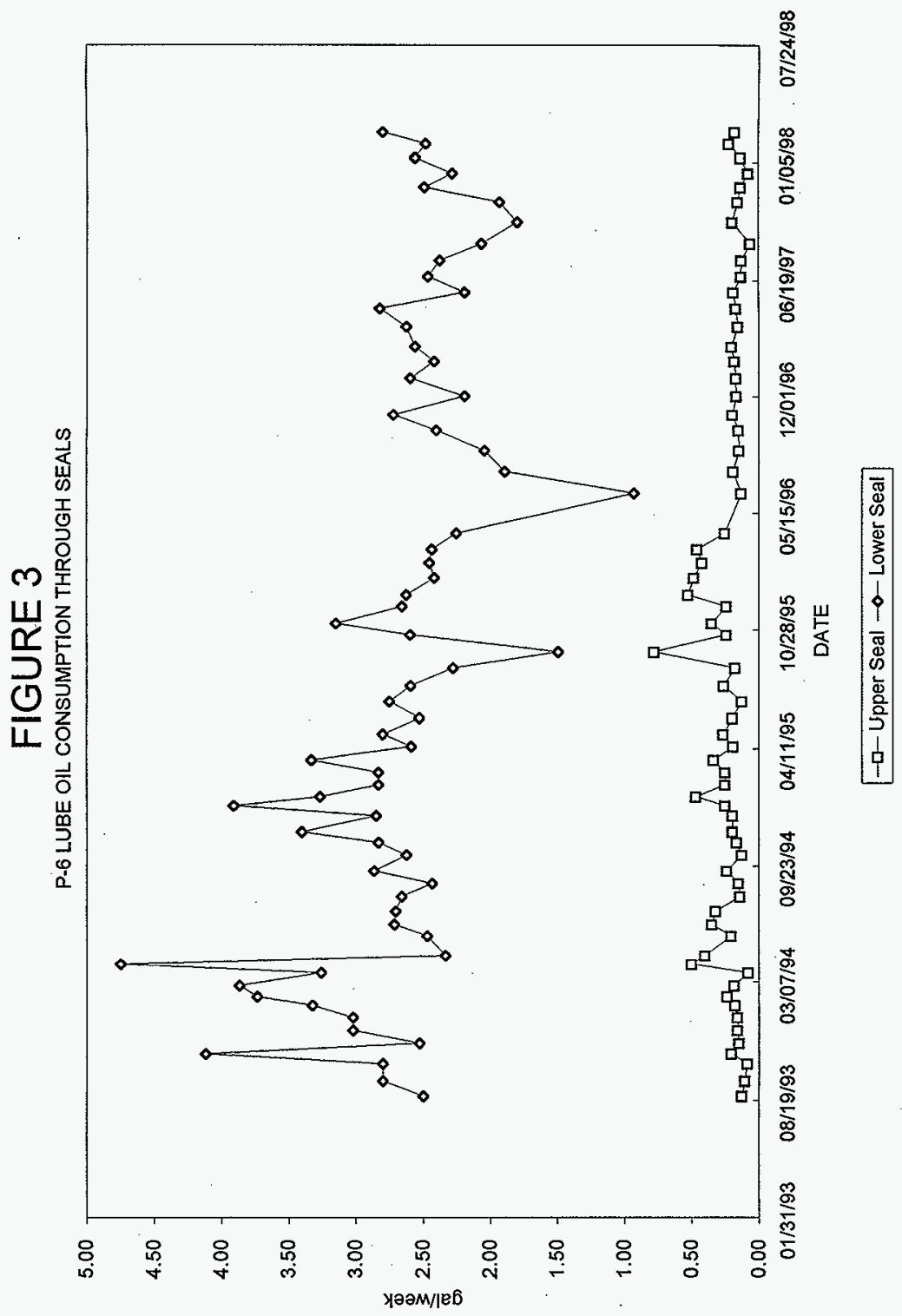


HTS PUMPS

ESTIMATED

MAIN MOTOR, PONY MOTOR and SEAL OPERATING TIME

$02 / 01 / 98$

\begin{tabular}{|c|c|c|c|c|c|c|c|}
\hline & Date & $\mathrm{P}-1$ & $\mathrm{P}-2$ & $\mathrm{P}-3$ & $P-4$ & $\mathrm{P}-5$ & $\mathrm{P}-6$ \\
\hline Main Motor Time & $02 / 01 / 98$ & 60,314 & 69,495 & 69,531 & 159,746 & 159,560 & 159,728 \\
\hline Pony Motor Time & $02 / 01 / 98$ & 94,071 & 95,344 & 94,392 & 10,080 & 9,745 & 9,309 \\
\hline Total Pump Time & $02 / 01 / 98$ & 154,385 & 164,879 & 163,923 & 169,826 & 169,105 & 169,747 \\
\hline Upper Seal Time & $02 / 01 / 98$ & 154,385 & 134,132 & 134,878 & 131,322 & 39,994 & 54,093 \\
\hline Upper Seal Changes & $02 / 01 / 98$ & 0 & 2 & 3 & 1 & $1 *$ & 5 \\
\hline Lower Seal Time & $02 / 01 / 98$ & 154,385 & 134,132 & 163,923 & 169,826 & 169,305 & 143,268 \\
\hline Lower Seal Changes & $02 / 01 / 98$ & 0 & 1 & 0 & 0 & 0 & 2 \\
\hline
\end{tabular}

note: P-1 Pump changed out at 10150 hours in April 1980.

Total pump time is Main Motor + Pony Motor time

Seal time is Main Motor + Pony Motor

* P-5 was shut down 05/26/93 for first upper seal change e 129,311 hrs which was 14.75 years on the seal when changed.

NOTE: The pump time is estimated from 09/06/93 when the PDS was shut down.

Assume secondary pumps run 8,600 hours/year $(8,760$ less 160 hours for maintenance) on main motor. 4.4 years $X 8600$ hours $/$ year $=37,840$ hours. Pony motor time insignificant.

Assume primary pumps run 8700 hours/year on pony motors. $4.4 \times 8700=38,280$ hours. 


\section{ANNUAL SYSTEM ASSESSMENT REPORT \\ for \\ SYSTEM $51 \mathrm{C}$}

Date of This Report January 30, 1998
Date of Previous Report January 31, 1992

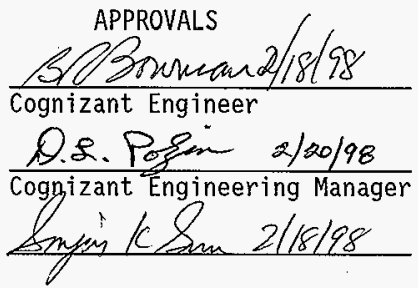

1. SCOPE

System/Component

Title

$51 \mathrm{C}$

Dump Heat Exchangers and Preheaters

\section{SUMMARY EVALUATION}

The Dump Heat Exchangers have remained dormant and inoperable since the 1992 report due to the FFTF standby conditions, except for the preheaters, which have been maintained at a minimum of two per 1oop in accordance with MOE requirements.

Three preheaters, one in each loop, were abandoned in place due to the extreme difficulties in repairing those units $(Q-1, Q-6, Q-9)$. For the remaining nine units, a program was established initially on a once a week basis, now monthly, to start and operate the preheaters in one loop. Longer periods of inactivity had caused innumerable startup problems. The program has appeared to work well for the last two years, both in the mechanical and electrical operations.

The fuel oil supply to the preheaters is trace heated to prevent wax coagulation in the fuel, which plugs the fuel filter. Three trace heat circuits failed this winter and troubleshooting was attempted. One circuit in the west was repaired, but not reinsulated due to the wet weather and the wet insulation. A second circuit in the south was not worked due to the extensive scaffold requirements. (The third circuit for Q-1 preheater supply was postponed since $Q-1$ is an abandoned unit.) At this point, annual fuel oil test results were returned and the cloud point was at $10^{\circ} \mathrm{F}$. An anti-gel fluid was added to the tanks and circulated to the preheaters, which reduced the cloud point to $15^{\circ} \mathrm{F}$ below zero. Further trace heat repairs will not be required since procedures were established to add the anti-gel with each fuel oil refill.

In an effort to minimize heat losses from the $\mathrm{DHX}$ s during standby, a barrier was installed on the tornado grill above the dampers to prevent convective heat loss. The barrier consists of a thin sheet of silicone foam rubber sealed with RTV at the lap joints covered with a two inch layer of fiberglass insulation board. This barrier was very efficient in reducing the heat Toss, but would have to be removed if startup proceeds. 
HNF-2380

Rev. 0, Page 272

2. continued

During this standby period, the Dump Heat Exchanger stacks became a major target for starling roosting with the birds returning in the thousands to swoop down and roost in the louvered areas of the stacks. This allowed access into the internal of the stack where they deposited wastes onto the dampers and the tornado grill above the dampers. Subsequent to the addition of the insulation barrier on the tornado grill, the wastes accumulated on this barrier as well. In 1997, screens were installed over the louvered portion of the stack and were successful in preventing large flocks of birds. Small flocks still came and roosted on the handrails and equipment around $E-11$ and created quite a mess. This equipment needs to be cleaned for personnel health reasons as well as equipment health. The flocks were dispersed using pyrotechnics and propane cannons. Propane cannons placed on the SSF roof continue to operate on a daily basis at dusk to prevent the starling roosting at night with great success.

To determine if the bird wastes on the dampers had migrated from the top of the dampers to the tube bundle fin surfaces, an inspection program of the south units was conducted. A manway between the dampers and tube bundle was opened to visually inspect the tubes. A grating over the tubes prevented direct visual. Due to the $350^{\circ} \mathrm{F}$ air temperature inside, remote viewing using Dyncorp NDE personnel and their remote camera was conducted with mixed results. Aligning the camera lens vertically downward through the sma11 (1-3/16" $\left.\times 1-1 / 2^{\prime \prime}\right)$ holes was extremely difficult with the camera bundle resting on a 20 foot long aluminum angle. The small sampling of tubes that were visible indicated a good correlation to the grating surface. If the grating is clean, the tubes are clean. During the inspection of E-11, it was noted that a section of grating had slipped off the support beam and was resting on the tube support assembly. Two work requests were initiated; for startup activities only, to inspect the other eight units for this grating condition and to repair the grating.

To prevent further degradation of the inlet plenum of the DHXs, sheet metal covers were added to the sloped surface of the plenum near the isolation gates. Water and dirt accumulation will be avoided in this area to prevent corrosion of the corten steel.

To prevent bird intrusion into the cruciform area between the DHX units, a) 1 openings above the 540 foot elevation were closed with expanded metal. The birds will be excluded while the natural ventilation will still be provided.

3. ITEMS REQUIRING ACTION

A. Near Term. Items

Reenergize space heaters in fan motors to prevent

Required By $2 / 15 / 98$

further degradation from moisture (4F-97-249/W)

Megger fan motor stator windings per PMPs (4F-97-309/W) 3/31/98

Clean bird wastes from E-11 equipment (4F-98-168/W) 5/1/98

Evaluate condition of fan, motor and VSD journal bearings $9 / 30 / 98$ $(4 F-97-313 / W)$ 
3. continued

B. Long Term Items

Conduct studies for startup to replace preheaters with another type of heater, such as, electric under tube bundle or butane, directfired unit under tube bundle (4F-97-308/A). Intense maintenance labor, obsolete spare parts, and operational reliability combined with increasing fuel oil costs indicated a need for replacement.

Conduct studies for startup to replace variable speed electromagnetic coupling and Regutron units with direct motor fan connection and variable frequency drive units $(4 \mathrm{~F}-97-310 / \mathrm{W})$. The electromagnetic couplings have inner roller bearings that have already burned up on one unit. Repair of the bearings requires removal of unit. Combined with unreliable regutron controls, this study is imperative for startup.

4. TRENDS

The only trend available is for the operation of the preheaters which have operated much better since a monthly exercising of the systems is performed by loop.

5. SYSTEM AGING, SPARE PARTS CONSIDERATIONS, AND LONG TERM MAINTENANCE PHILOSOPHY

A. Discuss effects of system aging.

The preheaters are the only items to continue to age due to operation; which is very limited. The units are operated one loop (three units) per month for about an hour and then twice a year about one preheater per loop for two days during pump outages. The aging effect is minimal. of greater aging concern is the idleness of other DHX components, i.e., damper actuators, fan bearings and linkages.

B. Discuss the strategy for near term spare parts and their availability strategy.

Spare parts still exist and have been maintained for the preheaters. A review of the spare parts listing indicated that the categories for the fan drive train spares and the isolation gate actuator spares were eliminated and would have to be reevaluated for startup activities. Many of the spares in the drive train category were for the VSD and Regutron, which may be replaced for startup anyway.

C. Standby Maintenance P1an: Discuss a plan which ensures essential system functions for standby are provided and minimizes equipment degradation.

Preheater maintenance is required. The current plan to postpone most preventive maintenances, until the run times indicate the maintenance is required, remains valid. Other $p$ lanned maintenance is excessive and has proved to create more problems than are 
5.C. continued

solved. Running the preheaters for a few hours once a month has aiso resulted in ease of startup and operations. Preventing the units from sitting idle for six months and then restarting them has been an added benefit to operations.

Other maintenance required is lubrication of the dampers for the preheaters and opening and inspecting the drive train journal bearings to assess their health.

\section{CHECKOFF LIST}

A. Accessible parts of the entire system or component have been thoroughly walked down at least once in the past 30 days to view current performance, equipment status and condition. Yes $x$ No

COMMENTS (exceptions): None

B. Are there any conditions which might require limitations different from operating limits as defined in the SDDs, the FSAR, or the Plant Technical Specifications? Yes No $\mathrm{X}$

COMMENTS (exceptions): Technical Specifications are no longer applicable to the DHXs.

C. Are there trip settings, set points, interlocks, etc., that should be changed from those currently established? Yes_. No $\mathrm{x}$

COMMENTS (exceptions): None

D. Are there interface areas which have not performed acceptably, which require resolution? Yes No $x$

COMMENTS (exceptions): None

E. Are there temporary plant or procedural conditions which will and should remain in place? Yes No $\mathrm{x}$

COMMENTS (exceptions): None

F. Is any retesting or specjal testing (e.g., OSP) required? Yes_ No_ $x$ COMMENTS (exceptions): None

G. Are the current plant corrective maintenance, preventive maintenance, and calibration database items all properly identified and are planned actions acceptable? No

COMMENTS (exceptions): None

H. Are all other action items (NCRs, IRs, etc.) properly identified and assigned? Yes N/A No

COMMENTS (exceptions): None 
6. continued

I. Are there any special operating considerations? Yes__ No _ $x$ List or Reference: None

J. Are near term spare parts adequate? Yes $x$ No COMMENTS (exceptions): See 5.B.

K. Have any safety issues (radiological, industrial) been identified that remain unresolved? Yes No $\mathrm{x}$

COMMENTS (exceptions): None

L. Have all component data been entered into the Plant information database? Yes $x$ No

COMMENTS (exceptions): None

M. Have applicable SISI inspections been conducted? Yes_ $x$ No COMMENTS (exceptions): None

N. Has a cleanliness evaluation been completed? Yes_ $X$ No Are any issues still unresolved? Yes $x$ No

COMMENTS (exceptions): The cleaning of E-10 and E-11 externals, especially E-11 fan equipment, for bird wastes is vital to the health of the DHX equipment.

\section{REFERENCES}

None

8. ATTACHMENTS

None 


\section{ANNUAL SYSTEM ASSESSMENT REPORT}

(Sheet 1 of 12)

Date of This Report: January 27, 1998

Date of Previous Report January 13,1992
APPROVALS
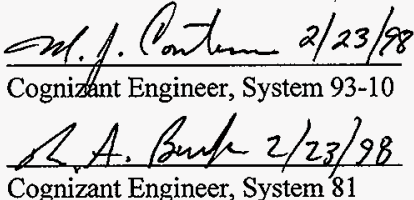

Cognizant Engineer, System 81

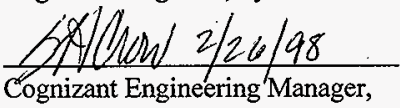

System 93-10

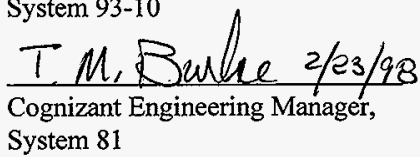

1. $\quad$ SCOPE

System/Component Title

$81 \mathrm{~A}$

$81 \mathrm{~B}$

$81 \mathrm{C}$

810

$81 \mathrm{E}$

$81 \mathrm{~F}$

$81 Y$

$81 Z$

93-10
Sodium Receiving/Unloading

Reactor Primary Sodium Processing

IDS/Primary Sodium Storage/Processing

NaK IDS Cooling

NaK Cold Trap Cooling

Reactor Secondary Sodium Processing

FSF Sodium Purification

FSF NaK Heat Transfer

Auxiliary Liquid Metal I\&C

The following components are shutdown, either permanently or for standby:

N-3, Primary Sodium Cesium Trap (standby-not required for standby operation)

P-41, Primary Sodium Storage Vessel Pump (permanent, pump is installed plant spare)

PIY-9337, FSF Cold Trap Inlet/Outlet Pressure (permanent, one of two sodium pressure transducers has failed-other system monitoring methods are in place) 


\title{
ANNUAL SYSTEM ASSESSMENT REPORT
}

\author{
(Sheet 2 of 12)
}

\section{SUMMARY EVALUATION}

System 81 and the associated instrumentation and control system 93-10 continue to operate satisfactorily in support of the standby condition of the facility. PN-7 identifies the Minimum Operable Equipment (MOE) for System 81. The MOE criteria is that either the cold trap or the System 85 plugging temperature indicator (PTI) must be operable, for each sodium system. As a result of this system assessment, PN-7 was changed to clarify that the associated equipment (e.g., EM pumps, cooling, etc.) is also required for the system to be considered operable.

The normal mode of operation while in standby for System 81 is to maintain the cold traps in hot standby and rely on the System 85 PTIs to alert the operator of an increasing level of impurities in the system. During defueling, there was a direct correlation between activities that opened sodium systems (e.g., floor valve activities on IDS) and system impurity levels; however, it generally took several months of defueling activity before the PTI on, for example, the Primary Sodium System, began cycling. When the PTIs no longer "straight-line," Operations has the option of putting the associated cold trap on-line to "clean-up" the sodium. This has been done on the Primary system, IDS, and Secondary Loop 3 at some time in the last five years. In all cases, the cold traps performed exactly as intended and within a day or two, the plugging temperature returned to normal ( $<260$ degrees $F$ ).

With the anticipated draining of Mobiltherm (MTL) from the plant in 1995, the normal cooling medium for the $\mathrm{NaK}$ in the $\mathrm{N}-5$ Primary Cold Trap Cooling system would have been lost. So, in 1994, an Operations Special Procedure (OSP) was performed to test operating N-5 without MTL. This test proved marginally successful, since the N-5 sodium flowrate had to be maintained very low ( $<15$ gallons per minute) while cold trap temperatures approached 260 degrees $\mathrm{F}$ ( 230 degrees $\mathrm{F}$ was the target). However, since then, Cell 569 was opened to develop the design for a sodium to NaK cross-connection to permit draining/flushing the $\mathrm{NaK}$ system. With the cell deinerted and the door ajar, the increased air flow through the cell has allowed N-5 to operate well within acceptable parameters: sodium flowrates exceeded 20 gallons per minute and internal cold trap temperature remained at about 230 degrees $\mathrm{F}$. This operating mode proved very effective and plugging temperature returned to normal within days. So long as the cell door remains partially open (the cell is only temporarily closed, rather than permanently closed), it is expected that there will be sufficient cooling for $\mathrm{N}-5 \mathrm{NaK}$ without any system or set point modifications. 


\section{ANNUAL SYSTEM ASSESSMENT REPORT}

(Sheet 3 of 12)

In November 1995 as part of preparations to drain the Secondary sodium to the Sodium Storage Facility, sodium was transferred from T-44, Secondary Drain Tank, to T-43, Primary Drain Tank and subsequently, from $T-43$ to $T-42$, Primary Overflow Tank. As a result, T-44 now contains approximately 3,200 gallons of sodium, T-43 contains about 2,100 gallons of sodium, and T -42 contains about 16,700 gallons of sodium. The current level (depth) of sodium in T-44 is $17.1 \%$, the level in T-43 is $16.4 \%$, and $47.2 \%$ in $\mathrm{T}-42$. These levels were determined by manually dipping each tank during the transfer operations. Transfer of sodium from T-44 and T-43 was stopped to ensure that a heel of sodium of at least $10 \%$ by volume remained in the tanks. However, the low level alarms for both T-44 and T -43 are locked in as a result of the sodium transfers. Apparently the instruments are calibrated at too high a value. The work packages that will correct these problems are identified later in this report.

It is not anticipated that any sodium will need to be transferred back to $T-43$ or $T-44$ should the plant restart. Both tanks contain less sodium than during plant operation so they can easily accommodate any drain activities that could arise from either a planned (maintenance) or unplanned (leak) event. There is likely adequate capacity in T-42 to accommodate the expansion of the Primary sodium at normal operating temperatures.

The components and instrumentation and controls (I\&C) in System 81 are operating acceptably for the standby condition. Random and age related I\&C failures have occurred and are expected to occur in the future. They will continue to be repaired using a graded approach consistent with the MOE list in PN-7. It is anticipated that the current backlog of repairs and periodic calibration tasks will continue, since manpower is limited and like-for-like spares are often not available. Modern replacements for the majority of the I\&C components are commercially available, however, installing these will likely involve plant modifications.

\section{ITEMS REOUIRING ACTION}

A. Near Term Items

Required By

Reactor Primary Sodium Processing and NaK Cold Trap Cooling I \& C

4F-97-1682W N-5 COLD TRAP TIC TEMPERATURE LOW

$98-1$

The process variable for the cold trap temperature controller indicated low when compared to other cold trap temperatures. 


\section{ANNUAL SYSTEM ASSESSMENT REPORT}

(Sheet 4 of 12)

A. Near Term Items (cont'd)

Required By

4F-97-2591W

SHOP WORK, CONSTRUCT EM PUMP CONTROLLER

TEST PANEL

98-1

This panel will be used to develop and test procedures and to train

Maintenance and Operations personnel to use the new controller which will replace all of the EM Pump C-1 controllers.

4F-96-1147W TI-41027 ON P-38 EM PUMP IS ERRATIC

$98-2$

The handswitch for selecting one of seven thermocouples causes erratic readings on the indicator.

4F-96-2247W

C-996, P-106 EM PUMP WINDING TEMP INDICATION.FAILED

$98-2$

The handswitch for selecting one of three thermocouples causes erroneous readings on the indicator.

4F-97-0492M REPLACE THE C-1 CONTROLLER IN C-980, P-39 98-2 4F-98-138M REPLACE THE C-1 CONTROLLER FOR P-38 98-2

Both of these documents support the upgrade of the EM Pump pumping section preheat controller.

IDS/Primary Sodium Storagè/Processing and NaK IDS Cooling I \& C

4F-97-2431W T-43 STORAGE TANK LOW LEVEL ALARM IS LOCKED IN

98-1

The low level alarm setpoints are specified too high.

4F-96-0565W TI-42024 READS HIGH, 42027 READS LOW, N-46 COLD TRAP TEMP

Readings taken with test instruments show calibration and/or repair is required.

Reactor Secondary Sodium Processing I \& C

4F-97-0758W - T-44 STORAGE TANK LEVEL ALARMS ALL ALARMING LOW

The low level alarm setpoints may be specified too high. 
HNF-2380

Rev. 0, Page 280

\section{ANNUAL SYSTEM ASSESSMENT REPORT}

(Sheet 5 of 12)

A. Near Term Items (cont'd)

Required By

4F-97-0784W N-40 COLD TRAP TEMPERATURE INDICATION IS OSS TT-43229

98-1

TI 43229 reads 20 deg F higher on 5 channels than TIC 43235.

4F-97-2350W

TT-43329 (N-41 COLD TRAP) READS 30 DEGREES HIGH

98-2

Readings taken with test instruments show calibration and/or repair is required.

4F-98-0029W REPLACE THE C-1 CONTROLLER IN

C-988, P-57

$98-2$

This document supports the upgrade of the EM Pump pumping section preheat controller.

B. Long Term Items

Required By

Reactor Primary Sodium Processing and NaK Cold Trap Cooling I \& C

4F-96-0401W LT-49004 (T-99 NAK STORAGE TANK) SPIKES

CAUSING ALARMS

Problem has not reoccurred, may closeout package.

4F-98-0001W N-5 NAK COLD TRAP INLET TEMP TI-49022 HAS

FAILED

Instrument displays erroneous readings.

4F-93-1547M

C-980 P-39 EM PUMP PREHEAT TIC-41024'S NOT

CONTROLLING

98-4

Field work complete, shopwork remains to complete repair of autotransformer and controller.

IDS/Primary Sodium Storage/Processing and NaK IDS Cooling I \& C

4F-98-141M

REPLACE THE C-1 CONTROLLER FOR P-40

98-3

This document supports the upgrade of the EM Pump pumping section preheat controller. 


\section{ANNUAL SYSTEM ASSESSMENT REPORT}

(Sheet 6 of 12)

B. Long Term Items (cont'd)

Required By

Reactor Secondary Sodium Processing I \& C

4F-96-1022W BAD LAMP SOCKET IN C-988,

ON LIGHT FOR P-57 EM PUMP $98-4$

Need to replace indicator light socket.

4F-98-140M

REPLACE THE C-1 CONTROLLER FOR P-58

$98-3$

4F-98-139M

REPLACE THE C-1 CONTROLLER FOR P-59

98-3

Both of these documents support the upgrade of the EM Pump

pumping section preheat controller.

FSF Sodium Purification I \& C

4F-96-1106W P-930 EM PUMP CURRENT INDICATOR PHASES

DIFFER

98-3

One phase indicates incorrectly due to incorrect wiring.

FSF NaK Heat Transfer I \& C

4F-96-2105W SMOKE MONITOR FOR NDHX E-920 IS

ERRATIC

98-4

Adjustment potentiometer produces erratic results.

\section{TRENDS}

All plant cold traps have been operated in the past five years for a variety of reasons, ranging from a PN-7 requirement when the associated PTI was inoperable, or as discussed previously, when a PTI began cycling. The differential pressure measured during operation for all cold traps remains acceptable. The differential pressure alarm set point is 20 psid. N-41, Secondary Loop 3 Cold Trap, which was used for initial clean-up of all Secondary sodium, operates with the highest differential pressure at about 7 psid at 15 gallons per minute flowrate. N-5, Primary Cold Trap operates at about 5 psid at a flowrate of about 20 gallons per minute. The differential pressure on these two cold traps has not changed significantly in at least ten years of operation. All other plant cold traps have very little $(<2$ psid $)$ differential pressure, which indicates that the plant cold traps have significant $(>20$ years) life remaining.

Also, see the discussion on aging in section 5. below. 


\section{ANNUAL SYSTEM ASSESSMENT REPORT}

(Sheet 7 of 12)

\section{SYSTEM AGING; SPARE PARTS CONSIDERATIONS, AND LONG TERM MAINTENANCE PHILOSOPHY}

A. Discuss effects of system aging.

Equipment such as power supplies, transmitters, and alarm units, are failing because internal parts such as electrolytic capacitors have reached their end of life.

Some instruments have been repaired enough times such that the integrity of the circuit board, adjacent components and solder points has been compromised causing subsequent failures or irrevocable damage. This is a contributing factor for upgrading the EM Pump pumping section preheat controllers (C-1).

B. Discuss the strategy for near term spare parts and their availability strategy.

The system 81 instrumentation is 25 years old and obsolete. Most instruments are no longer manufactured thus the availability of spares has diminished rapidly. Some instruments such as transmitters and alarm units are available from the manufacturers having the same model number, specifications, form, fit and function as the original, however the internal circuitry and calibration adjustments have been redesigned and updated. For many obsolete instruments (excluding liquid metal level, flow and pressure sensors), replacements are available which provide the same function. However, the form and fit are very different which then requires plant modifications to implement.

There is no active program for the repair of malfunctioning instruments removed from the plant. The shop has a large backlog of items which, if repaired, could be returned to the spares inventory. Sometimes, the plant device must be removed for repair then reinstalled. This method of doing business extends the down time of equipment significantly when compared to having a shop calibrated spare on hand before the equipment is taken out of service.

During standby, instruments and controls have been successfully repaired because spare units have been available from one or more of the following alternative sources: 1) In Plant Closed Loop Equipment, 2) Shutdown Equipment (P-41 for example), and 3) Instrument Repair Backlog Inventory.

In some cases, spare controllers and instruments which were originally configured to meet certain functional requirements and specifications, have been reconfigured to meet the functional requirements and specifications of an installed device needing replacement. 


\section{ANNUAL SYSTEM ASSESSMENT REPORT}

(Sheet 8 of 12)

There are budget constraints which affect the spare parts inventory. In the near term, spare parts of low cost are being replenished. Unless there is a known need, the procurement of high cost items is being deferred and no attempt is being made to maintain spares at the maximum inventory amount.

\section{Standby Maintenance Plan:}

For Standby the essential functions of System components are:

1) Provide monitoring and control of the EM Pumps which circulate sodium in the processing systems and the System 85 Plugging Temperature Indicators.

2) Provide monitoring and control of the EM Pump which circulates $\mathrm{NaK}$, if required, for the Cooling of the Primary Cold Trap, N-5.

3) Provide monitoring and control of the temperatures, flows, and pressures for each of the Cold Traps.

4) Provide monitoring and control of the sodium inventory in the Reactor Vessel, IDS Vessel, and each of the sodium and $\mathrm{NaK}$ overflow, storage, and drain tanks.

5) Provide monitoring and control of the FSF Sodium Vessel Inline Heater.

As needed and using a graded approach, corrective maintenance will continue to be performed to assure the instrumentation and controls are acceptable to support the above essential functions.

The System 81 and I \& C System 93-10 PM/S requirements were reviewed for the standby condition. Appropriate changes to the frequencies were made by ECN 642550 , which was released September 25, 1997. As manpower allows and using a graded approach, instrumentation will continue to be checked and adjusted for calibration per the requirements of the $\mathrm{PM} / \mathrm{S}$ Data Base.

These plans will be successful to limit equipment degradation only if manpower is provided to do the work. All the items listed in section 3.A. for the 98-1 quarter are scheduled. None of the 25 items currently listed as overdue or due by the PM/S Data Base are scheduled to be worked during 98-1. See check list item G for further discussion of this issue.

The C-1 controller for EM Pumps P-38, P-39, P-40, P-57, P-58 and P-59 controls the voltage applied to the pumping section during the preheat mode to maintain the required preheat temperature. These controllers have experienced a large number of failures and are obsolete. An upgrade task is in progress to replace 


\section{ANNUAL SYSTEM ASSESSMENT REPORT}

(Sheet 9 of 12)

them with state of the art digital controllers during the 98-2 and 98-3 quarters. If FFTF is to restart or remain in Standby for a long time, the C-2, C-3, and C-5 controllers for the pump resistance heaters will also be upgraded.

\section{CHECKOFF LIST}

A. Accessible parts of the entire system or component have been thoroughly walked down at least once in the past 30 days to view current performance, equipment status and condition.

Yes X No _

B. Are there any conditions which might require limitations different from operating limits as defined in the SDDs, the FSAR, or the Plant Technical Specifications? Yes_No $\underline{X}$

C. Are there trip settings, set points, interlocks, etc., that should be changed from those currently established?

Yes_No $\underline{X}$

D. Are there interface areas which have not performed acceptably, which require resolution?

Yes_No $\underline{X}$

E. Are there temporary plant or procedural conditions which will and should remain in place?

Yes_No $\underline{X}$

F. Is any retesting or special testing (e.g., OSP) required?

Yes_No $\underline{X}$

G. Are the current plant corrective maintenance, preventive maintenance, and calibration database items all properly identified and are planned actions acceptable?

Yes_. No X

COMMENTS:

All items are properly identified for the standby condition, however near term planned actions are not. Because of budget constraints, there are insufficient resources available to maintain the System 81 instrumentation per the requirements and frequencies established in the PM/S Database. There are 22 


\section{ANNUAL SYSTEM ASSESSMENT REPORT}

(Sheet 10 of 12)

PM/S activities for this system which are listed as past due and three which are listed to be performed this quarter, 98-1. None are scheduled to be performed.

Not performing these activities will have the following effects:

A. The instruments will knowingly, or worse unknowingly, display erroneous information.

B. There will be a loss of confidence in the accuracy of the EM pump or cold trap instrumentation and control.

C. Conduct of Operations will deteriorate as the operators' confidence in the equipment erodes.

D. Problems which may be identified and corrected by the routine task will not be found until the instrument demonstrates failure. Repair will require the use of engineering and work control time to disposition a corrective maintenance work package.

E. Erroneous indications will impede making correct and timely operational and engineering decisions. Only by monitoring accurate instrumentation will the operator or the engineer determine if a cold trap is loading up impurities, if it is dumping impurities to the sodium system or if it remains at equilibrium at 230 degrees $F$.

H. Are all other action items (NCRs, IRs, etc.) properly identified and assigned? Yes_No_N/A

l. Are there any special operating considerations?

Yes X No -

List or Reference:

As discussed previously, the N-5 NaK Cooling system benefits from additional air flow through Cell 569 since the cell door is open, slightly. However, there should be little need to operate $\mathrm{N}-5$ since no further reactor refueling/defueling activities are planned during standby.

All the FFTF EM pump voltage and current indicators have failed or become unreliable to the point that redesign of the instruments is required. Because FFTF is in standby, redesign and upgrade has been deferred. Operations has initiated procedure changes to delete the use of them for pump operation and monitoring. 


\section{ANNUAL SYSTEM ASSESSMENT REPORT}

(Sheet 11 of 12)

However, when these pump parameters need to be obtained, the procedures will allow the use of portable test equipment. During routine operation, since the EM pump voltage and current indicators are no longer maintained or monitored, the cold trap differential pressure instruments in conjunction with the system flow meters are used to monitor EM pump performance. Therefore, these instruments must be calibrated at the prescribed frequency.

The FSF cold trap differential pressure instrument PIY-9337 is out of service because of a failure of the pressure element that is welded into the system. Similar to the situation described above, N-932, FSF PTI flow, temperature and EM pump (P-930) voltage are monitored to determine cold trap performance.

J. Are near term spare parts adequate?

Yes $\underline{\mathrm{X}}$ No

COMMENTS: However, if the backup sources of a particular obsolete part are exhausted, the equipment may need to be modified to accommodate a new instrument. A preventive or corrective maintenance task then becomes a plant modification task. See Item 5.B for more discussion regarding this issue.

K. Have any safety issues (radiological, industrial) been identified that remain unresolved?

Yes_No $\mathrm{X}$

L. Have all component data been entered into the Plant information database? Yes $\underline{X}$ No

M. Have applicable SISI inspections been conducted?

Yes_No_N/A $\underline{X}$

N. Has a cleanliness evaluation been completed? Yes $X$ No Are any issues still unresolved? Yes _ No $\mathrm{X}$

\section{REFERENCES}

PN-7, Operation at Invesssel Refueling Temperature Conditions System 85 Annual System Assessment Report, 1998.

JCS Work Package Data Base

PM/S Activity Data Base

ECN 642550 


\section{ANNUAL SYSTEM ASSESSMENT REPORT}

(Sheet 12 of 12)

\section{ATTACHMENTS}

None. 


\section{ANNUAL SYSTEM ASSESSMENT REPORT \\ for \\ SYSTEM 82}

Date of This Report

January 28, 1998.

Date of Previous Report January 30, 1.992

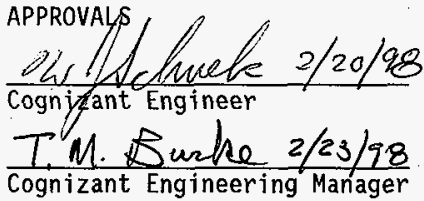

1. SCOPE

\section{System/Component}

$82 A, D, E, G, J$
Iitle

FFTF Inert Gas Receiving and Processing

2. SUMMARY EVALUATION

The 1ist of minimum operable equipment, MOE, attachment 1 to $\mathrm{PN}-7$, was reviewed as was the JCS 1 ist of system 82 work requests. Completed work packages for approximately the current Standby period were reviewed for trends. Spare parts lists were reviewed as directed. Results are reported below by subsystem.

In general there are no deficiencies which impair safety or continued operations in the current mode.

System 82 relief valves on the Primary and Secondary loops and on a variety of sodium and NaK storage tanks are periodically tested in the SISI program. Reference WHC-SD-SISI-006, FFTF Surveillance and In-Service Inspection Requirements, and HNF-SD-FF-SISI-015, In-Service Inspection Summary Report for Test Period January 1, 1996 to December 31, 1996. The 1997 summary report, HNF-2045.RPT, is due 3/31/98.

\section{System 82A, Argon Supply and Distribution}

The Argon Supply and Distribution System, 82A, was little affected by Shutdown and Standby and is functioning well.

For Standby the secondary loops' pressure and purge rates were lowered and about 3 SCFM of argon is being saved. The secondary loop oil bubblers are processing less gas and we anticipate that the tritiated oil carryover to the overflow drums is minimat.

The 1-SCFM vapor trap which processes cover gas sample gas to HTS-S has been shut down. The 5-SCFM vapor trap which processes Primary cover gas is not being challenged because the sodium temperature is $400^{\circ} \mathrm{F}$ at which temperature the sodium vapor pressure is extremely low. 
There is a failed trace heater on the P-5, secondary pump bleed line, (4F-96-886). At $400^{\circ} \mathrm{F}$ Standby conditions build up of sodium frost in the line should be very slow but not nonexistent. If, in the remote chance, the line should begin to $\mathrm{plug}$, the alarm response procedure and relief system are adequate to deal with any pressure increase.

The plant argon tanks, T-52A, B,C,D are functioning with only minor maintenance required, although they could use a paint job. $\mathrm{N}-22$, the thermal conductivity gas analyzer which overchecks argon deliveries, was installed in April, 1994.

In 1997, the FSF argon system was cross-tied into the FFTF plant argon system. Work package 4F-97-796, which will install the FSF flowmeter cabling, remains incomplete. Work package 4F-97-2767 will remove the FSF dewar check valve internals and connect the "economizer" regulator to the plant argon header. This modification gives operations several options, to fill the tank as a backup, to use the FSF dewar to supply the header, or to maintain the tank empty but kept inerted by the header.

\section{System 82D, Cel1 Atmosphere Processing System, CAPS}

The CAPS compressors and cryogenically cooled "cold boxes" were deenergized for FFTF Shutdown. The CAPS vacuum header is being serviced by three blower units, the two In-Containment CAPS Blowers, ICCBs R-200 and R-201, and the Ex-Containment CAPS Blower, ECCB R-202. See the CSRs for these units.

Radiation monitors at the ICCBs and the ECCB have been effective in detecting $\mathrm{Kr}-85$ releases from leaking fuel pins. Temporary Gas CAMs are available as spares for this function.

Contaminated artifact oil from the CAPS and ICCBs has saturated the ICCB outlet filter. By experience we know that small amounts of this $0 i 1$ reentrains in the gas stream accumulating slowly in the downstream pipe and $\mathrm{H} \& \mathrm{~V}$ duct. Work package 4F-97-870 will replace the existing outlet filter with a clean filter and will add an oil coalescing prefilter. While not urgent, this activity will correct a continuing problem which has a potential for personnel contamination.

\section{System 82E, Radioactive Argon Processing System, RAPS}

The RAPS was deenergized during preparations for FFTF Shutdown and will remain deenergized during the Standby period. Reactor cover gas is vented via the RAPS piping which has been cross-connected to the CAPS vacuum header during Standby. The internals of a check valve on RAPS compressor $R-10$ were removed to open this flow path. No maintenance is required on the RAPS system during Standby. 


\section{System 82G, Nitrogen Supply and Distribution}

Recently completed in early December 97, work package 4F-97-1764 cross-tied Instrument Air to High Pressure Nitrogen in containment to save gas during Standby. This has reduced nitrogen consumption by more than half. Because of this modification, $\mathrm{N}-24$, the Refueling Cover Gas Monitor, has assumed increased importance, that is, detection of air leakage from the LLFM cooling system into the reactor. However, such leakage is seen as very unlikely because there are two ASME boundaries between the LLFM coolant and the reactor.

\section{System 82J, Vacuum System}

In preparation for sodium drain activities, vacuum pumps $P-130$ and $P-131$ were refurbished with new seals in a11 accessible mechanical joints. They are in good operating condition and will pump down to a hard vacuum. These pumps include solenoid valves that close when the pump shuts down and are presently stored in the Sodium Storage Facility upper elevation.

P-135 has al so been refurbished in the same manner but has a leak somewhere on the suction side of the pump. It will serve adequately in service where a hard vacuum is not required. It is presently stored in the 400 area warehouse.

The remaining pumps are in various stages of cannibalization and are a] so in the warehouse.

3. ITEMS REQUIRING ACTION

A. Near Term Items

Required By

4F-97-2767, FSF Dewar Changes

98-2

B. Long Term Items

Required By

4F-97-870, ICCB Filter Modifications

$98-4$

4. IRENDS

\section{Plant Inert Gas Consumption}

Argon and Nitrogen usage have reached near minimum levels for the Standby conditions. Secondary argon purges were reduced. The FSF and Plant argon headers were crosstied, saving most of the FSF usage (dewar boiloff). Instrument air was substituted for nitrogen in in-containment headers reducing $\mathrm{N}_{2}$ consumption be more than half. 
5. SYSTEM AGING, SPARE PARTS CONSIDERATIONS, AND LONG TERM MAINTENANCE PHILOSOPHY

\section{A. Effects of System Aging}

Much of System 82, except inert gas supply and the CAPS vacuum header, are shutdown. The gas chromatograph within $\mathrm{N}-24$, the portable cover gas monitor, is obsolete but is currently functioning well; old valves with leaking seals were replaced in a recent modification. See System 93-8 ASAR.

\section{B. Near Term Spare Parts}

See System 93-8 ASAR for a discussion of $\mathrm{N}-24$ spare parts.

The CAPS ICCB and ECCB blowers are reliable units which back up one another. Adequate spares are available.

\section{Standby Maintenance P1an}

PMP/ICRS overdue work packages, and current workload are currently being reviewed and adjusted to align them with work force capacity. It is recommended that operating equipment such as fans, blowers, pumps, and similar equipment and their motors continue to receive regular lubrication. Some routine calibrations and testing may be reduced in frequency or eliminated during Standby. See also the System 93-8 ASAR.

\section{CHECKOFF LIST}

A. Accessible parts of the entire system or component have been thoroughly walked down at least once in the past 30 days to view current performance, equipment status and condition. Yes $\underline{X}$ No COMMENTS (exceptions): None

B. Are there any conditions which might require limitations different from operating limits as defined in the SDDs, the FSAR, or the $\mathrm{Plant}$ Technical Specifications? Yes No $\mathrm{X}$

COMMENTS (exceptions): SDDs are not being updated for Standby, however, the FSAR and its Technical specifications have been.

c. Are there trip settings, set points, interlocks, etc., that should be changed from those currently established? Yes No $\underline{X}$

COMMENTS (exceptions): None. 
D. Are there interface areas which have not performed acceptably, which require resolution? Yes No $\underline{x}$

COMMENTS (exceptions): None.

E. Are there temporary plant or procedural conditions which will and should remain in place? Yes__ No $X$

Attach list of $\operatorname{MOD}(L) / E C N(L) s$, and OSPs that are currently active. Provide justification for continuing temporary MOD $(L) s$ and $E C N$ (L)s.

COMMENTS (exceptions): None.

F. Is any retesting or special testing (e.g., OSP) required? Yes No $\underline{x}$

COMMENTS (exceptions): None.

G. Are the current plant corrective maintenance, preventive maintenance, and calibration database items all properly identified and are planned actions acceptable? Yes $X$ No

COMMENTS (exceptions): See 5.C. above

H. Are all other action items (NCRs, IRs, etc.) properly identified and assigned?

Yes $\mathrm{X}$ No__ (attach the summary of needed actions not in the data base)

COMMENTS (exceptions): None.

I. Are there any special operating considerations? Yes__ No $\underline{X}$ List or Reference: None.

J. Are near term spare parts adequate? Yes $X$ No _ COMMENTS (exceptions): None.

K. Have any safety issues (radiological, industrial) been identified that remain unresolved? Yes No $\underline{X}$

COMMENTS (exceptions): None.

L. Have all component data been entered into the.P7ant information database?

Yes $\mathrm{X}$ No

COMMENTS (exceptions): None 
M. Have applicable SISI inspections been conducted? Yes $\underline{X}$ No COMMENTS (exceptions): None.

N. Has a cleani iness evaTuation been completed? Yes $X$ No Are any issues still unresolved? Yes No $X$ COMMENTS (exceptions): None

\section{REFERENCES}

WHC-SD-ASAR-004, Apri1 14, 1992.

8. ATTACHMENTS

See the CSRs for the ICCBS and ECCB. 


\section{ANNUAL SYSTEM ASSESSMENT REPORT}

(Sheet 1 of 7 )

Date of This Report: January 27,1998

Date of Previous Report January 13,1992
APPROVALS

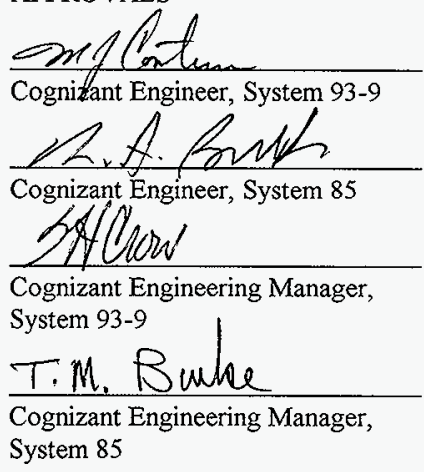

1. $\mathrm{SCQPE}$

System/Component

Title

85A HTS Primary Sodium Sampling/Monitoring

85B CLS Primary Sodium Sampling/Monitoring

85C HTS Secondary Sodium Sampling

85D CLS Secondary Sodium Sampling

85E Argon Cover Gas Sampling/Monitoring (reported in separate ASAR)

$85 Z$ FSF Sodium Sampling

93-9 Impurity Monitoring and Analysis System I \&C

System 85 consists of sodium and cover gas sampling equipment, including Plugging Temperature Indicators (PTIs), Multipurpose Samplers (MPSs) in both primary and secondary systems, cover gas sampling systems and equipment in both primary and secondary systems, a PTI and cover gas sampling system in IDS, and a PTI in FSF. The primary cover gas sampling system contains two compressors which deliver primary cover gas to the Fission Gas Monitoring System (94), a gas chromatograph, and grab sampling capability. The compressors are considered to be part of System 85. A limited-capability chromatograph is used during refueling operations. (See separate ASAR for System 85E) Component Status Reports (CSRs) for the MPSs and compressors are not included since this equipment has been shutdown for Stand-by. 


\section{ANNUAL SYSTEM ASSESSMENT REPORT}

(Sheet 2 of 7 )

The following are shutdown:

- $\quad$ All equipment associated with the HTS Primary Sodium Sampling/Monitoring Loop in HTS/S.

- The Secondary Multipurpose Samplers.

- $\quad$ All equipment associated with the Reactor Primary Argon Cover Gas Sampling/Monitoring Loop in HTS/S.

The following were never placed into service and have been routinely used as a source of spare parts for instrument systems 93-9 and 93-10.

- CLS Primary Sodium Sampling/Monitoring

- $\quad$ CLS Secondary Sodium Sampling

- CLS Primary Argon Cover Gas Sampling/Monitoring

\section{SUMMARYEVALUATION}

System 85 and the associated instrumentation and control system 93-9 continue to operate satisfactorily in support of the standby condition of the facility. The requirement of PN-7 for System 85 's Minimum Operable Equipment (MOE) is that either the Plugging Temperature Indicator (PTI) or its associated System 81 cold trap must be operable. The equipment on the MOE list is as follows: N-25, N-48, N-93, N-94, N-95 and N-931. All are PTls.

The instrumentation and controls for the System 85 equipment are operating acceptably for the standby condition. Random and age related failures have occurred and are expected to occur in the future. They will continue to be repaired using a graded approach consistent with the MOE list in PN-7. It is anticipated that the current backlog of repairs and periodic calibration tasks will continue, since manpower is limited and likefor-like spares are often not available. Modern replacements for the majority of the I\&C components are commercially available, however, installing these will likely involve plant modifications.

\section{ITEMS REOUTRING ACTION}

A. Near Term Items

Required By

HTS Secondary Sodium Sampling I \& C

$4 \mathrm{~F}-97-0746 \mathrm{~W}$

C-612A, LOOP 2 SAMPLING PANEL

$98-2$ ANNUNCIATOR RESET BUTTON INOPERABLE

Reset button does not reset alarms. 
HNF-2380

Rev. 0, Page 296

\section{ANNUAL SYSTEM ASSESSMENT REPORT}

(Sheet 3 of 7)

B. Long Term Items

$\underline{\text { Required By }}$

HTS Primary Sodium Sampling/Monitoring I \& C

4F-97-0261A

EVALUATE C-680 REPAIR/UPGRADE APPROACH

FY99

N-25 \& N-48 PTI controls have had many failures.

\section{TRENDS}

PTI performance is monitored daily and the plugging temperature for each is recorded on the Watchstation logs. Plant chemistry, as indicated by the PTIs, has been maintained very well during standby. There was a period of time as sodium drain was anticipated in 1995 and subsequently put on hold where the PTIs were ignored. However, when facility personnel recognized that this Stand-by period could last several years, attention to PTI operability was renewed. Gas and sodium samples have not been taken during Stand-by. The plant-installed chromatograph is not operable, however the refueling chromatograph, $\mathrm{N}-24$, has been operating satisfactorily (see separate ASAR for System 85E). There has been no indication based on PTI, Cold Trap (System 81), or chromatograph performance that sampling was warranted.

See further discussion on aging in section 5 . below.

5. SYSTEM AGING, SPARE PARTS CONSIDERATIONS, AND LONG TERM MAINTENANCE PHILOSOPHY

A. Discuss effects of system aging.

Equipment such as power supplies, transmitters, and alarm units, are failing because internal parts such as electrolytic capacitors have reached their end of life. The chart recorders for the PTIs continue to be a high maintenance concern as mechanical parts continue to wear. Unique pushbuttons on the PTI Control drawers are obsolete and continue to fail. Relays in the PTI Control Drawers are failing.

Some instruments have been repaired so many times that the integrity of the circuit board, adjacent components and solder points has been compromised causing subsequent failures or irrevocable damage. 


\section{ANNUAL SYSTEM ASSESSMENT REPORT}

(Sheet 4 of 7 )

B. Discuss the strategy for near term spare parts and their availability strategy.

The system 85 instrumentation is 25 years old and obsolete. Most instruments are no longer manufactured thus the availability of spares has diminished rapidly. Some instruments such as transmitters and alarm units are available from the manufacturers and have the same model number, specifications, form, fit, and function as the original, however the internal circuitry and calibration adjustments have been redesigned and updated. Use of these will require new or revised calibration procedures. For many obsolete instruments (excluding flow and $\mathrm{NaK}$ pressure sensors), replacements are available which provide the same function. However, the form and fit are very different which would require plant modifications to implement.

There is no active program for the repair of malfunctioning instruments removed from the plant. The shop has a large backlog of items which, if repaired, could be returned to the spares inventory. Sometimes, the plant device must be removed for repair then reinstalled. This method of doing business extends the down time of equipment significantly when compared to having a shop calibrated spare on hand before the equipment is taken out of service.

During Standby, instruments and controls have been successfully repaired because spare units have been available from one or more of the following alternative sources:

1) In plant Closed Loop Sodium Sampling Equipment

2) Shutdown Equipment (the Primary Sodium Sampling Panels for example)

3) Instrument Repair Backlog Inventory

In some cases, spare controllers and instruments which were originally configured to meet certain functional requirements and specifications, have been reconfigured to meet the functional requirements and specifications of an installed device needing replacement.

There are budget constraints which affect the spare parts inventory. In the near term, spare parts of low cost are being replenished. Unless there is a known need, the procurement of high cost items is being deferred and no attempt is being made to maintain spares at the maximum inventory amount. 


\section{ANNUAL SYSTEM ASSESSMENT REPORT}

(Sheet 5 of 7)

C. Standby Maintenance Plan.

For Standby the essential function of System 85 is to provide monitoring of the impurity level of the HTS Primary Sodium, the ISS Vessel Sodium, the HTS Secondary Sodium and the FSF Vessel Sodium.

As needed and using a graded approach, corrective maintenance will continue to be performed to assure the instrumentation and controls are acceptable to support the above essential function.

The System 85 and I \& C System 93-9 PM/S requirements were reviewed for the standby condition. Appropriate changes to the frequencies were made by ECN 642550 , which was released September 25,1997. As manpower allows and using a graded approach, instrumentation will continue to be checked and adjusted for calibration per the requirements of the PM/S Data Base.

These plans will be successful to limit equipment degradation only if manpower is provided to do the work. All the items listed in section 3.A. for the 98-1 quarter are scheduled. None of the 13 items currently listed as overdue or due by the PM/S Data Base are scheduled to be worked during 98-1. See check list item G for further discussion of this issue.

The controls for PTI's N-25 and N-48 in C-680 need to be upgraded, if the plant is to restart or remain in standby for a long time. A proposal to upgrade C-680 to a PC-based control system has been received from an FFTF Operations Engineer. It will be evaluated by Engineering. In addition the original 24 point chart recorder for C-680A needs to be replaced and will be included in the control upgrade.

\section{CHECKOFF LIST}

A. Accessible parts of the entire system or component have been thoroughly walked down at least once in the past 30 days to view current performance, equipment status and condition.

Yes $X$ No

B. Are there any conditions which might require limitations different from operating limits as defined in the SDDs, the FSAR, or the Plant Technical Specifications? Yes_No $\underline{X}$

C. Are there trip settings, set points, interlocks, etc., that should be changed from those currently established?

Yes_No $\mathrm{X}$ 


\section{ANNUAL SYSTEM ASSESSMENT REPORT}

(Sheet 6 of 7 )

D. Are there interface areas which have not performed acceptably, which require resolution?

Yes_No $\underline{X}$

E. Are there temporary plant or procedural conditions which will and should remain in place?

Yes_No $\underline{X}$

F. Is any retesting or special testing (e.g., OSP) required?

Yes_No $\mathrm{X}$

G. Are the current plant corrective maintenance, preventive maintenance, and calibration database items all properly identified and are planned actions acceptable?

Yes_. No $\underline{X}$

\section{COMMENTS:}

All items are properly identified for the standby condition, however near term planned actions are not. Because of budget constraints, there are insufficient resources available to maintain System 85 instrumentation per the requirements and frequencies established in the PM/S Database. There are eleven PM/S activities for this system which are listed as past due and two which are listed to be performed this quarter, 98-1. None are scheduled to be performed.

Not performing these activities will have the following effects:

- The instruments will knowingly, or worse unknowingly, display erroneous information.

- There will be a loss of confidence in the accuracy of the plugging temperature or in the proper operation of the PTI.

- Conduct of Operations will deteriorate as the operators' confidence in the equipment erodes.

- Problems which may be identified and corrected by the routine task are not found until the instrument demonstrates failure. Repair will require the use of engineering and work control time to disposition a corrective maintenance work package.

- Erroneous indications will impede making correct and timely operational and engineering decisions.

H. Are all other action items (NCRs, IRs, etc.) properly identified and assigned?

Yes_No_N/AX

I. Are there any special operating considerations?

Yes_No $\mathrm{X}$ 


\section{ANNUAL SYSTEM ASSESSMENT REPORT}

(Sheet 7 of 7 )

J. Are near term spare parts adequate?

Yes $\underline{X}$ No

COMMENTS: The answer is true in most cases. However, if the sources of a particular obsolete part are exhausted, the equipment may need to be modified to accommodate a new instrument. A preventive or corrective maintenance task then becomes a plant modification task.

K. Have any safety issues (radiological, industrial) been identified that remain unresolved?

Yes_ No $\underline{X}$

L. Have all component data been entered into the Plant information database?

Yes $\underline{X}$ No

M. Have applicable SISI inspections been conducted?

Yes_No_N/A X

N. Has a cleanliness evaluation been completed? Yes $\underline{X}$ No

Are any issues still unresolved? Yes _ No $\mathrm{X}$

\section{REFERENCES}

PN-7, Operation at Invessel Refueling Temperature Conditions

System 81 Annual System Assessment Report, 1998.

JCS Work Package Data Base

PM/S Activity Data Base

ECN 642550

\section{ATTACHMENTS}

None. 


\section{ANNUAL SYSTEM ASSESSHENT REPORT \\ for \\ SYSTEM $85 E$}

Date of This Report January 28, 1998

Date of Previous Report January 21, 1992

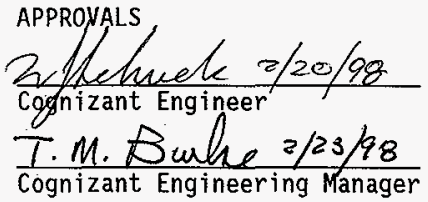

1. SCOPE

System/Component

$85 \mathrm{E}$
Title

Argon Cover Gas Sampling and Monitoring

\section{SUMMARY EVALUATION}

For FFTF Standby regular primary and secondary cover gas sampling and analysis was terminated; primary cover gas flow to HTS-S was secured and the CIS valves were closed as part of the Group 1 Systems Shutdown; secondary cover gas sampling and analys is was canceled shortly after the FFTF was ordered to Shutdown.

$\mathrm{N}-24$, the portable cover gas monitor, is in operation at the reactor vessel. The $\mathrm{N}-24$ gas chromatograph is set to detect nitrogen from air in-leakage to the reactor. A Delta- $\mathrm{F}$ oxygen monitor, also aboard $\mathrm{N}-24$, detects air in-leakage in the sampling equipment downstream of the reactor. $\mathrm{N}-24$ is operating well.

It is recommended that $\mathrm{N}-24$ remain in operation at the reactor for the Standby period. This is important because Instrument air has been substituted for nitrogen in the LLFM cooling system. Although the chances of an air leak into the reactor are very small because of two ASME boundaries between the LLFM cooling system and reactor cover gas, maintaining the ability to detect such a leak is prudent.

$\mathrm{N}-24$ will be useful in the future at the reactor, the IDS vessel and at the FSF vessel to characterize air ingestion during fuel handling operations. Such information will be useful in estimating cold trap usage should FFTF restart. 
A. Near Term Items

Required By

None.

$\mathrm{n} / \mathrm{a}$

B. Long Term Items

Required By

None.

$n / a$

4. TRENDS

No specific trending for system $85 E$ has been established. However, $\mathrm{N}-24$, a sensitive, self caljbrating, laboratory grade instrument, is monitored and logged each shift.

5. SYSTEM AGING, SPARE PARTS CONSIDERATIONS, AND LONG TERM MAINTENANCE PHILOSOPHY

See the System 93-8 ASAR.

\section{CHECKOFF LIST}

A. Accessible parts of the entire system or component have been thoroughly walked down at least once in the past 30 days to view current performance, equipment status and condition. Yes $X$ No _. COMMENTS (exceptions): None.

B. Are there any conditions which might require limitations different from operating limits as defined in the SDDs, the FSAR, or the Plant Technical Specifications? Yes_ No $\underline{X}$

COMMENTS (exceptions): None.

C. Are there trip settings, set points, interlocks, etc, that should be changed from those currently established? Yes__ No $X$

COMMENTS (exceptions): None.

D. Are there interface areas which have not performed acceptably, which require resolution? Yes__ No No $X$

COMMENTS (exceptions): None. 
E. Are there temporary plant or procedural conditions which will and should remain in place? Yes No $X$

Attach list of $M O D(L) / E C N(L) s$, and OSPs that are currently active. Provide justification for continuing temporary MOD (L)s and ECN (L.) $s$.

COMMENTS (exceptions): None.

F. Is any retesting or special testing (e.g., OSP) required? Yes No $X$

COMMENTS (exceptions): None.

G. Are the current plant corrective maintenance, preventive maintenance, and calibration database items all properly identified and are planned actions acceptable? Yes $\underline{X}$ No.

COMMENTS (exceptions): None.

H. Are all other action items (NCRs, IRs, etc.) properly identified and assigned?

Yes $\underline{X}$ No__ (attach the summary of needed actions not in the data base)

COMMENTS (exceptions): None.

I. Are there any special operating considerations? Yes_. No _ $\mathrm{X}$ List or Reference: None.

J. Are near term spare parts adequate? Yes $X$ No COMMENTS (exceptions): See the discussion in ASAR 93-8.

K. Have any safety issues (radiological, industrial) been identified that remain unresolved? Yes No $\mathrm{X}$

COMMENTS (exceptions): None.

L. Have all component data been entered into the Plant information database? Yes $X$ No

COMMENTS (exceptions): None.

M. Have applicable SISI inspections been conducted? Yes $X$ No COMMENTS (exceptions): None. 
N. Has a cleanliness evaluation been completed? Yes $X$ - No

Are any issues still unresolved? Yes No $X$

COMMENTS (exceptions): None.

7. REFERENCES

WHC-SD-ASAR-004, Apriך 14, 1992.

8. ATTACHMENTS

None. 


\section{ANNUAL SYSTEM ASSESSMENT REPORT}

(Sheet 1 of 8 )

Date of This Report_January 15, 1998

Date of Previous Report January 22, 1992

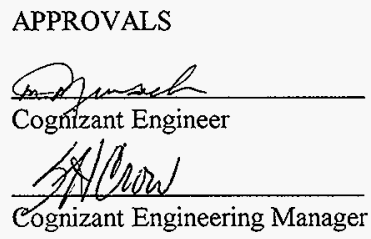

\section{SCOPE}

System 93-4. Service Piping Instrumentation (Part of System 23)

Sanitary Water System I\&C (23A/B)

Cooling; Tower and Water I\&C (23C/D)

Instrument Air I\&C (23J)

\section{SUMMARY EVALUATION}

A complete listing of the Minimum Operable Equipment from administrative procedure PN-7 is included in section 8 .

Sanitary Water System 1\&C (23A/B)

The sanitary water pumping, storage and delivery system is generally in good condition. It is a normally operating system which has been properly maintained. There is some concern regarding the delays in working corrective maintenance packages due to unavailability of craft.

Recurring electrical problems with the $\mathrm{T}-14$ water heater in Bldg $491 \mathrm{E}$ have been eliminated by replacement of the single large heater with two commercial water heaters $(T-14 \mathrm{~A}$ and $\mathrm{T}-14 \mathrm{~B})$.

\section{Cooling: Tower and Water I\&C (23C/D)}

The overall condition of this system is good. The majority of the components in the cooling tower and water system are operating normally. Only five of the eight cooling towers and associated equipment are in operation at this time. The other three cooling towers and associated equipment are in a lay-up condition. Normal corrective maintenance for this equipment has been taken care of with spare parts inventory or from off site procurement of spare parts.

Instrument Air I\&C (23J)

The plant air compressors, air dryers and delivery system are generally in good condition. It is a normally operating system which has been properly maintained. The back-up air bottle systems and Mobile Air Compressors have been laid up. 
HNF-2380

Rev. 0, Page 306

\section{ANNUAL SYSTEM ASSESSMENT REPORT}

(Sheet 2 of 8 )

\section{ITEMS REQURRING ACTION}

A. Near Term Items

$\underline{\text { Required By }}$

Sanitary Water System I\&C (23A/B)

4F-97-2007/W

FE-70031 OOS, P-467/468 HDR FLOW GAUGE

$98-1$

The work package to repair the water flow indicator/totalizer, FE-70032, in Bldg 481 should be worked in this quarter. This flow meter is used by Operations to assess the condition of the water system and by Engineering for determination of preventive maintenance scheduling requirements.

Cooling Tower and Water I\&C (23C/D)

4F-97-1805/I

COOLING WATER HEADER TEMP CAL

Annual calibration of the cooling water header temperature was last performed on November 12, 1992. This calibration should be performed in the second quarter of this year.

4F-97-2186/I T-12A\&B GROSS LEAK ALARMS CAL

Annual calibration of the gross leak alarms for the Cooling Water Expansion

Tanks, T-12A\&B, was last performed on February 22, 1995. This calibration should be performed in the first quarter of this year.

4F-97-2187/I COOLING WTR SUPPLY HEADER TEMP CAL.

Annual calibration of the cooling water supply header temperature loop was last performed on May 20,1996. This calibration should be performed in the second quarter of this year.

Instrument Air I\&C (23J)

None. 


\section{ANNUAL SYSTEM ASSESSMENT REPORT}

(Sheet 3 of 8 )

\section{B. Long Term Items}

Required By

\section{Sanitary Water System I\&C (23A/B)}

Pressure indicators PI-70034 and PI-70035 have been inoperable since last winter.

$98-4$ These gauges have been failing on about a two year cycle since they were installed. It is believed that water is migrating into the bourdon tubes then freezing during cold weather thus destroying the gauge mechanism. Resolutions were written and materials purchased for modification work packages 4F-96-2279/M and $4 \mathrm{~F}-97-521 / \mathrm{M}$ to correct this freezing problem. They should be worked in the fourth quarter prior to cold weather.

\section{Cooling Tower and Water I\&C (23C/D)}

Three of the eight cooling towers in this system are in lay-up. For restart activities, when this equipment is brought back into service, it will need to have the conductivity controls and indication system upgraded to be like the five cooling towers now in service.

$4 \mathrm{~F}-96-1283 / \mathrm{D}$

\section{COOLING WATER TOWER CIRC FANS, E-344 R-1 AND R-4} NEED NEW MOTORS.

E-344 R-1 was scavenged to replace a failing Cooling Water Tower Circ Fan ,E-19 R-4, (per 4F-96-870/W). E-344 R-4 was scavenged to be refurbished and placed in stores as an onsite spare. E-344 is currently laid up, therefore no ECN is required (per WCC LE). This package will track the need for replacement motors for E-344 should the plant get a restart order.

\section{Instrument Air I8C (23J)}

The backup air system gauges will need to be checked and the pressure regulators overhauled prior to placing the system into operation. The mobile air compressors were in operable condition when laid up but also will need to be checked prior to placing them back in service.

The T-196 air dryer will eventually need to be instrumented for alarm annunciation to the plant control room.

$T-25$ and $\mathrm{T}-194$ air dryers will need to be replaced prior to plant restart. 


\section{ANNUAL SYSTEM ASSESSMENT REPORT}

(Sheet 4 of 8 )

\section{TRENDS}

\section{Sanitary Water System I\&C (23A/B)}

System impairment may occur if the present trend of delayed corrective maintenance continues. In addition to the two modification work packages referenced in section 3.B, there are two Corrective Maintenance (CM), two Preventive Maintenance (PM), and three Instrument Calibration and Recall (ICR) documents that are 1997 work packages and ready to work (SCH-RTW). These work documents should be worked in 1998.

\section{Cooling Tower and Water I\&C (23C/D)}

Since going from a shutdown/laid up condition to a standby for the plant, some of the PM/ICR activities were restored to their original status of being performed on a regularly scheduled basis. Most of the PM/ICR activities, though, are performed on demand only. The philosophy here is that the equipment is to be run and operated till it fails or the calibration is suspect and then it will be corrected. Only those PM/ICR activities that are deemed critical or important are being performed on a regularly scheduled basis.

The PM/ICR backlog can be considered acceptable at this time. The three ICR work documents referenced in section 3.A are examples of activities just recently restored to their original scheduled basis. Those three work documents should be completed in a timely manner to ensure reliability with these instruments.

The Cooling Tower and Water I\&C is an old system with aging components and will start to fail more frequently as time goes on. Replacement items for this system's I\&C will become more difficult to obtain because of their age and vintage, or lack of suppliers.

\section{Instrument Air I\&C (23J)}

The current trend of delayed instrument calibrations could be a problem. For example, in a recent review of work packages that are SCH-RTW and in WCC HOLD, eight out of nine are past due calibration packages. Two of these are over one year past due (4F-96-1713/I and 4F-96-1720/I) and four: are over six months past due (4F-96-2305/I, 4F-97-341/I, 4F-97-342/I, and 4F-97-343/I). If installed air moisture indicators/alarms are not calibrated in a timely manner, there could be extensive system damage due to wet air if the on-line air dryer should fail and the moisture alarm was not functional. 


\title{
ANNUAC SYSTEM ASSESSMENT REPORT
}

\author{
(Sheet 5 of 8) \\ SYSTEM AGING, SPARE PARTS CONSIDERATIONS, AND LONG TERM \\ MAINTENANCE PHILOSOPHY
}

A. Discuss effects of system aging.

Sanitary Water System I\&C (23A/B)

Instruments used in this system are not particularly susceptible to aging. Temperature switches, indicators, and pressure gauges are readily available and have been replaced when the need was evident. Tank water heaters are long life items and have caused no problem in the last five years. The annunciator in Bldg 481B (C-1051) has been on line since commissioning of the system and probably will require increased maintenance due to degradation of power supply and plug-in circuit card components. The annunciator in Bldg 481 is of more recent origin and should not be a source of maintenance problems in the next two years

\section{Cooling Tower and Water I\&C (23C/D)}

The cooling tower conductivity control system was recently upgraded and thus this portion of the system should provide reliable service for the near future.

Most of the other instrumentation and annunciators in this system have aged to the point that they should be replaced. The incidence of failure is increasing, and although repairs are relatively simple, when spare parts can be obtained, the better long term solution may be to replace the old instruments and annunciators with newer, more up-to-date, components, either as a wholesale replacement or on a case by case basis.

\section{Instrument Air I\&C (23J)}

The T-25 and T-194 air dryers (including $\mathrm{I} \& \mathrm{C}$ ) are old and becoming unreliable. They may fail and need to be replaced in the near future. The $\mathrm{C}-627$ annunciator is also showing its age and may require increased maintenance in the near future. The air compressor control panels are only four years old and should continue to provide outstanding service.

B. Discuss the strategy for near term spare parts and their availability strategy.

$$
\text { Sanitary Water System I\&C (23A/B) }
$$

Spare parts are readily available in spares, shop stock, and from local suppliers. 
HNF-2380

Rev. 0, Page 310

\section{ANNUAL SYSTEM ASSESSMENT REPORT}

(Sheet 6 of 8 )

\section{Cooling Tower and Water I\&C (23C/D)}

Current spare parts are adequate for most of the equipment that is in operation now. The equipment in the plant can be repaired with the reserve of spares now in stock, or offsite procurement of replacement items can be utilized. However, for some, the components and equipment are getting quite old and a few manufacturers have gone out of business.

\section{Instrument Air I\&C (23)}

Spare parts are readily available in spares, shop stock, and local suppliers.

C. Standby Maintenance Plan: Discuss a plan which ensures essential system functions for standby are provided and minimizes equipment degradation. Assume the standby period extends for the next one to two years. Include in the plan, as a minimum: 1) the identification of hardware to be repaired, replaced, or upgraded; and 2) the frequency of routine field maintenance, ensuring material and spare parts are identified to support these activities (i.e., refurbish pumps, etc.).

\section{Sanitary Water System I\&C (23A/B)}

A long term I\&C maintenance plan is not necessary for this system since most of the instruments are not susceptible to aging problems. The only item which may need to be replaced is the C-1051 annunciator in Bldg 481A. Replacement is not warranted at this time due to the plant standby status. In the event of a restart however, it should be considered for replacement. Spare parts availability is satisfactory and no modification are needed.

\section{Cooling Tower and Water I\&C (23C/D)}

Most of the instrumentation will need replacement or an upgrade in the next few years if the plant receives a restart order. Replacement could be planned, or equipment and components could be replaced with newer, more up-to-date technology as they break.

Most of the units in this system have redundancy built into their system and the units are fairly generic and simple units. The equipment in the plant can be repaired with the reserve of spares now in stock, or offsite procurement of replacement items can be utilized.

\section{$\underline{\text { Instrument Air I\&C (23J) }}$}

A long term I\&C maintenance plan is not necessary for this system. 


\section{ANNUAL SYSTEM ASSESSMENT REPORT}

(Sheet 7 of 8 )

\section{CHECKOFF LIST}

A. Accessible parts of the entire system or component have been thoroughly walked down at least once in the past 30 days to view current performance, equipment status and condition. Yes X No

B. Are there any conditions which might require limitations different from operating limits as defined in the SDDs, the FSAR, or the Plant Technical Specifications? Yes_ No X

C. Are there trip settings, set points, interlocks, etc., that should be changed from those currently established? Yes__ No X

D. Are there interface areas which have not performed acceptably, which require resolution? Yes... No X

E. Are there temporary plant or procedural conditions which will and should remain in place? Yes_No_X

F. Is any retesting or special testing (e.g., OSP) required? Yes _ No X

G. Are the current plant corrective maintenance, preventive maintenance, and calibration database items all properly identified and are planned actions acceptable? Yes X No

H. Are all other action items (NCRs, IRs, etc.) properly identified and assigned? Yes_X_No__ (attach the summary of needed actions not in the data base)

I. Are there any special operating considerations? Yes__ No X

J. Are near term spare parts adequate? Yes X No

K. Have any safety issues (radiological, industrial) been identified that remain unresolved? Yes_N No_X

L. Have all component data been entered into the Plant information database?

Yes X No

M. Have applicable SISI inspections been conducted? Yes $\underline{X}$ No_

N. Has a cleanliness evaluation been completed? Yes X No Are any issues still unresolved? Yes $\mathrm{X}$ No_ 


\section{ANNUAL SYSTEM ASSESSMENT REPORT}

(Sheet 8 of 8 )

\section{REEERENCES}

None.

8. $\quad$ ATTACHMENTS

Listing of Minimum Operable Equipment from administrative procedure PN-7:

(23C):

Cooling Water Towers and their Associated Circ Pumps,

E-18/P-99, E-19/P-107, E-296/P-9, E-297/P-8, E-345/P-235

(23J):

Plant Air Compressors, R-1, R-2, R-189

(2 of 3$)$

Air Dryers, T-25, T-194, T-196 


\section{ANNUAL SYSTEM ASSESSMENT REPORT}

(Sheet 1 of 7 )

Date of This Report January 14, 1998

Date of Previous Report January 22, 1992

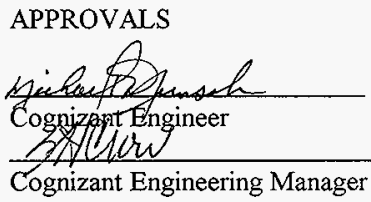

1. SCOPE

System 93-6, Heating \& Ventilation Instrumentation (part of System 25)

2. SUMMARY EVALUATION (Provide a general assessment of the overall health of the system. Include a discussion of the system's minimum operable equipment from plant procedure PN-7.)

A complete listing of the minimum operable equipment (MOE) from administrative procedure $\mathrm{PN}-7$ is included in section 8. Outstanding work documents for this equipment are included in Section 3.A.

The overall condition of this system is good. The majority of the components of the H\&V system are operating normally. Normal corrective maintenance for this equipment has been taken care of with spare parts inventory or from off site procurement of spare parts.

3. ITEMS REQUIRING ACTION (Items on PTS, Procedures, Software, etc.)

A. Near Term Items

$\underline{\text { Required By }}$

4F-96-539/W

E-224 SHUTS DOWN ON LOW FLOW

E-224 (Miscellaneous Cells Inert Gas Cooler) has shut down a number of times since the retest was signed off complete for $4 \mathrm{~F}-94-1091 / \mathrm{W}$. (MOE)

$4 \mathrm{~F}-97-1968 / \mathrm{W}$

E-565 BELTS ARE SLIPPING

(3-blank) 1998

E-565 (HTS-East Air Conditioning Unit) drive belts are squealing when on-line. (MOE)

$4 \mathrm{~F}-97-2273 / \mathrm{W}$

LLFM COOLER (E-231-R) WILL NOT RUN

$98-1 R$

E-231-R (LLFM Inert Gas Cooler) would not run. While attempting to jog the cooler for weekly equipment run time the gas cooler power supply breaker tripped as soon as the breaker panel's face mounted "jog" pushbutton was depressed. An attempt to run the unit using the normal operating procedure had the same result. In both cases, only the breaker tripped and not the thermal overload. Inspection of the breaker cubicle found nothing unusual. (MOE) 


\section{ANNUAL SYSTEM ASSESSMENT REPORT}

(Sheet 2 of 7)

A. Near Term Items (cont'd)

Required By

$4 \mathrm{~F}-97-2742 / \mathrm{W}$

E-68 MOTOR BELTS ARE SLIPPING

$98-1 R$

On C-401 it was noted that Containment $\mathrm{H} \& \mathrm{~V}$ flow for E-68 (CTMT Bldg Air

Conditioning Unit) was at 17,000 CFM (set point at 19,000 CFM) with the flow controller output maxed out at $0 \%$ in AUTO. The flow controller is normally at approximately $70 \%$ in AUTO while maintaining 19,000 CFM. The E- 68 dampers were verified full open. The motor belts were found to be making the belt squeaking noise continuously. (MOE)

4F-97-2010/W JC-85050-B (E-69 HTR) WIRING IS DAMAGED 98-1

While troubleshooting $4 \mathrm{~F}-97-87 / \mathrm{W}$, it was noticed that the Power Controller, JC-85050-B for E-69, heater cabinet has several burned relays, burnt wiring, overheated connections and safety cutouts. Heater circuit is inoperable.

4F-96-1738/P E-69 HEATER INSPECTION (waiting on 4F-97-2010/W) 98-2R PMP inspection of E-69 (CTMT Bldg Air Conditioning Unit), heater and associated circuitry.

4F-97-155/M MODIFY C-185 CONTROL SYSTEM, DELETE PLC'S $98-1 \mathrm{C}$ The coolers are controlled from $\mathrm{C}-185$ ( $\mathrm{H} \& \mathrm{~V}$ Control Panel) via a programmable controller system which is aged and increasingly unreliable. No spare parts exist, and repair is increasingly futile. The reliable operation of the IEM Cell gas coolers, E-218 and E-219, is required until all FFTF components that need to be washed in the sodium removal system have been processed. The subassembly coolers, E-220 and E-221, are not operating now and would not be required until after a reactor restart occurred. The scope statement in the resolution will define which components are to be included, and whether another document should be generated at a later time for follow-on work.

4F-97-2031/W REPLACE R-901 THERMAL OVERLOAD BLOCKS $98-1$ During the performance of $4 \mathrm{~F}-97-1859 / \mathrm{W}$, it was noted that the thermal overload block terminal insulators are damaged. The unit was returned to service, but the overload mechanism must be replaced. The unit may not shut down if overheated, and in fact, from appearances it has probably already run in that condition. 


\section{ANNUAL SYSTEM ASSESSMENT REPORT}

(Sheet 3 of 7)

B. Long Term Items

Required By

UPGRADE C-186 CONTROL SYSTEM

SU1

Replace the programmable logic controllers in the H\&V Control Panel, C-186, with an up-to-date, new control system. See $4 \mathrm{~F}-97-155 / \mathrm{M}$ for similar upgrade to the H\&V Control Panel, C-185.

UPGRADE C-185 CONTROL SYSTEM, PLC-A

Replace the programmable logic controller in the H\&V Control Panels, C-185-D and C-185-E, with comparable units as the new PLC in C-185-A and C-185-B (installed by $4 \mathrm{~F}-97-155 / \mathrm{M}$ ).

UPGRADE THE PANEL ANNUNCIATORS

The Johnson Controls and Honeywell panels for the H\&V controls require an up-to-date, new annunciator system. The existing annunciators are out of date and the spares for these units are becoming increasingly harder to find or even repair in the shop.

REPLACE THE HONEYWELL CONTROLLERS

The Honeywell controllers in the H\&V panels and in the field for control of the $H \& V$ equipment require replacement with up-to-date, new equipment. The Honeywell controllers are becoming antiquated and spares are becoming increasingly harder to obtain from outside sources.

4. TRENDS (Discuss trended parameters. See Appendix $K$ for typical parameters which can be used for trending studies.)

Power outages and testing (e.g., SC-12-4) have been damaging the programmable logic controllers in $\mathrm{C}-185$ and $\mathrm{C}-186$. The trend has been observed and the results are that the controllers are becoming less and less reliable. C-185 PLC-B is going to be replaced (4F-97-155/M) in the very near future. C-185 PLC-A and the two C-186 PLC's will need to be replaced in the near future if we receive a startup order. 


\section{ANNUAL SYSTEM ASSESSMENT REPORT}

(Sheet 4 of 7)

\section{SYSTEM AGNG SPARE PARTS CONSIDERATIONS, AND LONG TERM MAINTENANCE PHILOSOPHY}

A. Discuss effects of system aging.

There have been no major upgrades to any equipment in the entire system, leaving it vulnerable to component failures at any time. For most of the HVAC units and systems, this is not considered a big problem because most of the units in this system employ redundancy and the units are fairly generic and simple $H \& V$ units, but for others it could have noticeable consequences; those units and components that are considered more critical for the day-to-day operation of the plant, those that are not so generic in their manufacturer, or their manufacturer no longer exists. Most of the HVAC control panels are manufactured by Johnson Controls and Honeywell. Most of the equipment and their controls are manufactured by companies such as Johnson Controls, Honeywell, INDEECO, Chromalox, Datametrics, etc. The replacement of some of the parts for the items within the H\&V control panels is becoming more and more difficult to obtain because of the parts' vintage/age (circa 1970's technology), or the manufacturer has gone out of business.

B. Discuss the strategy for near term spare parts and their availability strategy.

Current spare parts are adequate for most of the equipment that is in the plant now. The equipment in the plant can be repaired with the reserve of spares now in stock, or offsite procurement of replacement items can be utilized.

With the modification work package to replace C-185 PLC-B with a newer technology PLC, there will now be more spares for the original manufacturer PLC's in C-185 and $\mathrm{C}-186$. The original manufacturer of this equipment, Datametrics, is no longer in business and there is no source for replacement parts. The controller spares have been repaired a lot, and when they are repaired it is difficult to determine if all functions are working. Now with the increase in these spares on site it is expected that the spares will be adequate for the remainder of the system. 


\section{ANNUAL SYSTEM ASSESSMENT REPORT}

(Sheet 5 of 7)

C. Standby Maintenance Plan: Discuss a plan which ensures essential system functions for standby are provided and minimizes equipment degradation. Assume the standby period extends for the next one to two years. Include in the plan, as a minimum: 1) the identification of hardware to be repaired, replaced, or upgraded; and 2) the frequency of routine field maintenance, ensuring material and spare parts are identified to support these activities (i.e., refurbish pumps, etc.).

Most of the System $25 \mathrm{H} \& \mathrm{~V}$ instrumentation will need replacement or upgrade beyond the next few years. Replacement could be planned, or instruments and controls could be replaced with newer, more up-to-date technology as they break. (Note: We can maintain the system over the next one to two years as stated above. After that period upgrades will be necessary.)

Most of the H\&V units have redundancy built into their system and the units are fairly generic and simple H\&V units. The equipment in the plant can be repaired with the reserve of spares now in stock, or offsite procurement of replacement items can be utilized.

C-185 PLC-B is to be replaced with a newer technology PLC. There will now be more spares for the original manufacturer PLC's in C-185 and C-186. The original manufacturer of this equipment, Datametrics, is no longer in business and there is no source for replacement parts. The controller spares have been repaired a lot, and when they are repaired it is difficult to determine if all functions are working. Now with the increase in these spares on site it is expected that the spares will be adequate for the remainder of the system.

\section{CHECKOFE LIST}

A. Accessible parts of the entire system or component have been thoroughly walked down at least once in the past 30 days to view current performance, equipment status and condition. Yes_X No -

B. Are there any conditions which might require limitations different from operating limits as defined in the SDDs, the FSAR, or the Plant Technical Specifications? Yes $X$ No

C. Are there trip settings, set points, interlocks, etc., that should be changed from those currently established? Yes_No_X

D. Are there interface areas which have not performed acceptably, which require resolution? Yes_No N 


\section{ANNUAL SYSTEM ASSESSMENT REPORT}

\section{(Sheet 6 of 7)}

E. Are there temporary plant or procedural conditions which will and should remain in place? Yes_No No X

F. Is any retesting or special testing (e.g., OSP) required? Yes_ No X

G. Are the current plant corrective maintenance, preventive maintenance, and calibration database items all properly identified and are planned actions acceptable? Yes_ No X

Since going from a shutdown/lay-up condition to a stand-by for the plant, some of the PM/ICR activities have been restored to their original status of being performed on a regularly scheduled basis. Most of the PM/ICR activities, though, are performed on demand only. The philosophy here is that the equipment is to be run and operated till it fails or the calibration is suspected and then it will be corrected. Only those PM/ICR activities that are deemed critical or important are being performed on a regularly scheduled basis. Thus far this philosophy has appeared to work well. There are no Recall Basis 1 (fixed frequency) PM/ICR activities that are past due.

H. Are all other action items (NCRs, IRs, etc.) properly identified and assigned? Yes X No__ (attach the summary of needed actions not in the data base)

I. Are there any special operating considerations? Yes_ No $\mathrm{X}$

J. Are near term spare parts adequate? Yes X No

K. Have any safety issues (radiological, industrial) been identified that remain unresolved? Yes_No $\underline{X}$

L. Have all component data been entered into the Plant information database? Yes_X No

M. Have applicable SISI inspections been conducted? Yes X No

N. Has a cleanliness evaluation been completed? Yes $\underline{X}$ No_ Are any issues still unresolved? Yes_ No_X

\section{REFERENCES}

None. 


\section{ANNUAL SYSTEM ASSESSMENT REPORT}

(Sheet 7 of 7)

\section{8. $\quad$ ATTACHMENTS}

Listing of Minimum Operable Equipment from administrative procedure PN-7:

Reactor Cavity Gas Coolers, E-201, E-202

HTS Cells $1 \& 2$ Gas Coolers, E-203, E-204, E-205

HTS Cell 3 \& Sodium Vessel Cell Gas Coolers, E-206, E-207, E-208

DS \& Miscellaneous Cells Gas Coolers, E-222, E-223, E-224

CRDM Gas Coolers, E-226, E-227

LLFM Gas Coolers, E-230, E-231

Reactor Head Cooling Fans, R-816, R-817

Center Island Gas Coolers, E-232, E-233

CTMT Bldg Air Conditioning Units, E-68, E-69

CTMT Bldg Exhaust Fans, R-3, R-4

CTMT Work Area Air Conditioner and associated circulation pump, E-25/P-228

CTMT Work Area Air Conditioner and associated circulation pump, E-26/P-229

Secondary Main Motor Cell Air Conditioning Units, E-558 M1 \& M2

Secondary Main Motor Cell Air Conditioning Units, E-608 M1 \& M2

Secondary Main Motor Cell Air Conditioning Units, E-609 M1 \& M2

HTS-South Exhaust Filter Fan Unit, R-752

Life Support Air Conditioning Units, E-525 M1, E-525 M2

Life Support Filter Fan Units, E-523, E-524 


\section{ANNUAL SYSTEM ASSESSMENT REPORT}

(Sheet 1 of 7)

Date of This Report January 28, 1998

Date of Previous Report January 24, 1992

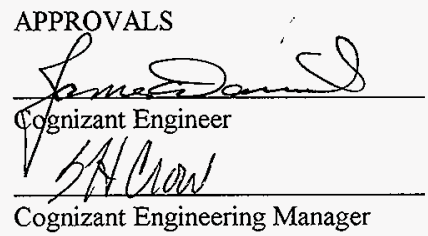

\section{1. $\quad$ SCOPE}

System 93-7, Plant Fire Protection Instrumentation System System M26, MASF Fire Protection Instrumentation System

\section{SUMMARYEVALUATION}

The Plant Fire Protection and Alarm System is operating normally and providing fire alarm and detection functions for the FFTF/FSF/MASF. Fire Alarm and Detection panels C199, C1351, C1359, C1361, FCC 1352, and C1354 are operating normally with no limiting conditions for operation which will impact plant availability. ALCPs 1350, 1355, 1356, and 1357 are operating normally with no system restrictions.

MASF Fire Protection Panel C1362 has been disconnected from the UPS power supply and was temporarily reconnected to building power. The UPS power supply was found deficient in design and will not provide the correct voltage for the supervisory trouble circuits. Panel $\mathrm{C} 1362$ supervisory trouble circuits are operating correctly on building power. This panel has no battery backup and will de-energize when there is a loss of building power. A new installation is planned and will correct any previous design error. This discrepancy was reported in Occurrence report RL-PHMC-FFTF-1997-0015.

The Halon Fire Suppression Systems have been deactivated for Rooms 135 and 404 . The computer systems for Rooms 135 and 404 have been de-energized and any further fire protection for the contents of these rooms would be of no value. The ability to detect a fire and discharge the Halon has been terminated. Computers and combustibles have been removed. The smoke detectors have been disconnected and the Halon discharge initiators have been removed. The notification circuits have also been disconnected. The panel remains energized but will not provide for alarm protection in case of fire. Any compliance testing has also been terminated. The Halon Fire Suppression System for Room 110 remains operational and will mitigate and suppress a fire. 


\section{ANNUAL SYSTEM ASSESSMENT REPORT}

(Sheet 2 of 7 )

The Fire Water Suppression System Instrumentation and Controls are operating correctly and performing its intended function. Backflow preventers are planned to be installed in 481 and 481A Pumphouse. Minor changes to the valve supervisory circuits are planned with this new installation.

Spare parts and components for maintenance on all systems remain available. New parts for some of the older Pyrotronics systems are more difficult to procure since a few of the modules are obsolete and are no longer manufactured.

Spare high voltage cards for FSF Fire System Panel C1361 are no longer manufactured and we have a limited number of spares. There is a need to consider a redesign of Panel $\mathrm{C} 1361$ if the FFTF mission is realized.

There is a need for improving some of the drawings that support the Fire System. Some drawings are difficult to follow and should be updated to reflect current design drawing standards.

Systems 93-7 and M26 equipment are not listed as applicable to the minimum operable equipment required by PN-7. These systems are controlled by PN-0.

3. ITEMS REQUTRING ACTION (Items on PTS, Procedures, Software, etc.)

\section{A. Near Term Items}

4A-97-00090/M The C1362 UPS power supply does not meet the operational criteria and will not provide the correct voltage for the supervisory trouble circuits. A new installation is planned with this modification and will correct any previous design error. This discrepancy was reported in Occurrence report RL-PHMC-FFTF-1997-0015. A temporary modification was performed to remove $\mathrm{C} 1362$ from the deficient power supply and energize this panel from building power. There is no compromise of design criteria except the fire alarm panel $\mathrm{C} 1362$ will de-energize when there is a loss of building power. This is an acceptable alternative to performing a smoke detector surveillance every shift until a new battery backup power supply source can be procured and installed. This work should be performed in work quarter 98-2. 


\section{ANNUAL SYSTEM ASSESSMENT REPORT}

(Sheet 3 of 7 )

A. Near Term Items (cont'd)

4A-97-00168/W The MASF sprinkler rise pressure gauges need to be replaced or recalibrated every five years in accordance with the National Fire Code (NFC) 25, "Inspection, Testing, and Maintenance of Water-Based Fire Protection Systems", paragraph 2-3.2. This work document will replace these gauges since this method will be cost effective. This work is scheduled to be completed in work quarter 98-1.

4F-97-02078/W C1355 periodically receives an intermittent alarm for device 6127, DHX-W Fuel Oil Level Alarm Switch. Previous parts replacement failed to correct the problem. Subsequent troubleshooting indicates that the fuel oil switch may be contributing to the problem. This work document will replace the fuel oil switch with a new one. This work is scheduled to be completed in work quarter 98-1

4F-97-02746/W On panel C1354 module 21-20 periodically indicates a failure and alarms the panel. The device $21-20$ is a smoke detector and is scheduled to be replaced in work quarter $98-1$.

\section{B. Long Term Items}

4F-97-00612/M The FSF Fire Alarm System is one of the High Voltage Systems that is currently obsolete and many of the replacement parts are no longer manufactured. The testing and maintenance costs are becoming prohibitive. Upgrade of this system should be performed during standby to reduce the effects of high maintenance and testing costs, allowing the system to be maintained as efficiently as possible.

4F-97-00167/W There is a need to develop a Preventive Maintenance procedure for the three MASF Duct smoke detectors. This work document will measure the differential pressure across these detectors and gather data for the compiling of a routine procedure. Completion date is during work phase 98-4.

4. TRENDS (Discuss trended parameters. See Appendix $\mathrm{K}$ for typical parameters which can be used for trending studies.)

The P-28/P-61 Fire System Pump batteries are checked by PMP-26A-E02 and their condition is satisfactory this reporting period. 


\section{ANNUAL SYSTEM ASSESSMENT REPORT}

(Sheet 4 of 7)

Batteries for ALCP 1351, 1359, 1361, and C199 are checked by PMP-26D-E02 and PMP-26D-E05. Their condition is satisfactory this reporting period.

PMP data and maintenance records do not show any trends developing that would require Engineering attention or design changes at this time. All systems are operating within the approved design requirements.

\section{SYSTEM AGING, SPARE PARTS CONSIDERATIONS, AND LONG TERM} MAINTENANCE PHILOSOPHY

A. Discuss effects of system aging.

The Reactor Service Building (C1351), Pump House (C1359), and Fuel Storage Facility (C1361) fire alarm systems are about twenty years old and are being affected by system aging. All the power supplies are constructed using electrolytic capacitors which have a limited lifetime. Several studies have been performed showing that this lifetime is rarely over twenty years. It will become increasingly important to verify the adequacy of these power supply filters. The backup batteries are subject to aging and will need to be replaced with new ones. Other components such as light bulbs and devices exposed to high heat are more likely to age rapidly and will need replacement due to thermal cycling and subsequent failure. Relay contacts accumulate pitting and corrosion due to environmental and electrical factors.

B. Discuss the strategy for near term spare parts and their availability strategy.

Spare parts are available for most expected maintenance problems. There are items that do not have spares but there is not an expectation that these items will fail. The lead time for procurement is relatively short.

The Pyrotronics System 3, CP-30 and CP-31 Systems are no longer manufactured and can no longer be obtained through the procurement process. The Pyrotronics System 3, CP-35 components will not interface with many of the CP-30/35 modules. FFTF is very limited on the number of spare parts for these older systems. Other locations on site may have a few spares that could be borrowed if needed. 


\section{ANNUAL SYSTEM ASSESSMENT REPORT}

(Sheet 5 of 7)

C. Standby Maintenance Plan: Discuss a plan which ensures essential system functions for standby are provided and minimizes equipment degradation. Assume the standby period extends for the next one to two years. Include in the plan, as a minimum: 1) the identification of hardware to be repaired, replaced, or upgraded; and 2) the frequency of routine field maintenance, ensuring material and spare parts are identified to support these activities (i.e., refurbish pumps, etc.).

The level of effort to maintain the Fire Systems availability will depend largely in part to the time expended for redesigning the remaining systems needing upgrade. To assure spare parts availability and to reduce maintenance costs ALCP 1361 should be upgraded during standby to eliminate the manpower intensive detector sensitivity checks and the battery bank, which requires a high level of preventive maintenance.

\section{CHECKOFF LIST}

A. Accessible parts of the entire system or component have been thoroughly walked down at least once in the past 30 days to view current performance, equipment status and condition. Yes X No

COMMENTS (exceptions):

The C1362 Fire Alarm Panel was disconnected from the inverter power supply and connected to building power. The Halon Fire Suppression Systems for Rooms 135 and 404 have been disconnected and remain laid up.

B. Are there any conditions which might require limitations different from operating limits as defined in the SDDs, the FSAR, or the Plant Technical Specifications? Yes. $\mathrm{X}$ No

COMMENTS (exceptions):

During a Loss of Offsite Electrical Power to Panel C1362 the battery will not supply power to maintain the system in an operational condition. The inverter has been disconnected and there is no battery backup.

C. Are there trip settings, set points, interlocks, etc., that should be changed from those currently established? Yes_ No $\underline{X}$

D. Are there interface areas which have not performed acceptably, which require resolution? Yes_No X $\mathrm{X}$ 


\section{ANNUAL SYSTEM ASSESSMENT REPORT}

(Sheet 6 of 7)

E. Are there temporary plant or procedural conditions which will and should remain in place? Yes X No

Attach list of MOD(L)/ECN(L)s, and OSPs that are currently active. Provide justification for continuing temporary MOD (L)s and ECN (L)s.

COMMENTS (exceptions):

Approved MOD(L)/ECN(L) 4A-97-00176/L and $645777 \mathrm{~L}$ remain in place and will be replaced by a permanent change to upgrade MASF Fire Alarm Panel C1362 with a correctly designed power supply system that will correct the trouble power supply circuit. The current power supply from the inverter will not correctly power this panel. The present inverter produces square waves that are processed incorrectly by panel $\mathrm{C} 1362$.

F. Is any retesting or special testing (e.g., OSP) required? Yes_ No $\underline{\mathrm{X}}$

G. Are the current plant corrective maintenance, preventive maintenance, and calibration database items all properly identified and are planned actions acceptable? Yes_ X No -

H. Are all other action items (NCRs, IRs, etc.) properly identified and assigned? Yes $\_$No_ (attach the summary of needed actions not in the data base)

I. Are there any special operating considerations? Yes__ No $\underline{X}$

List or Reference: None

J. Are near term spare parts adequate? Yes_X No_-

K. Have any safety issues (radiological, industrial) been identified that remain unresolved? Yes_No $\underline{X}$

L. Have all component data been entered into the Plant information database?

Yes $\mathrm{X}$ No

M. Have applicable SISI inspections been conducted? Yes_ No_

COMMENTS (exceptions): N/A 


\section{ANNUAL SYSTEM ASSESSMENT REPORT}

(Sheet 7 of 7)

N. Has a cleanliness evaluation been completed? Yes $X$ No Are any issues still unresolved? Yes _ No X

\section{REFERENCES}

WCC Database, Facility Spare Parts Inventory (HIP)

\section{ATTACHMENTS}

None. 


\section{ANNUAL SYSTEM ASSESSMENT REPORT}

(Sheet 1 of 5 )

Dhate of This Report January 22, 1998

Date of Previous Report _January 20,1992

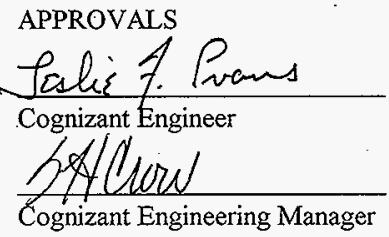

1. SCOPE

93-8, Inert Gas Receiving_and Processing Instrumentation System (part of System 82)

2. SUMMARY EVALUATION (Provide a general assessment of the overall health of the . system. Include a discussion of the system's minimum operable equipment from plant procedure $\mathrm{PN}-7$.)

The instrumentation associated with Startup System 82D (ICCB \& ECCB including the CAPS Header) are operating within acceptable parameters to support Standby Operations of the FFTF.

PN-7 require two of three of the following components, ICCB \#1 (R-200), ICCB \#2 (R201) and ECCB (R-202), to be operable. The instrumentation and electrical equipment to support this equipment are operable at this time.

The N-24 Refueling Gas Chromatograph is operating within acceptable parameters to support Standby Operations.

PN-7 has no requirements on $\mathrm{N}-24$.

3. ITEMS REQUIRING ACTION (Items on PTS, Procedures, Software, etc.)

A. Near Term Items

Required By

4F-97-1997 R-202 DC OVER VOLTAGE TRIPS $98-4$

This is an intermittent problem which will require additional time to isolate the cause.

B. Long Term Items

None. 
HNF-2380

Rev. 0, Page 328

\section{ANNUAL SYSTEM ASSESSMENT REPORT}

(Sheet 2 of 5)

4. TRENDS (Discuss trended parameters. See Appendix K for typical parameters which can be used for trending studies.)

No specific trending has been performed or is being planned for system $82 \mathrm{D}$ and component $\mathrm{N}-24$ instrumentation and electrical equipment.

5. SYSTEM AGING, SPARE PARTS CONSIDERATIONS, AND LONG TERM MAINTENANCE PHILOSOPHY

A. Discuss effects of system aging.

\section{System 82D}

System aging has appeared in electronic instrumentation. This has been traced to heat affects on resistors and capacitors. As these failures occur, they are being repaired or the failed instrument replaced if replacement devices are available.

The ECCB is new instrumentation and is not showing any signs of aging.

Spare parts to support Honeywell controllers repair are no longer available and the controllers can no longer be purchased. Units which are failing are not being repaired, but some are being salvaged for unique spare parts.

Spare parts can no longer be reordered for the RIS annunciators. Many of the cards now failing have reached end-of-life and cannot be repaired.

\section{N-24 Gas Chromatograph}

System aging has not been, and is not expected to become, a problem with this system in the near term.

B. Discuss the strategy for near term spare parts and their availability strategy.

\section{System 82D}

The unique repair parts are no longer available for many of the instruments. These instruments when removed from the plant are repaired for reuse as a short term solution for spare parts when ever possible. 


\section{ANNUAL SYSTEM ASSESSMENT REPORT}

(Sheet 3 of 5)

\section{N-24 Gas Chromatograph}

This gas chromatograph is obsolete already but spare parts can be obtained by special order.

C. Standby Maintenance Plan: Discuss a plan which ensures essential system functions for standby are provided and minimizes equipment degradation. Assume the standby period extends for the next one to two years. Include in the plan, as a minimum: 1) the identification of hardware to be repaired, replaced, or upgraded; and 2) the frequency of routine field maintenance, ensuring material and spare parts are identified to support these activities (i.e., refurbish pumps, etc.).

\section{System 820}

No special maintenance is being performed on System $82 \mathrm{D}$ for standby. The instrumentation is being repaired upon failure under corrective maintenance. No instrumentation upgrades are necessary to support standby operation for the next year or two.

Preventive maintenance (e.g., motor lubrication) is being routinely performed on the ICCB and ECCB motors. Package 4F-97-25434/P is the only outstanding Preventive Maintenance package and has a due date of January 10, 1998.

\section{N-24 Gas Chromatograph}

The Refueling Gas Chromatograph is a computer controlled unit with built-in checks of operations and therefore does not require additional calibration or maintenance checks.

\section{CHECKOFF LIST}

A. Accessible parts of the entire system or component have been thoroughly walked down at least once in the past 30 days to view current performance, equipment status and condition. Yes X No

B. Are there any conditions which might require limitations different from operating limits as defined in the System Design Descriptions (SDD), the FSAR, or the Plant Technical Specifications? Yes__ No X

C. Are there trip settings, set points, interlocks, etc., that should be changed from those currently established? Yes_ No X 


\section{ANNUAL SYSTEM ASSESSMENT REPORT}

(Sheet 4 of 5)

D. Are there interface areas which have not performed acceptably, which require resolution? Yes_No즈

E. Are there temporary plant or procedural conditions which will and should remain in place? Yes _ No X

Attach list of MOD(L)/ECN(L)s, and OSPs that are currently active. Provide justification for continuing temporary MOD $(\mathrm{L}) \mathrm{s}$ and $\mathrm{ECN}(\mathrm{L}) \mathrm{s}$.

F. Is any retesting or special testing (e.g., OSP) required? Yes_ No X

G. Are the current plant corrective maintenance, preventive maintenance, and calibration database items all properly identified and are planned actions acceptable? Yes X No -

H. Are all other action items (NCRs, IRs, etc.) properly identified and assigned? Yes $X$ _ No_ (attach the summary of needed actions not in the data base)

I. Are there any special operating considerations? Yes__ No X

List or Reference: None

J. Are near term spare parts adequate? Yes $\underline{X}$ No

COMMENTS (exceptions): At present there is no instrument or electrical equipment required for Standby Operation which is inoperable because of a lack of spare parts. The spare parts appear to be adequate to support standby operations at this time.

K. Have any safety issues (radiological, industrial) been identified that remain unresolved? Yes__ NoX

L. Have all component data been entered into the Plant information database? Yes $\underline{X}$ No

M. Have applicable SISI inspections been conducted? Yes $\underline{X}$ No_-

N. Has a cleanliness evaluation been completed? Yes $\underline{X}$ No_ Are any issues still unresolved? Yes No $\underline{X}$ 


\section{ANNUAL SYSTEM ASSESSMENT REPORT}

\section{(Sheet 5 of 5 )}

\section{REFERENCES}

None.

8. ATTACHMENTS

None. 


\section{ANNUAL SYSTEM ASSESSMENT REPORT}

(Sheet 1 of 5)

Date of This Report _ January 16, 1997

Date of Previous Report January 14, 1992

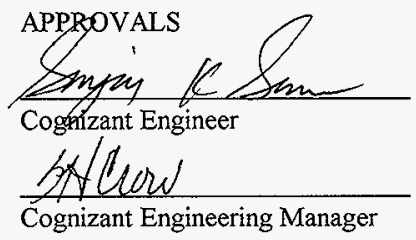

1. SCOPE:

System 93-15, Trace Heat Control

2. SUMMARY EVALUATION (Provide a general assessment of the overall health of the system. Include a discussion of the system's minimum operable equipment from plant procedure $\mathrm{PN}-7$.)

The FFTF trace heat systems continue to perform their design requirements and will support: all phases of plant operations. There have been some trace heat monitoring computer ( $\mathrm{C} 850, \mathrm{C} 852, \mathrm{C} 864$, and $\mathrm{C} 866)$ and software problems over the past years, but these have been resolved in a timely manner and the system is performing adequately. The temperature control portion on the system has experienced the most problems over the past years (i.e., problems with the temperature controllers, power controllers, temperature set-point controllers, thermocouples, and heaters).

Over the last several years there have been areas in the plant sodium piping systems where heaters have failed, and repair has not been done. These heaters were not repaired because the adjacent heaters provided sufficient heat input.

3. ITEMS REQUTRING ACTION (Items on PTS, Procedures, Software, etc.)

\section{A. Near Term Items}

There are always a baseline number of documents required to be worked on the Trace Heat System. These work items deal with repairing failed temperature controllers, power controllers, set-point controllers and thermocouples. 


\section{ANNUAL SYSTEM ASSESSMENT REPORT}

(Sheet 2 of 5 )

\section{B. Long Term Items}

Routine software issues, such as screen lockups, faded display, communication between the computer and data loggers, are currently being resolved by the software cognizant engineer. It may be necessary to look down the road for a new temperature monitoring software, since this one is difficult to use at times and is getting outdated.

Both sets of heaters on the primary HTS pump P-2 drain line have failed (4F-91$1827 / \mathrm{W})$. It will be necessary to reheat this section of pipe before the plant can be shut down.

4. TRENDS (Discuss trended parameters. See Appendix K for typical parameters which can be used for trending studies.)

An increase in the failures of the temperature control system components has been noticed over the years. These components are on full time in certain areas of the plant to maintain heat input, due to the standby conditions of the plant. There has been an increase in the number of heaters that have failed in the plant also. In certain cases the spare set of heaters has also failed. These heaters have not been repaired.

The trace heat monitoring computer equipment and data loggers seem to be operating without many problems over the years. The trace heat monitoring software has performed without problems over the years also, but is not the most "user friendly" software around. The software has a tendency to lock up.

\section{SYSTEMAGING SPARE PARTS CONSIDERATIONS, AND LONG TERM} MAINTENANCE PHILOSOPHY

A. Discuss effects of system aging.

More and more problems are arising with the heat control portion of the Trace Heat System. Since the removal of fuel from the reactor, decay heat is not being produced, the trace heat system has been running continuously for many years in areas where heat loss is the greatest. This is shortening the life of the heaters, and the power controllers for the heaters. 


\section{ANNUAL SYSTEM ASSESSMENT REPORT}

(Sheet 3 of 5)

The trace heat monitoring software is starting to get old also. See comments in Section 4.

The trace heat monitoring computers are PC based 386 machines and are becoming outdated compared to industry standard computers, which are now based on the Pentium Processor. The computer processor technology in the Fluke Data logger is also starting to be outdated.

B. Discuss the strategy for near term spare parts and their availability strategy.

Currently all power controllers (JC), set-point controllers (HC), and temperature controllers (TC) are being repaired by instrument technicians using off the shelf material currently available. Repair parts for the PC based computers and data loggers are also available from outside vendors.

C. Standby Maintenance Plan: Discuss a plan which ensures essential system functions for standby are provided and minimizes equipment degradation. Assume the standby period extends for the next one to two years. Include in the plan, as a minimum: 1) the identification of hardware to be repaired, replaced, or upgraded; and 2) the frequency of routine field maintenance, ensuring material and spare parts are identified to support these activities (i.e., refurbish pumps, etc.).

The Trace Heat System is currently in full operation during these standby conditions and will remain in full operation until there is no longer a need for heat input to the sodium systems. The system is being maintained to its full extent.

All power controllers (JC), set-point controllers (HC), and temperature controllers (TC) are being repaired by instrument technicians using off the self material currently available. Repair parts for the PC based computers and data loggers are also available from outside vendors. Routine field maintenance on the system is being performed regularly. All failed temperature, power, and set-point controllers are being repaired and replaced as they fail in the plant. Currently, heaters are only being replaced if they are on a section of piping that may have a tendency to cool down significantly. Otherwise, they will be replaced later "down the road".

The main area of degradation on the trace heat system during standby is the heaters. Since there is no more decay heat being produced, the heaters are on full time providing heat to the sodium system, thus reducing the life of the heater. An adequate amount of heaters are in our spare inventory or new type of heater can be ordered in certain cases. 


\section{ANNUAL SYSTEM ASSESSMENT REPORT}

(Sheet 4 of 5 )

\section{CHECKOFF LIST}

A. Accessible parts of the entire system or component have been thoroughly walked down at least once in the past 30 days to view current performance, equipment status and condition. Yes $\mathrm{X}$ No

B. Are there any conditions which might require limitations different from operating limits as defined in the SDDs, the FSAR, or the Plant Technical Specifications? Yes_ No $\mathrm{X}$

C. Are there trip settings, set points, interlocks, etc., that should be changed from those currently established? Yes_. No $\mathrm{X}$

COMMENTS (exceptions): Limits are now being evaluated on a case-by-case basis. ECN's are written to update all limits files.

D. Are there interface areas which have not performed acceptably, which require resolution? Yes_No $\mathrm{X}$

E. Are there temporary plant or procedural conditions which will and should remain in place? Yes_ No $\mathrm{X}$

Attach list of MOD(L)/ECN(L)s, and OSPs that are currently active. Provide justification for continuing temporary MOD (L)s and ECN (L)s.

F. Is any retesting or special testing (e.g., OSP) required? Yes _ No _ X

G. Are the current plant corrective maintenance, preventive maintenance, and calibration database items all properly identified and are planned actions acceptable? Yes X No

COMMENTS(exceptions): All PMPs for this system are classified as Recall Basis 3. Currently PMPs are performed at $\mathrm{Cog}$. Engineers request for this system. There are only a few outstanding PMP for this system currently.

H. Are all other action items (NCRs, IRs, etc.) properly identified and assigned? Yes X No__ (attach the summary of needed actions not in the data base

I. Are there any special operating considerations? Yes_ No X 


\section{ANNUAL SYSTEM ASSESSMENT REPORT}

(Sheet 5 of 5 )

J. Are near term spare parts adequate? Yes_X_No_

COMMENTS (exceptions): All parts are being repaired by the craft on a asneeded basis.

K. Have any safety issues (radiological, industrial) been identified that remain unresolved? Yes__ No X

L. Have all component data been entered into the Plant information database?

Yes No $X$

COMMENTS (exceptions): Most of the FFTF trace heat system, for example JC's, HC's, and TC's, are not on JCS. Efforts to add to JCS have met with limited success due to the large size of the database and subsequent cost to implement. Presently the trace heat index is on a PC computer and reports are available "on request" for field use. This is an acceptable condition.

M. Have applicable SISI inspections been conducted? Yes_ No

COMMENTS (exceptions): N/A

N. Has a cleanliness evaluation been completed? Yes_ No_

Are any issues still unresolved? Yes_ No

COMMENTS (exceptions): N/A

\section{REFERENCES}

None.

\section{8. $\quad$ ATTACHMENTS}

None. 


\section{ANNUAL SYSTEM ASSESSMENT REPORT}

(Sheet 1 of 9 )

Date of This Report Febuary 11, 1998

Date of Previous Report January 15, 1992

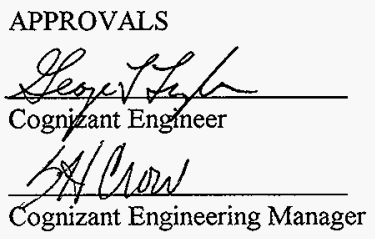

1. SCOPE

System/Component

System 96A

System 96B

System $96 Z$

System M18

\section{Title}

Process Radiation Monitoring

Area Radiation Monitoring

FSF Radiation Monitoring

MASF Radiation Monitoring

2. SUMMARY EVALUATION (Provide a general assessment of the overall health of the system. Include a discussion of the system's minimum operable equipment from plant procedure PN-7.)

The equipment which makes up the radiation monitoring systems is fifteen to twenty years old. The electronics within the system is displaying the effects of that aging. To date, replacement of failed components with spare items has enabled the system to continue operating. In the event of permanently installed equipment failure, temporary equipment may replace permanent equipment. Hence it is not absolutely necessary to assure the permanently installed equipment continues operating without repair.

All equipment is operational with the exception of C-357, ICCB monitor, which requires installation of replacement parts and calibration. Availability of selected spare parts is the greatest concern. 


\section{ANNUAL SYSTEM ASSESSMENT REPORT}

(Sheet 2 of 9 )

3. ITEMS REQUIRING ACTION (Items on PTS, Procedures, Software, etc.)

A. Near Term Items

$\underline{\text { Required By }}$

$4 \mathrm{~F}-97-1651 / \mathrm{W}$

RISH-69008B - containment northeast mezzanine

98-1 cell 501 Area Radiation Monitor (ARM) and Hi Gamma Evacuation Alarm (HGEA) - alarm horn incontainment failing.

4F-97-1767/W

RISH-69008A - CTMT northwest mezzanine cell 503 ARM and HGEA - HGEA failure.

$4 \mathrm{~F}-97-2105 / \mathrm{W}$

C-346-A, Cask Loading Station and Upper Reactor Service Building (RSB) exhaust radiation monitor chart recorder failed.

$4 F-97-2762 / W$

RISH-52400, the temporary Continuous Air 98-1 Monitor (CAM) used as a process radiation monitor, monitoring the exhaust from the Ex-Containment Cell Atmosphere Processing System (CAPS) blowers for radioactive gas - gas sampling pump is noisy.

4F-98-97/W

RISH-83019, ARM for the Interim Examination and Maintenance (IEM) Cell operating area cell 560 - failure alarm does not reset when system is returned to operation from test mode.

$4 \mathrm{~F}-98-100 / \mathrm{W}$

RISH-96100-B, equipment airlock Cell 506 ARM and HGEA - ratemeter failure. 


\section{ANNUAL SYSTEM ASSESSMENT REPORT}

(Sheet 3 of 9)

B. Long Term Items

Required By
4F-98-0042/W(J3) Determine the discriminator sensitivity of all 98-4 temporary radioactive gas CAMs to determine suitability of the units to used as RISH-52400, process radiation monitor for Ex-CTMT CAPS (ECCB) blowers.
$4 \mathrm{~F}-97-2576 / \mathrm{M}$
Defeat the locked in main annunciator alarm from C-156-A, which resulted from the shutdown of the CAPS process radiation monitors.
4F-97-1002/M
Modify the discriminators of several temporary, $98-4$ radioactive gas CAMs to allow their use as RISH-52400, process radiation monitor for the ECCBs.
$4 \mathrm{~F}-97-1864 / \mathrm{W}$
Evaluate the need for a drip cover to prevent $98-4$ condensate from dripping into RISH-52400, process radiation monitor for the ECCBs.
$4 \mathrm{~F}-95-00561 / \mathrm{W}$
C-346-A, Cask Loading Station and Upper $98-4$ RSB exhaust radiation monitor - monitor spuriously alarms during periods of high ambient temperatures in the RSB

4. TRENDS (Discuss trended parameters. See Appendix K for typical parameters which can be used for trending studies.)

No specific trending has been performed or is being planned for systems $96 \mathrm{~A}, 96 \mathrm{~B}, 96 \mathrm{Z}$ and M18.

5. SYSTEM AGING, SPARE PARTS CONSIDERATIONS, AND LONG TERM MAINTENANCE PHILOSOPHY

A. Discuss effects of system aging.

Aging of the mechanical components within the system has not resulted in increased failures, except for the ah-oo-gah horns in the high gamma alarm system. Two of the six horns have failed within the last year. Aging of electronics within the system has resulted in increased calibration problems and equipment failure. 
HNF-2380

Rev. 0, Page 340

\section{ANNUAL SYSTEM ASSESSMENT REPORT}

(Sheet 4 of 9)

B. Discuss the strategy for near term spare parts and their availability strategy.

Spare parts for C-357, the process radiation monitor for the in-containment cell atmosphere processing system blowers, will be purchased, as required, from the manufacturer. All other equipment within the systems $96 \mathrm{~A}, 96 \mathrm{~B}$ and $96 \mathrm{Z}$ is not supported by manufacturers. Spare electronic parts will be obtained from equipment which has been secured for standby, except for the Hi-Gamma Evacuation system. Replacement ah-oo-gah horns and time delay relays used in the Hi-Gamma evacuation system are no longer available. The Hi-Gamma evacuation system will be modified to allow use of components which are available.

Equipment within the system M18 is supported by manufacturers. Spare electronic parts are obtained from equipment manufacturers.

C. Standby Maintenance Plan: Discuss a plan which ensures essential system functions for standby are provided and minimizes equipment degradation. Assume the standby period extends for the next one to two years. Include in the plan, as a minimum: 1) the identification of hardware to be repaired, replaced, or upgraded; and 2) the frequency of routine field maintenance, ensuring material and spare parts are identified to support these activities (i.e., refurbish pumps, etc.).

\section{System 96A. Process Radiation Monitoring}

The facility environmental specifications have been revised, deleting the requirement for continuous monitoring of the effluent paths for radioactive gaseous and particulate effluents. In case of a failure of a permanently installed effluent monitor, we could replace that monitor with a temporary CAM until the part required for the repair is in hand. Or we could shut down the continuous monitoring of the effluent path. If quick repair of the installed units is desired, then purchase of two detectors and two detector pre-amplifiers is recommended. Otherwise, sufficient spare parts have been obtained from secured monitors to support the system for the next two years.

\section{System 96B, Area Radiation Monitoring}

Yearly calibration of system components is required.

The Hi-Gamma Evacuation System has to be modified to allow replacement of failed alarm horns with alternative replacements. 


\section{ANNUAL SYSTEM ASSESSMENT REPORT}

(Sheet 5 of 9 )

\section{System 96Z, FSF Radiation Monitoring}

Sufficient spare parts are in inventory to operate the system for the next two years.

System M18, MASF Radiation Monitoring

A spare scintillation detector should be purchased or temporary CAMS should continue to be used for monitoring until detectors are repaired. Otherwise, sufficient spare parts are in stock to operate the system for the next two years.

\section{CHECKOFF LIST}

A. Accessible parts of the entire system or component have been thoroughly walked down at least once in the past 30 days to view current performance, equipment status and condition. Yes $\mathrm{X}$ No

B. Are there any conditions which might require limitations different from operating limits as defined in the SDDs, the FSAR, or the Plant Technical Specifications? Yes__No $\mathrm{X}$

C. Are there trip settings, set points, interlocks, etc., that should be changed from those currently established? Yes_. No $\underline{X}$

D. Are there interface areas which have not performed acceptably, which require resolution? Yes X. No

COMMENTS (exceptions): C-346-A, Reactor Service Building upper exhaust monitor, fails frequently when temperatures are elevated in the RSB 550 deck area. (See 4F-95-561/W.)

In the event of spurious alarms caused by high RSB temperatures, The C-346-A function will be temporarily performed by portable CAMS, until C-346-A is replaced, or airconditioned.

E. Are there temporary plant or procedural conditions which will and should remain in place? Yes__ No $\mathrm{X}$

Attach list of MOD(L)/ECN(L)s, and OSPs that are currently active. Provide justification for continuing temporary MOD (L)s and ECN (L)s.

F. Is any retesting or special testing (e.g, OSP) required? Yes_ No $\underline{X}$ 


\section{ANNUAL SYSTEM ASSESSMENT REPORT}

(Sheet 6 of 9)

G. Are the current plant corrective maintenance, preventive maintenance, and calibration database items all properly identified and are planned actions acceptable? Yes_ X No

H. Are all other action items (NCRs, IRs, etc.) properly identified and assigned? Yes X No__ (attach the summary of needed actions not in the data base)

I. Are there any special operating considerations? Yes_. No $\mathrm{X}$

J. Are near term spare parts adequate? Yes_ No X

COMMENTS (exceptions):

1. Effluent monitoring detectors and preamplifiers can not be obtained.

2. Ah-oo-gah horn and timing relays for in-CTMT and ex-CTMT high gamma alarm systems are out of stock and no longer manufactured.

K. Have any safety issues (radiological, industrial) been identified that remain unresolved? Yes__ No $\underline{X}$

L. Have all component data been entered into the Plant information database? Yes $\underline{X}$ No

M. Have applicable SISI inspections been conducted? Yes $\mathrm{X}$ No_

COMMENTS (exceptions): N/A

N. Has a cleanliness evaluation been completed? Yes_X No Are any issues still unresolved? Yes_ No X

\section{REFERENCES}

None.

8. ATTACHMENTS

SYSTEM 96-A OPERATIONAL STATUS SYSTEM 96-B OPERATIONAL STATUS 


\section{ANNUAL SYSTEM ASSESSMENT REPORT}

(Sheet 7 of 9)

\section{SYSTEM 96-A OPERATIONAL STATUS}

\begin{tabular}{|c|c|c|c|}
\hline Process Monitoring: & PANEL & MONITOR & STATUS \\
\hline NASA RADIATION & C. 514 & RE-50361 & SECURED BX 4F-94-606/D \\
\hline NASA RADIATION & C-511 & RE-50500 & SECURED BY 4F-94-606/D \\
\hline NASARADIATION & $\mathrm{C}-512$ & RE- 50600 & SECURED BY 4F-94-606/D \\
\hline NASA RADIATION & $\mathrm{C}-513 \mathrm{R}$ & RE-50700 & SECURED BY 4F-94-606/D \\
\hline NASA RADIATION & $c-514$ & RE- 50800 & SECURED BY 4F-94-606/D \\
\hline CAPs Cold Box Bypass & C-157-B & RE-54901 & Secure with the blocking of HV-54505 \\
\hline RAPS/CAPS diversion to H\&V & $\mathrm{C}-117$ & RE-54902A \& B & Secure with blocking of HV-S4901 A \& B \\
\hline T- 49 outlet control(RAPS) & $C-156 B$ & RE-54029A/B & Secured by $4 \mathrm{~F}-92-1402 / \mathrm{D}$ \\
\hline T-49 CAPS diversion from RAPS & C-156B & RE- 54213 & Secured by $4 F-95-605 / D$ \\
\hline T-133 outlet flow & $\mathrm{C}-157 \mathrm{~B}$ & RE- 54505 & Secured by $4 \mathrm{~F}-92-1402 \mathrm{D}$ \\
\hline CESIUM TRAP FILIER MONITOR & $\mathrm{C}-514$ & RE-83051 & Secured \\
\hline ICCB noble gas det & C-357 & RE-52143 & Operational \\
\hline $1 C C B^{1 x} 1$ det. & $C-357$ & $\mathrm{RE}-52144$ & Operational \\
\hline IEM Cell Iodine & $\mathrm{C}-358$ & RE-96072 & SECURED BY ECN-610543 \\
\hline FMOTA Glovebox Aroa Trit Mon & C-359 & RE-96073 & SECURED BY $93-625 / \mathrm{D}$ \\
\hline Effluent Monitors: & Panel & Detector & Status \\
\hline $\begin{array}{c}\begin{array}{c}\text { AEB-E COMBINED EXHAUST PARTIC } \\
\text { NOBIE } \\
\text { TRIT }\end{array} \\
\end{array}$ & $\begin{array}{l}\text { C-350 } \\
\text { C-350 } \\
\text { C-356 } \\
\end{array}$ & $\begin{array}{l}\text { RE-96010 } \\
\text { RE-96011 } \\
\text { RE-96012 } \\
\end{array}$ & $\begin{array}{l}\text { RE-96010; On-line } \\
\text { RE-96011; On-line } \\
\text { RE-96012 Secured by 93-1057/D }\end{array}$ \\
\hline $\begin{array}{c}\text { HTS-S EXHAUST } \\
\text { NOBI,E }\end{array}$ & $\begin{array}{l}\mathrm{C}-348 \\
\mathrm{C}-348 \\
\end{array}$ & $\begin{array}{l}\text { RE-96060 } \\
\text { RE-96061 }\end{array}$ & Operating \\
\hline $\begin{array}{c}\text { LWR RSB EXHAUST } \\
\text { NOBIE }\end{array}$ & $\begin{array}{l}\mathrm{C}-346 \\
\mathrm{C}-346 \\
\end{array}$ & $\begin{array}{l}\text { RE-96030 } \\
\text { RE-96031 } \\
\end{array}$ & Operating \\
\hline Heating \& Ventilation: & Panel & Detector & Status \\
\hline RSB UNLNED CELIS & C344 & RE96071 & Secured by F2-1403 \\
\hline HTS-S BLDG & $\mathrm{C} 345$ & $\begin{array}{l}\text { RE-96051 } \\
\text { RE-96051A } \\
\end{array}$ & Secured by $4 \mathrm{~F}-95-72 / \mathrm{D}$ \\
\hline $\begin{array}{l}\text { 550'RSB EXHAUST PARTIC } \\
\text { NOBIE }\end{array}$ & $\begin{array}{l}\mathrm{C}-346 \mathrm{~A} \\
\mathrm{C}-346 \mathrm{~A}\end{array}$ & $\begin{array}{l}\text { RE-96030A } \\
\text { RE-96031A } \\
\end{array}$ & Operating \\
\hline $\begin{array}{c}\text { Contral Bldg GASEOUS } \\
\text { PARTIC }\end{array}$ & $\begin{array}{l}C-349 \\
C-349\end{array}$ & $\begin{array}{l}\text { RE- } 96020 \\
\text { RE- } 96021\end{array}$ & Secured by $93-1057 / \mathrm{D}$ \\
\hline PPS Radiation Monitors & Panel & Detector & Status \\
\hline Cis & $\mathrm{C} 117$ & $\begin{array}{l}\text { RE-96101 AP,BP,CP } \\
\text { RE-96102AP,BP,CR }\end{array}$ & $\begin{array}{l}\text { SECURED BY } 94-562 / \mathrm{D} \\
\text { SECURED BY } 94-562 / \mathrm{D}\end{array}$ \\
\hline CTRL, RM H\&V NLET BETA & $\mathrm{C} 177 \mathrm{~B}$ & $\begin{array}{l}\text { RE-96085A } \\
\text { RE-9608SB }\end{array}$ & secured by $4 \mathrm{~F}-95-40 / d$ \\
\hline CTRL RM AREA GAMMA & & $\begin{array}{l}\text { RE-96086A } \\
\text { RE-96086B } \\
\end{array}$ & secured by $4 \mathrm{~F}-95-40 / d$ \\
\hline POST ACC HIGH RANGE GAMMA & & $\begin{array}{l}\text { RE-83028A } \\
\text { RE-83028B }\end{array}$ & secured by $4 \mathrm{~F}-95-40 / d$ \\
\hline
\end{tabular}




\section{ANNUAL SYSTEM ASSESSMENT REPORT}

(Sheet 8 of 9 )

Area Monitors:

Operable Monitors:

Instrument No. Location

$69008 \mathrm{~A}^{*}$

$69008 \mathrm{~B}^{*}$

$69008 \mathrm{C}^{*}$

$96100 \mathrm{~A}^{*}$

$96100 \mathrm{~B}^{*}$

$96100 \mathrm{C}^{*}$

83001

83011

83013

$83018^{* *}$

83019
NW Mezzanine Area 503

NE Mezzanine Area 501

S Mezzanine Area 502

RSB Operating Floor East Cell 258

Equipment Airlock Cell 506

RSB Operating Floor West Cell 258

Inside CTMT near Personnel Airlock

IEM Cell Op. Area, Elev. 532', Cell 520

IEM Cell Op. Area, Elev. 516', Cell 550

Near EM Pump Cell Area Cell 577

IEM Cell Op. Area, Elev. 503', Cell 560

* High-gamma evacuation monitor

** Monitors charcoal filter on EMP Cell exhaust 


\section{ANNUAL SYSTEM ASSESSMENT REPORT}

(Sheet 9 of 9)

Secured Monitors: By F2-1400

$\begin{array}{ll}\text { Instrument No. } & \text { Location } \\ 83002 & \text { Loop 1 Valve Operating Area, Cell 552B } \\ 83003 & \text { AEB-E Radiation Tool Room, Cell 322 } \\ 83004 & \text { AEB-E Access Control Area, Cell 323 } \\ 83005 & \text { HTS-South, Cell 484 } \\ 83006 & \text { HTS-South, Cell 485 } \\ 83007 & \text { HTS-South, Cell 481 } \\ 83008 & \text { RSB, Elev, 537', Cell 244 } \\ 83009 & \text { RSB, Elev. 522', Cell 224 } \\ 83010 & \text { RSB, Elev. 508', Cell 212 } \\ 83012 & \text { Loop 2 Valve Operating Area, Cell 553B } \\ 83014 & \text { Upper Cooler Area-East, Cell 561 } \\ 83015 & \text { Upper Cooler Area-West, Cell 562 } \\ 83016 & \text { Lower Cooler Area-East, Cell 577 } \\ 83017 & \text { Lower Cooler Area-West, Cell 578 } \\ 83020 & \text { CLS Loop 1 \& 2 Valve Operating Area, Cell 536B } \\ 83022 & \text { Loop 3 Valve Operating Area, Cell 554B } \\ 83023 & \text { Secondary Pump Tower - West } \\ 83024 & \text { Secondary Pump Tower - East } \\ 83025 & \text { Secondary Pump Tower - South } \\ 83026 & \text { Cell 441 Stairwell }\end{array}$

SECURED BY 95-785/M

$69009 \mathrm{~A}$

$69009 \mathrm{~B}$

$69009 \mathrm{C}$
Head Compartment West Wall Head Compartment East Wall Head Compartment South Wall 


\section{ANNUAL SYSTEM ASSESSMENT REPORT}

(Sheet 1 of 5)

Date of This Report January 28.1998

Date of Previous Report None
APPROVALS

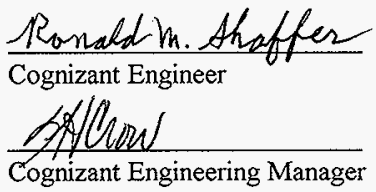

1. $\underline{\mathrm{SCOPE}}$

System L12, Landlord Electrical

2. SUMMARY EVALUATION

The landlord system provides $13.8 \mathrm{KV}$ to all buildings in the 400 Area. A transformer at each building reduces the $13.8 \mathrm{KV}$ to $480 \mathrm{VAC} / 277 \mathrm{VAC}$. This system powers all the equipment, lighting, receptacles, heating, and air conditioning for all service and office buildings in the 400 Area. The overall health of this system is good; however, there are areas of this system that need preventive maintenance work.

\section{ITEMS REQUIRING ACTION}

A. Near Term Items

$\underline{\text { Required By }}$

4L-96-296/M INSTALL 2 EMERG LIGHTS @4732A FOR LSC

Building 4732 has two areas where emergency lights need to be installed.

4L-97-211/M INSTALL EMERG LIGHT IN 4732B

Building 4732B has two areas where emergency lights need to be installed.

4L-95-170/W 4701A ELEC POWER WOULD NOT TRANSFER

The building power $480 \mathrm{VAC}$ for the security building $4701 \mathrm{~A}$ is provided by a transfer switch located in a manhole. Water has damaged the controls for the switch and the electrical box has rusted. The switch needs to be removed from the manhole so the electrical box can be painted and rewired. In addition steps should be taken to prevent water from getting into the box and the heater for the box should be repaired.

There is no work planned for the $13.8 \mathrm{KV}$ system supplying power to buildings other than FFTF. 
HNF-2380

Rev. 0, Page 347

\section{ANNUAL SYSTEM ASSESSMENT REPORT}

(Sheet 2 of 5 )

B. Long Term Items

Required By

There is no work planned for the $13.8 \mathrm{KV}$ system supplying power to buildings other than FFTF.

\section{TRENDS}

Over the past several years various modification work packages have been written to correct the problem of 400 Area office equipment overloading their supply breakers. The original design for loading on these circuits did not foresee the increase of loads on these circuits that we have today. The increased load has come from computers, printers, foot heaters, and other electronics products. These problems are being taken care of on a case by case basis as they develop.

The landlord system was taken over by FFTF Engineering after the landlord maintenance organization (B\&U) for the 400 Area was eliminated. As the work load has increased for the $13.8 \mathrm{KV}$ and $480 \mathrm{VAC}$ systems, the engineering manpower has decreased. The preventive maintenance on these systems has not been kept up to date due to the higher priorities of other work.

5. SYSTEM AGING, SPARE PARTS CONSIDERATIONS, AND LONG TERM MAINTENANCE PHILOSOPHY

A. Discuss effects of system aging.

The landlord electrical system aging effects are the same as any other electrical systems. Electrical systems do age and deteriorate with time due to loss of electrical insulation properties from many causes. There is an erroneous conception that electrical systems are static; therefore, nothing can deteriorate. Electrical systems can deteriorate due to a loss of electrical insulation from moisture and dirt. The loss in electrical insulation can cause an electrical system to fail. In addition, breakers must be capable of moving very fast (milliseconds) to clear an electrical fault. There have not been any major upgrades to electrical equipment in the entire landlord system, and preventive maintenance has not been kept up to date. This leaves the system vulnerable to component failure at any time. For some parts of this electrical system a failure will not be a problem. A failure in other parts of the system would have notable consequences. 


\section{ANNUAL SYSTEM ASSESSMENT REPORT}

(Sheet 3 of 5)

B. Discuss the strategy for near term spare parts and their availability strategy.

There are no spare parts on site for most of the equipment. These systems and components can generally be repaired using generic items purchased from off site suppliers with relatively short procurement times. There are a few instances where the equipment manufacturer no longer exists and there are no longer spares available. In these instances, the system components will need to be modified with new and state of the art replacement items.

C. Standby Maintenance Plan: Discuss a plan which ensures essential system functions for standby are provided and minimizes equipment degradation. Assume the standby period extends for the next one to two years. Include in the plan, as a minimum: 1) the identification of hardware to be repaired, replaced, or upgraded; and 2) the frequency of routine field maintenance, ensuring material and spare parts are identified to support these activities.

To maintain system L12 over the next two years, the preventive maintenance items listed in "Near Term Items" and must be completed.

\section{CHECKOFF LIST}

A. Accessible parts of the entire system or component have been thoroughly walked down at least once in the past 30 days to view current performance, equipment status and condition. Yes X No

B. Are there any conditions which might require limitations different from operating limits as defined in the SDDs, the FSAR, or the Plant Technical Specifications? Yes_ No_ X

C. Are there trip settings, set points, interlocks, etc., that should be changed from those currently established? Yes_No X

D. Are there interface areas which have not performed acceptably, which require resolution? Yes_No_X

E. Are there temporary plant or procedural conditions which will and should remain in place? Yes__ No X

Attach list of MOD(L)/ECN(L)s, and OSPs that are currently active. Provide justification for continuing temporary MOD (L)s and ECN (L)s. 


\section{ANNUAL SYSTEM ASSESSMENT REPORT}

(Sheet 4 of 5)

F. Is any retesting or special testing (e.g., OSP) required? Yes_No X

G. Are the current plant corrective maintenance, preventive maintenance, and calibration database items all properly identified and are planned actions acceptable? Yes_No_X

COMMENTS (exceptions): About half of the landlord equipment does not have preventive maintenance procedures in the FFTF system. Some procedures are in the site landlord preventive maintenance system and are very difficult or impossible to change and update. These procedures should be updated and put into the FFTF preventive maintenance system if we receive a start up notice from the DOE.

H. Are all other action items (NCRs, IRs, etc.) properly identified and assigned? Yes_No_ X (attach the summary of needed actions not in the data base)

I. Are there any special operating considerations? Yes_ No_X

List or Reference: N/A

J. Are near term spare parts adequate? Yes X No

K. Have any safety issues (radiological, industrial) been identified that remain unresolved? Yes__ No X

L. Have all component data been entered into the Plant information database?

Yes_ No X

COMMENTS (exceptions): The landlord electrical components for the most part are not in the component database. They would be added if we receive a startup order.

M. Have applicable SISI inspections been conducted? Yes $\mathrm{X}$ No

N. Has a cleanliness evaluation been completed? Yes X No

Are any issues still unresolved? Yes_ No X

\section{REFERENCES}

Administrative study "Electrical Preventive Maintenance Administration Evaluation for FFTF/400 Area," work package 4F-97-247/A. 


\section{ANNUAL SYSTEM ASSESSMENT REPORT}

\section{(Sheet 5 of 5 )}

\section{ATTACHMENTS}

None. 